MARIA REGINA GONÇALVES DE SOUZA SORANO

DISTRIBUIÇÃO DE FORAMINÍFEROS PLANCTÔNICOS (0 - 100 M NA COLUNA D'ÁGUA) E SEU REGISTRO NO SEDIMENTO NA MARGEM CONTINENTAL SUDESTE BRASILEIRA, ENTRE SÃO SEBASTIÃO, SP, E CABO DE SÃO TOMÉ, RJ

Dissertação apresentada ao Instituto Oceanográfico da Universidade de São Paulo, como parte dos requisitos para a obtenção do título de Mestre em Ciências, área de Oceanografia Química e Geológica.

Orientadora: Prof. Dra. Silvia Helena de Mello e Sousa

São Paulo 
Universidade de São Paulo

Instituto Oceanográfico

\title{
DISTRIBUIÇÃO DE FORAMINÍFEROS PLANCTÔNICOS (0 - 100 M NA COLUNA D'ÁGUA) E SEU REGISTRO NO SEDIMENTO \\ NA MARGEM CONTINENTAL SUDESTE BRASILEIRA, ENTRE SÃO SEBASTIÃO, SP, E CABO DE SÃO TOMÉ, RJ
}

\author{
Maria Regina Gonçalves de Souza Sorano
}

Dissertação apresentada ao Instituto Oceanográfico da Universidade de São Paulo, como parte dos requisitos para a obtenção do título de Mestre em Ciências, área de Oceanografia Química e Geológica.

Julgada em

Conceito

Prof. Dr.

Conceito

Prof. Dr.

Conceito

Prof. Dr.

Conceito 
Aos meus pais

Aos meus queridos avós 
De tudo ficaram três coisas:

A certeza de que estava sempre começando,

a certeza de que era preciso continuar, e a certeza de que

seria interrompido antes de terminar" Fazer da interrupção um caminho novo, fazer da queda, um passo de dança, do medo, uma escada,

do sonho uma ponte,

da procura, um encontro"

Fernando Pessoa 


\section{Agradecimentos}

Agradeço à Prof $\mathrm{Dr}^{\mathrm{a}}$. Silvia Helena de Mello e Souza pela oportunidade, confiança e dedicação ao longo desses três anos.

À CAPES pela concessão da bolsa de estudo.

Ao instituto Oceanográfico pela oportunidade.

Ao Prof Dr. Michel pela oportunidade de embarque no navio oceanográfico "Prof. Besnard".

À Prof ${ }^{\mathrm{a}}$. Dr ${ }^{\mathrm{a}}$. Thais Navajas Corbisier pelo empréstimo do equipamento fotográfico.assim como, à Karen Taniguchi.

Ao Prof. Dr. Marcelo Simões pelos ensinamentos tafonômicos.

À Prof ${ }^{\mathrm{a}}$. Dr ${ }^{\mathrm{a}}$ Sueli Godoi pelo auxílio durante a análise dos dados físicos.

Ao Prof. Dr. Rubens Lopes pela concessão das amostras de plâncton utilizadas no presente trabalho.

Aos meus pais pelo apoio incondicional, confiança e incentivo.

À Miriam e minha sobrinha Nina, por todo apoio, amizade e companheirismo. Serei sempre grata!

Aos meus irmãos pelo carinho e por estarem sempre a meu lado sempre que precisei.

Ao Fê pelo carinho e, acima de tudo, pela amizade; por me deixar participar de sua vida e me fazer sorrir.

À amiga Patrícia e sua linda família, pela amizade e cumplicidade. A alegria das crianças faz a vida ficar mais leve.

À Maria de Lourdes pelo auxílio com as amostras de plâncton.

Agradeço também a Edílson e Clodoaldo pela ajuda durante todo esse período e principalmente durante a coleta de material a bordo do Besnard.

A todo o pessoal da biblioteca que quebraram vários galhos.

Ao Rubens pelo seu mau humor bem humorado.

Aos colegas de mestrado (Adriana, Juliana, Melina, Cáio, Maurício, Ângelo, Simone, Bibiane, Cacá, Nati, Thaís, Ricardo e tantos outros) pela troca de conhecimentos e companhia amigável. 
Aos colegas Marcelo, Samara, Marina e Kátia pela colaboração.

À Cíntia pela amizade e pelas risadas durante as coletas.

À Letícia que chegou agora no finalzinho, mas que colaborou com as conversas de laboratório e auxílio com as tabelas.

Á Sabrina, pela hospedagem em Botucatu durante o estágio de tafonomia.

À Didi e todo o pessoal da cantina pela amizade e bom humor sempre.

Ao Ronaldo pela ajuda com os programas de computador e principalmente ao Eder.

A todas as pessoas que participaram de maneira direta ou indireta na execução dessa dissertação. 
Índice

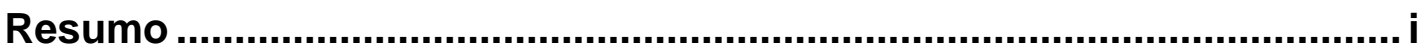

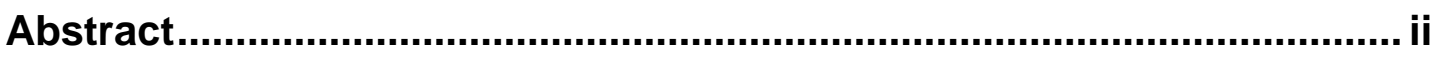

Capítulo I

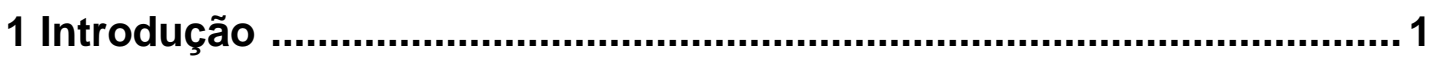

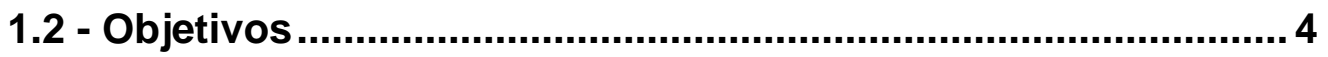

1.3 - Área de Estudo ................................................................... 5

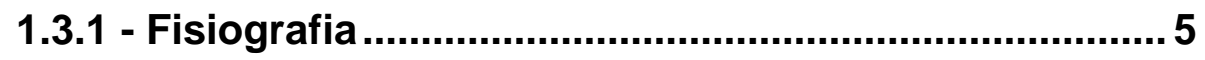

1.3.2 - Circulação Oceânica .................................................... 6

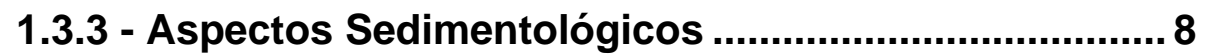

Capítulo II

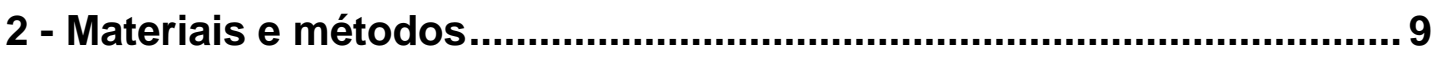

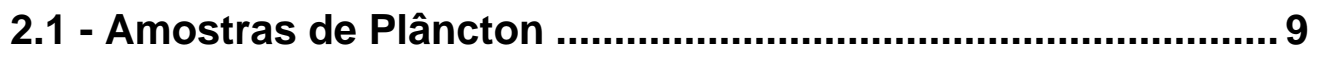

2.1.2 - Análise de Clorofila a .................................................. 13

2.1.3 - Análise Estatística ...................................................... 14

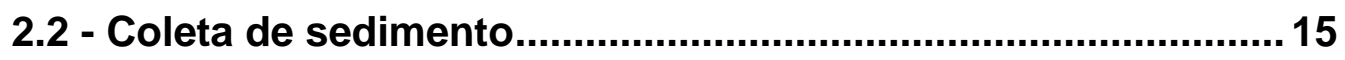

2.2.1 - Análise Granulométrica............................................. 16

2.2.2 - Analise da Tanatocenose ............................................ 16

2.2.3 - Analise Tafonômica ................................................... 17

Capítulo III

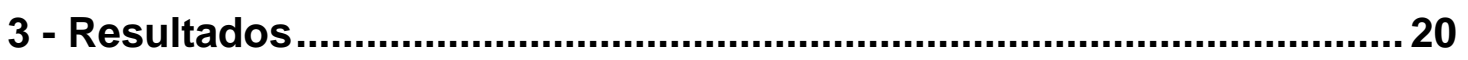

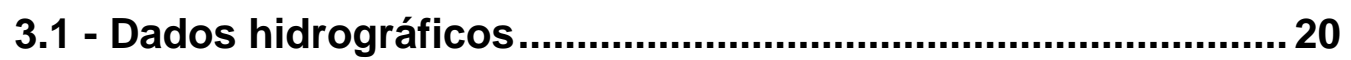

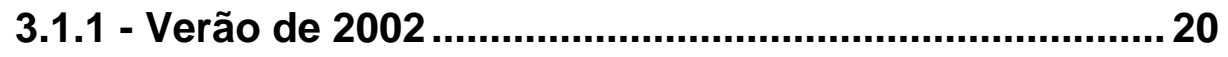

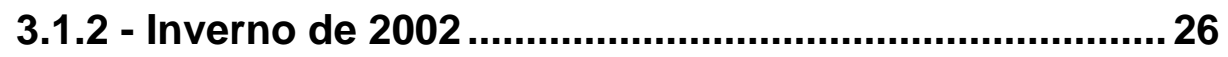

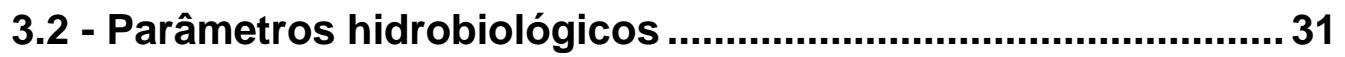

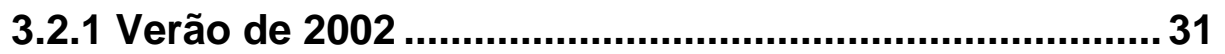




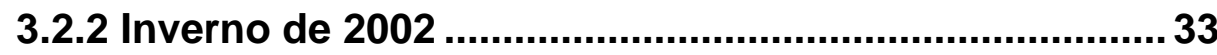

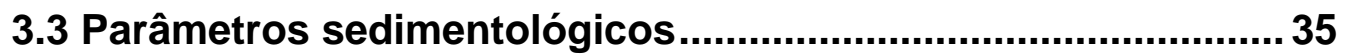

3.3.1 - Granulometria............................................................... 35

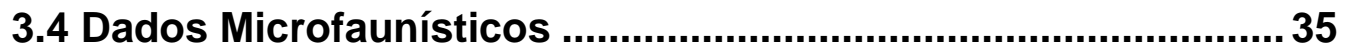

3.4.1. Distribuição dos foraminíferos planctônicos

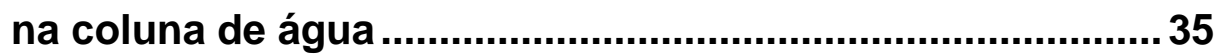

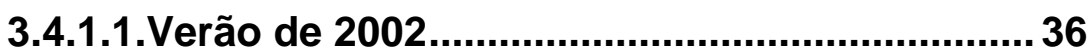

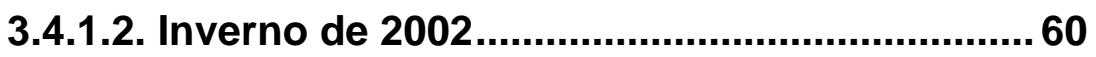

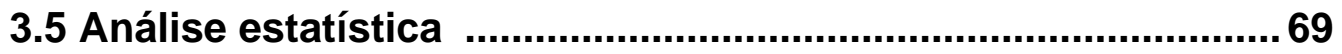

3.6 Análise da Tanatocenose ....................................................... 70

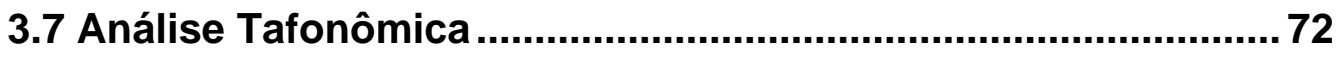

3.7.1 - Assinaturas tafonômicas ………………….................. 72

Capítulo IV

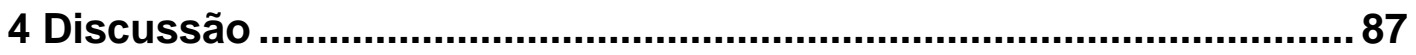

Capítulo V

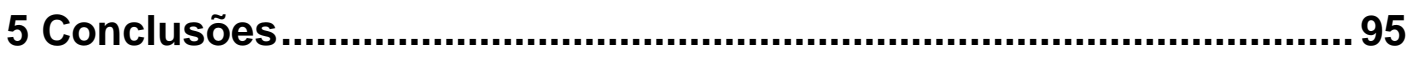

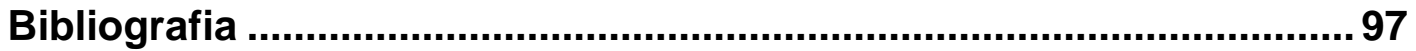

ANEXO 1

Lista das Espécies

ANEXO 2

Protocolo Tafonômico

Prancha 1

Prancha 2

Prancha 3 


\section{Resumo}

O presente trabalho tem como enfoque o estudo de foraminíferos planctônicos, na margem continental Sudeste Brasileira, entre São Sebastião, SP e Cabo de São Tomé, RJ através do levantamento das espécies existentes no plâncton. Buscou conhecer a distribuição sazonal e vertical na coluna d'água (0 a $100 \mathrm{~m}$ de profundidade) das espécies de foraminíferos planctônicos, correlacionar a presença desses organismos a fatores abióticos e bióticos no meio ambiente. Comparar a composição da biocenose e da tanatocenose assim como, realizar análise tafonômica das carapaças depositadas no fundo oceânico, a fim de avaliar o registro sedimentar desses organismos e considerar a utilização de assinaturas tafonômicas em carapaças de foraminíferos planctônicos na compreensão dos processos hidrodinâmicos na área de estudo. Para isso, foram analisadas amostras de plâncton, coletadas no verão/2002 e inverno/2002, e amostras de sedimento. Foram aplicadas metodologias usuais em análises de foraminíferos planctônicos.

Foi possível reconhecer que há grande diferença sazonal na abundância e no tamanho de foraminíferos planctônicos na margem continental Sudeste Brasileira. A distribuição vertical desses organismos no verão parece estar relacionada à profundidade da camada de mistura, variação da temperatura na água, e à cadeia alimentar. No intervalo de profundidade entre $0 \mathrm{~m}$ e $40 \mathrm{~m}$, predominam Globigerinoides ruber (pink) e Globigerinoides ruber (white). As espécies Globigerina bulloides, Neogloboquadrina dutertrei e Globigerinella siphonifera predominam entre $40 \mathrm{~m}$ e $60 \mathrm{~m}$ de profundidade, ao passo que entre $60 \mathrm{~m}$ e $80 \mathrm{~m}$ de profundidade ocorrem Globorotalia menardii, Orbulina universa e Globigerina falconenis. O registro sedimentar das espécies de foraminíferos planctônicos encontrado na área de estudo reflete a biocenose, podendo assim ser utilizado em análises ambientais e paleoceanográficas. As assinaturas tafonômicas observadas refletem as condições hidrodinâmicas locais. 


\begin{abstract}
The present work focuses on the study of planktonic foraminifera on the southeast Brazilian continental margin between São Sebastião, SP and São Tomé, RJ. This was done by means of a survey of the existing species in the plankton. The seasonal and vertical distribution in the water column (0-100 m depth) of the planktonic foraminifera species was also determined. In addition, a comparison of the biocenose and of the tatocenose was carried out as well as a tafonomic analysis of the tests deposited in the bottom. This was done in order to evaluate the sedimentary record of these organisms and consider the possibility of using tafonomic signatures in planktonic foraminifera tests in order to better understand the hydrodynamic processes in the study area. For this, plankton samples collected in the summer and winter of 2002, as well as sediment samples, were analyzed. Methodologies common to planktonic foraminfera analysis were applied.

The results show that there is a great seasonal difference in abundance and size of the planktonic foraminifera on the southeast Brazilian continental margin. The vertical distribution of these animals in the summer seems to be related to the depth of the mixture layer, variations in water temperature, and to the food chain. In the depth interval between $0 \mathrm{~m}$ and $40 \mathrm{~m}$, there was a predominance of Globigerinoides ruber (pink) and Globigerinoides ruber (white). The species Globigerina bulloides, Neogloboquadrina dutertrei and Globigerinella siphonifera are predominate between 40 and $60 \mathrm{~m}$. On the other hand, between 60 and $80 \mathrm{~m}$ Globorotalia menardii, Orbulina universa and Globigerina falconenis occur in greater quantities. The sedimentary record of the species of planktonic foraminifera found in the study area reflect the biocenose, being therefore appropriate for the usage in environmental and paleoceanographic analyses. The tafonomic signatures observed reflect the local hydrodynamic conditions.
\end{abstract}




\section{Capitulo I}

\section{1 - Introdução}

Foraminíferos são organismos protistas de enorme sucesso adaptativo (Pawlowski et al., 1998). Os primeiros registros fósseis remontam ao Cambriano ( $\cong 544 \mathrm{Ma}$ ) e a partir desse período geológico invadem o ambiente marinho, ocorrendo explosão na diversidade e em seu modo de vida. São organismos unicelulares eucariontes, pertencentes ao Filo Granureticulosa, Classe Foraminífera, que inclui espécies tanto planctônicas quanto bentônicas (Steineck \& Casey, 1990; Sen Gupta, 1999).

Esses organismos podem apresentar carapaça (ou teca) constituída por cristais de carbonato de cálcio orientados e não orientados, sílica, material quitinoso ou ainda por fragmentos selecionados de areia, espículas de esponjas ou outros detritos. Através dessa carapaça fluem, para dentro e para fora, longos pseudópodos reticulados e filiformes (Brasier, 1980; Sen Gupta, 1999). Foraminíferos bentônicos são adaptados para rastejar e para se fixar em plantas, hidróides e no fundo do mar enquanto os foraminíferos planctônicos apresentam adaptações que lhes permite flutuar. As carapaças das várias espécies de foraminíferos podem variar de 0,01 $\mathrm{mm}$ a $140 \mathrm{~mm}$ de diâmetro (Grell, 1973), divididas em câmaras esféricas, tubulares, espirais ou de outras formas.

O presente trabalho tem como enfoque o estudo de foraminíferos planctônicos na margem continental Sudeste Brasileira, assim sendo, será dada ênfase, nesse trabalho, aos foraminíferos da Ordem Globigerinida, a qual inclui apenas espécies de hábito planctônico (Sen Gupta, 1999).

As formas planctônicas de foraminíferos têm habitado os mares desde o período Jurássico (aproximadamente $135 \mathrm{Ma}$ ) e suas carapaças calcáreas têm se acumulado como depósitos de fundo desde essa época dando origem a estratos rochosos. Cerca de $35 \%$ do fundo oceânico atual são cobertos por vasas de foraminíferos formadas por carapaças de espécies planctônicas, particularmente do gênero Globigerina (Mücke \& Oberhänsli, 1999). Os foraminíferos planctônicos são divididos em espécies espinhosas (e.g., 
espécies de Globigerina e Globigerinoides) e não espinhosas (e.g., espécies de Globorotalia).

Esses organismos migram ao longo da coluna de água e essa migração é controlada principalmente por fatores físicos, químicos e biológicos, tais como luz, salinidade, temperatura, turbulência da água, concentração de clorofila-a e concentração de zooplâncton (Bé \& Hutson, 1977 e Sen Gupta, 1999). Às variações desses fatores ambientais, os foraminíferos planctônicos respondem com mudanças em sua distribuição na coluna d’água e em suas associações (Bé \& Tolderlund, 1971; Bé et al., 1973, Fairbranks \& Wiebe, 1980; Bijma et al., 1990; Boltovskoy et al., 1991; Ivanova et al., 1999; Mücke \& Oberhänsli, 1999), sendo, por esse motivo, considerados indicadores ambientais. Além disso, apresentam grande abundância e ampla distribuição nos sedimentos marinhos e possuem testas resistentes que podem ser preservadas, guardando informações ambientais através do tempo (Steineck \& Casey, 1990; Sen Gupta, 1999) ), fatos que corroboram a utilização desses organismos como excelentes indicadores ambientais ou "proxies". Sendo assim, desempenham importante papel no desenvolvimento das pesquisas ecológicas e paleoecológicas (Bé \& Tolderlund, 1971).

Estudos dos padrões de distribuição vertical, de mudanças sazonais nas associações de foraminíferos planctônicos e de sua correlação com parâmetros ambientais são utilizados, desde a metade do século $X X$, em trabalhos biogeográficos, paleoecológicos, paleoceanográficos e na compreensão da dinâmica de massas de água (Boltovskoy et al., 1996). E para melhor utilização desses organismos como "proxies" ambientais, é necessário que se conheça seu ciclo de vida, sua distribuição vertical, a profundidade de calcificação das carapaças (Mücke \& Oberhänsli, 1999), as relações presapredador e as relações simbióticas (Bé \& Hutson 1977).

Com esse enfoque, desenvolveu-se no Instituto Oceanográfico da Universidade de São Paulo, entre 2002 e 2006, o projeto "Avaliação da Utilização de Foraminíferos Planctônicos como indicadores Paleoceanográficos no Quaternário do Atlântico Sudoeste", no qual se insere o presente trabalho. Esse projeto buscou, entre outros objetivos, compreender a ecologia dos 
foraminíferos planctônicos na costa brasileira, mais especificamente entre o Embaiamento de São Paulo e Cabo de São Tomé - Cabo Frio.

Além da realização de estudos ecológicos da microfauna planctônica, é fundamental também compreender se as comunidades de foraminíferos planctônicos, que ocorrem na coluna de água estão representadas nos sedimentos dos fundos oceânicos. Tal fato revela-se de grande importância em estudos paleoceanográficos, visto que tais estudos utilizam amplamente as associações de foraminíferos planctônicos em reconstituições paleoambientais. A literatura tem demonstrado que a atuação de processos mecânicos denominados de bioestratinômicos (necrólise, transporte) interfere na gênese das acumulações (Kowalewski, 1996) de carapaças vazias de micro (Martin et al., 1996 e Martin, 1999) e macroorganismos (Holz \& Simões, 2002; Rodrigues, 2006).

A Bioestratinomia faz parte do ramo da ciência conhecida como Tafonomia, que tem por objetivo compreender a transição dos restos orgânicos da bioesfera para a litosfera, ou seja, investigar as condições e os processos que propiciam a preservação nos sedimentos de restos de animais ou de vegetais (Holz \& Simões, 2002). 


\section{2 - Objetivos}

Dentro desse contexto, a presente dissertação de mestrado buscou atingir os seguintes objetivos:

Realizar o levantamento de espécies de foraminíferos existentes no plâncton, na margem continental Sudeste Brasileira, entre São Sebastião, SP e Cabo de São Tomé, RJ;

Conhecer a distribuição sazonal (verão e inverno) e vertical na coluna d'água (0 a 100 m de profundidade) dos foraminíferos planctônicos;

> Correlacionar a presença desses organismos a fatores abióticos, tais como temperatura, salinidade e concentração de clorofila a no meio ambiente;

Comparar a composição de espécies de foraminíferos planctônicos presentes na biocenose e na tanatocenose;

Realizar análise tafonômica das carapaças de foraminíferos planctônicos, depositadas no fundo oceânico, a fim de avaliar o registro sedimentar desses organismos;

Avaliar a utilização de assinaturas tafonômicas em carapaças de foraminíferos na compreensão dos processos hidrodinâmicos na área de estudo. 


\section{3 - Área de Estudo}

\subsection{1 - Fisiografia}

A área de estudo está localizada na margem continental Sudeste Brasileira, entre $23^{\circ} 03^{\prime} 41$ e $2^{\circ} 01^{\prime} 00$ de latitude sul e $40^{\circ} 22^{\prime}, 20$ e 44ำ $17^{\prime} 35$ de longitude oeste. (Figura 1). Compreende a parte norte do Embaiamento de São Paulo e o extremo sul do setor Cabo de São Tomé - Cabo Frio (Zembruscki, 1979).

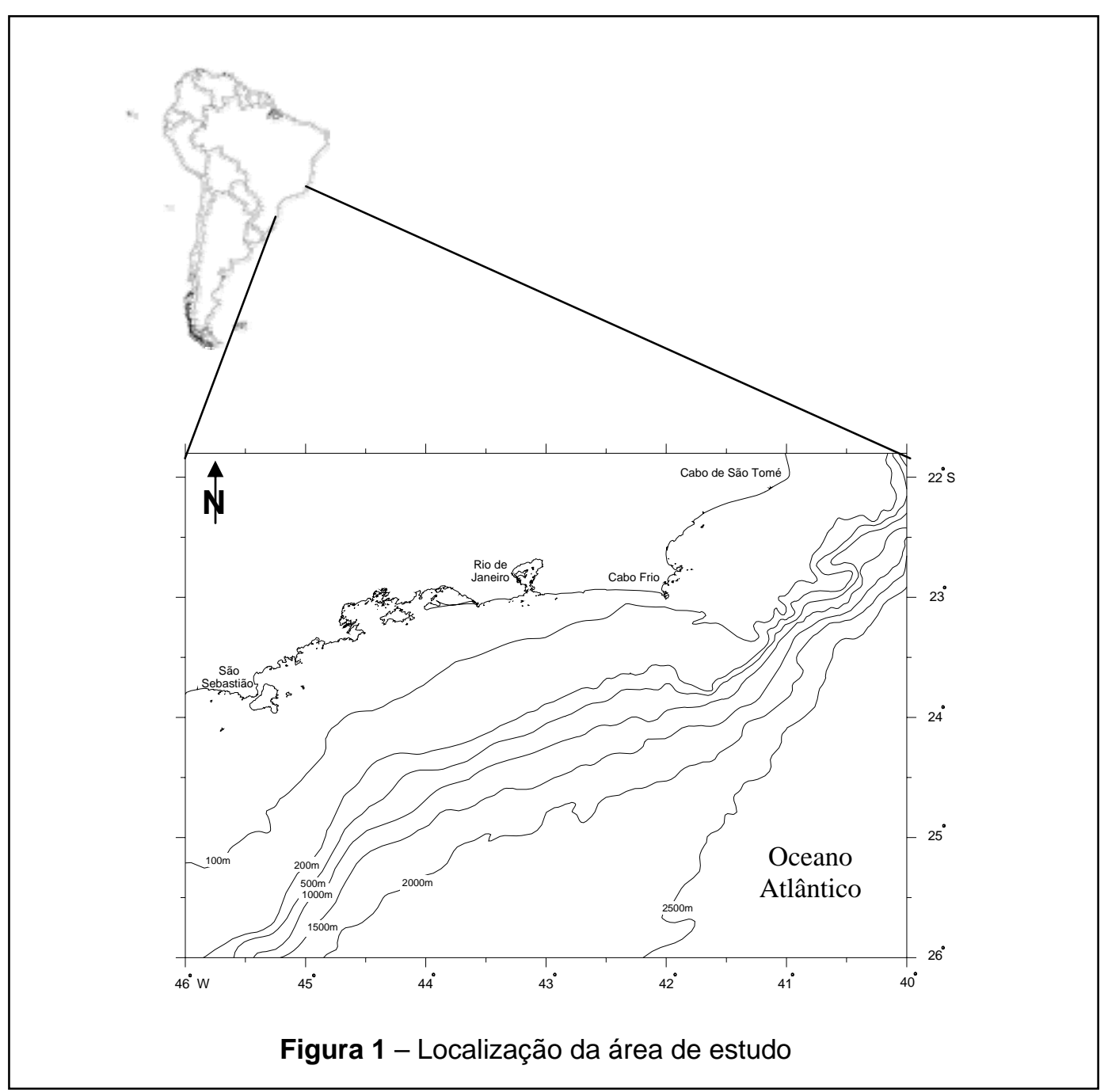

No setor Cabo de São Tomé - Cabo Frio, a plataforma é regular e uniforme, com gradiente médio de 1: 1000 medindo $80 \mathrm{~km}$ de largura, sendo mais estreita e rasa, que seu prolongamento para o sul (Zembruscki, 1979). A 
quebra da plataforma ocorre aproximadamente a $140 \mathrm{~m}$ de profundidade e 0 gradiente de declividade no talude superior é de 1: 55 (Mahiques et al., 2002). Na região de Cabo Frio ocorre, de norte para sul, modificação na orientação da linha de costa de NE - SW para E - W, além de variações na topografia e no relevo (Zembruscki, 1979).

No Embaiamento de São Paulo, tanto as plataformas média e externa quanto o talude superior apresentam, ao longo de toda a sua extensão vales e canais, indicando uma topografia bastante irregular (Mahiques, 1998). A profundidade de quebra da plataforma, nesse setor da margem continental brasileira, varia de $80 \mathrm{~m}$ a $100 \mathrm{~m}$ e atinge a largura máxima de $230 \mathrm{~km}$ de extensão. O talude apresenta baixos gradientes de declividade (050' a $2^{\circ}$ ) e estende-se até profundidades de 1600 m a 2900 m, começando a partir dessa profundidade o Platô de São Paulo (Zembruscki, 1979).

\subsection{2 - Circulação Oceânica}

A Corrente do Brasil (CB) é a corrente de contorno oeste do Giro Subtropical do Atlântico Sul (Figura 2) e flui sobre a margem continental Brasileira acompanhando, aproximadamente, a linha de quebra da plataforma continental (Tomczak \& Godfrey, 1994). Essa corrente é formada pela Água Tropical (AT, $T=25,0^{\circ} \mathrm{C} ; \mathrm{S}=37,1$ ) em superfície e pela Água Central do Atlantico Sul (ACAS, $T=14,0^{\circ} \mathrm{C} ; \mathrm{S}=35,5$ ) que flui pra sul no talude continental na camada inferior a 200 m (Castro \& Miranda, 1998; Stramma \& England, 1999, Silveira et al., 2000). 


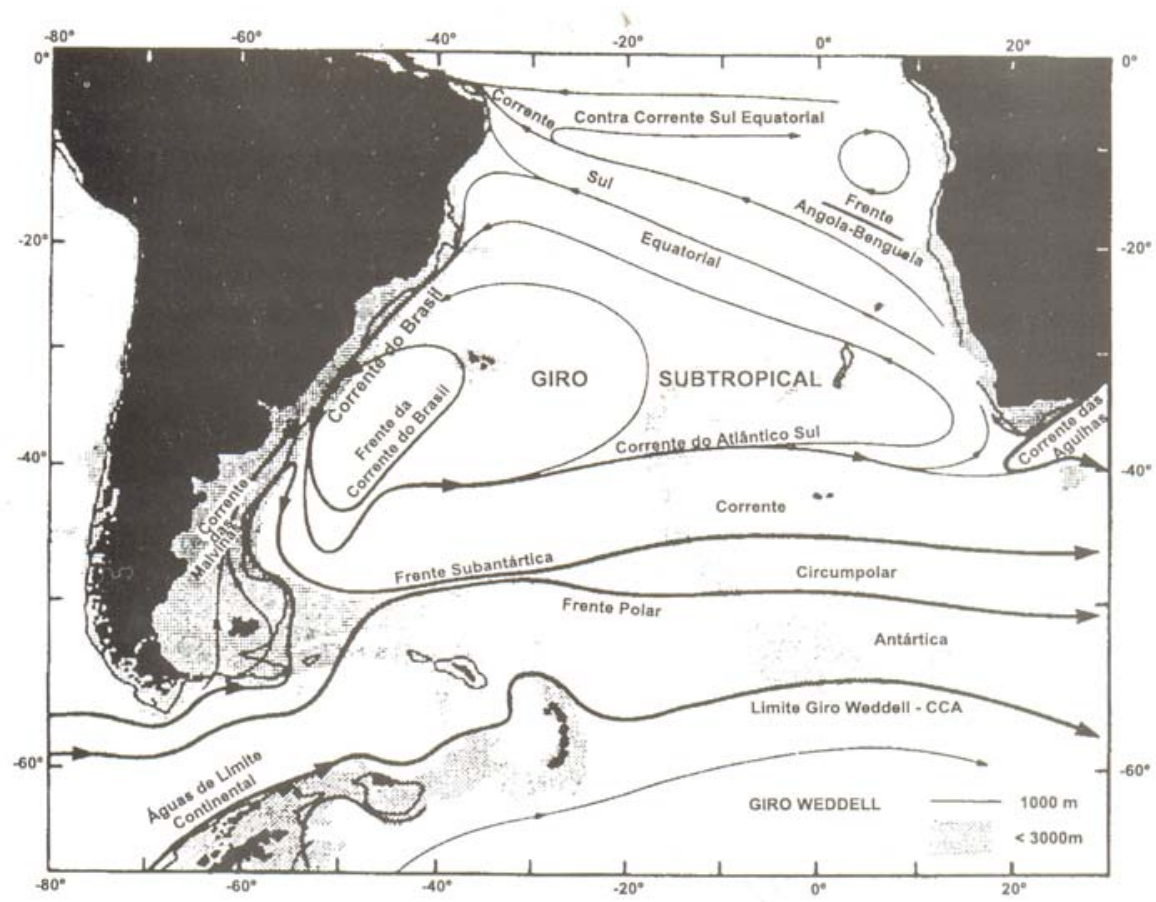

Figura 2 - Representação esquemática do Giro Subtropical do Atlântico Sul.

(Segundo Silveira et. al., 2002).

A plataforma continental interna é caracterizada pela interação entre a Água Costeira $(A C, T=22 ; S=35,0)$, a AT e a ACAS, sendo que nessa região da plataforma, as ondas e os ventos desempenham papel fundamental nos processos hidrodinâmicos (Castro et al., 1987) Os limites termohalinos das massas de água AT e ACAS são aparentemente difíceis de serem definidos. Estudos realizados por Godoi (2005) demonstram que esses limites na área em questão seriam de $18,99{ }^{\circ} \mathrm{C}$ e 36,20 . Em termos gerais, ao largo da costa leste Brasileira, abaixo da ACAS, deslocam-se para norte, a Água Intermediária Antártica (AIA; $\mathrm{T}=3^{\circ} \mathrm{C}$ a $6^{\circ} \mathrm{C} ; \mathrm{S}=34,2$ a 34,6$)$, até cerca de $1500 \mathrm{~m}$; e para sul, a Água Profunda do Atlântico Norte (APAN; T $=3^{\circ} \mathrm{C}$ a $4^{\circ} \mathrm{C}, \mathrm{S}=34,6$ a 35), até aproximadamente $3000 \mathrm{~m}$ (Silveira et al., 2000).

Nas regiões do Cabo de São Tomé e Cabo Frio, a plataforma continental torna-se bastante estreita devido à mudança na orientação da linha de costa. Esse fato faz com que a CB gire ciclonicamente para oeste, aproximando-a da linha de quebra da plataforma continental, favorecendo assim, a formação de meandros (Campos et al., 2000). Ademais, os ventos que sopram de NW durante o verão na região de Cabo Frio, também favorecem a 
ocorrência de vórtices ou meandros na $\mathrm{CB}$, além de forçarem as águas superficiais em direção a mar aberto, devido ao transporte de Ekman (Signorini et al., 1989; Silveira et al., 2000; Mahiques et al., 2004; Mahiques et al, 2005), promovendo assim a penetração da ACAS pelo fundo e seu conseqüente afloramento na plataforma interna (Castro, 1996). Esse processo é conhecido como ressurgência e devido ao afloramento de água fria e rica em nutrientes, ocorre aumento na produtividade primária marinha, e conseqüentemente, na deposição de matéria orgânica no local (Gaeta et al., 1994; Mahiques et al., 2004).

\subsection{3 - Aspectos Sedimentológicos}

A plataforma continental entre a llha de São Sebastião e Cabo Frio é recoberta predominantemente por areia, com algumas ocorrências de areia lamosa e de lama cascalhosa (Mahiques et al., 2004).

Por sua vez, o talude continental nessa região é caracterizado por sedimentação lamosa, dominantemente síltica, cuja fração arenosa é constituída quase totalmente por componentes biodetríticos, principalmente foraminíferos (Kowsmann \& Costa, 1975; Alves \& Ponzi, 1984).

Os processos sedimentares na área de estudo são influenciados, principalmente, pela morfologia da plataforma, talude e pelo padrão de meandramento da CB. Assim sendo, variações na taxa de sedimentação são observadas, sendo que as maiores taxas ocorrem nas áreas de ressurgência (50 - $61 \mathrm{~mm} \mathrm{Kyr}^{-1}$ ) e ao sul do Canal de Búzios (32 - $37 \mathrm{~mm} \mathrm{Kyr}^{-1}$ ), localizado nas proximidades da llha de São Sebastião (Mahiques et al., 2002). Ainda segundo esses autores, o meandramento da CB seria também responsável pela formação de um depósito em forma de arco no talude superior. 


\section{Capítulo II}

\section{2 - Materiais e Métodos}

\section{1 - Amostras de Plâncton}

O material analisado na presente dissertação de mestrado foi previamente coletado em janeiro e agosto de 2002, durante os cruzeiros de verão e inverno do projeto DEPROAS (Dinâmica do Ecossistema de Plataforma da Região Oeste do Atlântico Sul), na margem continental dos estados de São Paulo e Rio de Janeiro, abrangendo parcialmente os setores conhecidos como Embaiamento de São Paulo e Cabo de São Tomé - Cabo Frio, entre a ilha de São Sebastião e Cabo de São Tomé.

As amostras foram coletadas ao longo de radiais, perpendiculares à linha da costa, desde a plataforma interna ao talude superior (Figura 3 e Tabelas 1 e 2). Em razão dos foraminíferos planctônicos migrarem ao longo da coluna de água, optou-se neste trabalho, por analisar somente amostras coletadas durante o dia, entre 06h00min e 18h00min, aproximadamente. $\mathrm{Na}$ amostragem de plâncton foi utilizado o equipamento "Multi Plankton Sampler", equipado com cinco redes de plâncton, com malha de $64 \mu \mathrm{m}$. Durante a amostragem, as redes foram abertas e fechadas consecutivamente em cinco intervalos de profundidade, 0-20 m, 20-40 m, 40-60 m, 60-80 m e 80-100 m. Após a realização das coletas, as amostras foram acondicionadas em frascos plásticos contendo solução de formol a 4\%, para conservar a matéria orgânica, e bórax com o intuito de tamponar a solução, ou seja, de conservar o pH da solução em torno de 8.

Em laboratório, as amostras foram filtradas em malha de $100 \mu \mathrm{m}$, de acordo com metodologia adotada de Boltovskoy et al. (1996), a fim de separar os espécimes jovens, que não são, muitas vezes, passíveis de identificação. 


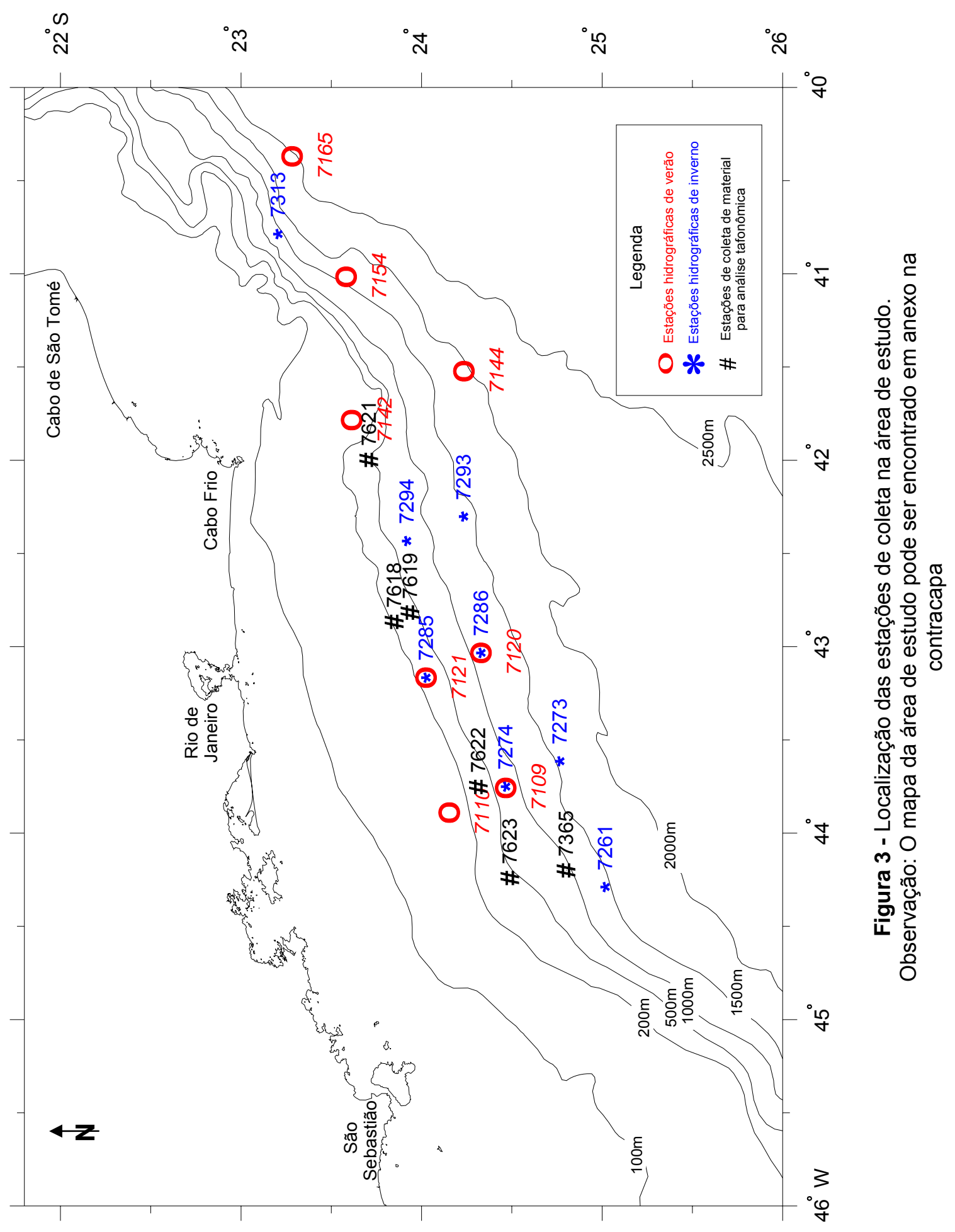




\begin{tabular}{c|c|c|c|c}
\hline Projeto & $\begin{array}{c}\text { Estação } \\
\text { Hidrográfica }\end{array}$ & Latitude & Longitude & $\begin{array}{c}\text { Profundidade local } \\
(\mathrm{m})\end{array}$ \\
\hline \hline DEPROAS & 7109 & $24^{\circ} 27^{\prime} 96$ & $43^{\circ} 45^{\prime} 47$ & 787 \\
\hline DEPROAS & 7110 & $24^{\circ} 09^{\prime} 02$ & $43^{\circ} 53^{\prime} 04$ & 155 \\
\hline DEPROAS & 7120 & $24^{\circ} 19^{\prime} 75$ & $43^{\circ} 02^{\prime} 00$ & 1121 \\
\hline DEPROAS & 7121 & $24^{\circ} 01^{\prime} 49$ & $43^{\circ} 09^{\prime} 96$ & 275 \\
\hline DEPROAS & 7142 & $23^{\circ} 36^{\prime} 79$ & $41^{\circ} 47^{\prime} 06$ & 160 \\
\hline DEPROAS & 7144 & $24^{\circ} 14^{\prime} 08$ & $41^{\circ} 31^{\prime} 34$ & 1952 \\
\hline DEPROAS & 7154 & $23^{\circ} 34^{\prime} 94$ & $41^{\circ} 00^{\prime} 95$ & 1565 \\
\hline DEPROAS & 7165 & $23^{\circ} 17^{\prime} 05$ & $40^{\circ} 22^{\prime} 20$ & 2522 \\
\hline
\end{tabular}

Tabela 1 - Localização e profundidade das estações hidrográficas de coleta de plâncton durante o verão de 2002.

Observação: a Tabela 1 pode ser encontrada em anexo na contra capa (verso do encarte)

\begin{tabular}{c|c|c|c|c}
\hline Projeto & $\begin{array}{c}\text { Estação } \\
\text { hidrográfica }\end{array}$ & Latitude & Longitude & $\begin{array}{c}\text { Profundidade local } \\
(\mathrm{m})\end{array}$ \\
\hline \hline DEPROAS & 7261 & $25^{\circ} 01^{\prime} 00$ & $44^{\circ} 17^{\prime} 35$ & 1430 \\
\hline DEPROAS & 7273 & $24^{\circ} 45^{\prime} 93$ & $43^{\circ} 36^{\prime} 88$ & 1578 \\
\hline DEPROAS & 7274 & $24^{\circ} 27^{\prime} 93$ & $43^{\circ} 45^{\prime} 04$ & 795 \\
\hline DEPROAS & 7285 & $24^{\circ} 0149$ & $43^{\circ} 0996$ & 280 \\
\hline DEPROAS & 7286 & $24^{\circ} 1975$ & $43^{\circ} 0200$ & 1120 \\
\hline DEPROAS & 7293 & $24^{\circ} 38^{\prime} 08$ & $42^{\circ} 50^{\prime} 36$ & 1159 \\
\hline DEPROAS & 7294 & $25^{\circ} 33^{\prime} 28$ & $43^{\circ} 12^{\prime} 21$ & 708 \\
\hline DEPROAS & 7313 & $23^{\circ} 03^{\prime} 41$ & $42^{\circ} 11^{\prime} 11$ & 1547 \\
\hline
\end{tabular}

Tabela 2 - Localização e profundidade das estações hidrográficas de coleta de plâncton durante o inverno de 2002

Observação: a Tabela 2 pode ser encontrada em anexo na contra capa (verso do encarte)

O material retido no filtro foi utilizado na triagem de testas de foraminíferos planctônicos. A triagem foi realizada sob estereomicroscópio com auxílio de estiletes, pincéis e placa de Petri quadriculada. Após a separação dos espécimes de foraminíferos planctônicos, procedeu-se a identificação dos indivíduos até o nível de espécie, sempre que possível. A identificação das espécies baseou-se, principalmente, em Postuma (1971); Kennett \& Srinivasan (1983); Hemleben et al. (1989) e Jones (1994). Posteriormente à identificação, os espécimes de foraminíferos foram fixados com cola Adraganta em lâminas secas. O detalhamento desse procedimento encontra-se especificado na Figura 4. 


\section{Triagem de Foraminíferos Planctônicos a Úmido}

A

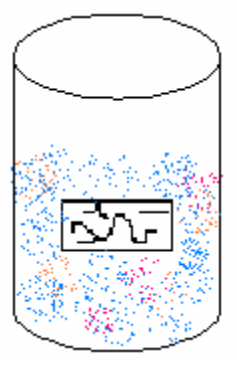

B

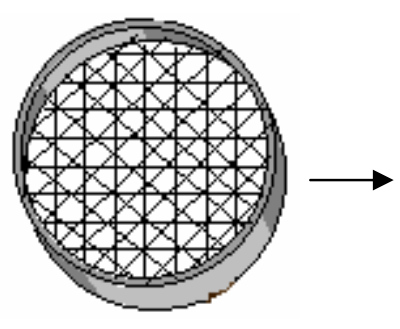

$\mathrm{F}$

$\mathrm{E}$

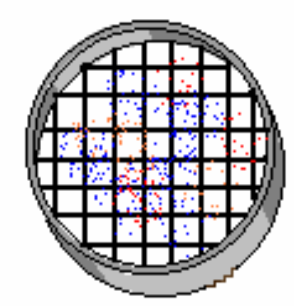

$\mathrm{D}$

G
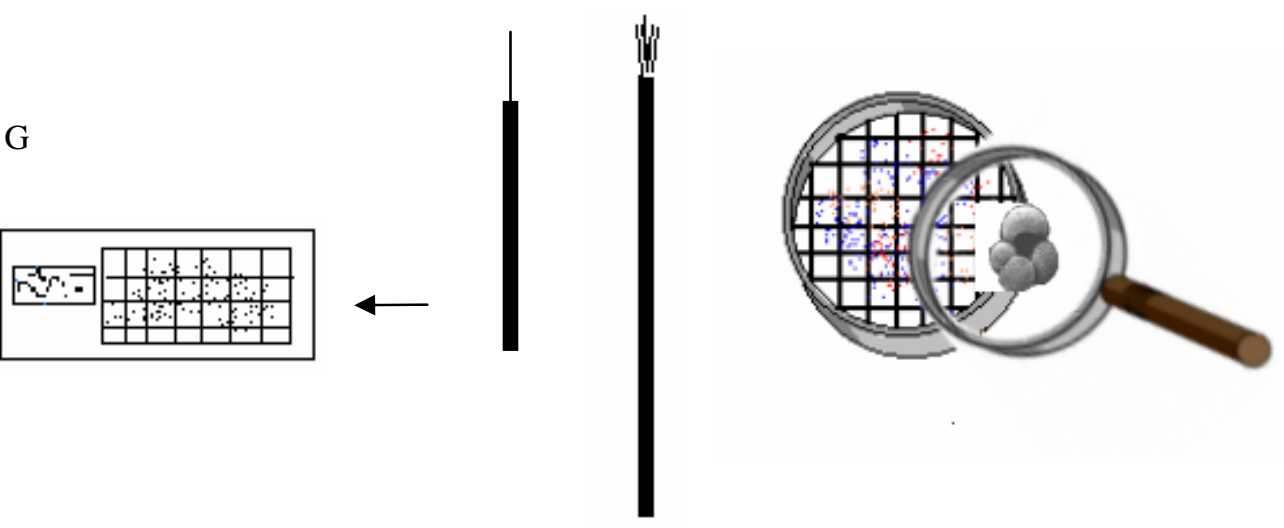

Figura 4 - llustração dos principais materiais e processos utilizados durante a triagem de foraminíferos planctônicos a úmido; A - Frasco de polietileno de $1000 \mathrm{ml}$, devidamente identificado com a etiqueta de coleta, contendo a amostra conservada em formol (4\%) e bórax; B - Filtro de $100 \mu \mathrm{m}$ utilizado com a intenção de separar organismos jovens dos adultos; C-Bandeja quadriculada utilizada para garantir a varredura total da amostra; D - Observação da amostra em estereomicroscópio; E Pincel utilizado para transferir os organismos de interesse para a lâmina seca; F Estilete utilizado para separar os espécimes de foraminíferos dos outros organismos aglomerados em decorrência da presença de ovos de Salpa. G Lâmina seca utilizada para acondicionar os espécimes. 
O volume total de água filtrada em cada rede nas estações hidrográficas foi calculado a partir da seguinte fórmula, segundo Tanaka (1973):

$$
\mathrm{V}=\mathrm{A} \times \mathrm{N} \times \mathrm{C}
$$

Onde:

$A=$ área de abertura da rede

$N$ = número de rotações efetuadas pelo fluxômetro

$\mathrm{C}=$ índice de correção do fluxômetro

A partir desses dados foi possível estabelecer a densidade de espécimes de foraminíferos planctônicos por volume total de água filtrada.

Os dados de temperatura e salinidade foram obtidos com o auxílio de um CTD durante os cruzeiros de verão e inverno do projeto DEPROAS em 2002 , e os gráficos foram gerados pelo programa Origin 6.0 Professional ${ }^{\circledR}$. A profundidade da base da camada de mistura foi determinada de acordo com metodologia apresentada por Tomczak \& Godfrey (1994) Segundo essa metodologia, a base da camada de mistura pode ser identificada, quando a temperatura local apresenta gradiente de $0,5{ }^{\circ} \mathrm{C}$ inferior à temperatura de superfície. A profundidade da interface AT/ACAS também foi estimada, utilizando os parâmetros termohalinos estabelecidos por Godoi (2005).

\subsection{2 - Análise de Clorofila a}

Os dados de concentração de clorofila a na água foram obtidos e gentilmente cedidos pelo Laboratório de Produtividade Primária do Instituto Oceanográfico da Universidade de São Paulo. O material destinado à análise de clorofila a foi coletado nos mesmos cruzeiros de coleta das amostras de plâncton (verão e inverno de 2002). Todavia, as amostragens de material destinado à análise de clorofila a foram realizadas em profundidades diferentes 
das amostras de plâncton, sendo elas: 0 m, 5 m, 10 m, 25 m, 50 m, 75 m e 100 m.

$\mathrm{Na}$ análise de clorofila a foi aplicado o método fluorimétrico (Welschmeyer, 1994), no qual um volume conhecido de água de cada estação foi filtrado em filtro de fibra de vidro, utilizando bomba de vácuo, com pressão variável entre $100 \mathrm{~mm}$ e $300 \mathrm{~mm} \mathrm{Hg}$. Após esse procedimento, a clorofila e os outros pigmentos foram extraídos pelo procedimento de imersão do filtro em solução de acetona $90 \%$, por um período de 24 horas a $4{ }^{\circ} \mathrm{C}$. Após esse período, os filtros foram macerados e novamente filtrados em filtro de fibra de vidro e o extrato filtrado (aproximadamente $10 \mathrm{~mL}$ ) foi analisado em fluorímetro. Os resultados são expressos em $\mu \mathrm{g} / \mathrm{L}$.

Clorofila a $\mu g / L=(r / r-1)\left(R_{a}-R_{d}\right)(v / V)$

Onde:

$r$ = razão das leituras antes e após a acidificação da solução pura de clorofila a; $\mathrm{R}_{\mathrm{a}}=$ leitura antes da acidificação;

$\mathrm{R}_{\mathrm{d}}=$ leitura após a acidificação;

$\mathrm{v}=$ volume do extrato em $\mathrm{mL}$;

$\mathrm{V}=$ volume de amostra filtrada em $\mathrm{mL}$

\subsection{3 - Análise Estatística}

Foi realizada análise de correlação linear segundo coeficiente de Pearson entre as espécies de foraminíferos planctônicos encontradas e as variáveis ambientais (profundidade, temperatura, salinidade, concentração de clorofila a) medidas no verão de 2002.

Considerou-se como significativos somente os valores de correlação com $\alpha \leq 0,05$ e $\alpha \leq 0,1$. 


\section{2 - Coleta de sedimento}

Foram realizadas coletas de sedimento destinadas às análises granulométrica, da tanatocenose e tafonômica, durante os cruzeiros oceanográficos realizados em dezembro de 2003 e 2004, no âmbito dos projetos "O papel do Canal de Búzios no transporte de sedimentos quaternários da margem continental do estado de São Paulo" e "Paleoprodutividade na plataforma continental do Estado de São Paulo", respectivamente.

A coleta de sedimento foi realizada através do equipamento "box-corer", em 6 estações oceanográficas, nas seguintes profundidades: 231m, 413m, 430m, 458m, 511m e 964m. A localização das estações de coleta pode ser observada na Figura 3 e a posição geográfica na Tabela 3.

Aproximadamente $1 \mathrm{~cm}$ do topo do sedimento da seção obtida no "boxcorer" foi armazenada em potes plásticos para a realização das análises supracitadas. Optou-se por recuperar o primeiro centímetro da camada superficial de sedimento, na tentativa de se trabalhar com o material sedimentar supostamente mais recentemente depositado no fundo marinho.

\begin{tabular}{c|c|c|c|c}
\hline Projeto & $\begin{array}{c}\text { Estação } \\
\text { Oceanográfica }\end{array}$ & Latitude & Longitude & $\begin{array}{c}\text { Profundidade } \\
\text { local } \\
(\mathrm{m})\end{array}$ \\
\hline BÚZIOS & 7365 & $24^{\circ} 47^{\prime} 98$ & $44^{\circ} 12^{\prime} 08$ & 964 \\
\hline PALEOPRODUTIVIDADE & 7618 & $23^{\circ} 14^{\prime} 13$ & $42^{\circ} 14^{\prime} 45$ & 231 \\
\hline PALEOPRODUTIVIDADE & 7619 & $23^{\circ} 15^{\prime} 58$ & $42^{\circ} 13^{\prime} 06$ & 511 \\
\hline PALEOPRODUTIVIDADE & 7621 & $23^{\circ} 11^{\prime} 08$ & $41^{\circ} 16^{\prime} 63$ & 413 \\
\hline PALEOPRODUTIVIDADE & 7622 & $24^{\circ} 05^{\prime} 23$ & $43^{\circ} 12^{\prime} 53$ & 430 \\
\hline PALEOPRODUTIVIDADE & 7623 & $24^{\circ} 08^{\prime} 15$ & $44^{\circ} 04^{\prime} 01$ & 458 \\
\hline
\end{tabular}

Tabela 3 - Localização e profundidades das estações de coleta de sedimento para análises granulométrica, da tanatocenose e tafonômica.

Observação: a Tabela 3 pode ser encontrada em anexo na contra capa (verso do encarte) 


\subsection{1 - Análise Granulométrica}

A determinação das características granulométricas foi feita por meio de análise em sedimentômetro Malvern 2000. A análise granulométrica foi realizada no Laboratório de Sedimentologia do IOUSP, após a eliminação do carbonato biodetrítico com uma solução de $\mathrm{HCl}$ a $10 \%$.

A escala granulométrica utilizada foi a de Wentworth, com os correspondentes valores de $\varphi\left(-\log _{2}(\mathrm{~mm})\right)$. O diâmetro médio foi determinado segundo os parâmetros estatísticos de Folk \& Ward (1957), utilizando para isso o programa LABSE, desenvolvido pelo Laboratório de Sedimentologia do Instituto de Geociências da Universidade de São Paulo.

\subsection{2 - Analise da tanatocenose}

Em laboratório, cerca de $10 \mathrm{~cm}^{3}$ de cada amostra foram peneirados a úmido em malha de $0,125 \mathrm{~mm}$ e secos em estufa a $60{ }^{\circ} \mathrm{C}$ por 24 horas. Após este procedimento foi realizada a triagem das testas de foraminíferos planctônicos, utilizando a metodologia modificada de Ivanova et al. (1999), na qual o material é quarteado até a obtenção de no mínimo 300 indivíduos de foraminíferos planctônicos, que são separados para identificação. O número total de foraminíferos em cada amostra é dado pela formula abaixo:

$$
F_{t}=A \times 2^{n}
$$

Onde:

$F_{t}=$ número total de foraminíferos planctônicos encontrados em amostra de $10 \mathrm{~cm}^{3}$.

A = número de indivíduos separados para identificação.

$\mathrm{n}=$ número de vezes que o procedimento de quarteamento da amostra foi executado 


\subsection{3 - Analise tafonômica}

O material coletado destinado à análise tafonômica foi fixado com formaldeido a $4 \%$ e tamponado com bórax, a fim de manter o $\mathrm{pH}$ próximo a 8 evitando assim, a dissolução das carapaças.

Em laboratório, $10 \mathrm{~cm}^{3}$ do sedimento coletado foram peneirados a úmido utilizando-se malhas de $0,125 \mathrm{~mm}$ e $0,250 \mathrm{~mm}$, e seco em estufa a 60 ${ }^{\circ} \mathrm{C}$ por 24 horas. De cada fração peneirada, foram separadas aleatoriamente 150 testas de foraminíferos planctônicos para a realização da análise tafonômica, segundo metodologia adaptada de Kidwell et al. (2001), perfazendo assim, um total de 1800 testas analisadas.

É importante ressaltar que durante o processo de lavagem do material foi tomada atenção especial, evitando assim a fragmentação do material por manuseio.

Foi desenvolvido um protocolo tafonômico ou metodológico (Anexo 2), onde estão listadas as principais assinaturas tafonômicas geralmente observadas nas testas de foraminíferos planctônicos, tendo por base os trabalhos desenvolvidos anteriormente em tafonomia de invertebrados marinhos (Ghilardi \& Simões, 2000; Kidwell et al., 2001; Simões \& Kowalewski, 2003 e Carroll et al., 2003) e de foraminíferos (Martin, 2000 e Cardoso, 2006) Esse protocolo apresenta 4 assinaturas tafonômicas (fragmentação, alteração da cor, alteração da textura/brilho e corrosão).

Todas as assinaturas tafonômicas foram analisadas independentemente para cada testa de foraminífero planctônico assim, uma mesma testa pode apresentar várias assinaturas tafonômicas concomitantemente. A análise das assinaturas tafonômicas foi realizada inicialmente sob estereomicroscópio, e posteriormente, as assinaturas observadas foram confirmadas em microscópio eletrônico de varredura.

Cada assinatura tafonômica foi detalhada de acordo com algumas características, tais como presença ou ausência da assinatura tafonômica, 
porcentagem de ocorrência da assinatura na carapaça de foraminífero, conforme relacionado abaixo:

- Fragmentação

(0) Fragmentação ausente.

(1) Menos de $10 \%$ da testa fragmentada (fragmentação total ou parcial de uma câmara).

(2) Entre 10 e $50 \%$ da testa fragmentada (até metade das câmaras com fragmentação).

(3) Mais do que $50 \%$ da testa fragmentada (mais da metade das câmaras com fragmentação).

- Alteração da cor

(0) Ausência de alteração na cor da carapaça (carapaça translúcida ou não translúcida).

(1) Presença de alteração na cor da carapaça.

As carapaças de foraminíferos planctônicos, quando não apresentam alteração tafonômica, exibem cor esbranquiçada translúcida. Entretanto, as carapaças esbranquiçadas não translúcidas foram consideradas com cor normal, pois se acredita que seja oriunda da alteração da textura/brilho, enquanto as outras cores encontradas (acastanhadas e pretas) podem ter como origem a precipitação de elementos químicos (e.g., ferro), segundo Duleba,(1994).

- Alteração da textura/brilho

(0) Ausência de alteração na textura da carapaça e com brilho.

(1) Presença de alteração na textura e sem brilho (carapaças com aspecto granular, opaco). 
Devido a processos físicos, químicos e/ou biológicos as testas de foraminíferos podem apresentar alteração em sua textura/brilho. Processos químicos, tais como, corrosão podem ocasionar a ocorrência da textura granular em carapaças carbonáticas, segundo Rodrigues,(2006).

- Corrosão ou dissolução

(0) Ausência de corrosão ou dissolução.

(1) Presença de corrosão ou dissolução.

Quanto à corrosão, essa apresenta origem química e a combinação das assinaturas alteração de cor e textura podem indicar a presença dessa assinatura tafonômica (Rodrigues, 2006). 


\section{Capítulo III}

\section{3 - Resultados}

\section{1 - Dados Hidrográficos}

\subsection{1 - Verão de 2002}

De maneira geral, os valores de salinidade variam de 35,20 a 37,23 . Na superfície ( $0 \mathrm{~m}$ a $20 \mathrm{~m}$ de profundidade), os maiores valores de salinidade são observados na estação 7165, localizada na isóbata de 2522 m, e os menores valores de salinidade ocorrem na estação 7110, localizada na isóbata de 155 m (Tabela 4).

A 100 m de profundidade, os valores de salinidade estão compreendidos entre 35,63 e 37,17 , sendo que os maiores valores são observados na estação 7165 e os menores valores estão situados na estação 7110 (Tabela 4).

A temperatura da água na superfície (de $0 \mathrm{~m}$ a $20 \mathrm{~m}$ de profundidade) apresenta variações entre $23,56{ }^{\circ} \mathrm{C}$ e $26,39{ }^{\circ} \mathrm{C}$. Os maiores valores de temperatura são constatados na estação 7165 e os menores valores de temperatura ocorrem na estação 7142, localizada na isóbata de $160 \mathrm{~m}$ (Tabela 4).

A $100 \mathrm{~m}$ de profundidade, os valores de temperatura estão compreendidos entre $16,08^{\circ} \mathrm{C}$ e $23,25^{\circ} \mathrm{C}$, sendo que os maiores valores são observados na estação 7144, localizada na isóbata de 1952 m, e os menores valores de temperatura são constatados na estação 7110 (Tabela 4).

Segundo os limites termohalinos estabelecidos por Godoi (2005), o limite entre a AT e a ACAS estaria situado entre 79 m na estação 7110 e 192 m de profundidade na estação 7144 .

A aplicação do método estabelecido por Tomzack \& Godfrey (1994) possibilitou inferir a profundidade da base da camada de mistura na área de estudo, cujos valores variam entre $18 \mathrm{~m}$ na estação 7142 a $53 \mathrm{~m}$ na estação 7144. 
Dados de temperatura e salinidade foram utilizados na elaboração de diagrama T-S espalhado (Figura 5). As Figuras 6 a 9 representam perfis de salinidade $\mathrm{x}$ profundidade e temperatura $\mathrm{x}$ profundidade, elaborados para algumas estações de estudo, que foram escolhidas por representarem os padrões de ocorrência dos referidos parâmetros na área de estudo. 


\begin{tabular}{|c|c|c|c|c|}
\hline $\begin{array}{l}\text { Estação } \\
\text { hidrográfica }\end{array}$ & $\begin{array}{l}\text { Profundidade } \\
\text { de coleta }(\mathrm{m})\end{array}$ & $\begin{array}{c}\text { Temperatura } \\
\left({ }^{\circ} \mathrm{C}\right)\end{array}$ & Salinidade & $\begin{array}{c}\text { Massa } \\
\text { de } \\
\text { água }\end{array}$ \\
\hline \multirow{6}{*}{7109} & 0 & 24,79 & 36,36 & $\overline{\text { AT }}$ \\
\hline & 20 & 25,14 & 36,83 & AT \\
\hline & 40 & 23,89 & 37,07 & AT \\
\hline & 60 & 23,24 & 37,07 & AT \\
\hline & 80 & 23,00 & 37,06 & AT \\
\hline & 100 & 21,75 & 36,75 & AT \\
\hline \multirow{6}{*}{7110} & 0 & 24,74 & 35,20 & AT \\
\hline & 20 & 24,20 & 35,78 & AT \\
\hline & 40 & 22,45 & 36,79 & AT \\
\hline & 60 & 20,49 & 36,37 & AT \\
\hline & 80 & 18,86 & 36,10 & ACAS \\
\hline & 100 & 16,08 & 35,63 & ACAS \\
\hline \multirow{6}{*}{7120} & 0 & 24,81 & 36,49 & AT \\
\hline & 20 & 24,73 & 36,50 & AT \\
\hline & 40 & 23,38 & 37,02 & AT \\
\hline & 60 & 22,90 & 37,00 & AT \\
\hline & 80 & 22,14 & 36,84 & AT \\
\hline & 100 & 20,61 & 36,51 & AT \\
\hline \multirow{6}{*}{7121} & 0 & 25,01 & 36,43 & AT \\
\hline & 20 & 24,25 & 36,56 & AT \\
\hline & 40 & 22,82 & 36,84 & AT \\
\hline & 60 & 21,79 & 36,72 & AT \\
\hline & 80 & 21,12 & 36,59 & AT \\
\hline & 100 & 18,74 & 36,10 & ACAS \\
\hline \multirow{6}{*}{7142} & 0 & 24,24 & 36,25 & AT \\
\hline & 20 & 23,56 & 36,67 & AT \\
\hline & 40 & 22,08 & 36,72 & AT \\
\hline & 60 & 21,53 & 36,66 & AT \\
\hline & 80 & 19,33 & 36,22 & AT \\
\hline & 100 & 17,72 & 35,91 & ACAS \\
\hline \multirow{6}{*}{7144} & 0 & 25,94 & 36,78 & AT \\
\hline & 20 & 26,05 & 36,86 & AT \\
\hline & 40 & 25,87 & 36,92 & AT \\
\hline & 60 & 25,21 & 36,96 & AT \\
\hline & 80 & 23,68 & 36,98 & AT \\
\hline & 100 & 23,25 & 37,06 & AT \\
\hline \multirow{6}{*}{7154} & 0 & 26,28 & 36,91 & AT \\
\hline & 20 & 26,29 & 36,91 & AT \\
\hline & 40 & 26,16 & 36,93 & AT \\
\hline & 60 & 25,12 & 37,00 & AT \\
\hline & 80 & 23,73 & 37,08 & AT \\
\hline & 100 & 23,05 & 37,07 & AT \\
\hline \multirow{6}{*}{7165} & 0 & 26,38 & 37,01 & AT \\
\hline & 20 & 26,39 & 37,00 & AT \\
\hline & 40 & 25,96 & 37,09 & AT \\
\hline & 60 & 24,07 & 37,23 & AT \\
\hline & 80 & 23,52 & 37,23 & AT \\
\hline & 100 & 23,11 & 37,17 & AT \\
\hline
\end{tabular}

Tabela 4 - Dados hidrográficos de temperatura e salinidade, obtidos durante o verão de 2002. 


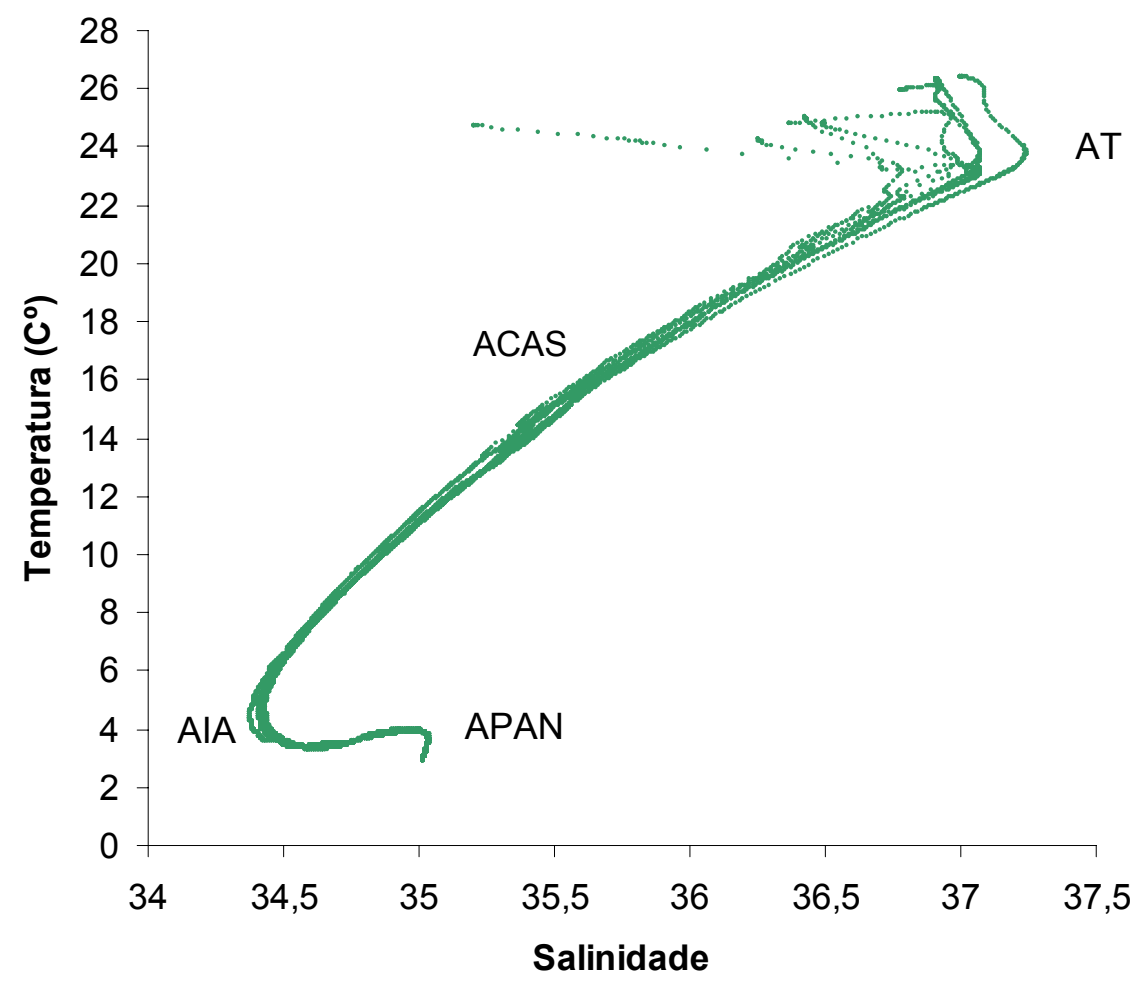

Figura 5 - Diagrama T-S espalhado das estações oceanográficas entre São Sebastião e Cabo Frio (verão de 2002). 


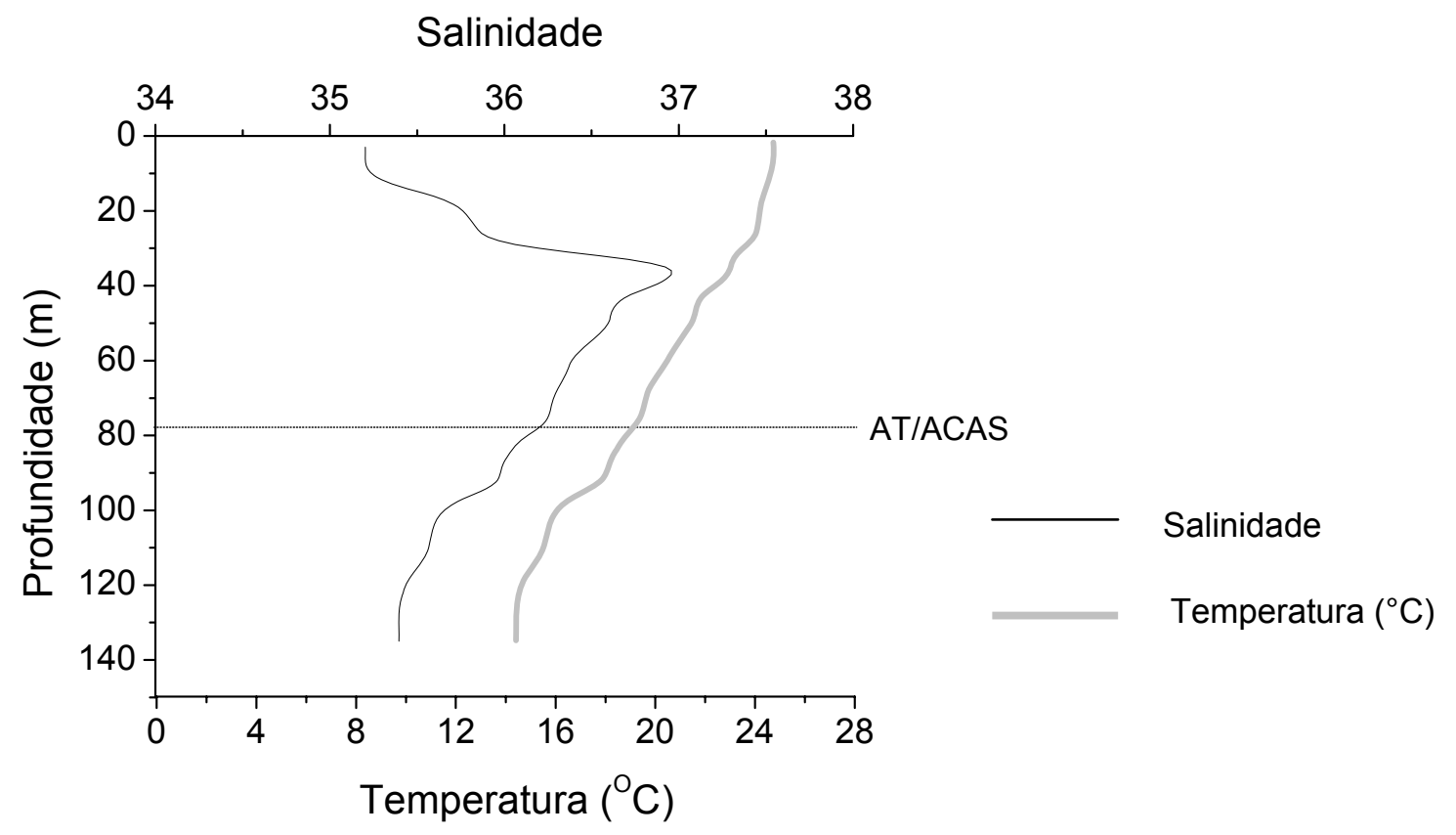

Figura 6 - Perfil de temperatura e salinidade na estação 7110 e limite entre a AT e a ACAS.

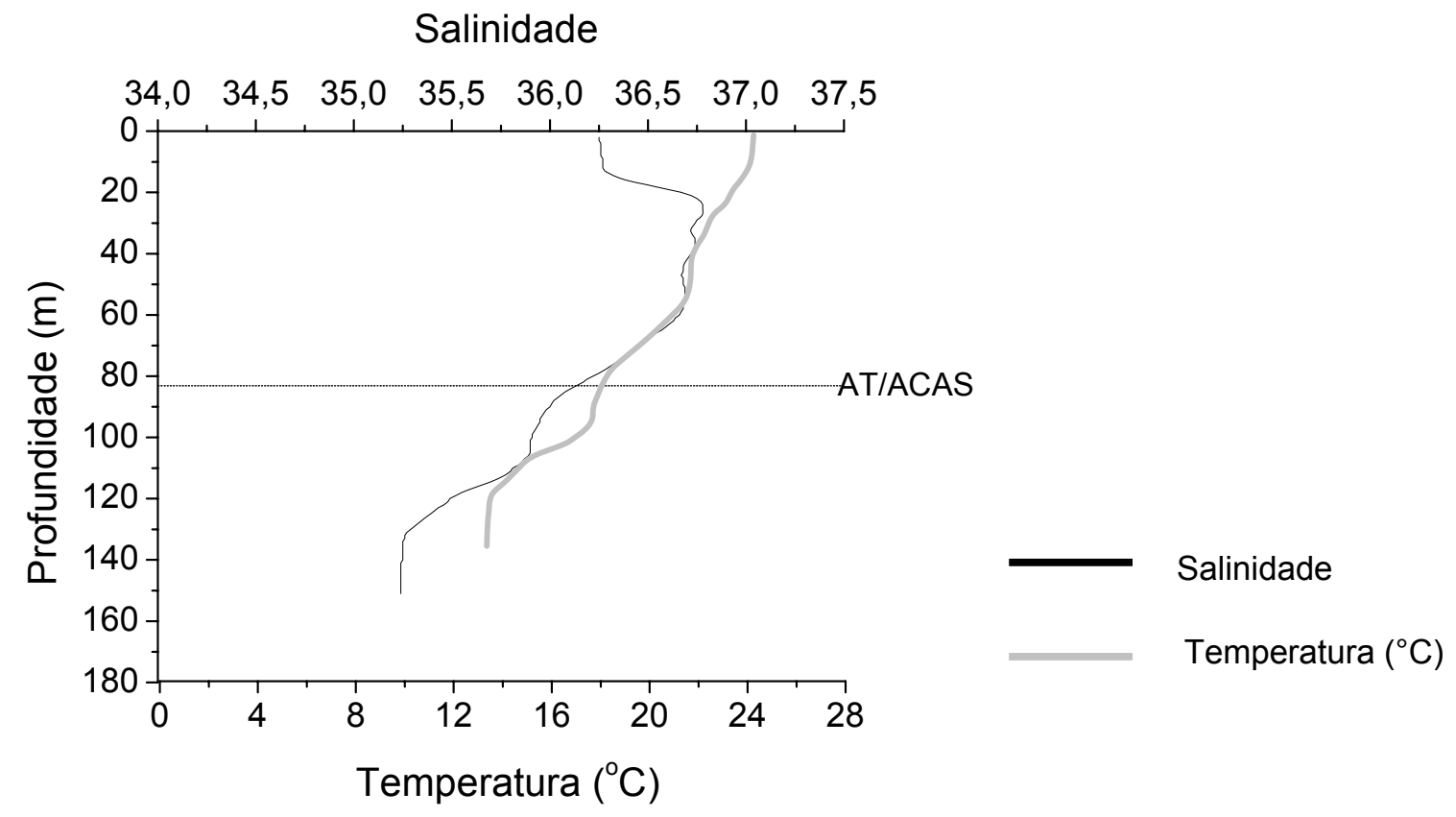

Figura 7 - Perfil de temperatura e salinidade na estação 7142 e limite entre a AT e a ACAS. 


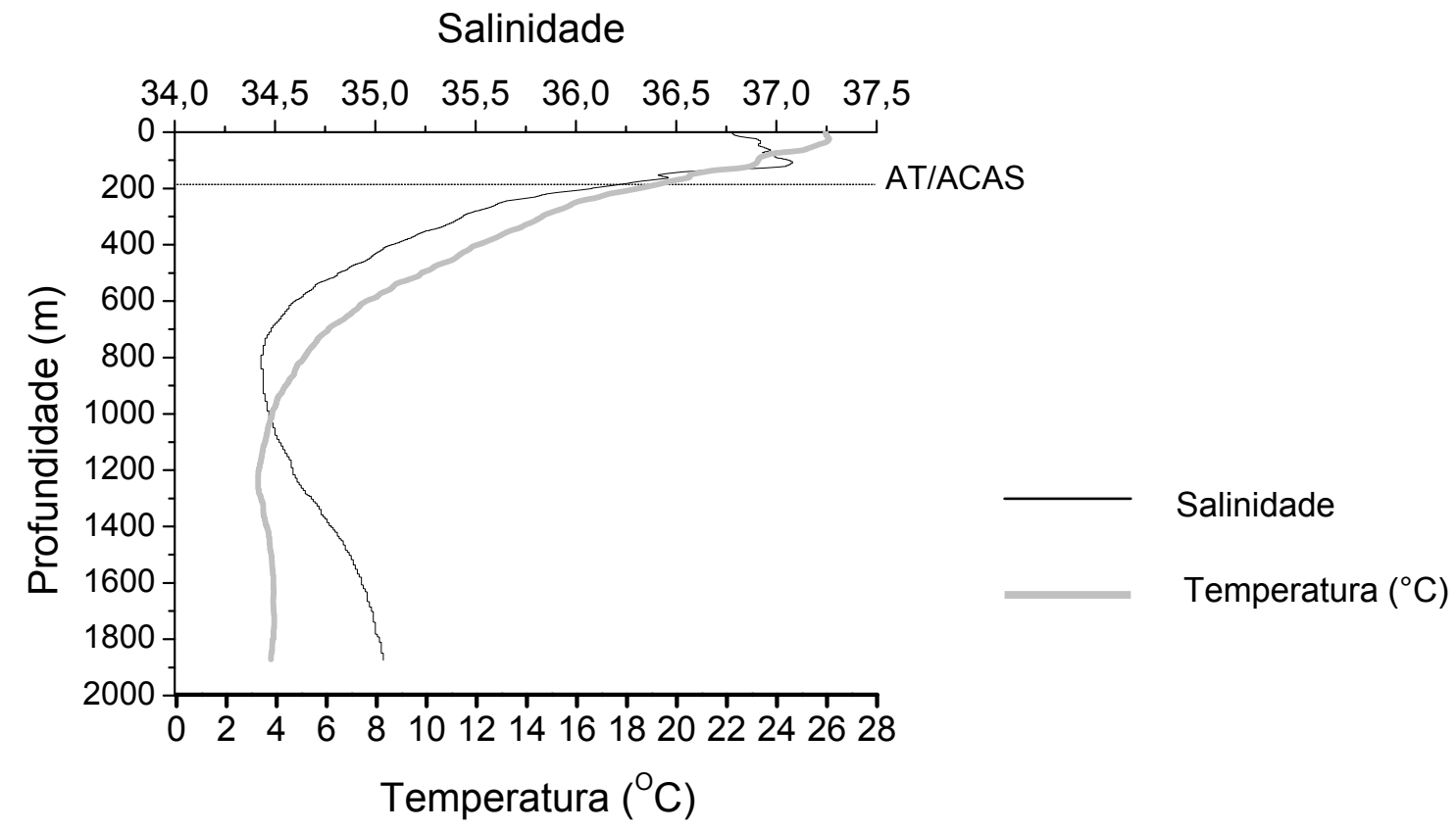

Figura 8 - Perfil de temperatura e salinidade na estação 7144 e limite entre a AT e a ACAS.

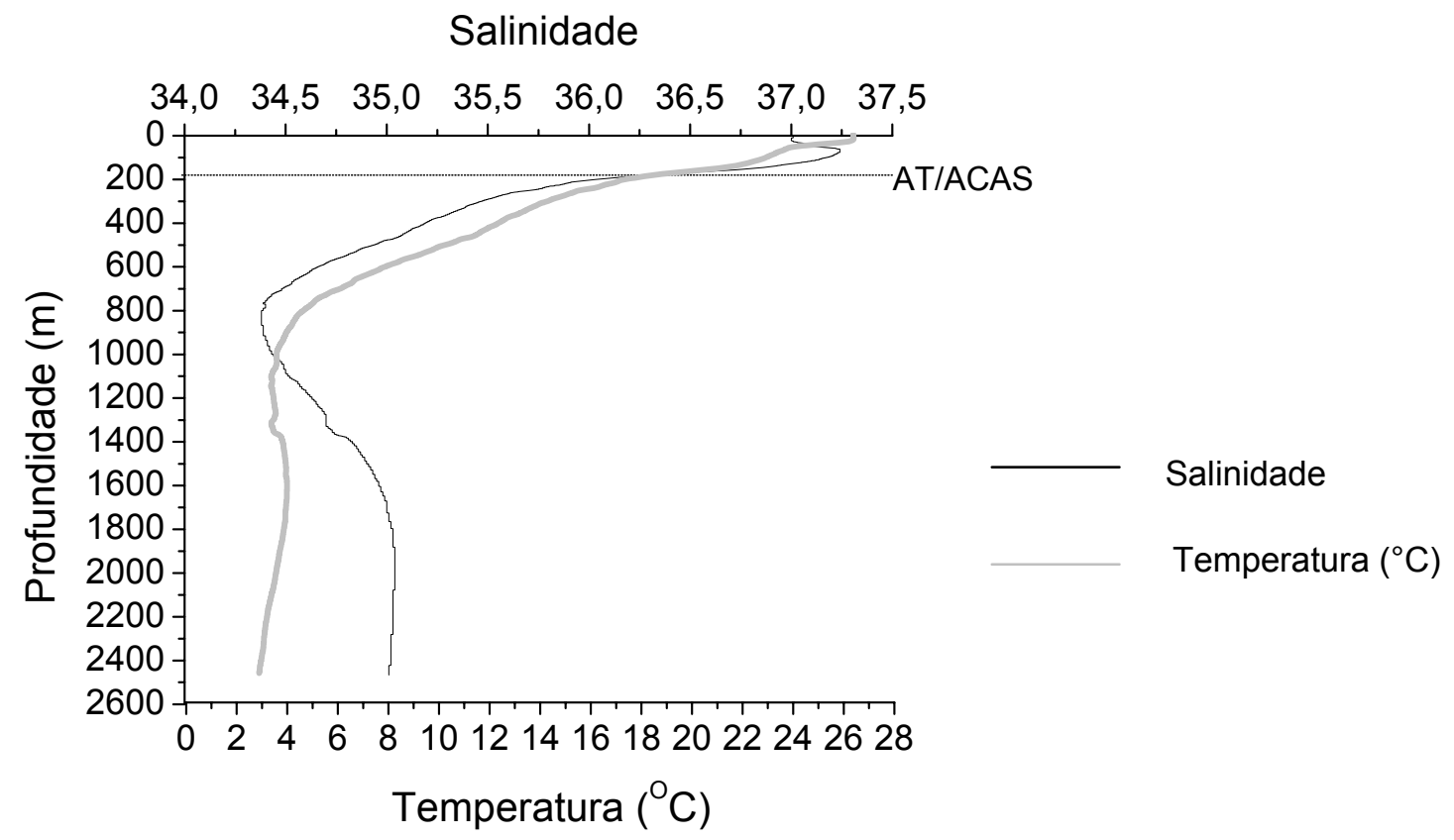

Figura 9 - Perfil de temperatura e salinidade na estação 7154 e limite entre a AT e a ACAS. 


\subsection{2 - Inverno de 2002}

De maneira geral, os valores de salinidade na superfície (0 m a $20 \mathrm{~m}$ de profundidade) variam de 35,42 a 37,39 . Os maiores valores de salinidade são observados na estação 7261 , localizada na isóbata de $1430 \mathrm{~m}$ e os menores valores de salinidade ocorrem na estação 7293 , localizada na profundidade de $1159 \mathrm{~m}$.

A 100 m de profundidade, os valores de salinidade estão compreendidos entre 36,26 e 37,32, sendo que o maior valor é observado na estação 7261 , localizada na isóbata de 1400 m, e o menor valor está situado na estação 7294, localizada na isóbata 700 m (Tabela 5).

A temperatura da água na superfície (de 0 a $20 \mathrm{~m}$ de profundidade) apresenta variações entre $22,74^{\circ} \mathrm{C}$ e $24,41^{\circ} \mathrm{C}$. O maior valor de temperatura é constatado na estação 7313, posicionada na isóbata de $1500 \mathrm{~m}$. Os menores valores, por outro lado, ocorrem na estação 7273 , localizada na profundidade de $1558 \mathrm{~m}$.

A $100 \mathrm{~m}$ de profundidade, os valores de temperatura estão compreendidos entre $19,80{ }^{\circ} \mathrm{C}$ e $22,82{ }^{\circ} \mathrm{C}$., sendo que o maior valor é observado na estação 7261 , localizada na isóbata de $1430 \mathrm{~m}$. O menor valor de temperatura é constatado na estação 7294, situada na profundidade de 708 m.

Segundo os limites termohalinos estabelecidos por Godoi (2005), o limite entre a AT e a ACAS estaria situado entre 109 m na estação 7294 e 216 m de profundidade na estação 7261.

A aplicação do método estabelecido por Tomzack \& Godfrey (1994) possibilitou verificar, que a profundidade da base da camada de mistura no inverno na área de estudo variou entre 59 m, na estação 7313, a 107 m, nas estações 7261 e 7273.

A indisponibilidade de dados de temperatura e salinidade para profundidades superiores a $200 \mathrm{~m}$, impossibilitou a elaboração do Diagrama T -S espalhado para o inverno de 2002. Assim sendo, a definição dos limites das massas de água AT, ACAS, AIA e APAN foi baseada no diagrama $T-S$ espalhado elaborado para o verão de 2002. Perfis de salinidade $x$ profundidade 
e temperatura x profundidade para algumas estações de coleta no inverno de 2002 estão representados nas Figuras 10 a 14. Nesse caso também, as estações escolhidas refletem os padrões de ocorrência dos parâmetros salinidade e temperatura para o inverno na área de estudo. 


\begin{tabular}{|c|c|c|c|c|}
\hline $\begin{array}{c}\text { Estação } \\
\text { hidrográfica }\end{array}$ & $\begin{array}{l}\text { Profundidade } \\
\text { de coleta }(\mathrm{m})\end{array}$ & $\begin{array}{c}\text { Temperatura } \\
\left({ }^{\circ} \mathrm{C}\right) \\
\end{array}$ & Salinidade & $\begin{array}{l}\text { Massas } \\
\text { De água }\end{array}$ \\
\hline \multirow{6}{*}{7261} & 0 & 23,17 & 37,31 & AT \\
\hline & 20 & 23,15 & 37,39 & AT \\
\hline & 40 & 23,13 & 37,39 & AT \\
\hline & 60 & 23,09 & 37,38 & AT \\
\hline & 80 & 23,0061 & 37,36 & $\mathrm{AT}$ \\
\hline & 100 & 22,8217 & 37,32 & $\mathrm{AT}$ \\
\hline \multirow{6}{*}{7273} & 0 & 22,74 & 36,83 & $\overline{\mathrm{AT}}$ \\
\hline & 20 & 22,74 & 36,83 & AT \\
\hline & 40 & 22,709 & 36,83 & AT \\
\hline & 60 & 22,69 & 36,84 & AT \\
\hline & 80 & 22,67 & 36,83 & AT \\
\hline & 100 & 21,63 & 36,60 & $\mathrm{AT}$ \\
\hline \multirow{6}{*}{7274} & 0 & 23,13 & 37,15 & $\mathrm{AT}$ \\
\hline & 20 & 22,97 & 37,28 & AT \\
\hline & 40 & 22,95 & 37,29 & AT \\
\hline & 60 & 22,94 & 37,29 & AT \\
\hline & 80 & 22,91 & 37,28 & AT \\
\hline & 100 & 22,70 & 37,22 & $\mathrm{AT}$ \\
\hline \multirow{6}{*}{7285} & 0 & 23,26 & 36,94 & AT \\
\hline & 20 & 23,27 & 36,94 & AT \\
\hline & 40 & 23,28 & 36,94 & AT \\
\hline & 60 & 23,23 & 36,94 & AT \\
\hline & 80 & 22,21 & 36,76 & AT \\
\hline & 100 & 20,90 & 36,53 & $\mathrm{AT}$ \\
\hline \multirow{6}{*}{7286} & 0 & 23,28 & 36,97 & $\overline{\mathrm{AT}}$ \\
\hline & 20 & 23,28 & 36,97 & AT \\
\hline & 40 & 23,29 & 36,97 & AT \\
\hline & 60 & 23,28 & 36,97 & AT \\
\hline & 80 & 23,14 & 36,93 & AT \\
\hline & 100 & 22,68 & 36,85 & AT \\
\hline \multirow{6}{*}{7293} & 0 & 22,74 & 35,42 & $\overline{\mathrm{AT}}$ \\
\hline & 20 & 23,27 & 36,70 & AT \\
\hline & 40 & 23,26 & 36,89 & AT \\
\hline & 60 & 23,25 & 36,88 & AT \\
\hline & 80 & 23,13 & 36,86 & AT \\
\hline & 100 & 22,41 & 36,73 & AT \\
\hline \multirow{6}{*}{7294} & 0 & 23,18 & 36,43 & AT \\
\hline & 20 & 22,94 & 36,40 & AT \\
\hline & 40 & 22,90 & 36,50 & AT \\
\hline & 60 & 22,93 & 36,73 & AT \\
\hline & 80 & 21,75 & 36,53 & AT \\
\hline & 100 & 19,80 & 36,26 & $\mathrm{AT}$ \\
\hline \multirow{6}{*}{7313} & 0 & 24,41 & 37,08 & AT \\
\hline & 20 & 24,44 & 37,09 & AT \\
\hline & 40 & 24,47 & 37,10 & AT \\
\hline & 60 & 23,75 & 37,01 & $\mathrm{AT}$ \\
\hline & 80 & 21,92 & 36,70 & $\mathrm{AT}$ \\
\hline & 100 & & 36,48 & AT \\
\hline
\end{tabular}

Tabela 5 - Dados hidrográficos de temperatura e salinidade, obtidos para o inverno de 2002. 


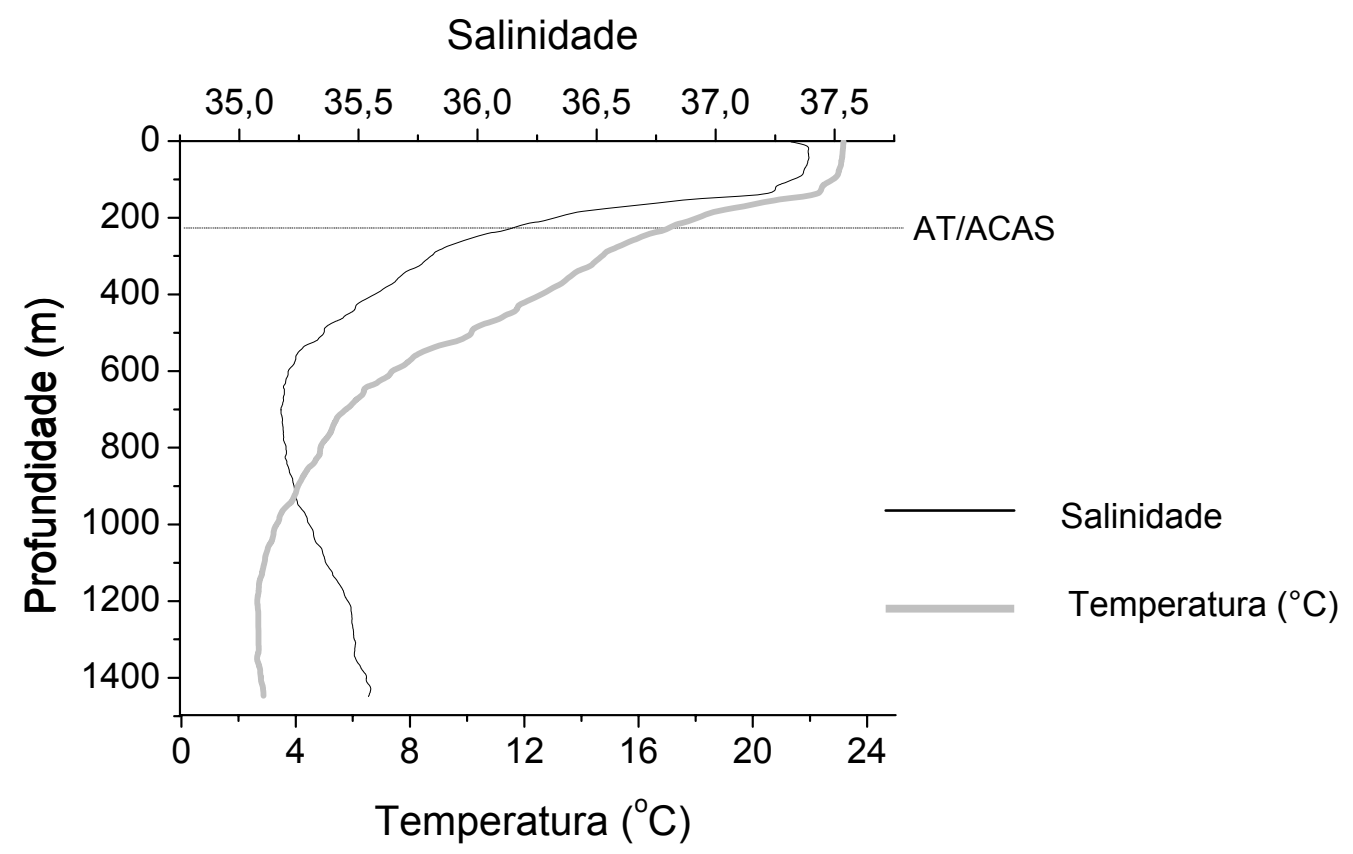

Figura 10 - Perfil de temperatura e salinidade na estação 7261 e limite entre a AT e a ACAS.

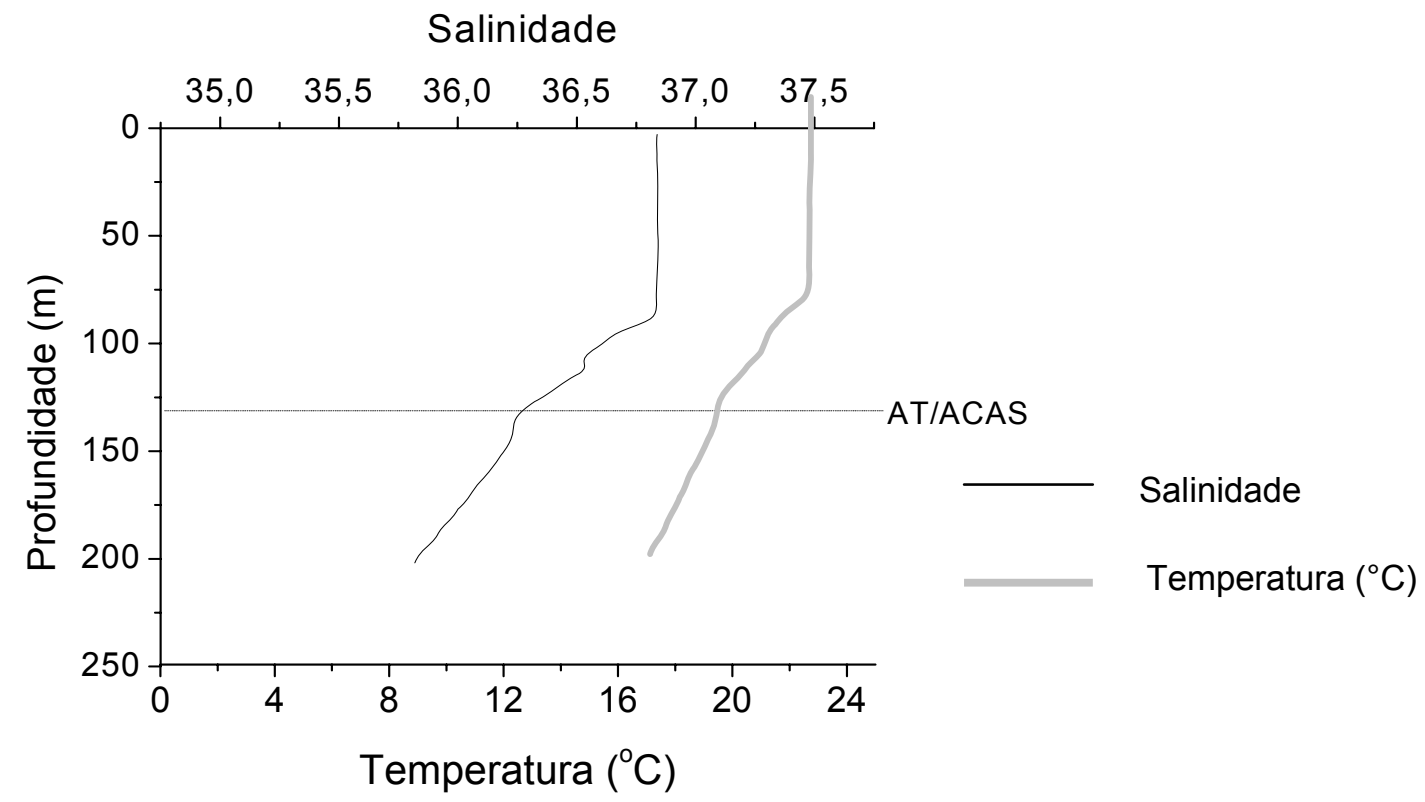

Figura 11 - Perfil de temperatura e salinidade na estação 7273 e limite entre a AT e a ACAS. 


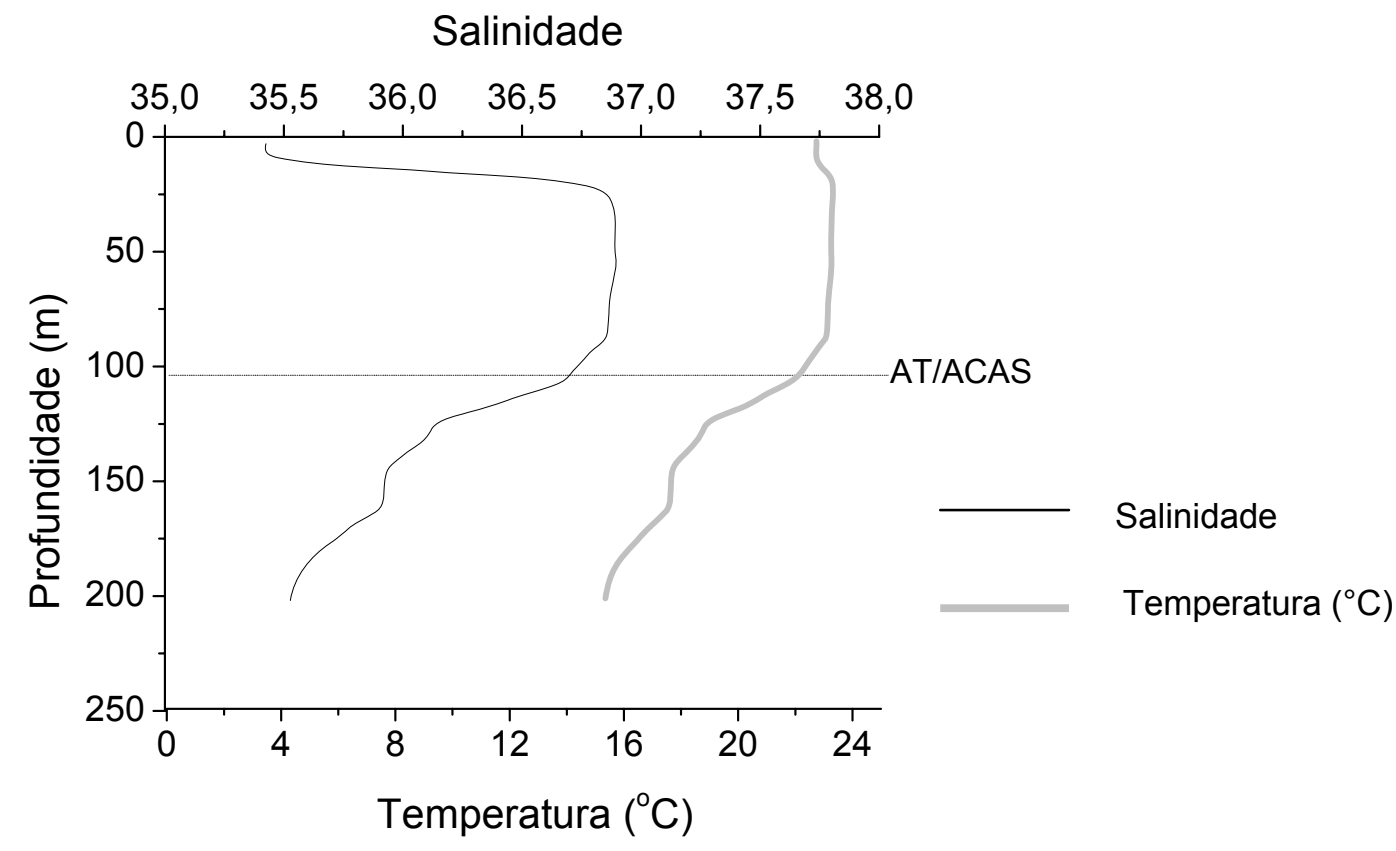

Figura 12 - Perfil de temperatura e salinidade na estação 7293 e limite entre a AT e a ACAS.

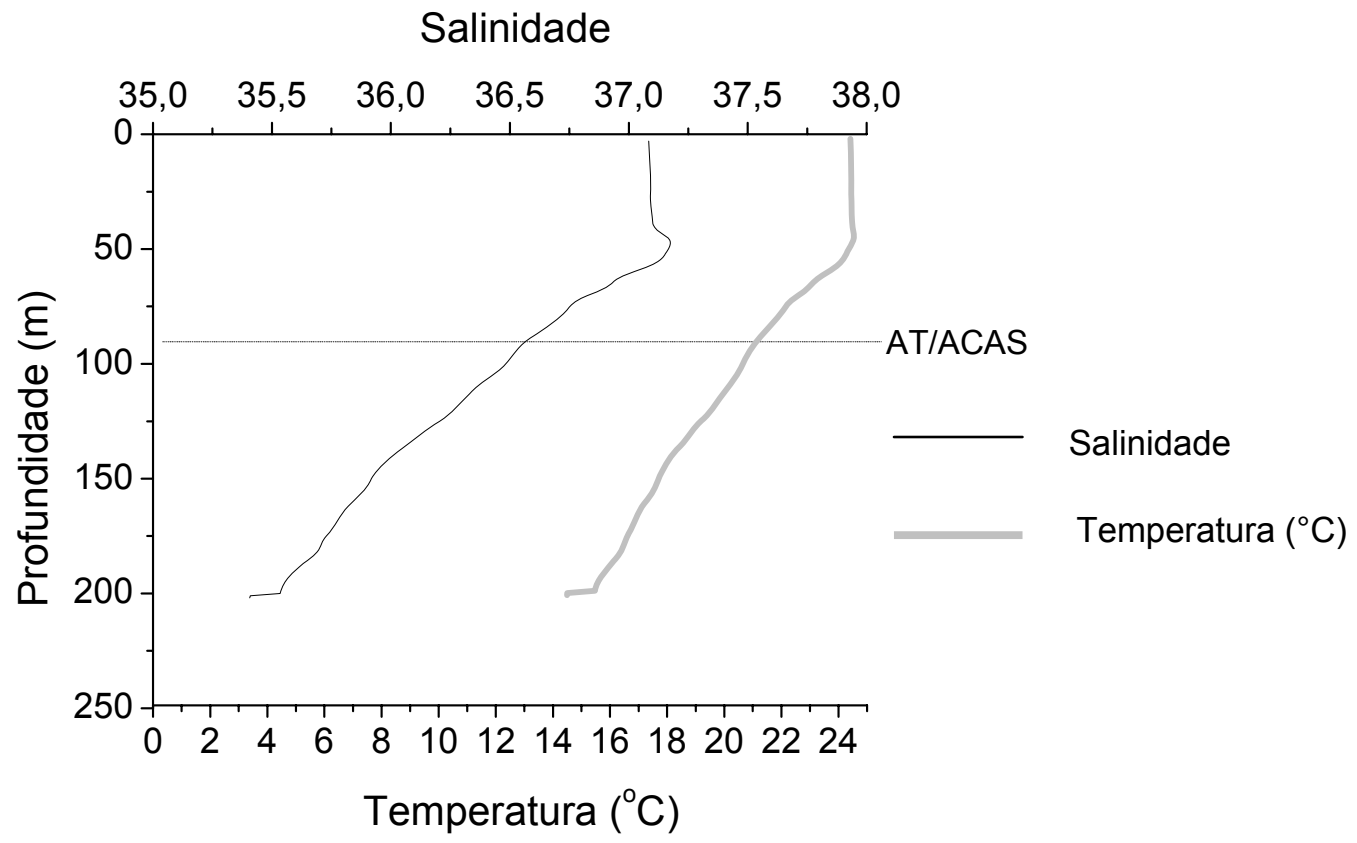

Figura 13 - Perfil de temperatura e salinidade na estação 7294 e limite entre a AT e a ACAS. 


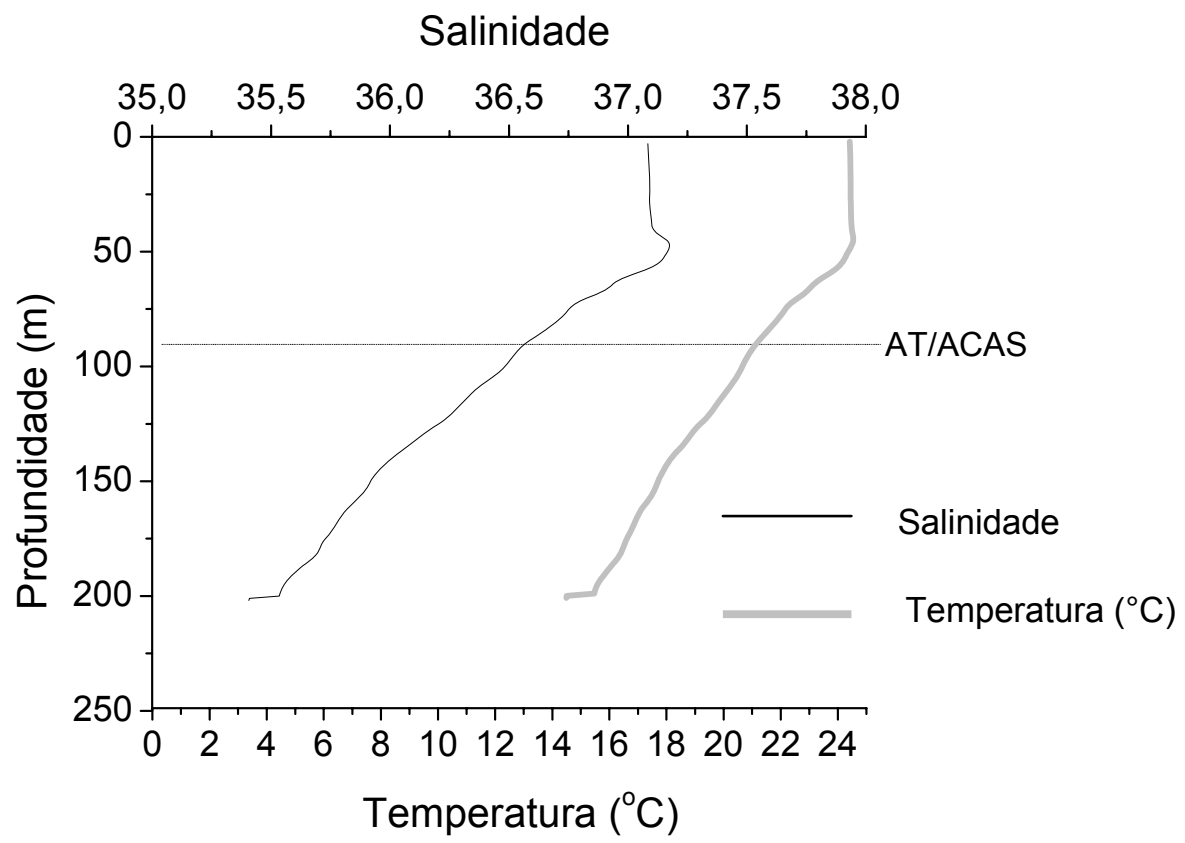

Figura 14 - Perfil de temperatura e salinidade na estação 7313 e limite entre a AT e a ACAS

\section{2 - Parâmetros hidrobiológicos}

\subsection{1 - Verão de 2002}

De maneira geral, os valores de clorofila a na superfície variam de 0,08 $\mu \mathrm{g} / \mathrm{L}$ a $0,42 \mu \mathrm{g} / \mathrm{L}$. O maior valor de clorofila a na superfície é observado na estação 7110. Por sua vez, os menores valores de clorofila a ocorrem nas estações 7154, localizada a 1565 m, e 7165 (Tabela 6).

A $100 \mathrm{~m}$ de profundidade, os valores de clorofila a estão compreendidos entre $0,21 \mu \mathrm{g} / \mathrm{L}$ e $0,37 \mu \mathrm{g} / \mathrm{L}$, sendo que os maiores valores são observados nas estações 7144 e 7165 , e o menor valor está situado na estação 7120 (Tabela $6)$.

Os maiores valores de concentração de clorofila a ocorrem no período de verão, notadamente em profundidades próximas ao domínio da ACAS (estações 7110, 7121 e 7142). 


\begin{tabular}{|c|c|c|}
\hline $\begin{array}{c}\text { Estação } \\
\text { hidrográfica }\end{array}$ & $\begin{array}{l}\text { Profundidade de } \\
\text { coleta }(\mathrm{m})\end{array}$ & $\begin{array}{c}\text { Clorofila } a \\
\quad(\mu g / L)\end{array}$ \\
\hline & 0 & 0,15 \\
\hline 7109 & $\begin{array}{c}5 \\
10 \\
25 \\
50 \\
75 \\
100 \\
\end{array}$ & $\begin{array}{l}0.15 \\
0.15 \\
0.15 \\
0.22 \\
0.21 \\
0.30 \\
\end{array}$ \\
\hline 7110 & $\begin{array}{c}0 \\
5 \\
10 \\
25 \\
50 \\
75 \\
100\end{array}$ & $\begin{array}{l}0.42 \\
0.45 \\
0.45 \\
0.39 \\
0.42 \\
1.05 \\
0.25\end{array}$ \\
\hline 7120 & $\begin{array}{c}0 \\
5 \\
10 \\
25 \\
50 \\
75 \\
100 \\
\end{array}$ & $\begin{array}{l}0.12 \\
0.12 \\
0.10 \\
0.12 \\
0.16 \\
0.26 \\
0.21 \\
\end{array}$ \\
\hline 7121 & $\begin{array}{c}0 \\
5 \\
10 \\
25 \\
50 \\
75 \\
100 \\
\end{array}$ & $\begin{array}{l}0.11 \\
0.10 \\
0.09 \\
0.11 \\
0.26 \\
0.51 \\
0.24\end{array}$ \\
\hline 7142 & $\begin{array}{c}0 \\
5 \\
10 \\
25 \\
50 \\
75 \\
100 \\
\end{array}$ & $\begin{array}{l}0.17 \\
0.18 \\
0.24 \\
0.35 \\
1.00 \\
0.47 \\
-----\end{array}$ \\
\hline 7144 & $\begin{array}{c}0 \\
5 \\
10 \\
25 \\
50 \\
75 \\
100 \\
\end{array}$ & $\begin{array}{l}0.14 \\
0.12 \\
0.14 \\
0.13 \\
0.25 \\
0.33 \\
0.37\end{array}$ \\
\hline 7154 & $\begin{array}{c}0 \\
5 \\
10 \\
25 \\
50 \\
75 \\
100 \\
\end{array}$ & $\begin{array}{l}0.08 \\
0.08 \\
0.07 \\
0.07 \\
0.13 \\
0.20 \\
0.32 \\
\end{array}$ \\
\hline 7165 & $\begin{array}{c}0 \\
5 \\
10 \\
25 \\
50 \\
75 \\
100 \\
\end{array}$ & $\begin{array}{l}0.08 \\
0.09 \\
0.09 \\
0.09 \\
0.14 \\
0.18 \\
0.37 \\
\end{array}$ \\
\hline
\end{tabular}

Tabela 6- Dados de clorofila a, obtidos para o verão de 2002. ---- representa dado não disponível. 


\subsection{2 - Inverno de 2002}

Durante o inverno, os valores de clorofila a na superfície variam de 0,20 $\mu \mathrm{g} / \mathrm{L}$ a $0,37 \mu \mathrm{g} / \mathrm{L}$. O maior valor de clorofila a na superfície é observado na estação 7293, e o menor valor de clorofila a ocorre na estação 7294 (Tabela 7).

A 100 m de profundidade, os valores de clorofila a estão compreendidos entre $0,07 \mu \mathrm{g} / \mathrm{L}$ e $0,40 \mu \mathrm{g} / \mathrm{L}$, sendo que o maior valor é observado na estação 7293, e os menores valores estão situados nas estações 7285 e 7313 (Tabela 7).

No verão, os valores de concentração de clorofila a são relativamente menores em comparação com os valores obtidos para o inverno. 


\begin{tabular}{|c|c|c|}
\hline $\begin{array}{c}\text { Estação } \\
\text { hidrográfica }\end{array}$ & $\begin{array}{l}\text { Profundidade de } \\
\text { coleta }(\mathrm{m})\end{array}$ & Clorofila $a(\mu \mathrm{g} / \mathrm{L})$ \\
\hline \multirow{7}{*}{7261} & 0 & 0,34 \\
\hline & 5 & 0,34 \\
\hline & 10 & 0,33 \\
\hline & 25 & 0,38 \\
\hline & 50 & 0,41 \\
\hline & 75 & 0,36 \\
\hline & 100 & 0,17 \\
\hline \multirow{7}{*}{7273} & 0 & 0,25 \\
\hline & 5 & 0,26 \\
\hline & 10 & 0,27 \\
\hline & 25 & 0,26 \\
\hline & 50 & 0,35 \\
\hline & 75 & 0,35 \\
\hline & 100 & 0,23 \\
\hline \multirow{7}{*}{7274} & 0 & 0,27 \\
\hline & 5 & 0,25 \\
\hline & 10 & 0,26 \\
\hline & 25 & 0,29 \\
\hline & 50 & 0,36 \\
\hline & 70 & 0,40 \\
\hline & 100 & 0,29 \\
\hline \multirow{7}{*}{7285} & 0 & 0,22 \\
\hline & 5 & 0,27 \\
\hline & 10 & 0,25 \\
\hline & 25 & 0,25 \\
\hline & 50 & 0,25 \\
\hline & 75 & 0,28 \\
\hline & 100 & 0,07 \\
\hline \multirow{7}{*}{7286} & 0 & 0,26 \\
\hline & 5 & 0,25 \\
\hline & 10 & 0,25 \\
\hline & 25 & 0,26 \\
\hline & 50 & 0,28 \\
\hline & 75 & 0,28 \\
\hline & 100 & 0,29 \\
\hline \multirow{7}{*}{7293} & 0 & 0,37 \\
\hline & 5 & 0,27 \\
\hline & 10 & 0,12 \\
\hline & 25 & 0,20 \\
\hline & 50 & 0,22 \\
\hline & 75 & 0,13 \\
\hline & 100 & 0,40 \\
\hline \multirow{7}{*}{7294} & 0 & 0,20 \\
\hline & 5 & 0,18 \\
\hline & 10 & 0,20 \\
\hline & 25 & 0,21 \\
\hline & 50 & 0,34 \\
\hline & 75 & 1,06 \\
\hline & 100 & 0,38 \\
\hline \multirow{7}{*}{7313} & 0 & 0,21 \\
\hline & 5 & 0,20 \\
\hline & 10 & 0,19 \\
\hline & 25 & 0,19 \\
\hline & 50 & 0,46 \\
\hline & 75 & 0,39 \\
\hline & 100 & 0,07 \\
\hline
\end{tabular}

Tabela 7 - Dados de clorofila a, obtidos para o inverno de 2002. 


\section{3 - Parâmetros sedimentológicos}

\subsection{1 - Granulometria}

A análise granulométrica mostrou predominância de silte arenoso nas amostras de sedimento de topo em praticamente todas as estações de coleta, com exceção da estação 7618, onde ocorre a predominância de silte (Tabela 8).

\begin{tabular}{c|c|c|c|c}
\hline $\begin{array}{c}\text { Estação de } \\
\text { coleta }\end{array}$ & Profundidade (m) & $\begin{array}{c}\text { Diâmetro } \\
\text { médio(Ø) }\end{array}$ & Classificação & Massa de água \\
\hline \hline 7365 & 964 & ------- & -------- & AIA \\
\hline 7618 & 231 & 5,0 & Silte grosso & ACAS \\
\hline 7619 & 511 & 4,94 & Silte grosso & AIA \\
\hline 7621 & 413 & 4,36 & Silte grosso & ACAS \\
\hline 7622 & 430 & 4,85 & Silte grosso & ACAS/AIA \\
\hline 7623 & 458 & 5,05 & Silte médio & AIA \\
\hline
\end{tabular}

Tabela 8 - Dados granulométricos dos sedimentos de superfície.

------ representa dado não disponível.

\section{4 - Dados Microfaunísticos}

\subsection{1 - Distribuição dos foraminíferos planctônicos na coluna de} água

A análise das amostras de plâncton sob estereomicroscópio possibilitou observar a presença de organismos pertencentes a diversos filos tais como: Chordata, Crustacea, Ctenophora, Molusca, Chetognatha, entre outros. Todavia, apenas os espécimes pertencentes ao filo Granoreticulosa, Classe Foraminifera foram retirados das amostras e analisados.

A presença expressiva nas amostras de plâncton de ovos de Salpa, organismo pertencente ao filo Chordata, dificultou o processo de triagem, pois esses organismos apresentam uma substância gelatinosa, que tem a capacidade de aglutinar muitos organismos, dentre os quais espécimes de foraminíferos planctônicos. Por este motivo, a malha utilizada no peneiramento não foi capaz de separar muitas vezes os foraminíferos planctônicos menores do que $100 \mu \mathrm{m}$, o que precisou ser feito após a triagem dos espécimes com o auxílio de uma escala micrométrica. 


\subsubsection{1 - Verão de 2002}

Foram encontrados 1399 indivíduos de foraminíferos planctônicos relativos a 10 espécies pertencentes a 6 gêneros (ANEXO 1), com tamanho de testas variando entre $0,125 \mathrm{~mm}$ e $0,350 \mathrm{~mm}$. Em geral, a freqüência de foraminíferos planctônicos nas estações de coleta são baixos com valores variando de 0,9 a 13,25 indivíduos por litro, sendo que em $20 \%$ das amostras analisadas não foram encontrados espécimes de foraminíferos planctônicos (Tabela 9).

Os maiores valores de freqüência foram constatados nas estações 7120 , 7154 e 7144, localizadas nas isóbatas de $1100 \mathrm{~m}, 1500 \mathrm{~m}$ e $1900 \mathrm{~m}$ respectivamente. Em contraposição, os menores valores foram observados nas estações 7121 e 7142, localizadas nas isóbatas de $200 \mathrm{~m}$ e $100 \mathrm{~m}$, respectivamente.

As espécies Globigerina bulloides, Globigerinoides ruber (pink), Globigerinoides ruber (white), Globigerinella siphonifera e Globorotalia menardii representam $93,5 \%$ do total de espécimes observados, sendo que as demais espécies constituem menos de $7 \%$ da comunidade existente.

A distribuição das espécies de foraminíferos planctônicos ao longo da coluna d'água nas estações hidrográficas pode ser observada na Tabela 10 e na Figura 15. 


\begin{tabular}{|c|c|c|c|c|}
\hline $\begin{array}{l}\text { Estação } \\
\text { hidrográfica }\end{array}$ & $\begin{array}{l}\text { Profundidade } \\
\text { de coleta (m) }\end{array}$ & $\begin{array}{l}\text { Volume } \\
\text { filtrado } \\
\left(\mathrm{m}^{3}\right)\end{array}$ & $\begin{array}{c}\text { Abundância } \\
\text { de } \\
\text { foraminíferos } \\
\text { planctônicos }\end{array}$ & $\begin{array}{c}\text { Freqüência } \\
\left(\text { Espcimes } / \mathrm{m}^{3}\right)\end{array}$ \\
\hline \multirow{5}{*}{7109} & $0-20$ & 22,86 & 38 & 1,66 \\
\hline & $20-40$ & 15,84 & 37 & 2,34 \\
\hline & $40-60$ & 14,84 & 11 & 0,74 \\
\hline & $60-80$ & 13,8 & 0 & 0 \\
\hline & $80-100$ & 49,73 & 10 & 0,2 \\
\hline \multirow{5}{*}{7110} & $0-20$ & 20,71 & 14 & 0,68 \\
\hline & $20-40$ & 17,29 & 24 & 1,39 \\
\hline & $40-60$ & 16,49 & 51 & 3,09 \\
\hline & $60-80$ & 23,62 & 32 & 1,35 \\
\hline & $80-100$ & 69,07 & 23 & 0,33 \\
\hline \multirow{5}{*}{7120} & $0-20$ & 38 & 133 & 3,5 \\
\hline & $20-40$ & 11,82 & 25 & 2,12 \\
\hline & $40-60$ & 2,11 & 28 & 13,25 \\
\hline & $60-80$ & 10,12 & 13 & 1,28 \\
\hline & $80-10$ & 17,46 & 0 & 0 \\
\hline \multirow{5}{*}{7121} & $0-20$ & 46,61 & 65 & 1,39 \\
\hline & $20-40$ & 18,53 & 0 & 0 \\
\hline & $40-60$ & 12,32 & 14 & 1,14 \\
\hline & $60-80$ & 14,22 & 0 & 0 \\
\hline & 80-100 & 23,28 & 0 & 0 \\
\hline \multirow{5}{*}{7142} & $0-20$ & 27,06 & 42 & 1,55 \\
\hline & $20-40$ & 20,22 & 6 & 0,3 \\
\hline & $40-60$ & 26,41 & 0 & 0 \\
\hline & $60-80$ & 20,14 & 10 & 0,5 \\
\hline & $80-100$ & 21,79 & 16 & 0,73 \\
\hline \multirow{5}{*}{7144} & $0-20$ & 13,24 & 87 & 6,57 \\
\hline & $20-40$ & 16,85 & 29 & 1,72 \\
\hline & $40-60$ & 22,9 & 32 & 1,4 \\
\hline & $60-80$ & 17,78 & 44 & 2,47 \\
\hline & $80-100$ & 14,54 & 12 & 0,83 \\
\hline \multirow{5}{*}{7154} & $0-20$ & 26,71 & 106 & 3,97 \\
\hline & $20-40$ & 15,15 & 75 & 4,95 \\
\hline & $40-60$ & 19,64 & 28 & 1,43 \\
\hline & $60-80$ & 54,51 & 49 & 0,9 \\
\hline & $80-100$ & 16,13 & 58 & 3,6 \\
\hline \multirow{5}{*}{7165} & $0-20$ & 31,73 & 251 & 7,91 \\
\hline & $20-40$ & 18,17 & 26 & 1,43 \\
\hline & $40-60$ & 24,39 & 0 & 0 \\
\hline & $60-80$ & 29,57 & 10 & 0,34 \\
\hline & $80-100$ & 28,43 & 0 & 0 \\
\hline
\end{tabular}

Tabela 9 - Dados de volume de água filtrada, abundância e freqüência de foraminíferos planctônicos encontrados de $0 \mathrm{~m}$ a $100 \mathrm{~m}$ de profundidade na coluna de água durante o verão de 2002. 


\begin{tabular}{|c|c|c|c|c|c|c|c|c|c|}
\hline \multirow{2}{*}{ Espécies } & \multirow{2}{*}{$\begin{array}{c}\text { Profundidades } \\
(\mathrm{m})\end{array}$} & \multicolumn{8}{|c|}{ Estação hidrográfica de coleta } \\
\hline & & 7109 & 7110 & 7120 & 7121 & 7142 & 7144 & 7154 & 7165 \\
\hline \multirow{5}{*}{$\begin{array}{c}\text { Globigerina } \\
\text { bulloides }\end{array}$} & $0-20$ & 0,13 & 0,10 & 0,13 & 0,00 & 0,00 & 0,30 & 0,19 & 0,50 \\
\hline & $20-40$ & 0,13 & 0,17 & 0,08 & 0,00 & 0,15 & 0,06 & 0,20 & 0,28 \\
\hline & $40-60$ & 0,00 & 0,06 & 1,42 & 0,16 & 0,00 & 0,17 & 0,00 & 0,00 \\
\hline & $60-80$ & 0,00 & 0,08 & 0,40 & 0,00 & 0,15 & 0,17 & 0,02 & 0,03 \\
\hline & $80-100$ & 0,04 & 0,07 & 0,00 & 0,00 & 0,14 & 0,00 & 0,56 & 0,00 \\
\hline \multirow{5}{*}{$\begin{array}{l}\text { Globigerina } \\
\text { falconensis }\end{array}$} & $0-20$ & 0,00 & 0,00 & 0,00 & 0,00 & 0,00 & 0,00 & 0,00 & 0,00 \\
\hline & $20-40$ & 0,00 & 0,00 & 0,00 & 0,00 & 0,00 & 0,00 & 0,00 & 0,00 \\
\hline & $40-60$ & 0,00 & 0,00 & 0,00 & 0,00 & 0,00 & 0,00 & 0,00 & 0,00 \\
\hline & $60-80$ & 0,00 & 0,04 & 0,00 & 0,00 & 0,00 & 0,11 & 0,00 & 0,00 \\
\hline & 80-100 & 0,02 & 0,01 & 0,00 & 0,00 & 0,23 & 0,07 & 0,06 & 0,00 \\
\hline \multirow{5}{*}{$\begin{array}{l}\text { Globigerinella } \\
\text { calida }\end{array}$} & $0-20$ & 0,00 & 0,00 & 0,00 & 0,00 & 0,04 & 0,23 & 0,04 & 0,03 \\
\hline & $20-40$ & 0,00 & 0,00 & 0,00 & 0,00 & 0,00 & 0,00 & 0,07 & 0,00 \\
\hline & $40-60$ & 0,00 & 0,00 & 0,00 & 0,00 & 0,00 & 0,00 & 0,00 & 0,00 \\
\hline & $60-80$ & 0,00 & 0,00 & 0,00 & 0,00 & 0,05 & 0,11 & 0,00 & 0,03 \\
\hline & $80-100$ & 0,00 & 0,00 & 0,00 & 0,00 & 0,05 & 0,07 & 0,00 & 0,00 \\
\hline \multirow{5}{*}{$\begin{array}{l}\text { Globigerinoides } \\
\text { ruber (pink) }\end{array}$} & $0-20$ & 0,61 & 0,39 & 2,50 & 0,99 & 0,85 & 2,49 & 2,36 & 3,53 \\
\hline & $20-40$ & 0,63 & 0,23 & 1,27 & 0,00 & 0,10 & 0,36 & 3,63 & 0,44 \\
\hline & $40-60$ & 0,13 & 0,49 & 1,42 & 0,24 & 0,00 & 0,22 & 0,81 & 0,00 \\
\hline & $60-80$ & 0,00 & 0,17 & 0,30 & 0,00 & 0,10 & 0,28 & 0,15 & 0,07 \\
\hline & 80-100 & 0,00 & 0,03 & 0,00 & 0,00 & 0,00 & 0,00 & 0,31 & 0,00 \\
\hline \multirow{5}{*}{$\begin{array}{l}\text { Globigerinoides } \\
\text { ruber (white) }\end{array}$} & $0-20$ & 0,87 & 0,14 & 0,63 & 0,36 & 0,63 & 2,95 & 0,86 & 3,21 \\
\hline & $20-40$ & 1,14 & 0,69 & 0,51 & 0,00 & 0,05 & 0,71 & 0,92 & 0,55 \\
\hline & $40-60$ & 0,27 & 1,39 & 9,48 & 0,41 & 0,00 & 0,74 & 0,51 & 0,00 \\
\hline & $60-80$ & 0,00 & 0,72 & 0,40 & 0,00 & 0,05 & 0,11 & 0,73 & 0,07 \\
\hline & 80-100 & 0,00 & 0,13 & 0,00 & 0,00 & 0,14 & 0,34 & 2,36 & 0,00 \\
\hline \multirow{5}{*}{$\begin{array}{c}\text { Globigerinoides } \\
\text { sacculifer }\end{array}$} & $0-20$ & 0,04 & 0,00 & 0,16 & 0,02 & 0,00 & 0,00 & 0,11 & 0,19 \\
\hline & $20-40$ & 0,13 & 0,00 & 0,00 & 0,00 & 0,00 & 0,00 & 0,00 & 0,00 \\
\hline & $40-60$ & 0,00 & 0,06 & 0,00 & 0,00 & 0,00 & 0,00 & 0,00 & 0,00 \\
\hline & $60-80$ & 0,00 & 0,04 & 0,10 & 0,00 & 0,00 & 0,00 & 0,00 & 0,00 \\
\hline & 80-100 & 0,02 & 0,00 & 0,00 & 0,00 & 0,00 & 0,07 & 0,25 & 0,00 \\
\hline \multirow{5}{*}{$\begin{array}{l}\text { Globigerinoides } \\
\text { siphonifera }\end{array}$} & $0-20$ & 0,00 & 0,05 & 0,08 & 0,02 & 0,00 & 0,08 & 0,00 & 0,00 \\
\hline & $20-40$ & 0,19 & 0,17 & 0,08 & 0,00 & 0,00 & 0,12 & 0,00 & 0,00 \\
\hline & $40-60$ & 0,13 & 1,03 & 0,00 & 0,08 & 0,00 & 0,09 & 0,00 & 0,00 \\
\hline & $60-80$ & 0,00 & 0,17 & 0,00 & 0,00 & 0,05 & 0,45 & 0,00 & 0,00 \\
\hline & $80-100$ & 0,00 & 0,03 & 0,00 & 0,00 & 0,14 & 0,21 & 0,06 & 0,00 \\
\hline \multirow{5}{*}{$\begin{array}{c}\text { Globorotalia } \\
\text { menardii }\end{array}$} & 0-20 & 0,00 & 0,00 & 0,00 & 0,00 & 0,00 & 0,38 & 0,37 & 0,47 \\
\hline & $20-40$ & 0,06 & 0,00 & 0,00 & 0,00 & 0,00 & 0,30 & 0,13 & 0,11 \\
\hline & $40-60$ & 0,07 & 0,00 & 0,00 & 0,00 & 0,00 & 0,09 & 0,10 & 0,00 \\
\hline & $60-80$ & 0,00 & 0,00 & 0,00 & 0,00 & 0,00 & 0,56 & 0,00 & 0,03 \\
\hline & $80-100$ & 0,08 & 0,00 & 0,00 & 0,00 & 0,00 & 0,00 & 0,00 & 0,00 \\
\hline \multirow{5}{*}{$\begin{array}{c}\text { Neogloboquadrina } \\
\text { dutertrei }\end{array}$} & $0-20$ & 0,00 & 0,00 & 0,00 & 0,00 & 0,00 & 0,08 & 0,00 & 0,00 \\
\hline & $20-40$ & 0,00 & 0,00 & 0,17 & 0,00 & 0,00 & 0,18 & 0,00 & 0,00 \\
\hline & $40-60$ & 0,00 & 0,06 & 0,95 & 0,16 & 0,00 & 0,00 & 0,00 & 0,00 \\
\hline & $60-80$ & 0,00 & 0,13 & 0,00 & 0,00 & 0,05 & 0,34 & 0,00 & 0,03 \\
\hline & $80-100$ & 0,00 & 0,06 & 0,00 & 0,00 & 0,00 & 0,07 & 0,00 & 0,00 \\
\hline \multirow{5}{*}{ Orbulina universa } & $0-20$ & 0,00 & 0,00 & 0,00 & 0,00 & 0,00 & 0,08 & 0,00 & 0,00 \\
\hline & $20-40$ & 0,06 & 0,00 & 0,00 & 0,00 & 0,00 & 0,00 & 0,00 & 0,00 \\
\hline & $40-60$ & 0,07 & 0,00 & 0,00 & 0,00 & 0,00 & 0,04 & 0,00 & 0,00 \\
\hline & $60-80$ & 0,00 & 0,00 & 0,00 & 0,00 & 0,05 & 0,22 & 0,00 & 0,03 \\
\hline & $80-100$ & 0,00 & 0,00 & 0,00 & 0,00 & 0,00 & 0,00 & 0,00 & 0,00 \\
\hline
\end{tabular}

Tabela 10 - Freqüência de foraminíferos planctônicos ao longo da coluna d'água durante o verão de 2002. 


\section{Estação 7109}

Nessa estação, são encontradas 8 espécies, Globigerina bulloides, Globigerina falconensis, Globigerinoides ruber (pink), Globigerinoides ruber (white), Globigerinoides sacculifer, Globigerinella siphonifera, Globorotalia menardii e Orbulina universa (Tabela 10).

A maior freqüência de indivíduos de foraminíferos planctônicos é constatada entre $0 \mathrm{~m}$ e $60 \mathrm{~m}$ de profundidade na coluna d'água. As espécies encontradas nesse intervalo de profundidade são G. bulloides, G. ruber (pink), G. ruber (white), G. sacculifer, G. siphonifera e Orbulina universa. As espécies G. ruber (pink), G. ruber (white) são as mais freqüentes, exibindo valores máximos de 0,63 especimes $/ \mathrm{m}^{3}$ e 1,14 especimes $/ \mathrm{m}^{3}$, respectivamente (Tabela 10).

Nesse intervalo de profundidade $(0 \mathrm{~m}$ a $60 \mathrm{~m})$ a concentração de clorofila a varia de 0,15 a $0,22 \mu \mathrm{g} / \mathrm{L}$, a temperatura apresenta variação entre $23,24^{\circ} \mathrm{C}$ e $25,14{ }^{\circ} \mathrm{C}$ e a salinidade de 36,36 a 37,83 .

Entre $20 \mathrm{~m}$ e $40 \mathrm{~m}$ de profundidade ocorre decréscimo na temperatura, a qual coincide com o aumento na freqüência de G. ruber (withe), G. sacculifer e G. siphonifera.

Entre $80 \mathrm{~m}$ e $100 \mathrm{~m}$ de profundidade, a freqüência de indivíduos é expressivamente menor, e as espécies encontradas são G. bulloides $(0,04$ especimes $\left./ \mathrm{m}^{3}\right)$, G. falconensis $\left(0,02\right.$ especimes $\left./ \mathrm{m}^{3}\right)$ e G. menardii. $(0,8$ especimes $/ \mathrm{m}^{3}$ ). Nesse intervalo de profundidade, a concentração de clorofila $a$ varia de $0,21 \mu \mathrm{g} / \mathrm{L}$ a $0,30 \mu \mathrm{g} / \mathrm{L}$, a temperatura de $21,75{ }^{\circ} \mathrm{C}$ a $23,00{ }^{\circ} \mathrm{C}$ e a salinidade de 36,75 a 37,06 . (Figura 15). 


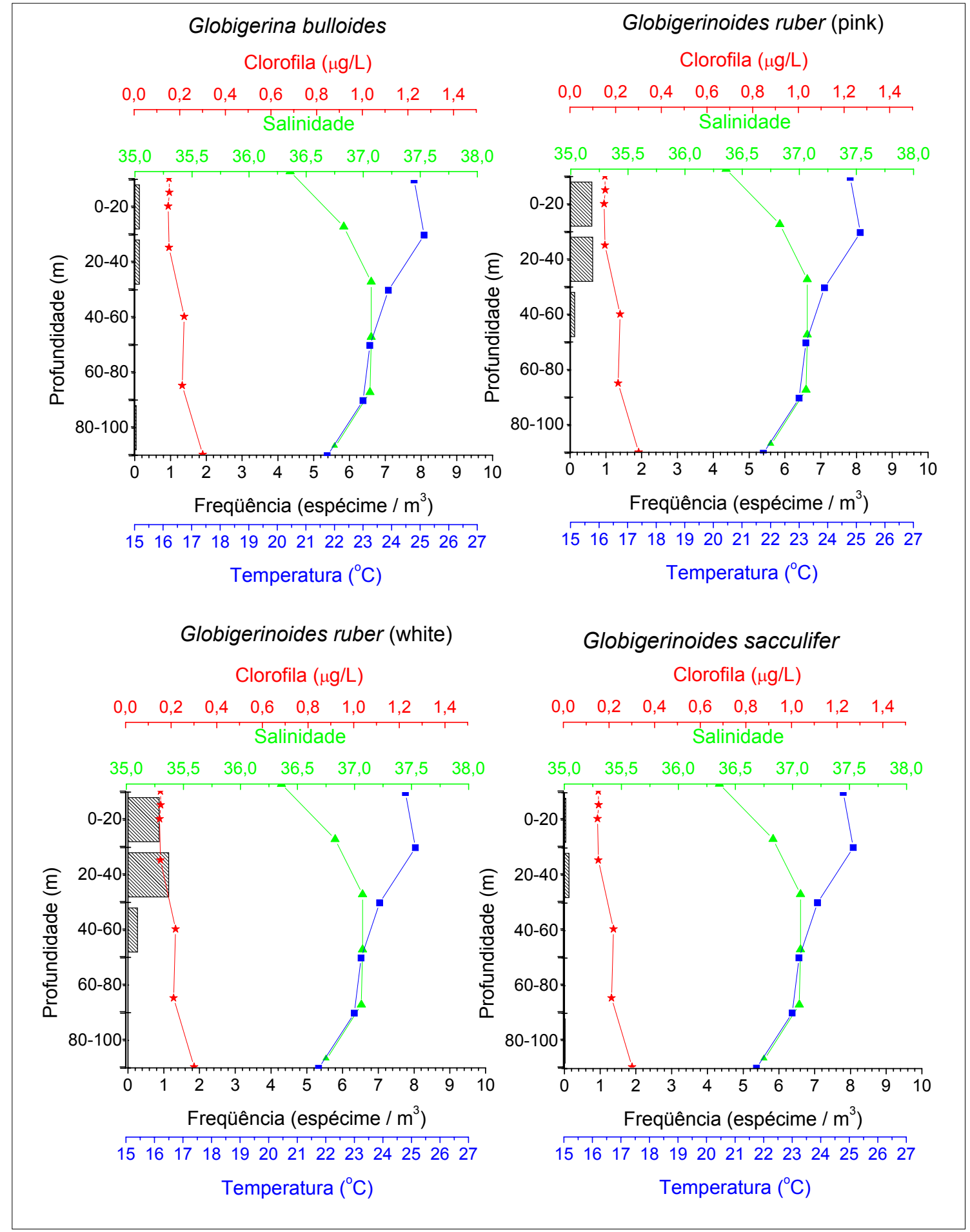

Figura 15 - Distribuição de foraminíferos planctônicos, temperatura, salinidade e concentração de clorofila a ao longo da coluna d`água na estação hidrográfica 7109. 


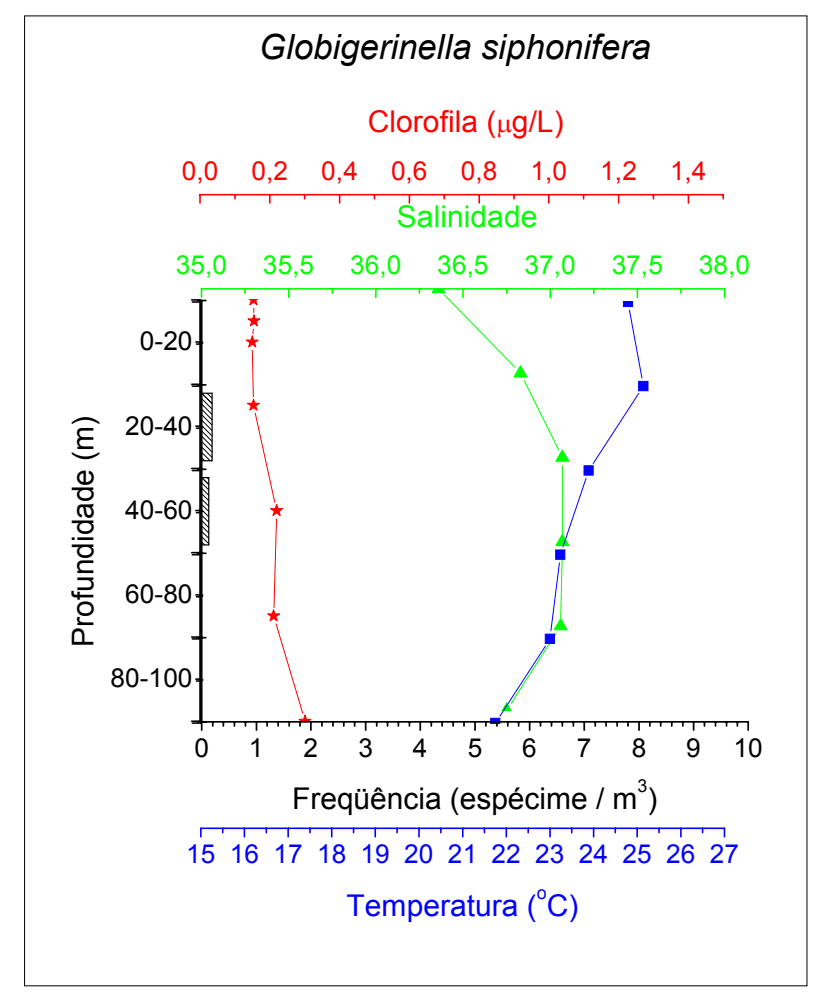

Figura 15 (continuação) - Distribuição de foraminíferos planctônicos, temperatura, salinidade e concentração de clorofila a ao longo da coluna d’água na estação hidrográfica 7109.

\section{Estação 7110}

Nessa estação, são encontradas 7 espécies, G. bulloides, $G$. falconensis, G. ruber (pink), G. ruber (white), G. sacculifer, G. siphonifera e N. dutertrei (Tabela 10).

G. ruber (pink), G. ruber (white) e G. siphonifera são observadas em todas as profundidades analisadas, sendo que os maiores valores de freqüência são constatados entre $40 \mathrm{~m}$ e $60 \mathrm{~m}$ de profundidade. Nesse intervalo de profundidade, a concentração de clorofila a é de 0,42 $\mu \mathrm{g} / \mathrm{L}$, a temperatura apresenta variação entre $20,49{ }^{\circ} \mathrm{C}$ e $22,45^{\circ} \mathrm{C}$ e a salinidade de 36,37 a 36,79 (Figura 16).

$N$. dutertrei é constatada a partir de $40 \mathrm{~m}$ de profundidade, e apresenta maior valor de freqüência a $80 \mathrm{~m}$ de profundidade, onde a concentração de clorofila a é $1,04 \mu \mathrm{g} / \mathrm{L}$, a temperatura é $18,8^{\circ} \mathrm{C}$ e a salinidade é 36,1 (Figura 16). 
G. falconensis e G. sacculifer apresentam as menores freqüências, variando entre 0,01 espécimes $/ \mathrm{m}^{3}$ e 0,04 espécimes $/ \mathrm{m}^{3}$ e 0,04 espécimes $/ \mathrm{m}^{3}$ e 0,06 espécimes $/ \mathrm{m}^{3}$, respectivamente.

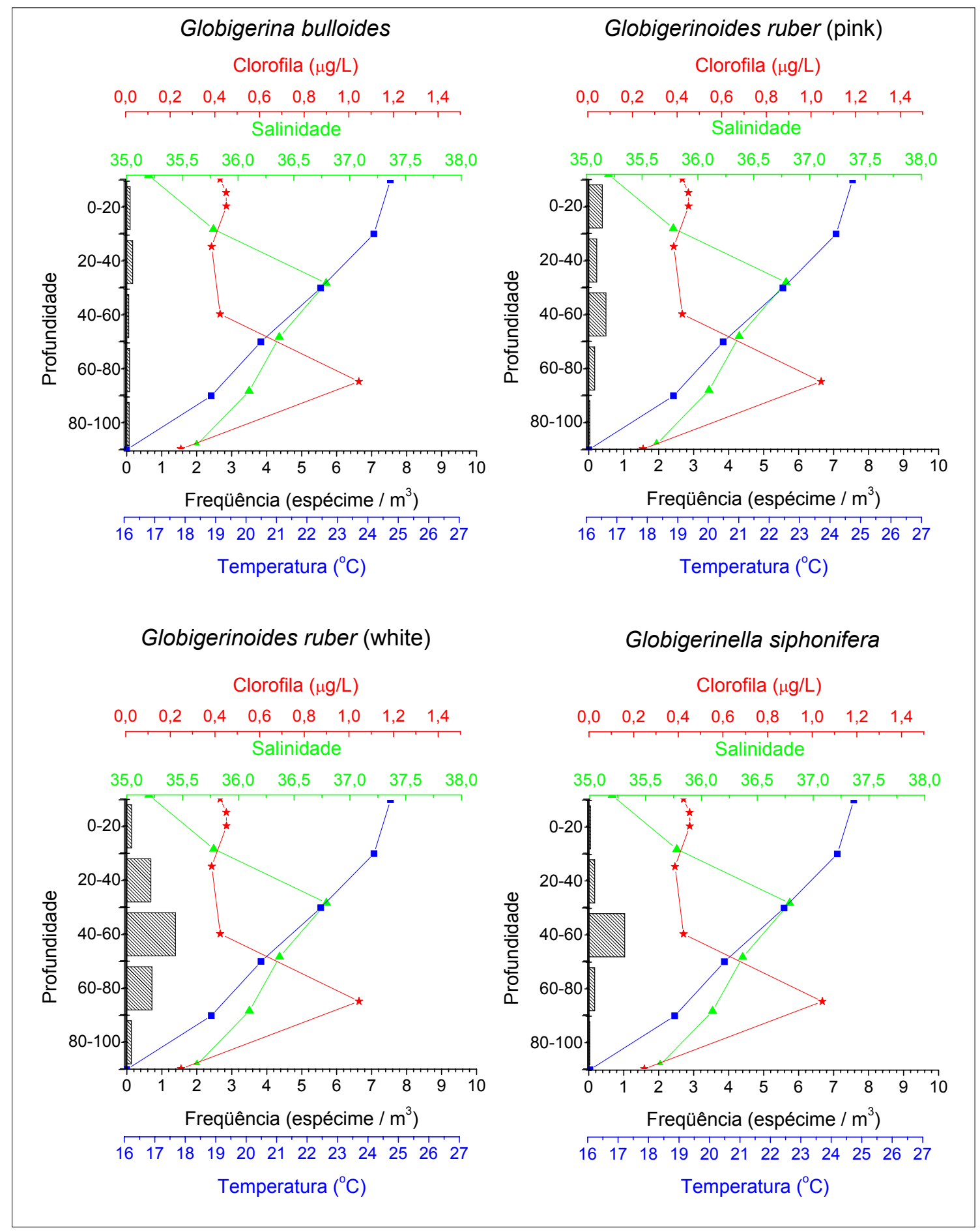

Figura 16 - Distribuição de foraminíferos planctônicos, temperatura, salinidade e concentração de clorofila a ao longo da coluna d’água na estação hidrográfica 7110. 


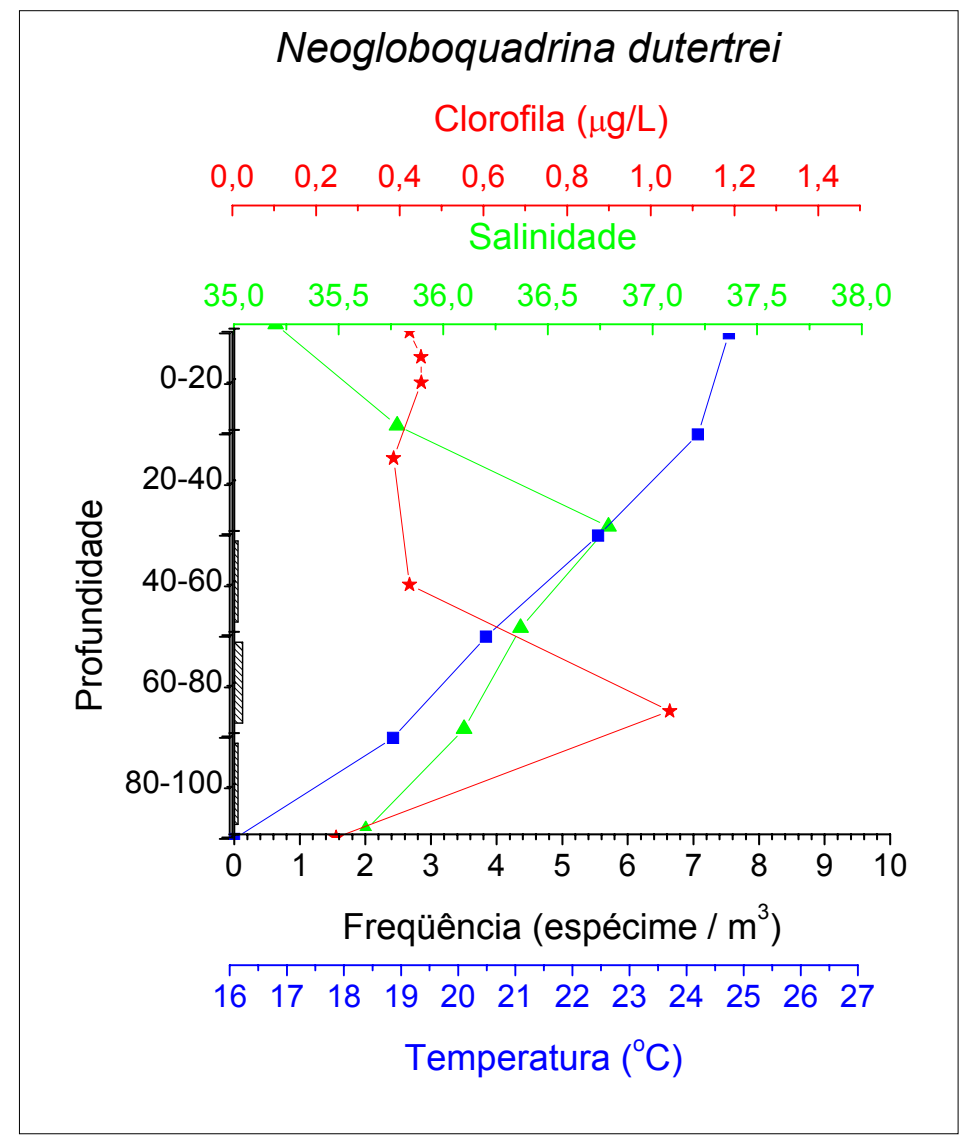

Figura 16 (continuação) - Distribuição de foraminíferos planctônicos, temperatura, salinidade e concentração de clorofila a ao longo da coluna d’água na estação hidrográfica 7110.

\section{Estação 7120}

Nessa estação, foram observadas 6 espécies, G. bulloides, G. ruber (pink), G. ruber (white), G. sacculifer, G. siphonifera e N. dutertrei, que estão distribuídas no intervalo de 0 a $80 \mathrm{~m}$ de profundidade na coluna d'água. Não foram constatados espécimes de foraminíferos planctônicos na profundidade de $100 \mathrm{~m}$ (Tabela 10).

A maior freqüência de foraminíferos planctônicos foi constatada principalmente entre 40 e 60 m de profundidade na coluna d'água (Figura 17). As espécies encontradas nesse intervalo de profundidade foram G. bulloides, G. ruber (pink), G. ruber (white) e N. dutertrei. As espécies G. ruber (pink), G. ruber (white) são as mais freqüentes, exibindo valores máximos de 1,4 especimes $/ \mathrm{m}^{3}$ e 9,4 especimes $/ \mathrm{m}^{3}$, respectivamente Nesse intervalo de 
profundidade, a temperatura apresenta variação de $22,90{ }^{\circ} \mathrm{C}$ e $23,38{ }^{\circ} \mathrm{C}$, a salinidade encontra-se em torno de 37,0 e a concentração de clorofila a é de $0,15 \mu \mathrm{g} / \mathrm{L}$.

A espécie menos freqüente é $G$. siphonifera, que apresenta valor máximo de 0,08 especimes $/ \mathrm{m}^{3}$.

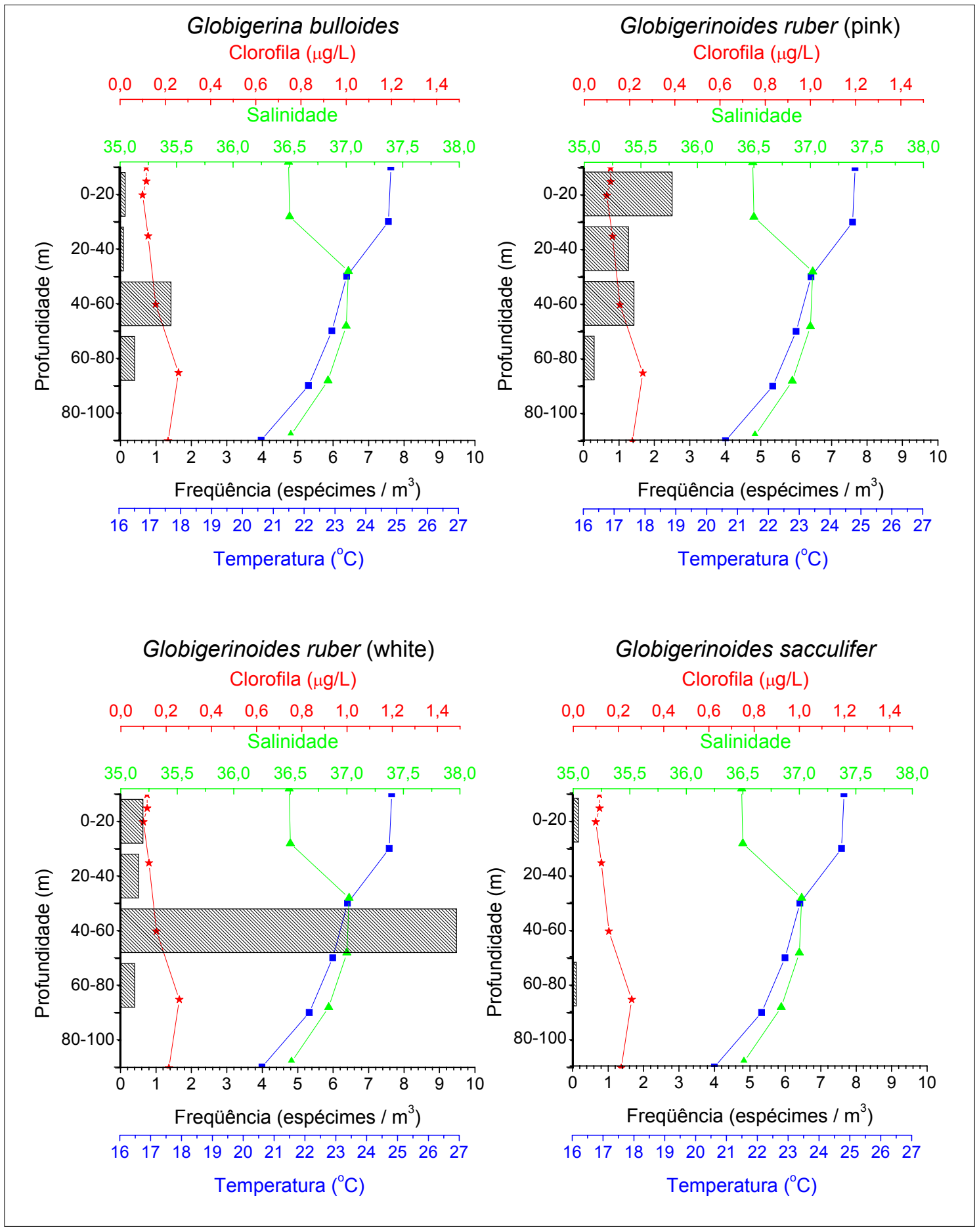

Figura 17 - Distribuição de foraminíferos planctônicos, temperatura, salinidade e concentração de clorofila a ao longo da coluna d’água na estação hidrográfica 7120 . 


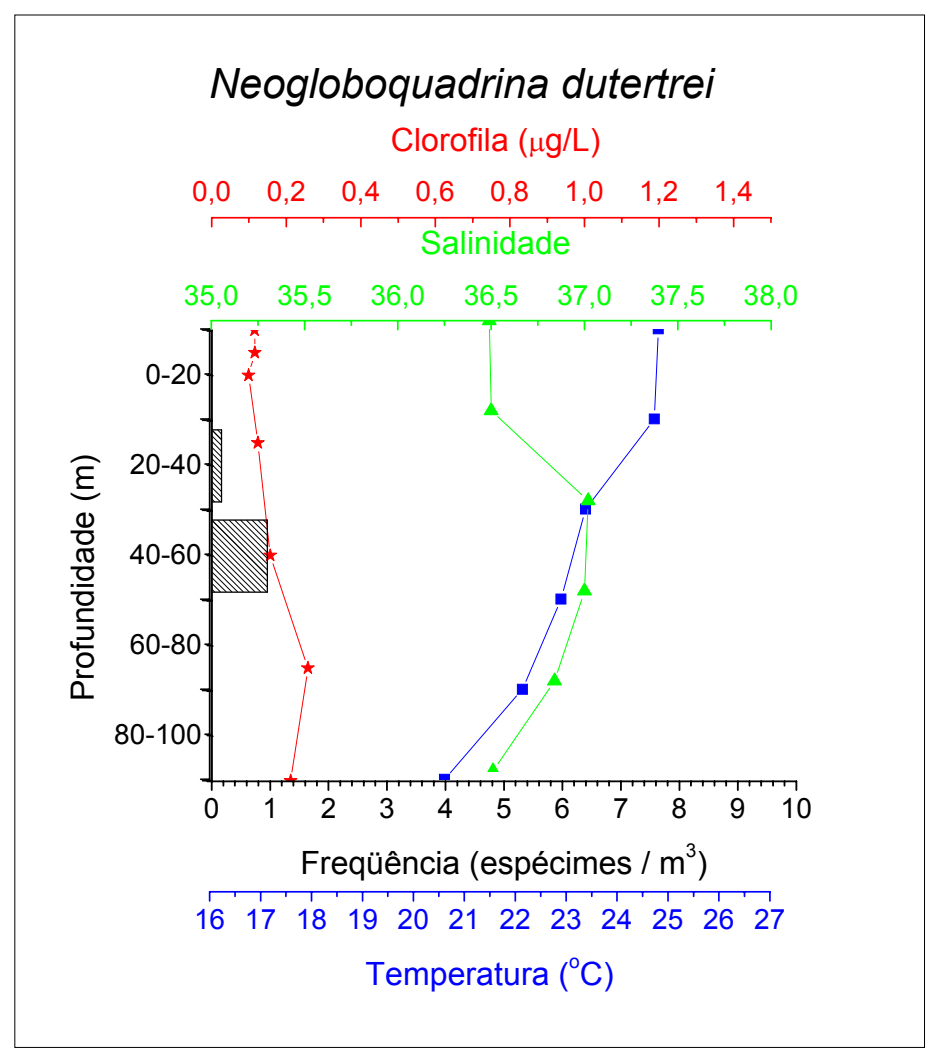

Figura 17 (continuação) - Distribuição de foraminíferos planctônicos, temperatura, salinidade e concentração de clorofila a ao longo da coluna d’água na estação hidrográfica 7120. 


\section{Estação 7121}

Nessa estação, são observadas 6 espécies de foraminíferos planctônicos, G. bulloides, G. ruber (pink), G. ruber (white), G. sacculifer, G. siphonifera e N. dutertrei. Entretanto, com exceção de G. ruber (pink) todas as outras espécies identificadas apresentam freqüências inferiores a 0,4 espécimes $/ \mathrm{m}^{3}$ (Tabela 10 e Figura 18).

G. ruber (pink) apresenta, entre $0 \mathrm{~m}$ e $20 \mathrm{~m}$ de profundidade, valores máximos de 0,99 espécimes $/ \mathrm{m}^{3}$. A concentração de clorofila $a$, nesse intervalo, manteve-se em torno de $0,1 \mu \mathrm{g} / \mathrm{L}$ e a temperatura apresenta variação entre $24,25^{\circ} \mathrm{C}$ a $25,01^{\circ} \mathrm{C}$ e a salinidade é de 36,50 .

As espécies menos freqüentes são $G$. sacculifer, que apresenta valor máximo de 0,02 espécimes $/ \mathrm{m}^{3}$ entre $0 \mathrm{~m}$ e $20 \mathrm{~m}$ de profundidade e $G$. siphonifera, cuja freqüência varia de 0,02 espécimes $/ \mathrm{m}^{3}$ a 0,08 espécimes $/ \mathrm{m}^{3}$ entre $0 \mathrm{~m}$ e $60 \mathrm{~m}$ de profundidade na coluna d'água. 


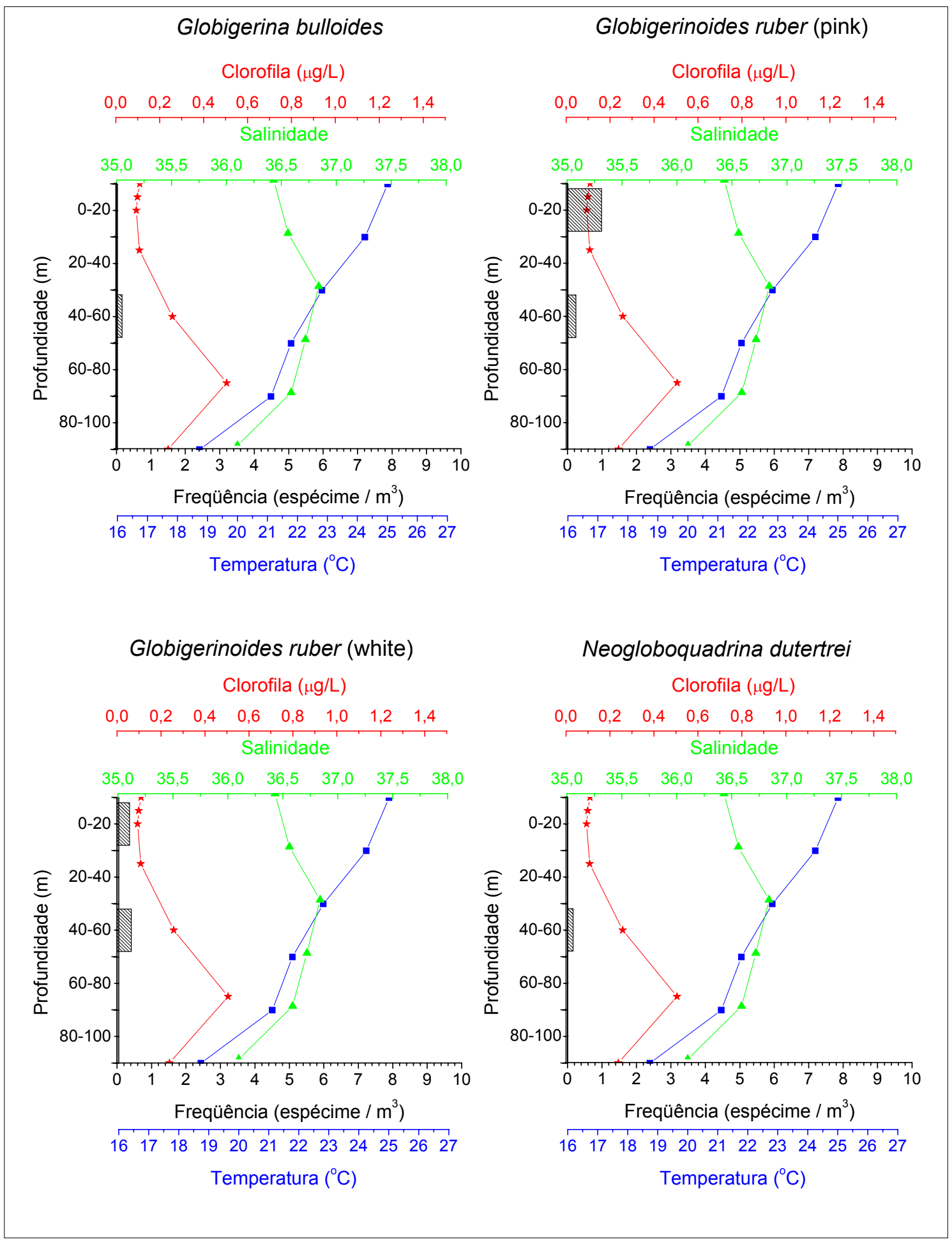

Figura 18 - Distribuição de foraminíferos planctônicos, temperatura, salinidade e concentração de clorofila a ao longo da coluna d’água na estação hidrográfica 7121. 


\section{Estação 7142}

Foram observadas 8 espécies nessa estação, Globigerina bulloides, Globigerina falconensis, Globigerinella calida, Globigerinoides ruber (pink), Globigerinoides ruber (white), Globigerinoides siphonifera, Globigerinella siphonifera, N. dutertrei e Orbulina universa (Tabela 10).

À semelhança da estação anterior, na estação 7142, as espécies G. ruber (pink) e G. ruber (white) apresentam valores máximos de freqüência na superfície $\left(0,85\right.$ espécimes $/ \mathrm{m}^{3}$ e 0,63 espécimes $/ \mathrm{m}^{3}$, respectivamente).

Nesse intervalo de profundidade $(0 \mathrm{~m}$ e $20 \mathrm{~m})$, a temperatura apresenta variação entre $23,56{ }^{\circ} \mathrm{C}$ e $24,24{ }^{\circ} \mathrm{C}$, a salinidade entre 36,25 e 36,67 , e a concentração de clorofila a varia entre $0,17 \mu \mathrm{g} / \mathrm{L}$ e $0,24 \mu \mathrm{g} / \mathrm{L}$.

Já na profundidade de $100 \mathrm{~m}$, nota-se a presença das espécies $\mathrm{G}$. bulloides, G. calida, G. falconensis, G. ruber (white) e G. siphonifera. Entretanto, essas espécies ocorrem com freqüência inferior a 0,23 espécimes $/ \mathrm{m}^{3}$ (Figura 19). Nessa profundidade os valores de temperatura e salinidade são de $17,72^{\circ} \mathrm{C}$ e 35,91 , respectivamente.

As espécies menos freqüentes, nessa estação oceanográfica, são $G$. calida, $N$. dutertrei e $O$. universa apresentando máximo de freqüência em torno de 0,05 espécimes $/ \mathrm{m}^{3}$. 


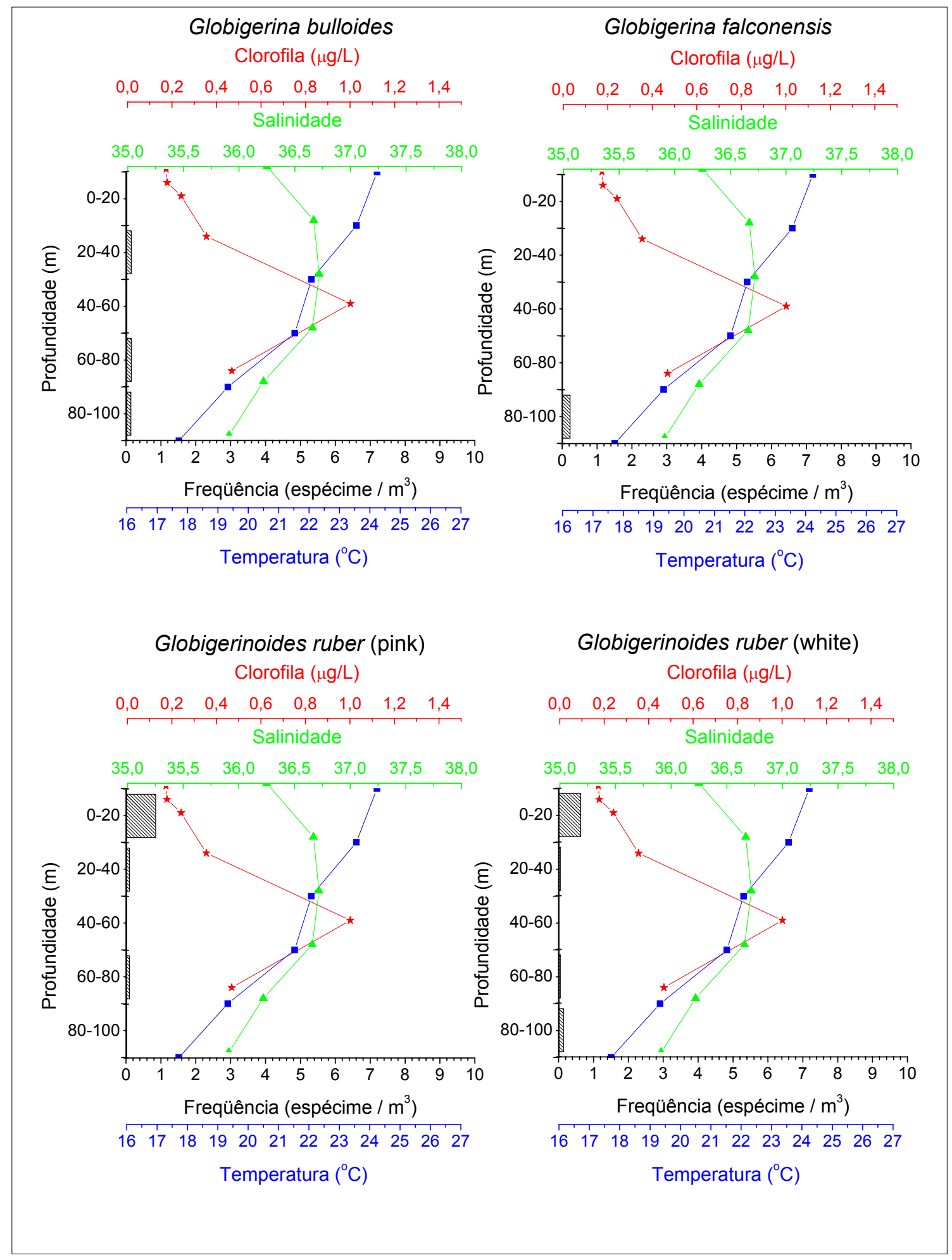

Figura 19 - Distribuição de foraminíferos planctônicos, temperatura, salinidade e concentração de clorofila a ao longo da coluna d água na estação hidrográfica 7142. 


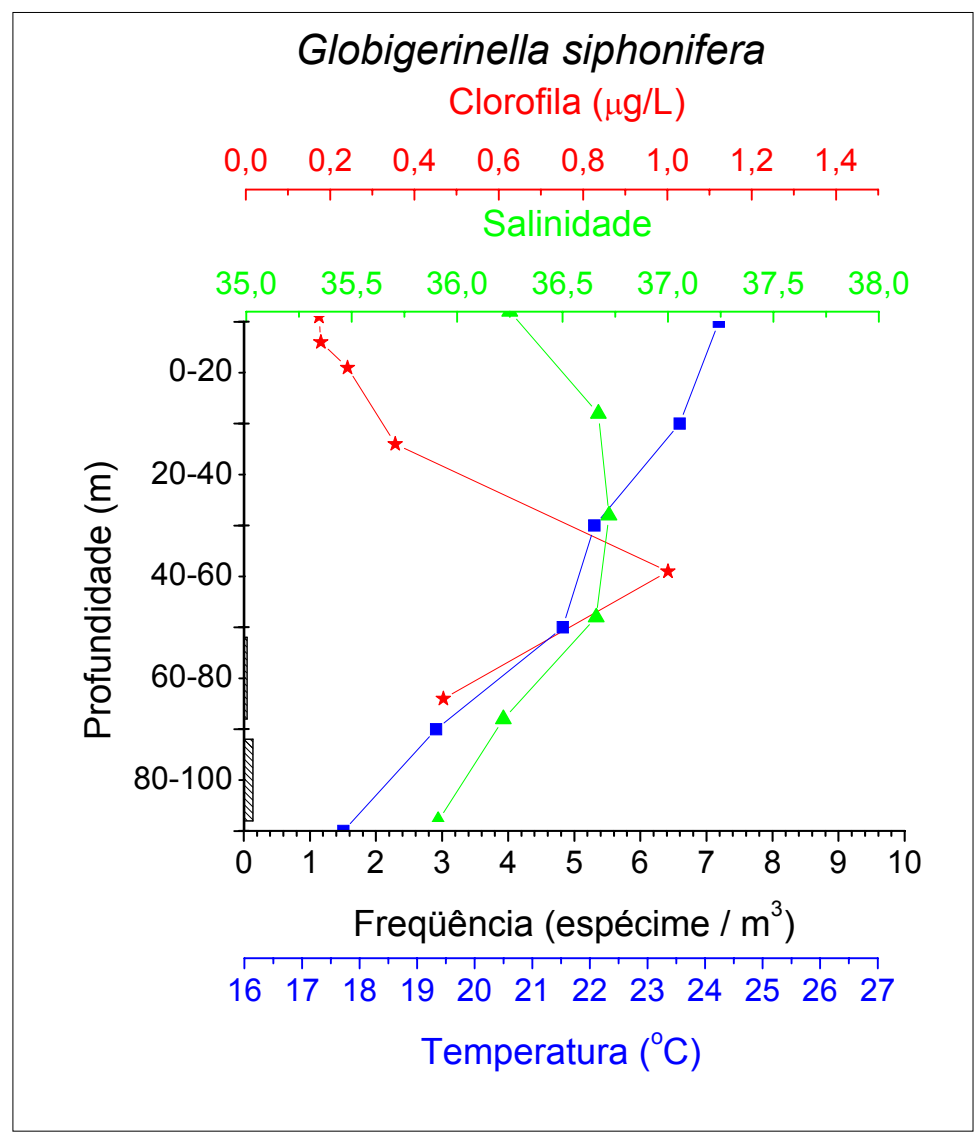

Figura 19 (continuação) - Distribuição de foraminíferos planctônicos, temperatura, salinidade e concentração de clorofila a ao longo da coluna d’água na estação hidrográfica 7142.

\section{Estação 7144}

São encontradas 10 espécies de foraminíferos planctônicos, sendo elas Globigerina bulloides, Globigerina falconensis, Globigerinella calida, Globigerinoides ruber (pink), Globigerinoides ruber (white), Globigerinoides sacculifer, Globigerinella siphonifera, Globorotalia menardii, Neogloboquadrina dutertrei e Orbulina universa (Tabela 10). Essa estação se revelou a mais rica em espécies.

À semelhança das estações 7121 e 7142 , na estação 7144 as espécies G. ruber (pink) e G. ruber (white) apresentam na superfície (0 m a $20 \mathrm{~m}$ de profundidade) máximos de freqüência, com valores de 2,49 espécimes $/ \mathrm{m}^{3} \mathrm{e}$ 
2,95 espécimes $/ \mathrm{m}^{3}$, respectivamente. Nesse intervalo de profundidade, a temperatura varia entre $25,94^{\circ} \mathrm{C}$ e $26,05^{\circ} \mathrm{C}$, a salinidade entre 36,78 e 36,86 e a concentração de clorofila a oscila entre 0,12 $\mu \mathrm{g} / \mathrm{L}$ e 0,14 $\mu \mathrm{g} / \mathrm{L}$ (Figura 20).

Entretanto, no intervalo de 20 a $100 \mathrm{~m}$, onde a temperatura varia entre $23,25^{\circ} \mathrm{C}$ e $25,87^{\circ} \mathrm{C}$, a salinidade entre 36,92 e 37,07 e a concentração de clorofila a de $0,25 \mu \mathrm{g} / \mathrm{L}$ a $0,37 \mu \mathrm{g} / \mathrm{L}$, as espécies $\mathrm{G}$. ruber (pink) e G. ruber (white) apresentam freqüências bem menores, entre 0,22 espécimes $/ \mathrm{m}^{3}$ e 0,36 espécimes $/ \mathrm{m}^{3}$, e entre 0,11 espécimes $/ \mathrm{m}^{3}$ e 0,74 espécimes $/ \mathrm{m}^{3}$ respectivamente.

Nessa estação oceanográfica, nota-se certa coincidência entre a diminuição da temperatura e da freqüência de G ruber (pink) e G. ruber (white), em contraposição observa-se aumento na freqüência de G. bulloides, $G$. siphonifera, G. menardii, N dutertrei e O. universa.

G. sacculifer ocorre entre $80 \mathrm{~m}$ e $100 \mathrm{~m}$ de profundidade e apresenta $\mathrm{o}$ menor valor de freqüência entre todas as espécies observadas nessa estação $\left(0,07\right.$ espécimes $\left./ \mathrm{m}^{3}\right)$. 


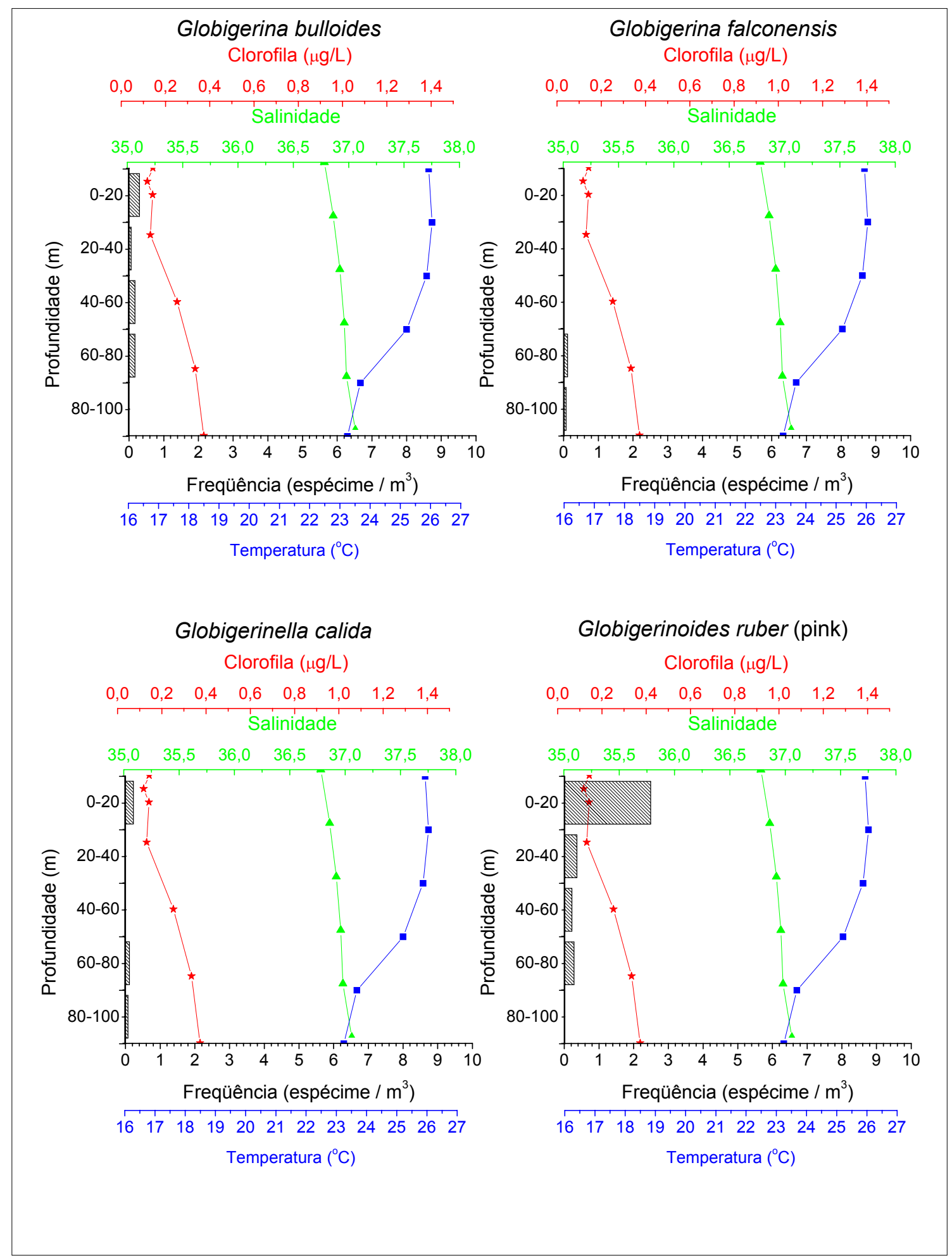

Figura 20 - Distribuição de foraminíferos planctônicos, temperatura, salinidade e concentração de clorofila a ao longo da coluna d’água na estação hidrográfica 7144. 


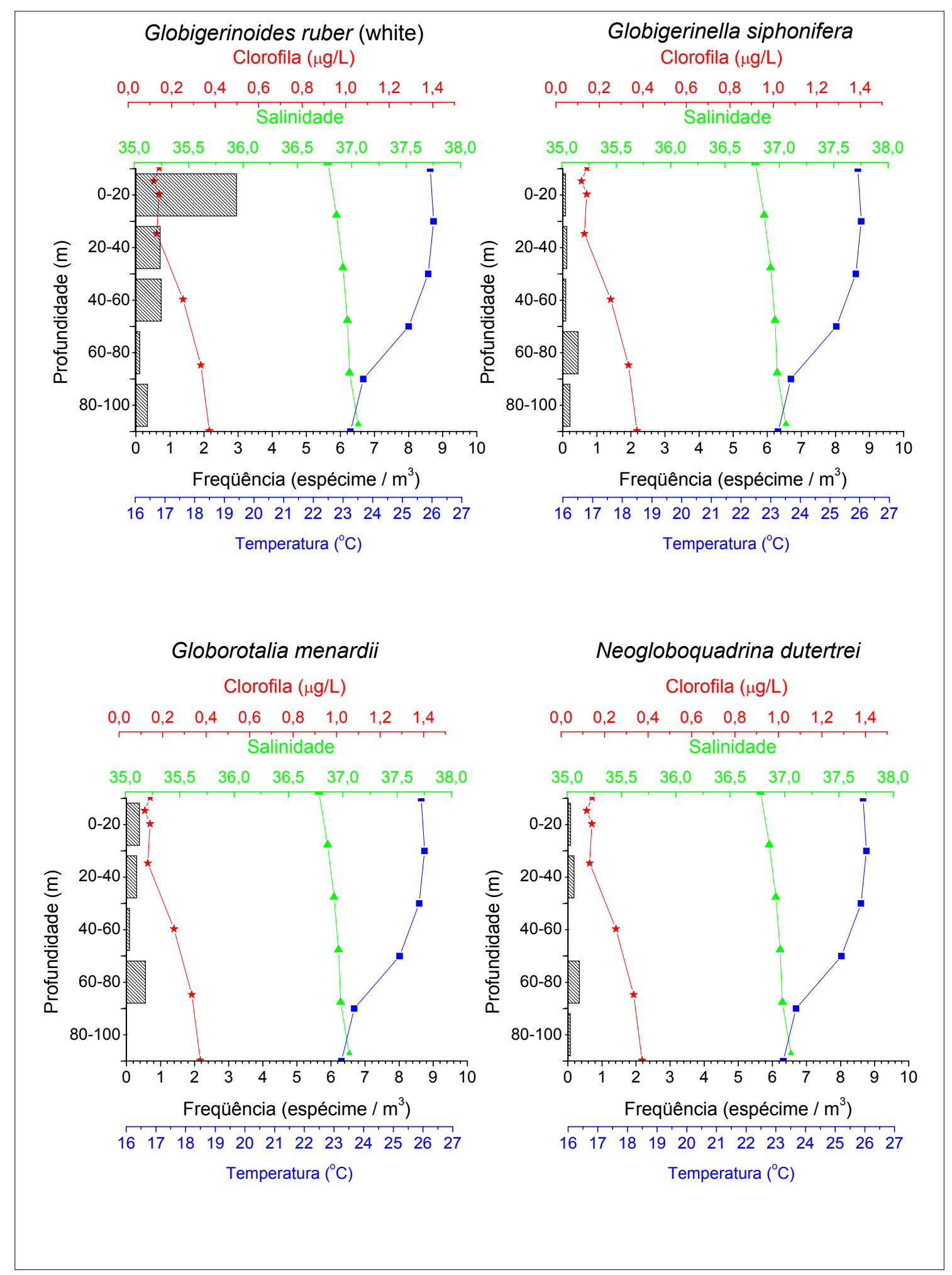

Figura 20 (continuação) - Distribuição de foraminíferos planctônicos, temperatura, salinidade e concentração de clorofila a ao longo da coluna d’água na estação hidrográfica 7144. 


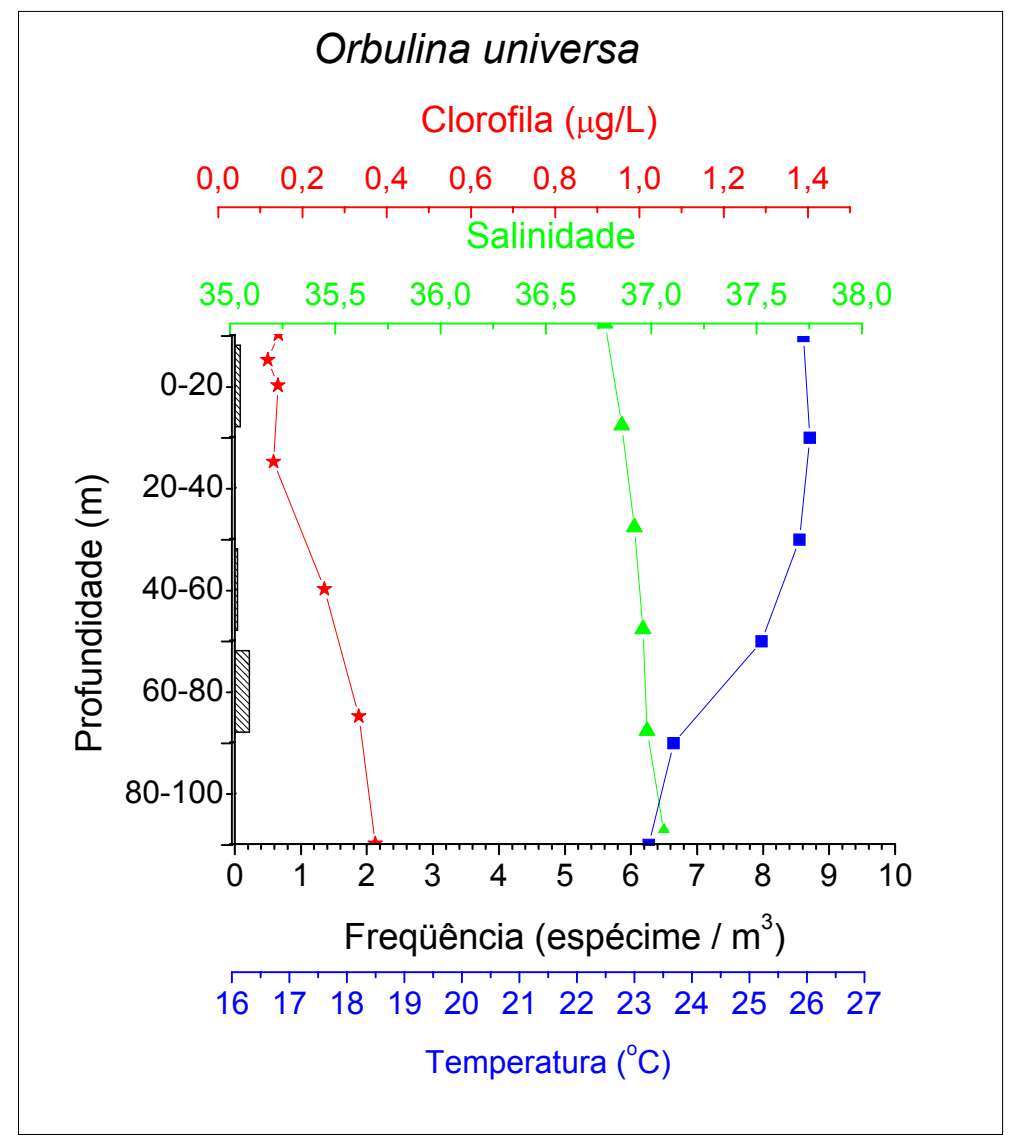

Figura 20 (continuação) - Distribuição de foraminíferos planctônicos, temperatura, salinidade e concentração de clorofila a ao longo da coluna d’água na estação hidrográfica 7144 .

\section{Estação 7154}

Foram encontradas nessa estação 8 espécies de foraminíferos planctônicos, quais sejam, G. bulloides, G. falconensis, G. calida, G. menardii, G. ruber (pink), G. ruber (white), G. sacculifer e G. siphonifera (Tabela 10).

Entre $0 \mathrm{~m}$ e $40 \mathrm{~m}$ de profundidade, as espécies mais freqüentes são $G$. ruber (pink), apresentando valor máximo de 3,63 espécimes $/ \mathrm{m}^{3}$ e G. ruber (white) com freqüência máxima de 0,92 espécimes $/ \mathrm{m}^{3}$.

É importante ressaltar, que nessa estação de coleta, o valor máximo de freqüência da espécie G. ruber (white), 2,36 espécimes $/ \mathrm{m}^{3}$, ocorre a $100 \mathrm{~m}$ de profundidade, ao passo que em todas as outras estações, o maior valor de 
freqüência dessa espécie ocorre em geral em intervalos de profundidades menores, entre $0 \mathrm{~m}$ e $60 \mathrm{~m}$ (Figura 21).

Esse aumento na freqüência de G. ruber (white) coincide com a diminuição da temperatura que varia entre $23,05^{\circ} \mathrm{C}$ e $25,12^{\circ} \mathrm{C}$, no intervalo de $60 \mathrm{~m}$ a $100 \mathrm{~m}$ de profundidade, enquanto a salinidade oscila entre $37,00 \mathrm{e}$ 37,08 , e a concentração de clorofila a aumenta de $0,13 \mu \mathrm{g} / \mathrm{L}$ para $0,32 \mu \mathrm{g} / \mathrm{L}$ (Figura 21).

As espécies menos freqüentes são G.bulloides $\left(0,56\right.$ espécimes $\left./ m^{3}\right), G$ falconensis $\left(0,06\right.$ espécimes $\left./ \mathrm{m}^{3}\right), \quad G$. sacculifer $\left(0,25\right.$ espécimes $\left./ \mathrm{m}^{3}\right), \quad G$. siphonifera $\left(0,06\right.$ espécimes $\left./ \mathrm{m}^{3}\right)$ e G. menardii $\left(0,37\right.$ espécimes $\left./ \mathrm{m}^{3}\right)$ (Figura 21).

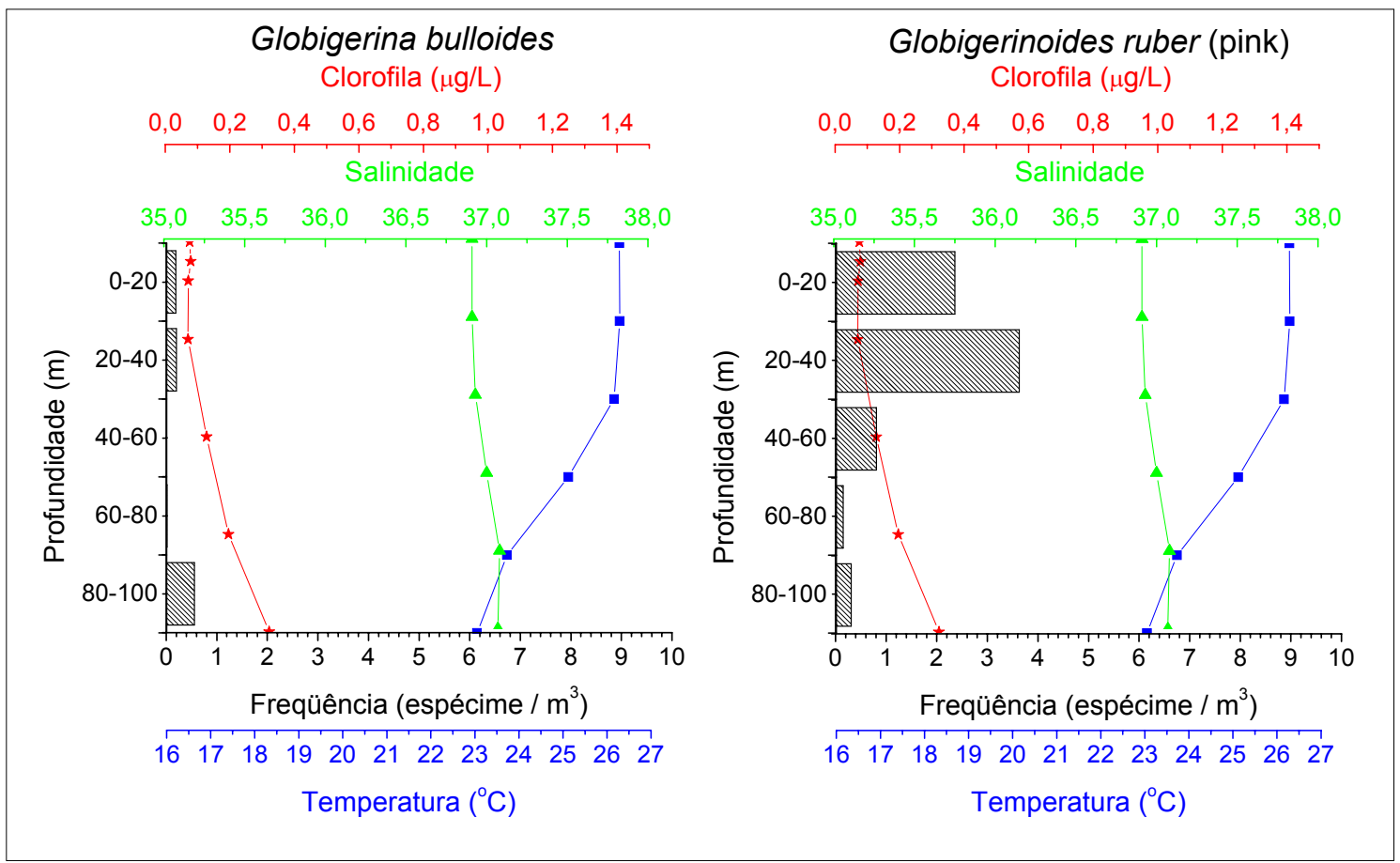

Figura 21 - Distribuição de foraminíferos planctônicos, temperatura, salinidade e concentração de clorofila a ao longo da coluna d’água na estação hidrográfica 7154 . 


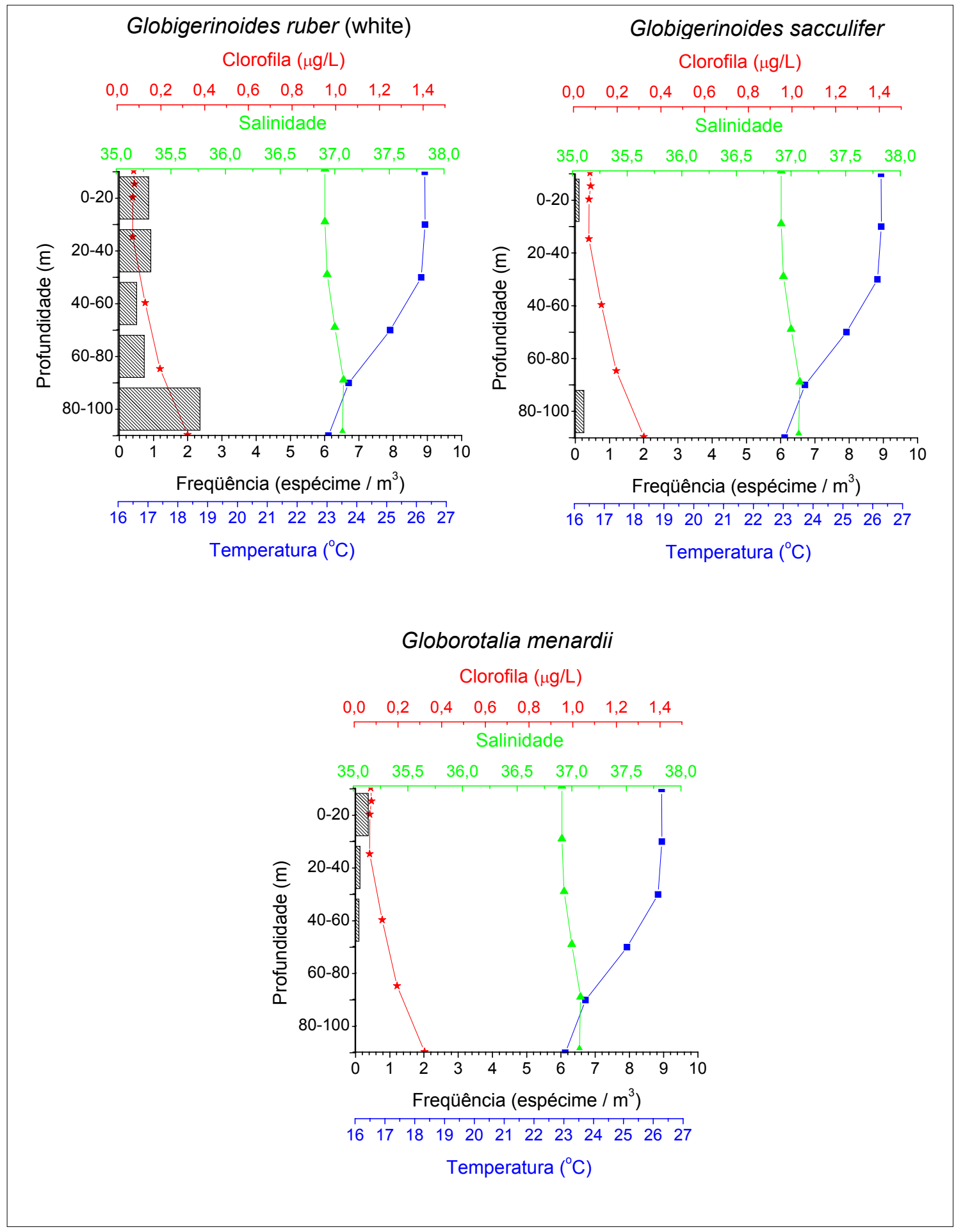

Figura 21 (continuação) - Distribuição de foraminíferos planctônicos, temperatura, salinidade e concentração de clorofila a ao longo da coluna d’água na estação hidrográfica 7154. 


\section{Estação 7165}

Foram encontradas 8 espécies, de G. bulloides, G. calida, G. menardii, G. ruber (pink), G. ruber (white), G. sacculifer, N. dutertrei e O. universa.

As espécies mais freqüentes são $G$. bulloides $\left(0,50\right.$ espécimes $\left./ \mathrm{m}^{3}\right), G$. menardii $\left(0,47\right.$ espécimes $\left./ \mathrm{m}^{3}\right)$, G. ruber (pink) $\left(3,53\right.$ espécimes $\left./ \mathrm{m}^{3}\right)$ e G. ruber (white) (3,21 espécimes $\left./ \mathrm{m}^{3}\right)$, que apresentam máximos de freqüência entre $0 \mathrm{~m}$ e $20 \mathrm{~m}$ de profundidade na coluna de água (Figura 22).

À semelhança de outras estações, as espécies G. ruber (pink) e G. ruber (white) são mais abundantes na superfície (0 m a $20 \mathrm{~m}$ de profundidade).

Nessa estação, a partir de $20 \mathrm{~m}$ de profundidade, ocorre diminuição na freqüência das espécies de foraminíferos planctônicos encontrados. Esse fato coincide com o aumento da salinidade que passa a apresentar valores entre 37,09 e 37,23 (Figura 22).

As espécies menos freqüentes são $G$. calida $\left(0,03\right.$ espécimes $\left./ \mathrm{m}^{3}\right), G$. sacculifer $\left(0,19\right.$ espécimes $\left./ \mathrm{m}^{3}\right)$, G. dutertrei $\left(0,03\right.$ espécimes $\left./ \mathrm{m}^{3}\right)$ e 0 . universa $\left(0,03\right.$ espécimes $\left./ \mathrm{m}^{3}\right)$. 


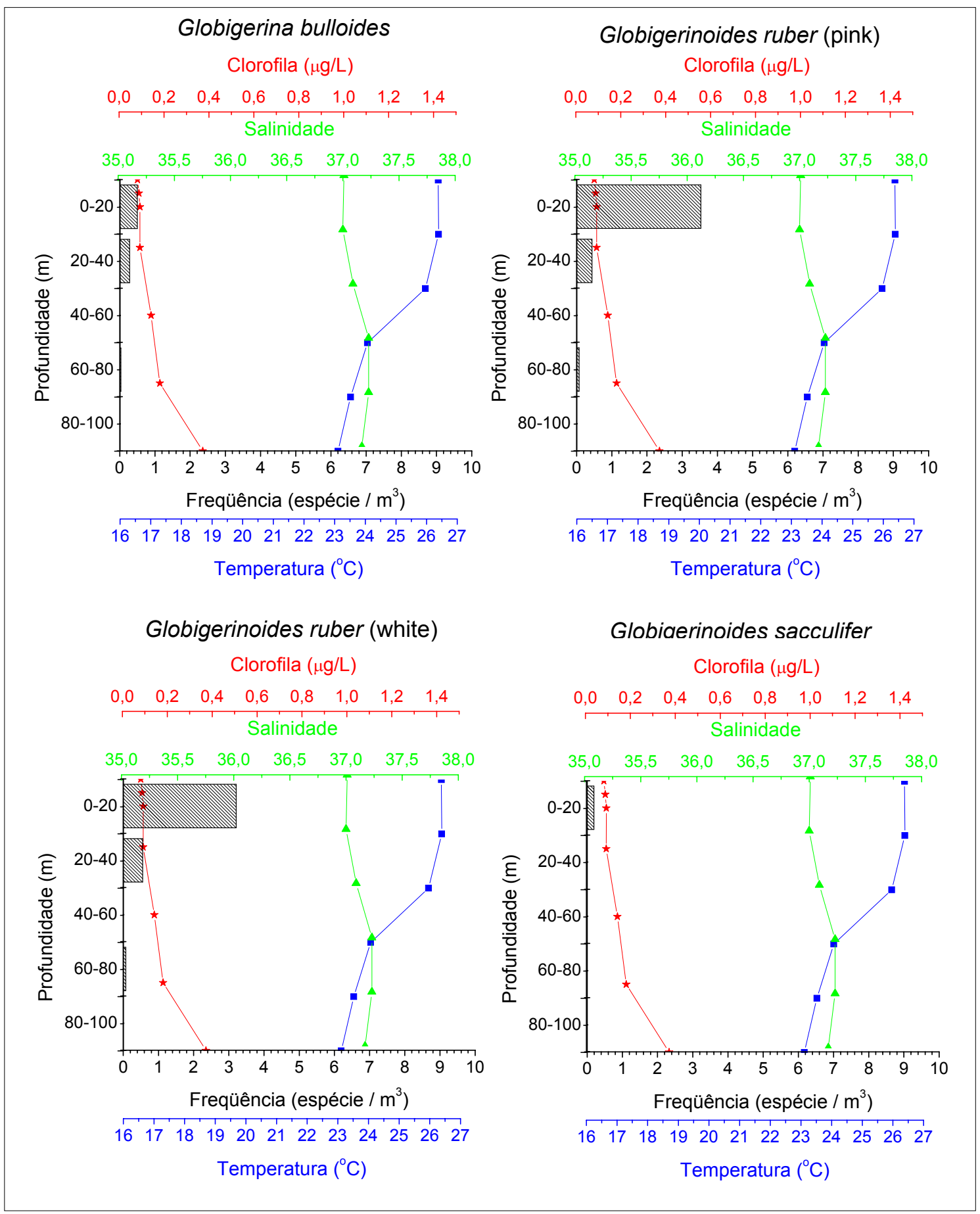

Figura 22 - Distribuição de foraminiferos planctônicos, temperatura, salinidade e concentração de clorofila a ao longo da coluna d’água na estação hidrográfica 7165. 


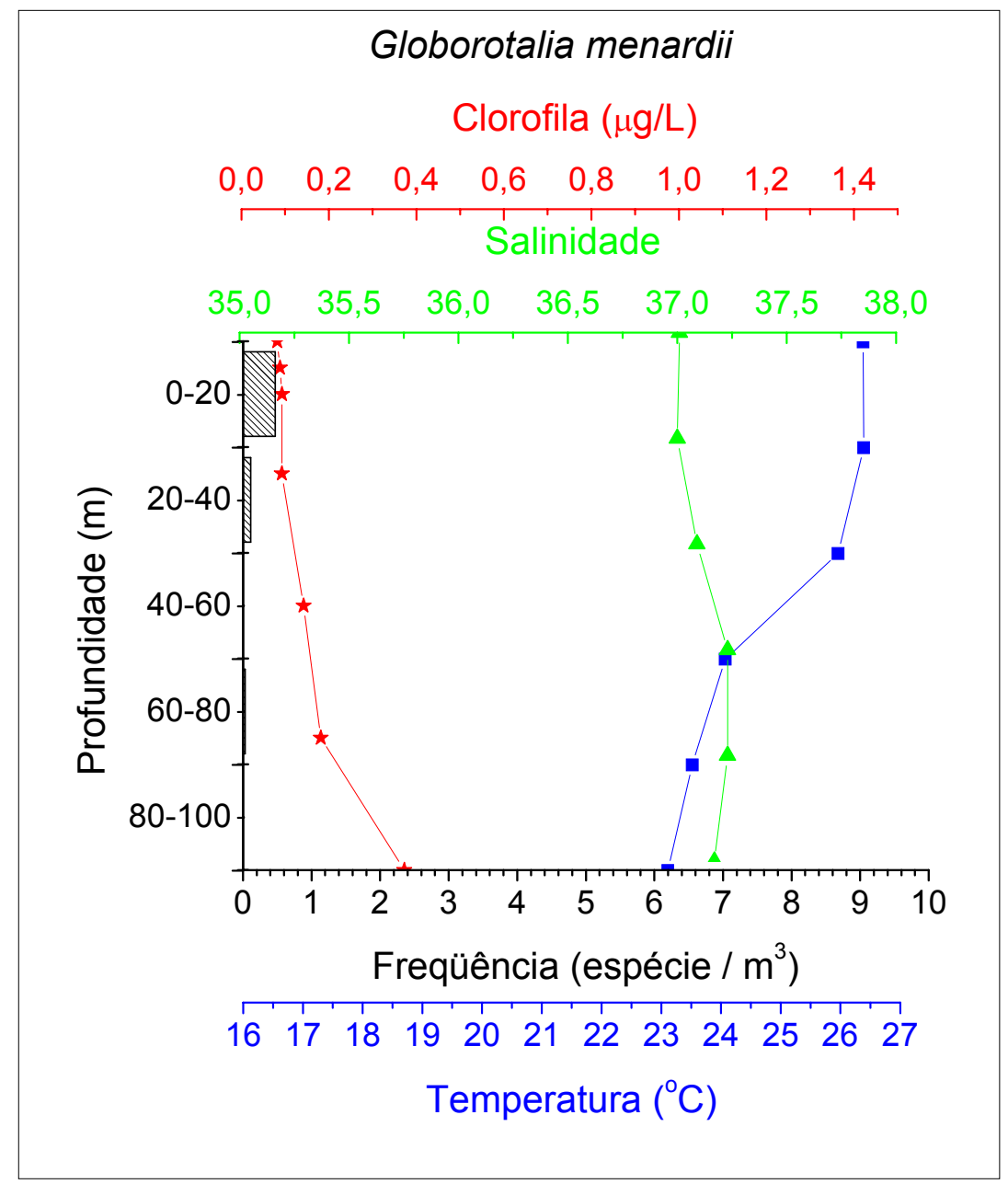

Figura 22 (continuação) - Distribuição de foraminíferos planctônicos, temperatura, salinidade e concentração de clorofila a ao longo da coluna d’água na estação hidrográfica 7165 . 


\subsubsection{2 - Inverno de 2002}

O material de plâncton amostrado durante o inverno de 2002 apresenta, de maneira geral, número menor de indivíduos pertencentes aos filos Crustacea, Ctenofora, Molusca, Chetognatha, entre outros, quando comparado ao material coletado durante o verão do mesmo ano. Ademais, o número de foraminíferos planctônicos, encontrados nas 40 amostras de inverno analisadas, foi extremamente baixo sendo que em $65 \%$ delas não foi encontrada nenhuma testa desses organismos (Tabela 11). Os 249 indivíduos de foraminíferos observados apresentam tamanhos entre $30 \mu \mathrm{m}$ e $80 \mu \mathrm{m}$, sendo provavelmente formas juvenis, e por esse motivo não foram identificados. Portanto, serão apresentados aqui apenas dados de abundância e freqüência dos espécimes de foraminíferos planctônicos, por intervalo de profundidade. 


\begin{tabular}{|c|c|c|c|c|}
\hline $\begin{array}{c}\text { Estação } \\
\text { higrográfica }\end{array}$ & $\begin{array}{c}\text { Prof de } \\
\text { coleta (m) }\end{array}$ & $\begin{array}{l}\text { Volume } \\
\text { filtrado } \\
\left(\mathrm{m}^{3}\right)\end{array}$ & $\begin{array}{c}\text { Abundância } \\
\text { de } \\
\text { foraminíferos } \\
\text { planctônicos }\end{array}$ & $\begin{array}{c}\text { Freqüência } \\
\left(\text { Espcimes } / \mathrm{m}^{3}\right)\end{array}$ \\
\hline \multirow{5}{*}{7261} & $0-20$ & 51,37 & 0 & 0 \\
\hline & $20-40$ & 19,64 & 0 & 0 \\
\hline & $40-60$ & 24,83 & 3 & 0,12 \\
\hline & $60-80$ & 20,59 & 0 & 0 \\
\hline & $80-100$ & 17,41 & 0 & 0 \\
\hline \multirow{5}{*}{7273} & $0-20$ & 51,64 & 0 & 0 \\
\hline & $20-40$ & 44,41 & 0 & 0 \\
\hline & $40-60$ & 26,65 & 1 & 0,04 \\
\hline & $60-80$ & 19,9 & 3 & 0,15 \\
\hline & $80-100$ & 21,23 & 0 & 0 \\
\hline \multirow{5}{*}{7274} & $0-20$ & 86,93 & 0 & 0 \\
\hline & $20-40$ & 22,17 & 0 & 0 \\
\hline & $40-60$ & 38 & 1 & 0,03 \\
\hline & $60-80$ & 28,31 & 3 & 0,11 \\
\hline & $80-100$ & 15,91 & 0 & 0 \\
\hline \multirow{5}{*}{7285} & $0-20$ & 61,88 & 110 & 1,78 \\
\hline & $20-40$ & 35,32 & 3 & 0,08 \\
\hline & $40-60$ & 32,14 & 6 & 0,19 \\
\hline & $60-80$ & 25,88 & 0 & 0 \\
\hline & $80-100$ & 12,43 & 0 & 0 \\
\hline \multirow{5}{*}{7286} & $0-20$ & 47,99 & 6 & 0,13 \\
\hline & $20-40$ & 39,76 & 0 & 0 \\
\hline & $40-60$ & 35,3 & 7 & 0,2 \\
\hline & $60-80$ & 28,22 & 0 & 0 \\
\hline & $80-100$ & 20,7 & 0 & 0 \\
\hline \multirow{5}{*}{7293} & $0-20$ & 119,67 & 0 & 0 \\
\hline & $20-40$ & 6,22 & 97 & 15,58 \\
\hline & $40-60$ & 5,82 & 0 & 0 \\
\hline & $60-80$ & 6,37 & 4 & 0,63 \\
\hline & $80-100$ & 3,42 & 0 & 0 \\
\hline \multirow{5}{*}{7294} & $0-20$ & 94,88 & 3 & 0,03 \\
\hline & $20-40$ & 4,98 & 0 & 0 \\
\hline & $40-60$ & 5,75 & 0 & 0 \\
\hline & $60-80$ & 5,63 & 2 & 0,36 \\
\hline & $80-100$ & 5,6 & 0 & 0 \\
\hline \multirow{5}{*}{7313} & $0-20$ & 52,56 & 0 & 0 \\
\hline & $20-40$ & 20,06 & 0 & 0 \\
\hline & $40-60$ & 36,18 & 0 & 0 \\
\hline & $60-80$ & 34,88 & 0 & 0 \\
\hline & $80-100$ & 25,29 & 0 & 0 \\
\hline
\end{tabular}

Tabela 11 - Dados de volume de água filtrada, abundância e freqüência de foraminíferos planctônicos encontrados de $0 \mathrm{~m}$ a $100 \mathrm{~m}$ na coluna de água, durante o inverno de 2002. 


\section{Estação 7261}

Foram encontradas testas de foraminíferos planctônicos apenas entre as profundidades de $40 \mathrm{~m}$ e $60 \mathrm{~m}$, com a freqüência máxima de 0,1 espécimes / $\mathrm{m}^{3}$ (Tabela 11 e Figura 23).

Nesse intervalo de profundidade, o valor de concentração de clorofila a apresenta máximo de $0,41 \mu \mathrm{g} / \mathrm{L}$. A temperatura é de $23^{\circ} \mathrm{C}$ e a salinidade 37 .

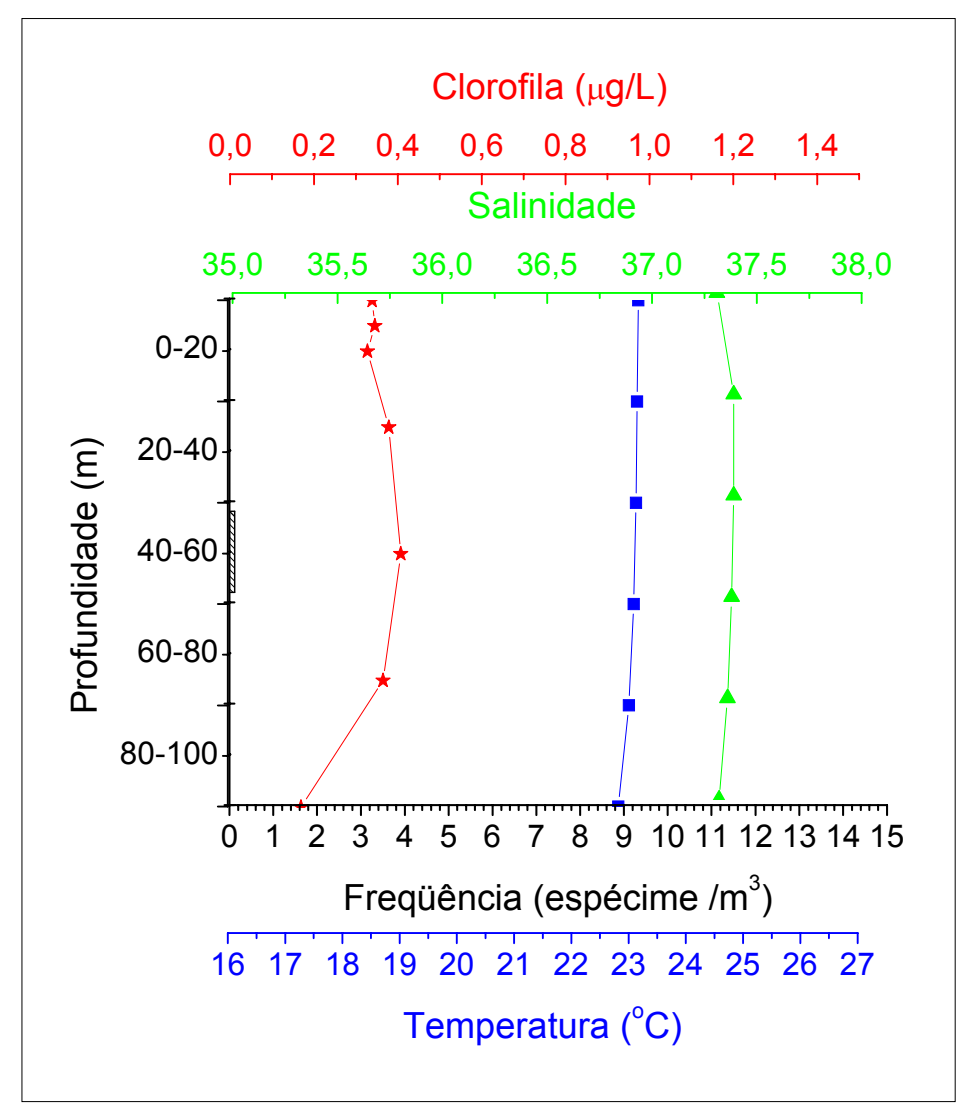

Figura 23 - Distribuição de espécimes de foraminíferos planctônicos, temperatura, salinidade e concentração de clorofila a ao longo da coluna d’água na estação hidrográfica7261. 


\section{Estação 7273}

Foram encontrados foraminíferos planctônicos entre 40 e $80 \mathrm{~m}$ de profundidade na coluna d'água, com valores máximos de freqüência $(0,1$ espécimes $/ \mathrm{m}^{3}$ ) a $80 \mathrm{~m}$ de profundidade (Tabela 11 e Figura 24).

Nesse intervalo de profundidade, o valor de concentração de clorofila a encontrado é de 0,35 $\mu \mathrm{g} / \mathrm{L}$ (Tabela 7). A temperatura apresenta variação entre $22,67^{\circ} \mathrm{C}$ e $22,71^{\circ} \mathrm{C}$ e a salinidade oscila entre 36,83 e 36,84 .

Nessa estação oceanográfica, a profundidade onde se observa o máximo de freqüência de foraminíferos planctônicos coincide com o máximo de concentração de clorofila a (Figura 24).

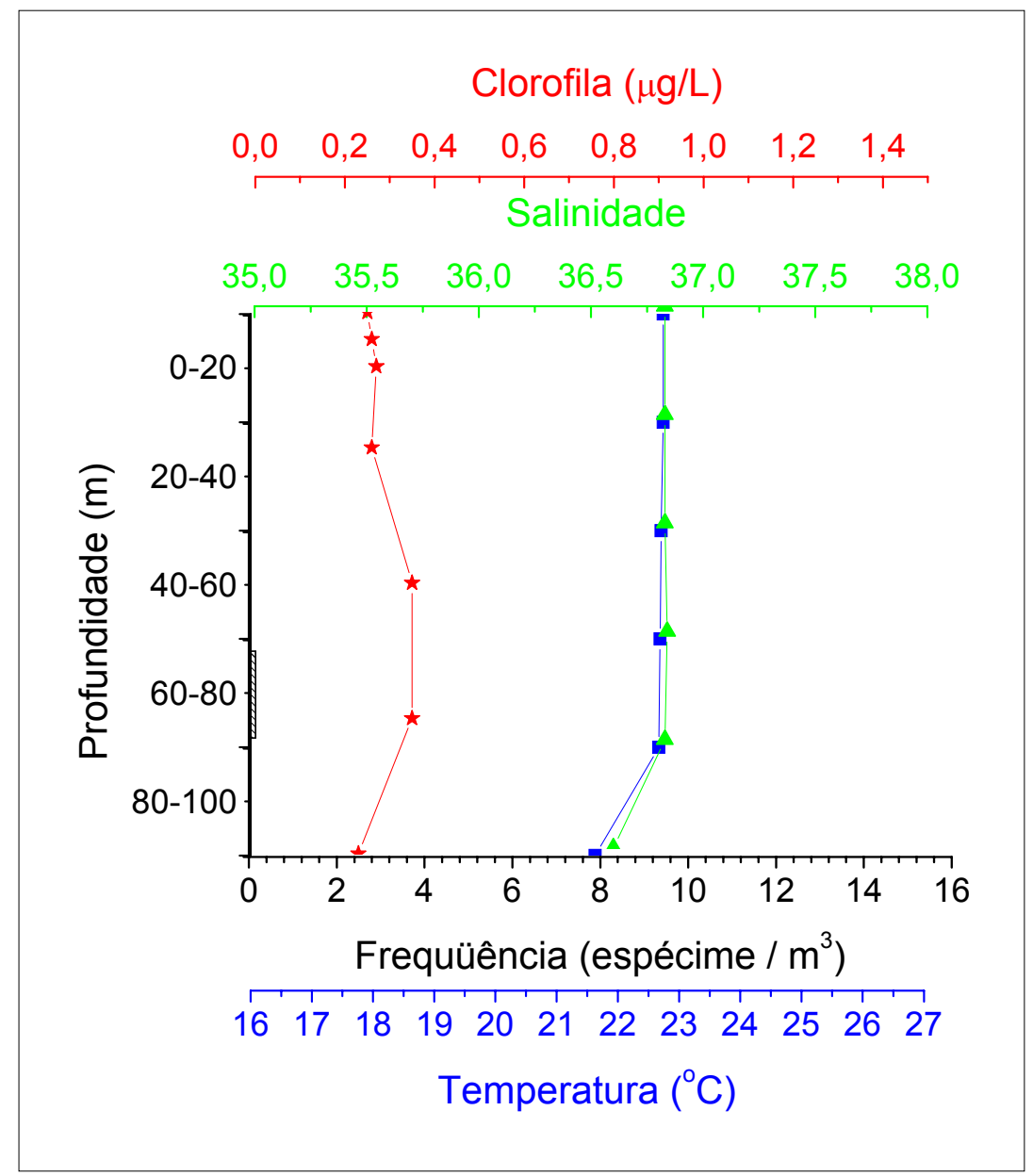

Figura 24 - Distribuição de espécimes de foraminíferos planctônicos, temperatura, salinidade e concentração de clorofila a ao longo da coluna d’água na estação hidrográfica 7273. 


\section{Estação 7274}

Apresenta foraminíferos planctônicos ente $40 \mathrm{~m}$ e $80 \mathrm{~m}$ de profundidade na coluna d'água. A freqüência desses organismos varia de 0,03 espécimes $/ \mathrm{m}^{3}$ a 0,11 espécimes $/ \mathrm{m}^{3}$ (Tabela 11 e Figura 25).

Nesse ponto de coleta, o valor de concentração de clorofila a varia de $0,36 \mu \mathrm{g} / \mathrm{L}$ a $0,40 \mu \mathrm{g} / \mathrm{L}$, a temperatura entre $22,67^{\circ} \mathrm{C}$ e $22,70{ }^{\circ} \mathrm{C}$ e a salinidade oscila entre 37,28 e 37,29 .

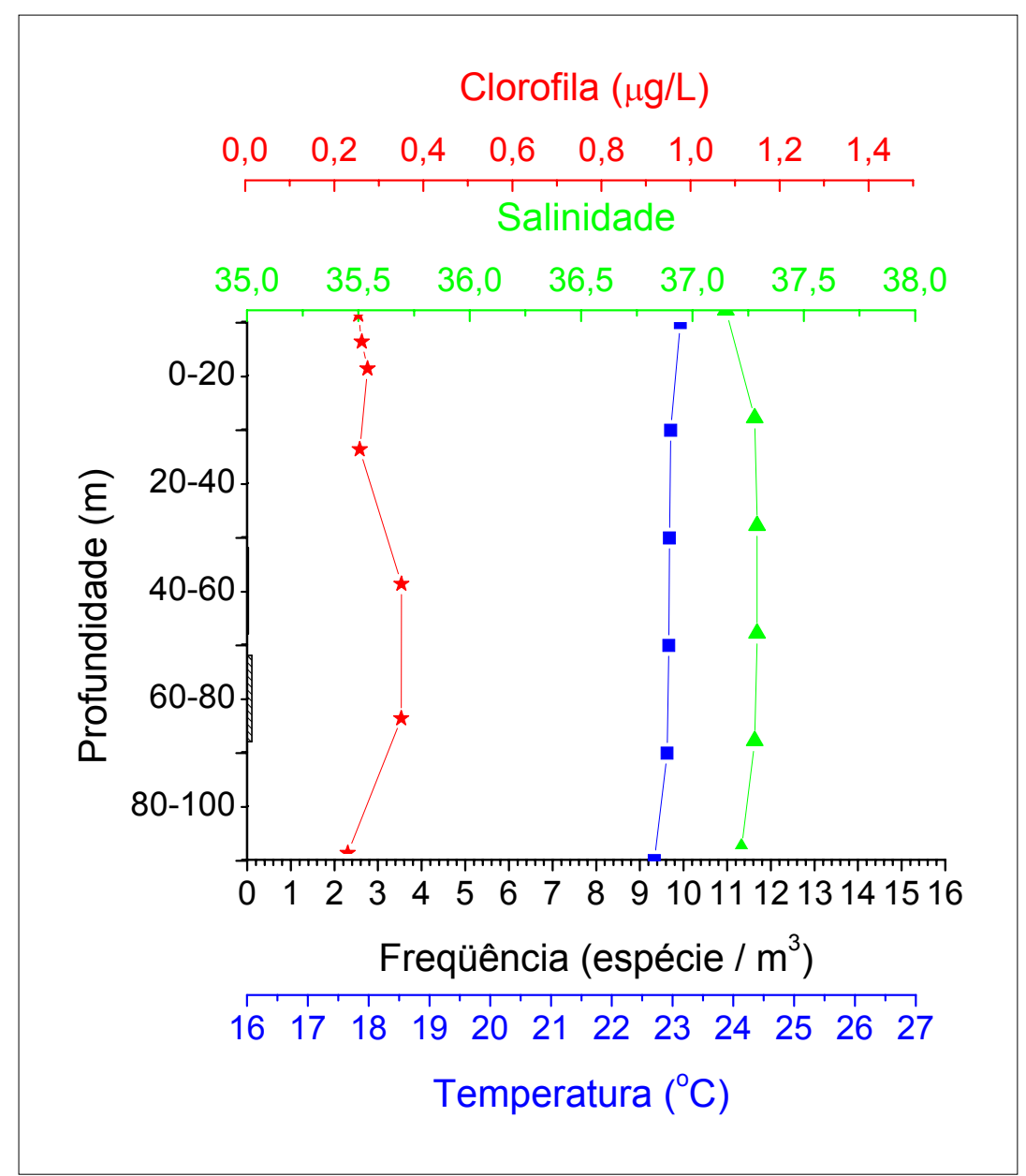

Figura 25 - Distribuição de espécimes de foraminíferos planctônicos, temperatura, salinidade e concentração de clorofila a ao longo da coluna d’água na estação hidrográfica 7274 . 


\section{Estação 7285}

São encontradas testas de foraminíferos planctônicos entre $0 \mathrm{~m}$ e $60 \mathrm{~m}$ de profundidade. $\mathrm{O}$ valor máximo de 1,78 espécimes $/ \mathrm{m}^{3}$ é constatado entre 0 $\mathrm{m}$ e $20 \mathrm{~m}$ de profundidade (Tabela 11 e Figura 26).

No intervalo de profundidade entre $0 \mathrm{~m}$ e $60 \mathrm{~m}$, o valor de concentração de clorofila a varia de $0,22 \mu \mathrm{g} / \mathrm{L}$ a $0,27 \mu \mathrm{g} / \mathrm{L}$. A temperatura varia entre $23,23^{\circ} \mathrm{C}$ e $23,28^{\circ} \mathrm{C}$ e a salinidade é de 36,94 .

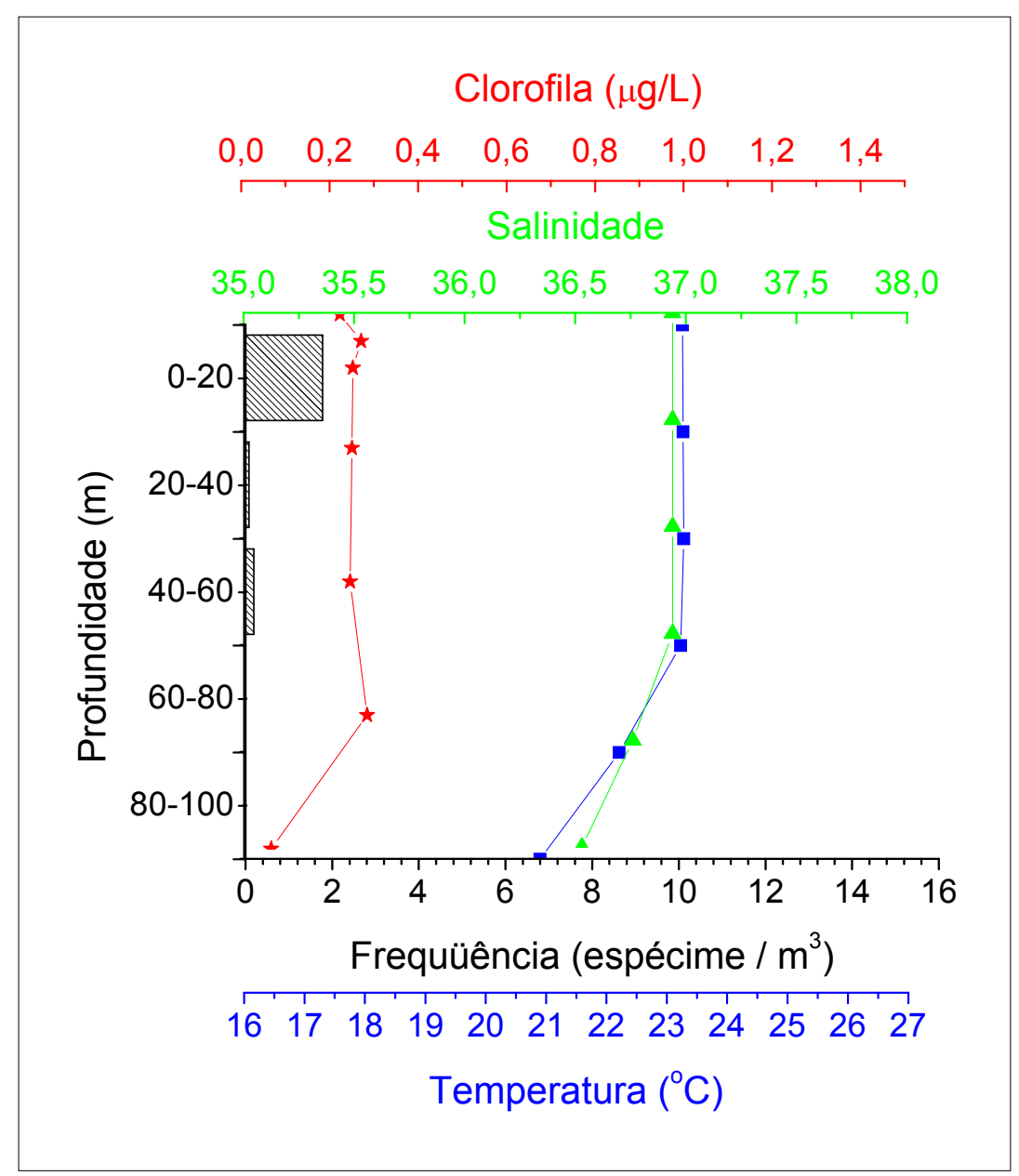

Figura 26 - Distribuição de espécimes de foraminíferos planctônicos, temperatura, salinidade e concentração de clorofila a ao longo da coluna d’água na estação hidrográfica 7285 . 


\section{Estação 7286}

Apresenta foraminíferos planctônicos entre $0 \mathrm{~m}$ e $20 \mathrm{~m}$ de profundidade e entre 40 m e 60 m de profundidade, com freqüências de 0,13 espécimes $/ \mathrm{m}^{3}$ e 0,20 espécimes $/ \mathrm{m}^{3}$, respectivamente (Tabela 11 e Figura 27 ).

Nessa estação, a concentração de clorofila a entre $0 \mathrm{~m}$ e $60 \mathrm{~m}$ de profundidade varia entre $0,25 \mu \mathrm{g} / \mathrm{L}$ e $0,28 \mu \mathrm{g} / \mathrm{L}$ (Tabela 7). A temperatura apresenta valores entre $23,28^{\circ} \mathrm{C}$ e $23,29^{\circ} \mathrm{C}$ e a salinidade é de 36,97 .

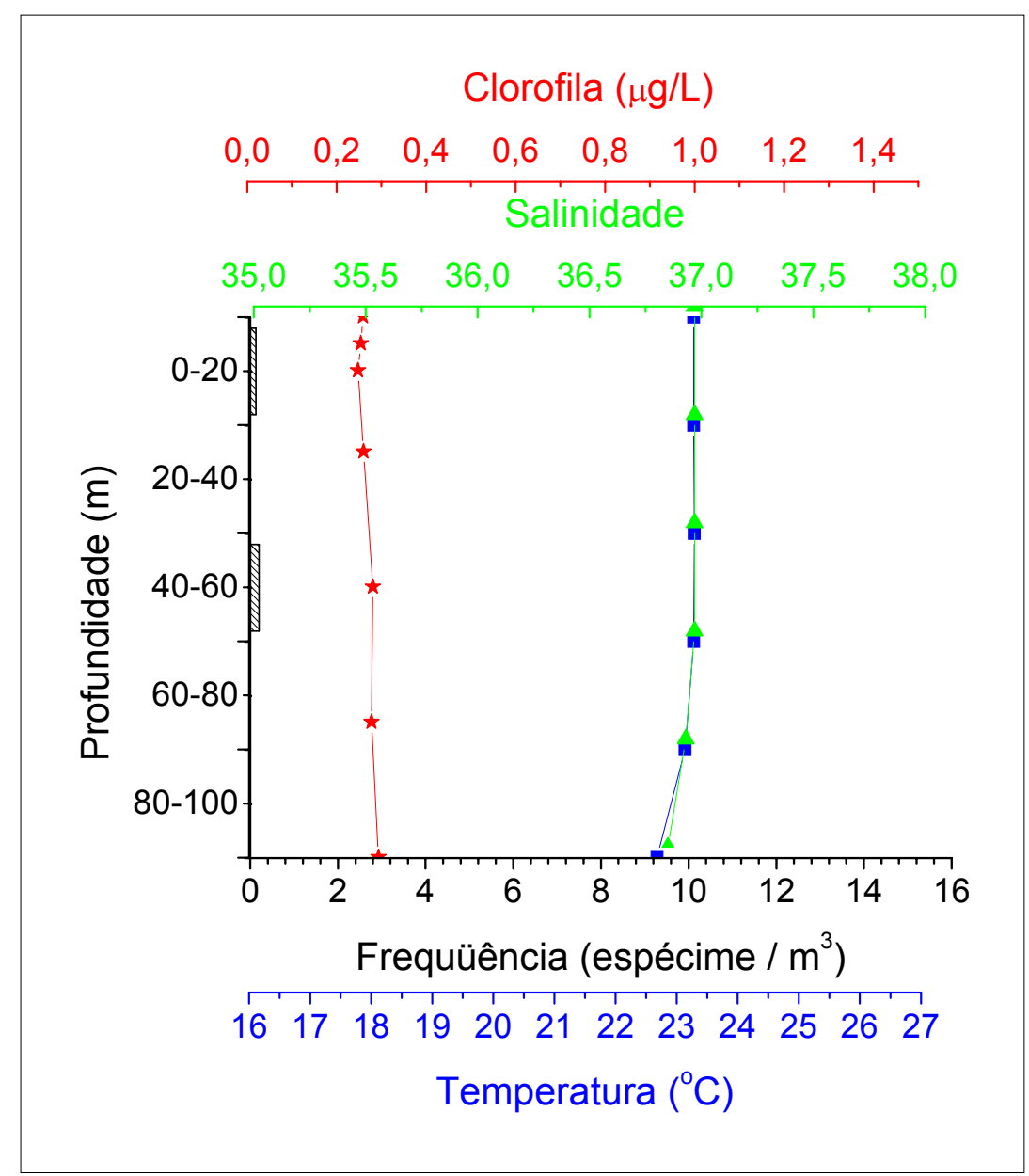

Figura 27 - Distribuição de espécimes de foraminíferos planctônicos, temperatura, salinidade e concentração de clorofila a ao longo da coluna d’água na estação hidrográfica 7286. 


\section{Estação 7293}

Essa estação apresenta o maior número de indivíduos de foraminíferos planctônicos. Entre $20 \mathrm{~m}$ e $40 \mathrm{~m}$ de profundidade, os foraminíferos planctônicos ocorrem com freqüência de 15,5 espécimes $/ \mathrm{m}^{3}$, sendo que entre $60 \mathrm{~m}$ e $80 \mathrm{~m}$ de profundidade, a freqüência passa a ser de 0,6 espécimes $/ \mathrm{m}^{3}$ (Tabela $11 \mathrm{e}$ Figura 28).

No intervalo entre $20 \mathrm{~m}$ e $40 \mathrm{~m}$ de profundidade, a concentração de clorofila a é de $0,20 \mu \mathrm{g} / \mathrm{L}$ (Tabela 7 ). A temperatura apresenta valores entre $23,26{ }^{\circ} \mathrm{C}$ e 23,27 e a salinidade entre 36,70 e 36,89 . Por outro lado, no intervalo entre $60 \mathrm{~m}$ e $80 \mathrm{~m}$ de profundidade a concentração de clorofila a é de $0,1 \mu \mathrm{g} / \mathrm{L}$, enquanto os valores de temperatura e a salinidade permanecem os mesmos.

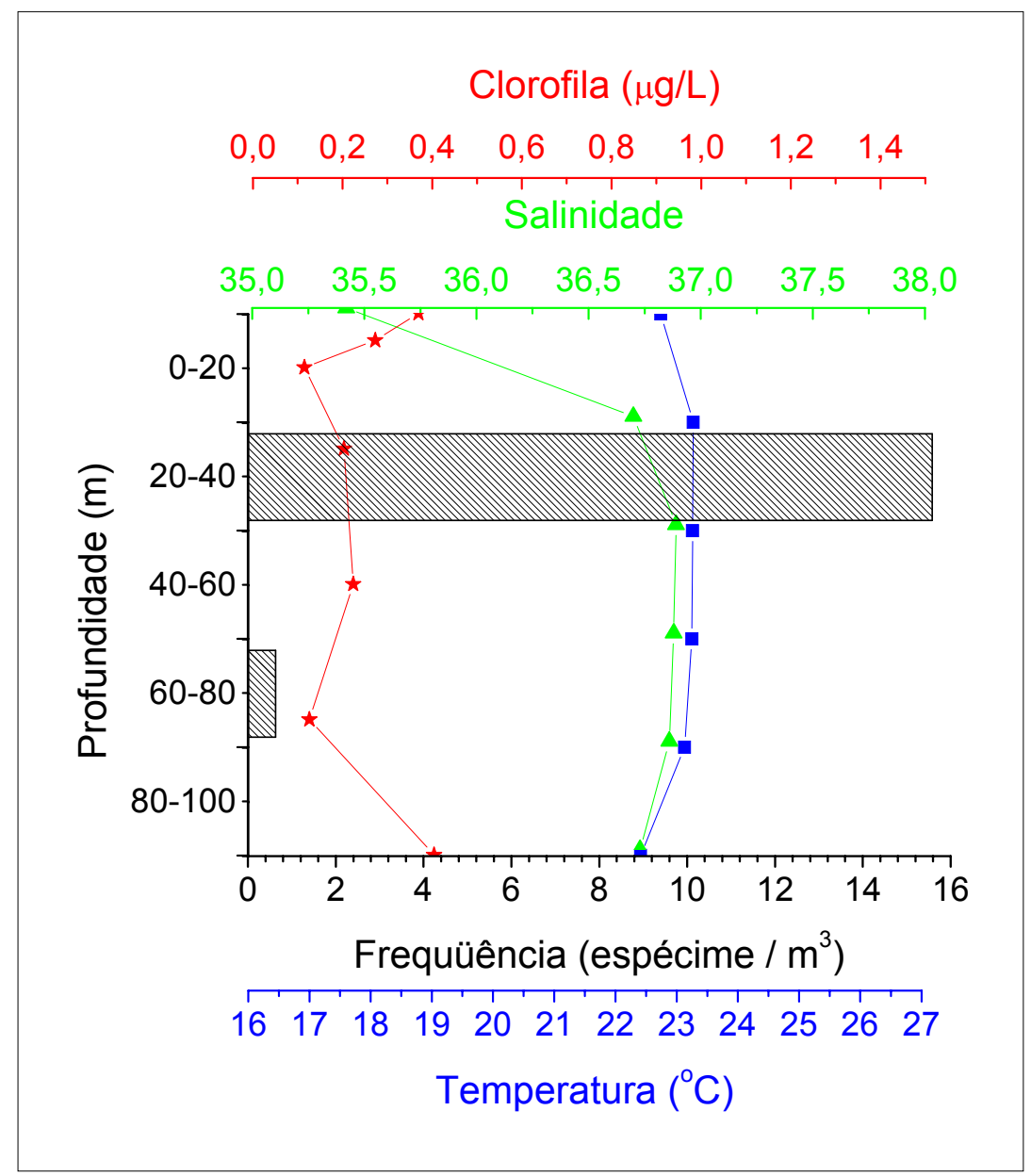

Figura 28 - Distribuição de espécimes de foraminíferos planctônicos, temperatura, salinidade e concentração de clorofila a ao longo da coluna d’água na estação hidrográfica 7293. 


\section{Estação 7294}

Apresenta testas de foraminíferos planctônicos somente entre as profundidades de $0 \mathrm{~m}$ e $20 \mathrm{~m}$ e entre $60 \mathrm{~m}$ e $80 \mathrm{~m}$, com freqüências de 0,03 espécimes $/ \mathrm{m}^{3}$ e 0,36 espécimes $/ \mathrm{m}^{3}$, respectivamente (Tabela 11 e Figura 29).

A concentração de clorofila a entre $0 \mathrm{~m}$ e $80 \mathrm{~m}$ varia entre $0,18 \mu \mathrm{g} / \mathrm{L}$ e $1,06 \mu \mathrm{g} / \mathrm{L}$, a temperatura oscila entre $21,75^{\circ} \mathrm{C}$ e $23,18^{\circ} \mathrm{C}$ e a salinidade varia entre 36,40 e 36,73 (Tabela 7). Nessa estação, o aumento da freqüência de indivíduos de foraminíferos planctônicos coincide com 0 aumento da concentração de clorofila a e com a diminuição da temperatura.

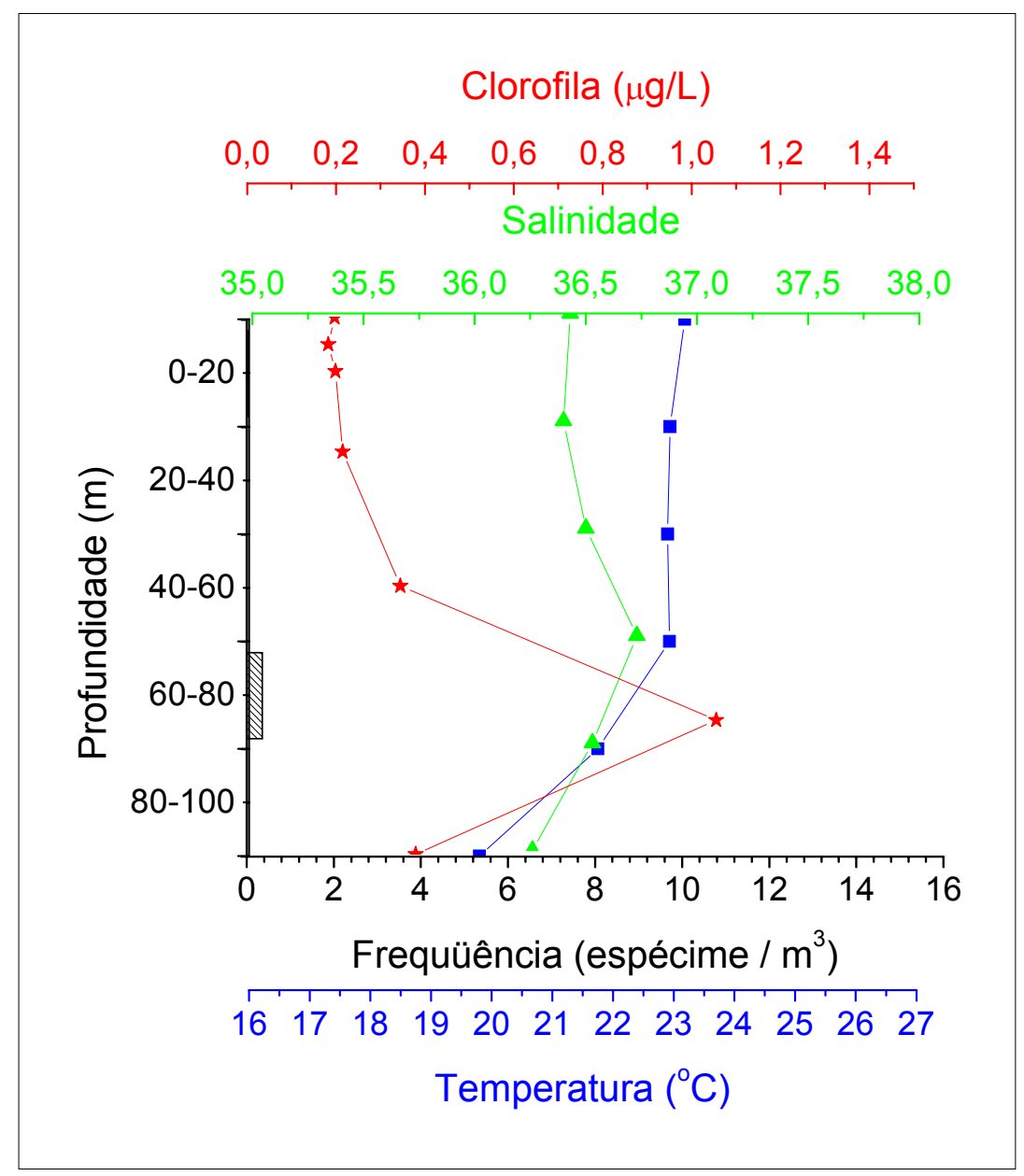

Figura 29 - Distribuição de espécimes de foraminíferos planctônicos, temperatura, salinidade e concentração de clorofila a ao longo da coluna d’água, na estação hidrográfica 7294. 


\section{Estação 7313}

Não foi encontrada nenhuma testa de foraminífero planctônico entre $0 \mathrm{~m}$ e $100 \mathrm{~m}$ de profundidade na coluna d'água (Tabela 11). A concentração de clorofila a variou de $0,21 \mu \mathrm{g} / \mathrm{L}$ na superfície a $0,46 \mu \mathrm{g} / \mathrm{L}$ na profundidade de 40 $\mathrm{m}$, diminuindo para $0,07 \mu \mathrm{g} / \mathrm{L}$ a $100 \mathrm{~m}$ de profundidade (Tabela 7). A temperatura variou de $24,41^{\circ} \mathrm{C}$ na superfície a $20,69{ }^{\circ} \mathrm{C}$, a $100 \mathrm{~m}$ de profundidade. A salinidade manteve-se em torno de 37.

\section{5 - Análise Estatística}

Os valores de correlação obtidos na aplicação da análise de correlação simples segundo o coeficiente de Pearson são apresentados na Tabela 12. Os valores em negrito têm grau de significância $\alpha \leq 0,05$, sendo que os valores em itálico têm grau de significância $\alpha \leq 0,10$. A espécie $G$. falconensis apresenta correlação positiva com a profundidade $(\alpha \leq 0,10)$, enquanto $G$. bulloides ( $\alpha \leq$ 0,05), G. calida ( $\alpha \leq 0,05)$, G. ruber (pink) $(\alpha \leq 0,05)$, G.ruber (withe) $(\alpha \leq 0,05)$, G. sacculifer $(\alpha \leq 0,10)$ e $G$. menardii $(\alpha \leq 0,05)$ respondem negativamente ao aumento de profundidade (Tabela 12).

As espécies $G$. falconensis $(\alpha \leq 0,05)$ apresentam correlação negativa com a temperatura e G. ruber (pink) $(\alpha \leq 0,05)$, G. ruber (white) $(\alpha \leq 0,05)$ G. sacculifer $(\alpha \leq 0,10)$ e $G$. menardii $(\alpha \leq 0,05)$ apresentam correlação positiva com este parâmetro.

Quanto à correlação com o parâmetro salinidade, a espécie G. menardii responde positivamente, entretanto, com grau de significância menor ou igual a 0,10 .

As espécies G. ruber (pink) ( $\alpha \leq 0,05)$, G. ruber (white) $(\alpha \leq 0,10)$ e $G$. menardii $(\alpha \leq 0,10)$ respondem negativamente ao aumento de concentração de clorofila $a$, enquanto $G$. falconensis $(\alpha \leq 0,05)$ e $G$. siphonifera $(\alpha \leq 0,10)$ respondem positivamente. 


\begin{tabular}{l|c|c|c|c}
\multicolumn{1}{c|}{ Espécies } & Profundidade & Temperatura & Salinidade & Clorofila a \\
\hline \hline G. bulloides & $-0,21$ & 0,19 & 0,05 & $-0,18$ \\
\hline G. falconensis & $\mathbf{0 , 4 3}$ & $\mathbf{- 0 , 4 5}$ & $-0,15$ & $\mathbf{0 , 2 9}$ \\
\hline G. calida & $-0,14$ & 0,20 & 0,10 & $-0,14$ \\
\hline G. ruber (pink) & $\mathbf{- 0 , 5 9}$ & $\mathbf{0 , 4 6}$ & 0,00 & $\mathbf{- 0 , 3 7}$ \\
\hline G. ruber (white) & $\mathbf{- 0 , 3 8}$ & $\mathbf{0 , 3 7}$ & 0,10 & $-0,23$ \\
\hline G. sacculifer & $-0,26$ & 0,22 & 0,10 & $-0,16$ \\
\hline G. siphonifera & 0,06 & $-0,15$ & $-0,08$ & 0,22 \\
\hline G. menardii & $\mathbf{- 0 , 2 8}$ & $\mathbf{0 , 4 6}$ & 0,26 & $-0,25$ \\
\hline N. dutertrei & 0,19 & $-0,19$ & 0,03 & 0,17 \\
\hline O. universa & 0,08 & 0,16 & 0,18 & 0,01 \\
\hline G. & $\mathbf{0}$ de signican
\end{tabular}

Grau de significância $\alpha \leq 0,05$ e $\alpha \leq 0,10$

Tabela 12 - Valores do coeficiente correlação simples encontrados entre as variáveis ambientais e biológicas.

\section{6 - Análise da Tanatocenose}

A análise da tanatocenose possibilitou identificar 15 espécies de foraminíferos planctônicos nas amostras de sedimento (Tabela 13). Do total de 15 espécies identificadas nos sedimentos, seis espécies não foram encontradas nas amostras de plâncton. São elas: Globigerinoides $s p$, Globorotalia scitula, Globorotalia tumida, Globorotalia hirsuta, Neogloboquadrina pachyderma, Pulleniatina obliquiloculata e Globorotalia truncatulinoides. Nas amostras de sedimento, à exceção de G. truncatulinoides, as demais espécies citadas foram encontradas apenas nas estações oceanográficas 7365, 7376, 7618 e 7621 . Essas espécies apresentam as menores freqüências em comparação com as demais espécies encontradas no sedimento (Tabela 13).

As espécies G. ruber (white) e G. ruber (pink) são as mais abundantes (84,9\% e 10\%, respectivamente) no registro sedimentar, assim como nas amostras de plâncton.Entretanto, na biocenose, observa-se predominância da espécie G. ruber (pink), ao contrário do que é constatado na tanatocenose.. Orbulina universa é constatada com baixa freqüência tanto no sedimento como no plâncton, enquanto $G$. calida apesar de estar presente no plâncton, exibe freqüência muito superior no sedimento $(5,42 \%)$ (Tabela 13$)$. 
As demais espécies observadas na tanatocenose (Globigerina bulloides, Globigerina falconensis, Globorotalia menardii, Neogloboquadrina dutertrei e Globigerinella siphonifera) ocorrem com freqüências muito similares as da biocenose.

\begin{tabular}{l|c|c|c|c|c|c}
\hline & \multicolumn{5}{|c}{ Estação Oceanográfica } \\
& 7618 & 7619 & 7621 & 7622 & 7623 & 7376 \\
\hline Fração (mm) & 0,125 & 0,125 & 0,125 & 0,125 & 0,125 & 0,125 \\
\hline Fração da amostra analisada & $1 / 8$ & $1 / 32$ & $1 / 64$ & $1 / 8$ & $1 / 64$ & $1 / 32$ \\
\hline Total de carapaças analisadas & 458 & 598 & 315 & 322 & 332 & 374 \\
\hline Total de carapaças em 10cc & 3664 & 19136 & 20160 & 2576 & 21248 & 11968 \\
\hline \hline G. sp & 0 & 0 & 0 & 0 & 128 & 0 \\
\hline G. bulloides & 32 & 1152 & 960 & 40 & 2368 & 800 \\
\hline G. calida & 40 & 512 & 1088 & 112 & 1152 & 480 \\
\hline G. siphonifera & 56 & 128 & 0 & 40 & 128 & 96 \\
\hline G. ruber (pink) & 160 & 1344 & 1280 & 232 & 1920 & 992 \\
\hline G. ruber (withe) & 2880 & 15040 & 16256 & 2016 & 14272 & 8224 \\
\hline G. sacculifer & 32 & 0 & 0 & 0 & 0 & 96 \\
\hline G. scitula & 0 & 0 & 0 & 0 & 0 & 32 \\
\hline G. tumida & 0 & 0 & 0 & 0 & 0 & 224 \\
\hline G. hirsuta & 88 & 0 & 0 & 0 & 0 & 0 \\
\hline G. menardii & 168 & 512 & 320 & 72 & 576 & 544 \\
\hline N. dutertrei & 104 & 128 & 0 & 16 & 256 & 256 \\
\hline N. pachyderma & 0 & 0 & 128 & 0 & 0 & 32 \\
\hline G. truncatulinoides & 96 & 192 & 128 & 16 & 128 & 128 \\
\hline O. universa & 8 & 64 & 0 & 32 & 256 & 64 \\
\hline P. obliquiloculata & 0 & 64 & 0 & 0 & 64 & 0 \\
\hline & & & & & &
\end{tabular}

Tabela 13 - Espécies de foraminíferos planctônicos identificadas no sedimento. 


\section{7 - Análise Tafonômica}

\subsection{1 - Assinaturas tafonômicas}

Apesar da visualização das assinaturas tafonômicas ser melhor visualizadas em microscópio eletrônico de varredura, foi possível identificá-las sob estereomicroscópio, na maioria das testas de foraminíferos planctônicos analisadas (Prancha 2 e 3 ).

Nas carapaças de foraminíferos planctônicos analisadas foram observadas as seguintes assinaturas tafonômicas: fragmentação, alteração de cor, alteração brilho/textura e corrosão.

\section{Fragmentação}

A fragmentação pode ter origem física, devido ao processo de transporte de partículas, origem química, que pode ocasionar fragilização da carapaça pelo processo de dissolução/corrosão e/ou origem biológica, através de bioturbação do sedimento (Rodriques 2006). Entretanto, mesmo realizando uma análise cuidadosa das carapaças, não foi possível diferenciar o processo que originou a fragmentação das carapaças de foraminíferos, e por esse motivo, no presente trabalho não se distinguiu fragmentação física, de fragmentação química e/ou de fragmentação biológica.

Espécimes de foraminíferos planctônicos mostrando fragmentação em seus diferentes estados podem ser observados na Figura 30 e na Prancha 3.

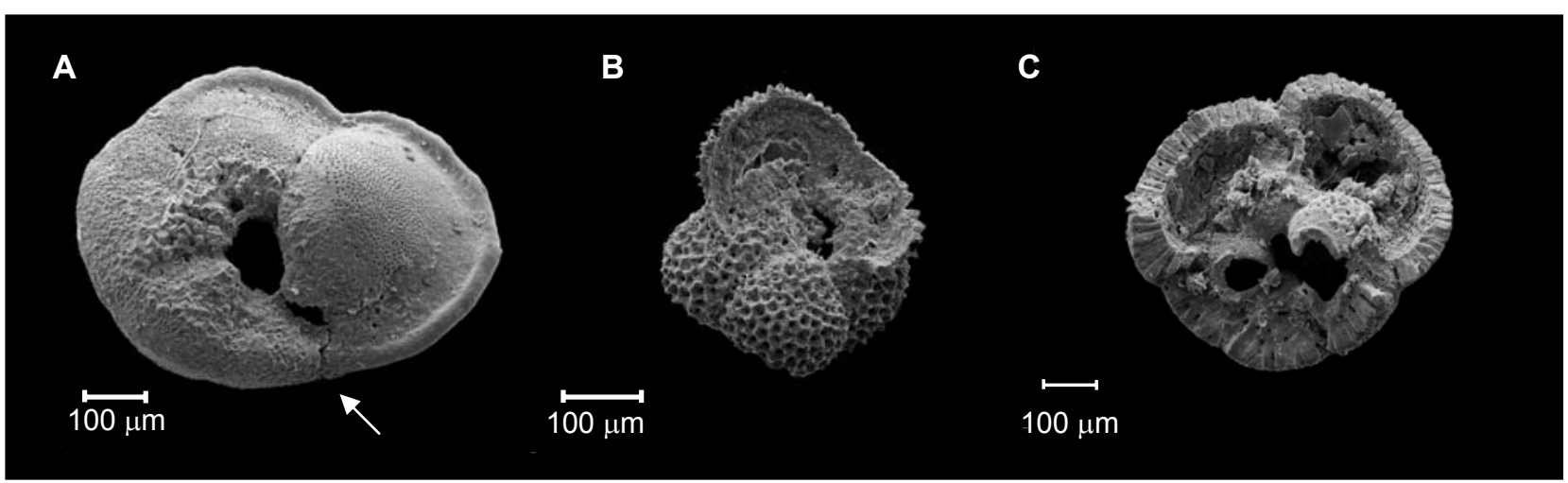

Figura 30 - Testas de foraminíferos planctônicos fragmentadas. A - testa apresentando menos de $10 \%$ de fragmentação; B - testa apresentando entre $10 \%$ e $50 \%$ de fragmentação; C - testa apresentando mais que 50\% de fragmentação. 


\section{Alteração da Cor}

A alteração da cor é uma assinatura tafonômica que só pode ser observada sob estereomicroscópio e em testas que não foram coradas durante o processo de fixação (e.g. uso do corante Rosa de Bengala).

As testas de foraminíferos planctônicos, originalmente brancas translúcidas ou brancas não translúcidas, podem apresentar cor alterada comumente para castanho, cinza ou preta (Figura 31).

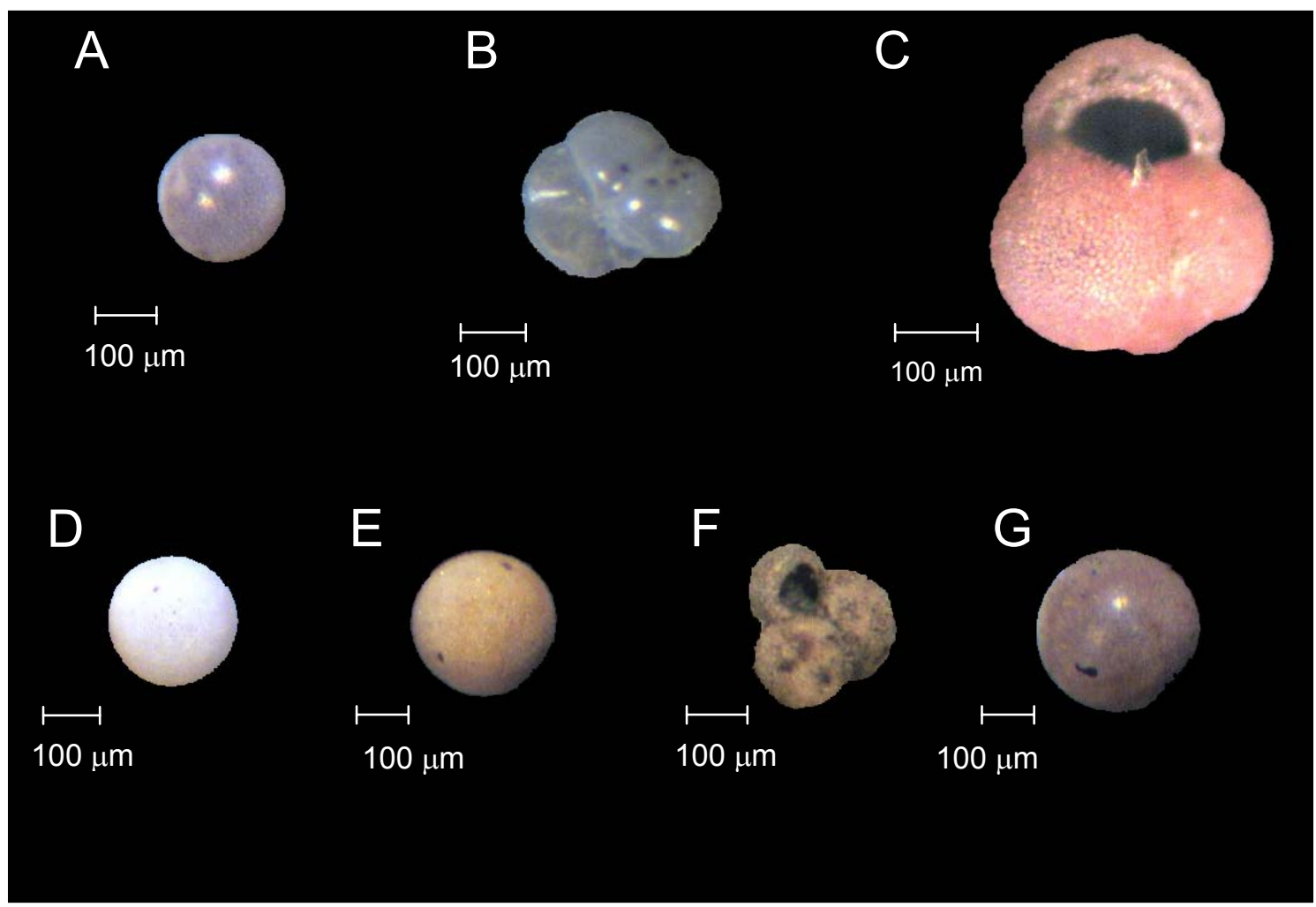

Figura 31 - Testas de foraminíferos planctônicos apresentando cor normal e alterada. A - D: testas de foraminíferos planctônicos apresentando coloração branca translúcida ou branca não translúcida ; E e F: testas apresentando coloração castanha e G: testa de foraminífero planctônico apresentando coloração cinza a preta. Observação: o espécime apresentado em $\mathrm{C}$ apresenta a cor rosa como coloração original. 


\section{Alteração da Textura/Brilho}

Devido a processos físicos (e.g. abrasão), químicos (e.g. dissolução) e/ou biológicos (e.g. bioturbação, passagem das carapaças pelo aparelho digestório de holoturia, copepoda, Bé \& Hutson, 1977), as testas de foraminíferos planctônicos podem apresentar textura granular, fosca ou opaca (Figura 32 e Prancha 3).

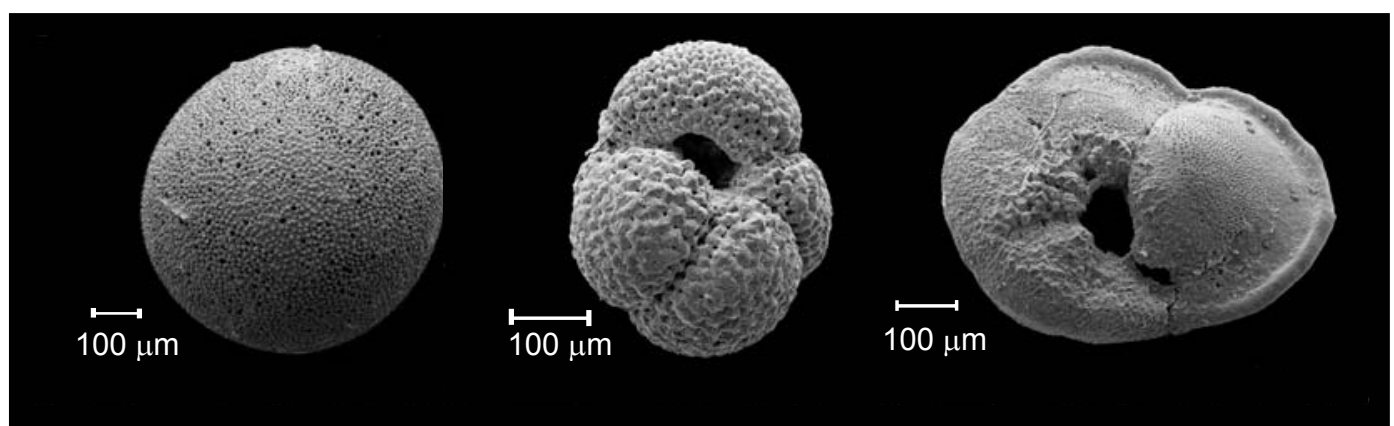

Figura 32 - Testas de foraminíferos planctônicos mostrando alteração no brilho/textura.

\section{Corrosão}

A corrosão se caracteriza por gerar nas carapaças de foraminíferos planctônicos algumas mudanças em suas características morfológicas, tais como, presença de margem serrilhada, aumento no tamanho dos poros, esfoliação da carapaça e textura granular (Figura 33 e Prancha 3). 


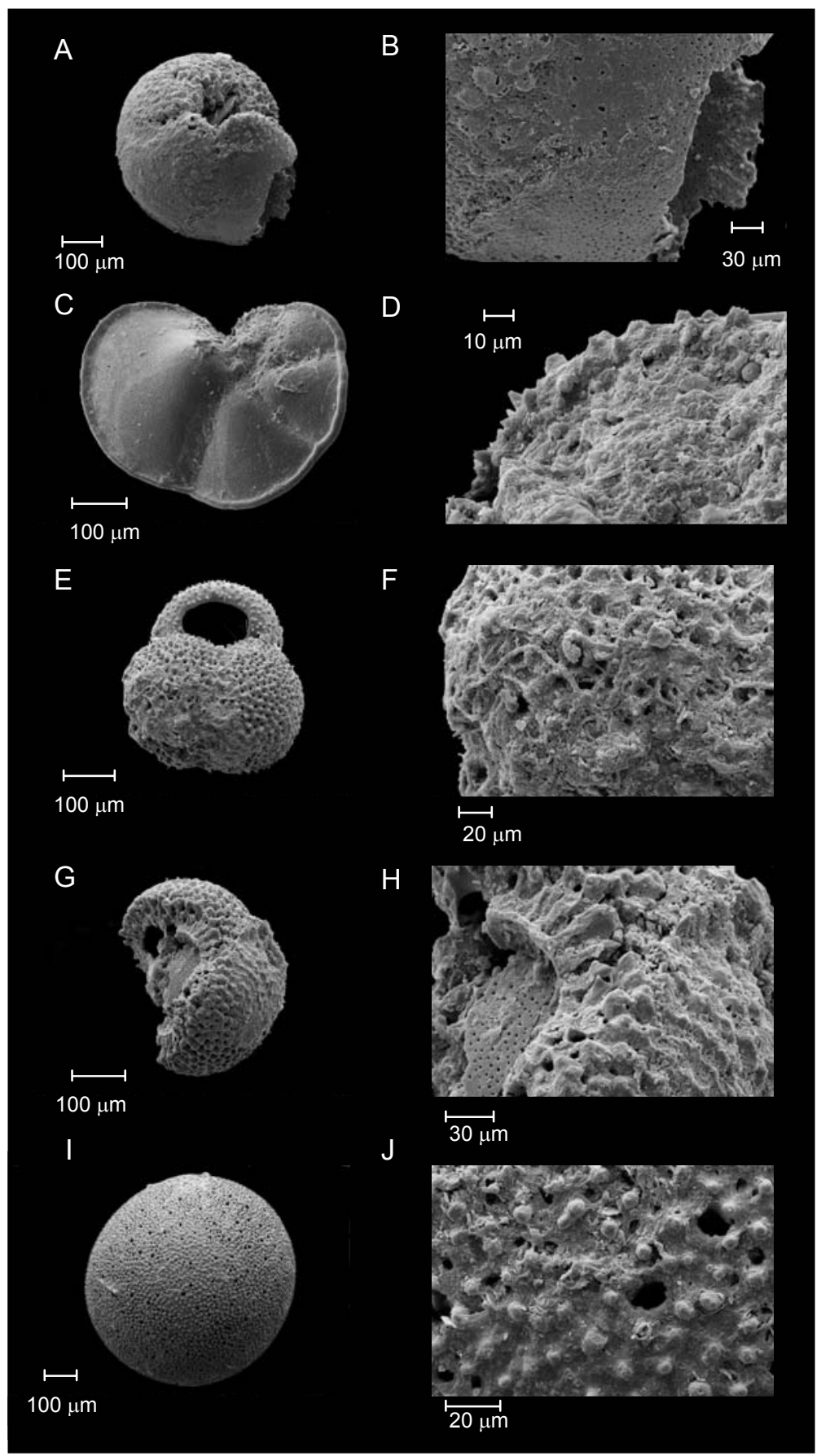

Figura 33 - Testas de foraminíferos planctônicos apresentando corrosão (A a J). Detalhes das testas corroídas mostrando em $\mathrm{B}$ borda serrilhada, em $\mathrm{D}, \mathrm{F}$ e H textura granular, em $\mathrm{J}$ poros maiores e em B e J carapaças esfoliadas. 
A freqüência das assinaturas tafonômicas foi calculada e sua distribuição em cada estação oceanográfica pode ser observada nas Tabelas 15 e 16 e nas Figuras 34 a 41.

De maneira geral, a fração $0,250 \mathrm{~mm}$ encontra-se melhor preservada quando comparada à fração de $0,125 \mathrm{~mm}$, pois se observou que na fração grossa as assinaturas tafonômicas (fragmentação, alteração da cor e do brilho natural e corrosão) são menos freqüentes nas carapaças de foraminíferos planctônicos em relação à fração $0,125 \mathrm{~mm}$. 


\section{Fração 0,125 mm}

Nessa fração, com exceção da estação 7365, localizada a 964 m de profundidade, todas as demais estações apresentam entre 91\% (estação 7622) e 97\% (estações 7619, 7621 e 7623) das carapaças com corrosão. Tais estações estão situadas a $413 \mathrm{~m}$ e $458 \mathrm{~m}$ de profundidade, respectivamente. A porcentagem de carapaças com alteração de brilho/textura praticamente coincide com a porcentagem de testas com corrosão. À exceção novamente da estação 7365, entre 68\% (estação 7618) e 87\% (estação 7622) das testas analisadas apresentam alteração de cor (Tabela 14). Essas estações estão localizadas a $231 \mathrm{~m}$ e $430 \mathrm{~m}$ de profundidade, respectivamente.

Na estação 7365, as assinaturas tafonômicas são pouco freqüentes. A corrosão é encontrada em apenas $34 \%$ das testas de foraminíferos planctônicos analisadas, a alteração de cor está presente em 19\% das carapaças, sendo que até $78 \%$ delas estão inteiras, não apresentando fragmentação (Tabela 15).

De maneira geral, a freqüência de fragmentação das carapaças foi baixa (menor que 33\%).

\begin{tabular}{|c|c|c|c|c|c|c|c|c|c|c|}
\hline $\begin{array}{c}\text { Estação } \\
\text { de coleta }\end{array}$ & $\begin{array}{c}\text { Fragmentação } \\
\text { Ausente }\end{array}$ & $\begin{array}{c}\text { Fragmentação } \\
<10 \%\end{array}$ & $\begin{array}{c}\text { Fragmentação } \\
\text { entre } 10 \mathrm{e} \\
50 \%\end{array}$ & $\begin{array}{c}\text { Fragmentação } \\
>50 \%\end{array}$ & $\begin{array}{c}\text { Cor } \\
\text { mantida }\end{array}$ & $\begin{array}{c}\text { Cor } \\
\text { alterada }\end{array}$ & $\begin{array}{c}\text { Brilho } \\
\text { mantido }\end{array}$ & Brilho & $\begin{array}{l}\text { Corrosão } \\
\text { ausente }\end{array}$ & $\begin{array}{l}\text { Corrosão } \\
\text { presente }\end{array}$ \\
\hline 7365 & $79 \%$ & $10 \%$ & $6 \%$ & $6 \%$ & $81 \%$ & $19 \%$ & $41 \%$ & $59 \%$ & $66 \%$ & $34 \%$ \\
\hline 7618 & $77 \%$ & $15 \%$ & $3 \%$ & $4 \%$ & $32 \%$ & $68 \%$ & $3 \%$ & $97 \%$ & $3 \%$ & $97 \%$ \\
\hline 7619 & $76 \%$ & $6 \%$ & $9 \%$ & $9 \%$ & $30 \%$ & $70 \%$ & $7 \%$ & $93 \%$ & $5 \%$ & $95 \%$ \\
\hline 7621 & $82 \%$ & $9 \%$ & $9 \%$ & $1 \%$ & $27 \%$ & $73 \%$ & $5 \%$ & $95 \%$ & $3 \%$ & $97 \%$ \\
\hline 7622 & $83 \%$ & $9 \%$ & $5 \%$ & $2 \%$ & $13 \%$ & $87 \%$ & $9 \%$ & $91 \%$ & $9 \%$ & $91 \%$ \\
\hline 7623 & $77 \%$ & $1 \%$ & $10 \%$ & $11 \%$ & $23 \%$ & $77 \%$ & $3 \%$ & $97 \%$ & $3 \%$ & $97 \%$ \\
\hline
\end{tabular}

Tabela 15 - Freqüência de ocorrência das assinaturas tafonômicas nas testas de foraminíferos planctônicos na fração $0,125 \mathrm{~mm}$. 


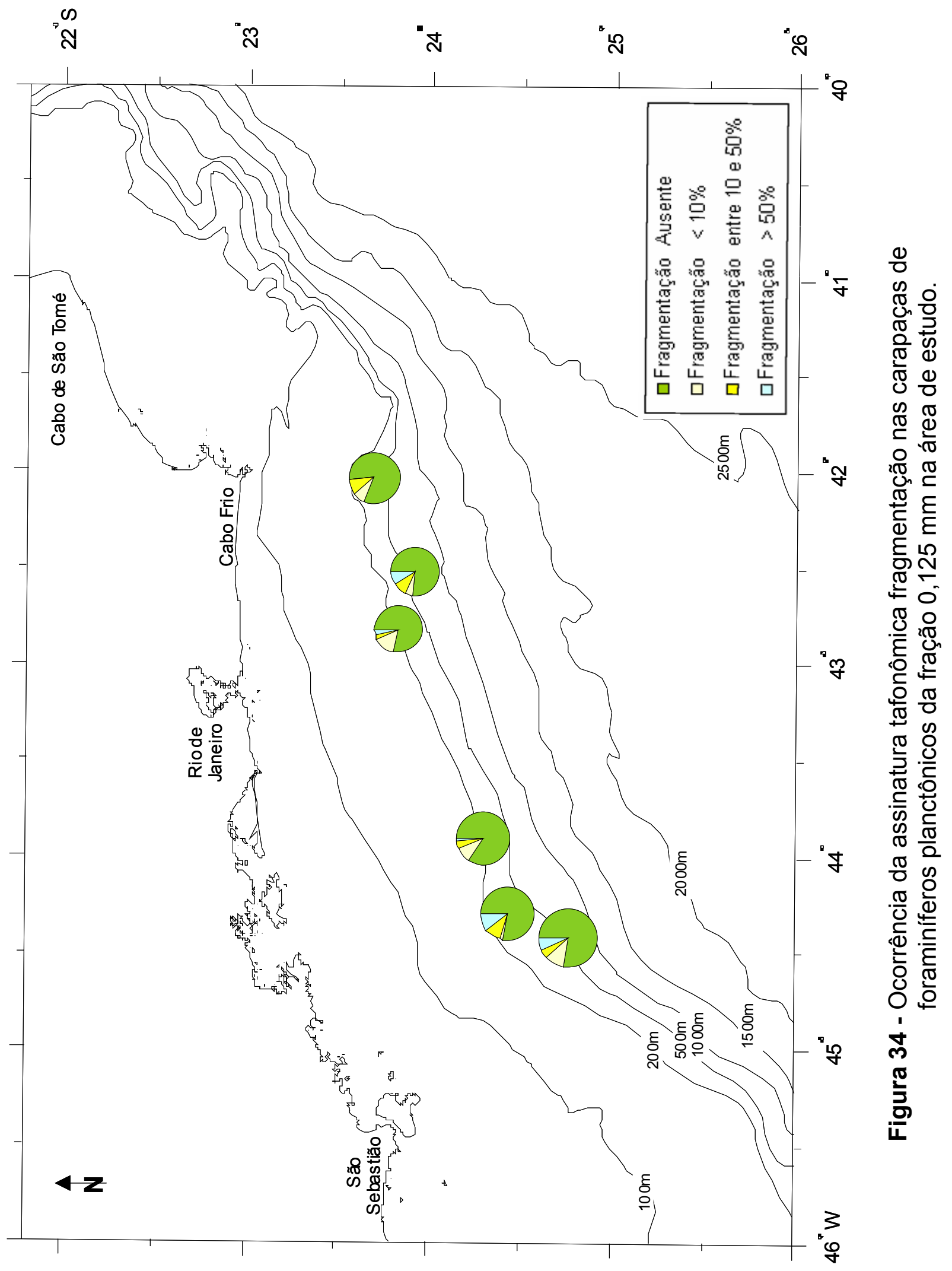




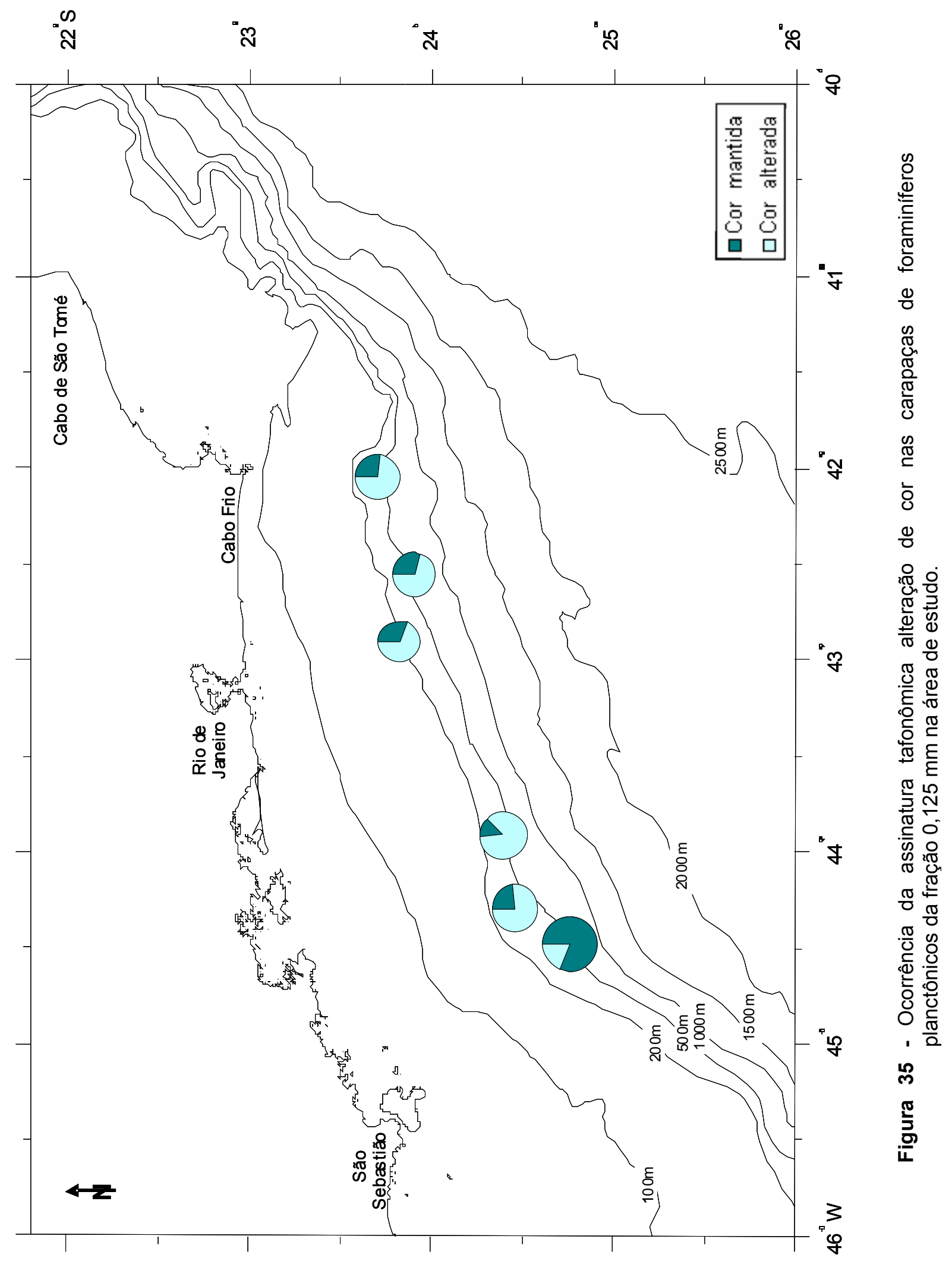




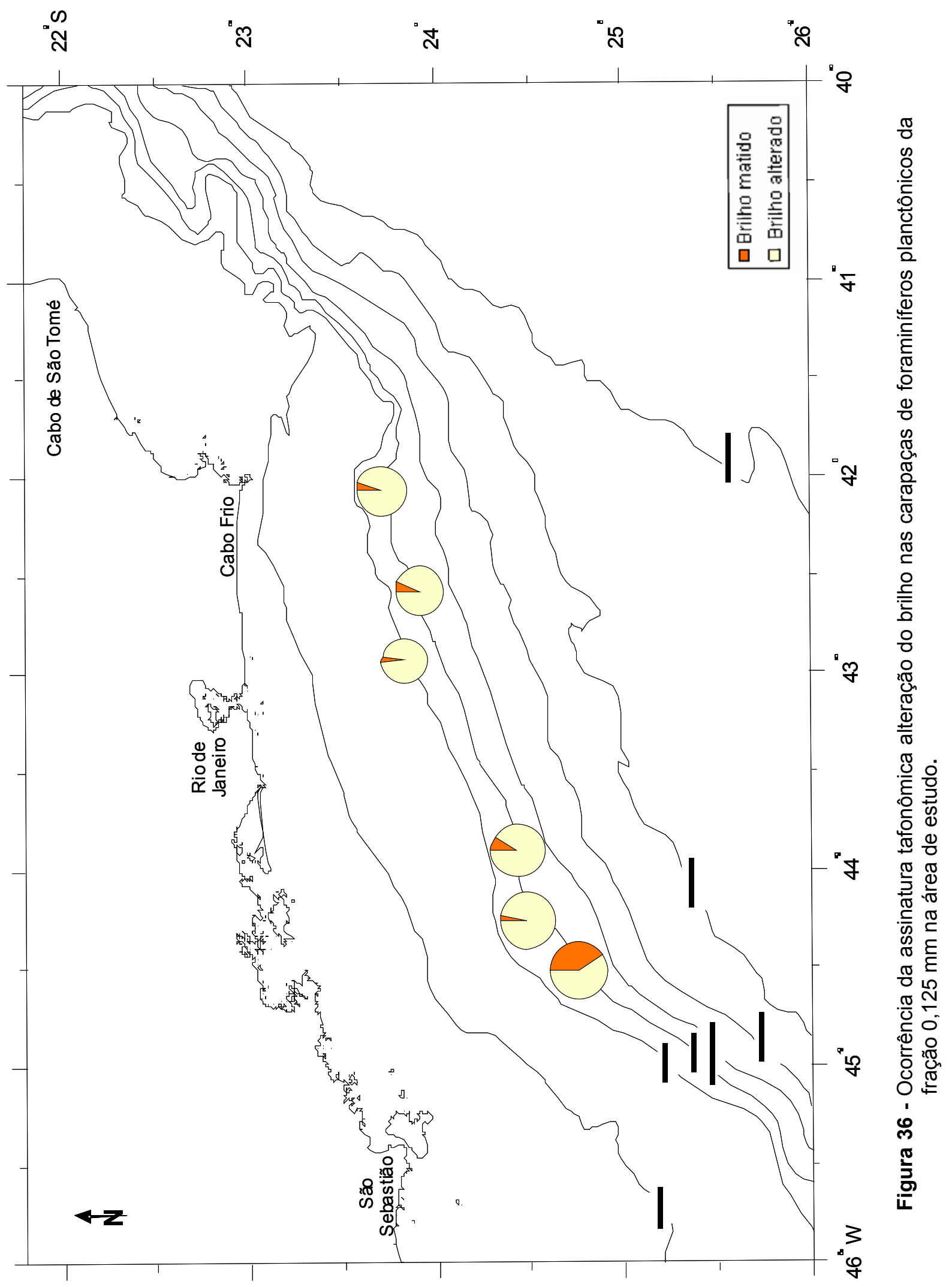




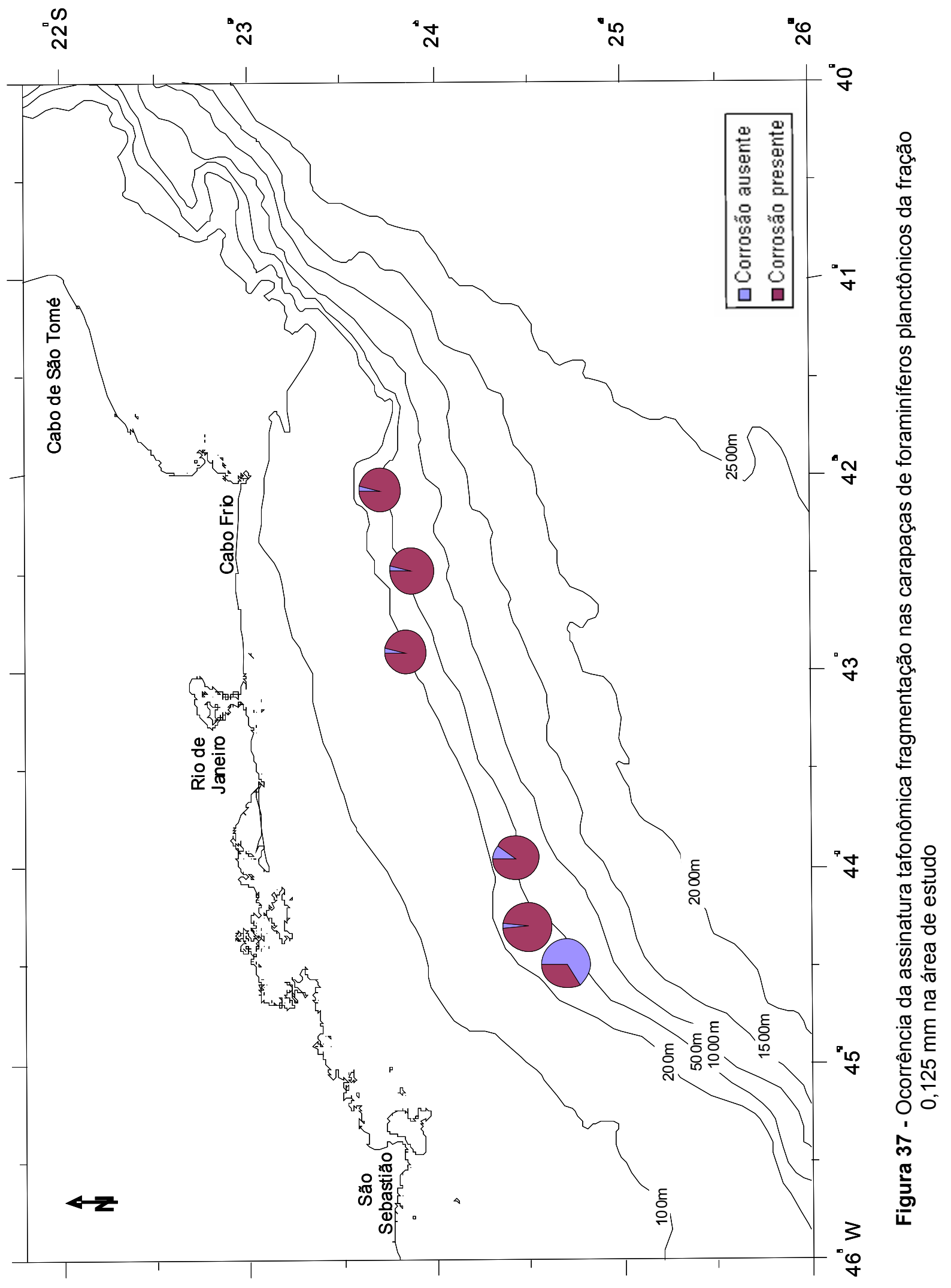




\section{Fração 0,250 mm}

As estações que apresentam as maiores freqüências de testas com corrosão são 7623 (97\%), 7619 (83\%) e 7622 (81\%). Essas estações estão localizadas entre as profundidades de $400 \mathrm{~m}$ e $500 \mathrm{~m}$. Também ocorre nessas estações as maiores freqüências de carapaças com alteração de cor (entre $49 \%$ e $59 \%$ ), assim como, de carapaças não fragmentadas (entre $77 \%$ e $85 \%$ ) (Tabela 16 e Figuras de 38 a 41).

$\mathrm{Na}$ estação 7365 , apenas $58 \%$ das carapaças apresentam corrosão, somente $21 \%$ delas apresentam alteração de cor e $73 \%$ das carapaças encontram-se não fragmentadas (Tabela 16).

Nas estações 7618 e 7621 , é constatada maior freqüência de carapaças fragmentadas (32\%) e relativamente a menor freqüência de carapaças com corrosão $(65 \%$ a $75 \%)$.

\begin{tabular}{|c|c|c|c|c|c|c|c|c|c|c|}
\hline $\begin{array}{l}\text { Estação } \\
\text { de coleta }\end{array}$ & $\begin{array}{c}\text { Fragmentação } \\
\text { Ausente }\end{array}$ & $\begin{array}{c}\text { Fragmentação } \\
<10 \%\end{array}$ & $\mid \begin{array}{c}\text { Fragmentação } \\
\text { entre } 10 \text { e } \\
50 \%\end{array}$ & $\begin{array}{c}\text { Fragmentação } \\
>50 \%\end{array}$ & mantida & $\begin{array}{c}\text { Cor } \\
\text { alterada }\end{array}$ & $\begin{array}{c}\text { Brilho } \\
\text { mantido }\end{array}$ & $\begin{array}{c}\text { Brilho } \\
\text { alterado }\end{array}$ & $\begin{array}{l}\text { Corrosão } \\
\text { ausente }\end{array}$ & $\begin{array}{l}\text { Corrosão } \\
\text { presente }\end{array}$ \\
\hline 7365 & $73 \%$ & $9 \%$ & $10 \%$ & $8 \%$ & $79 \%$ & $21 \%$ & $41 \%$ & $59 \%$ & $42 \%$ & $58 \%$ \\
\hline 7618 & $68 \%$ & $12 \%$ & $11 \%$ & $7 \%$ & $45 \%$ & $53 \%$ & $21 \%$ & $77 \%$ & $25 \%$ & $75 \%$ \\
\hline 7619 & $85 \%$ & $9 \%$ & $5 \%$ & $1 \%$ & $41 \%$ & $59 \%$ & $17 \%$ & $83 \%$ & $17 \%$ & $83 \%$ \\
\hline 7621 & $68 \%$ & $14 \%$ & $9 \%$ & $9 \%$ & $69 \%$ & $31 \%$ & $25 \%$ & $74 \%$ & $35 \%$ & $65 \%$ \\
\hline 7622 & $85 \%$ & $11 \%$ & $3 \%$ & $1 \%$ & $51 \%$ & $49 \%$ & $19 \%$ & $81 \%$ & $19 \%$ & $81 \%$ \\
\hline 7623 & $77 \%$ & $11 \%$ & $3 \%$ & $8 \%$ & $51 \%$ & $49 \%$ & $3 \%$ & $97 \%$ & $3 \%$ & $97 \%$ \\
\hline
\end{tabular}

Tabela 16 - Freqüência de ocorrência das assinaturas tafonômicas nas testas de foraminíferos planctônicos na fração $0,250 \mathrm{~mm}$. 


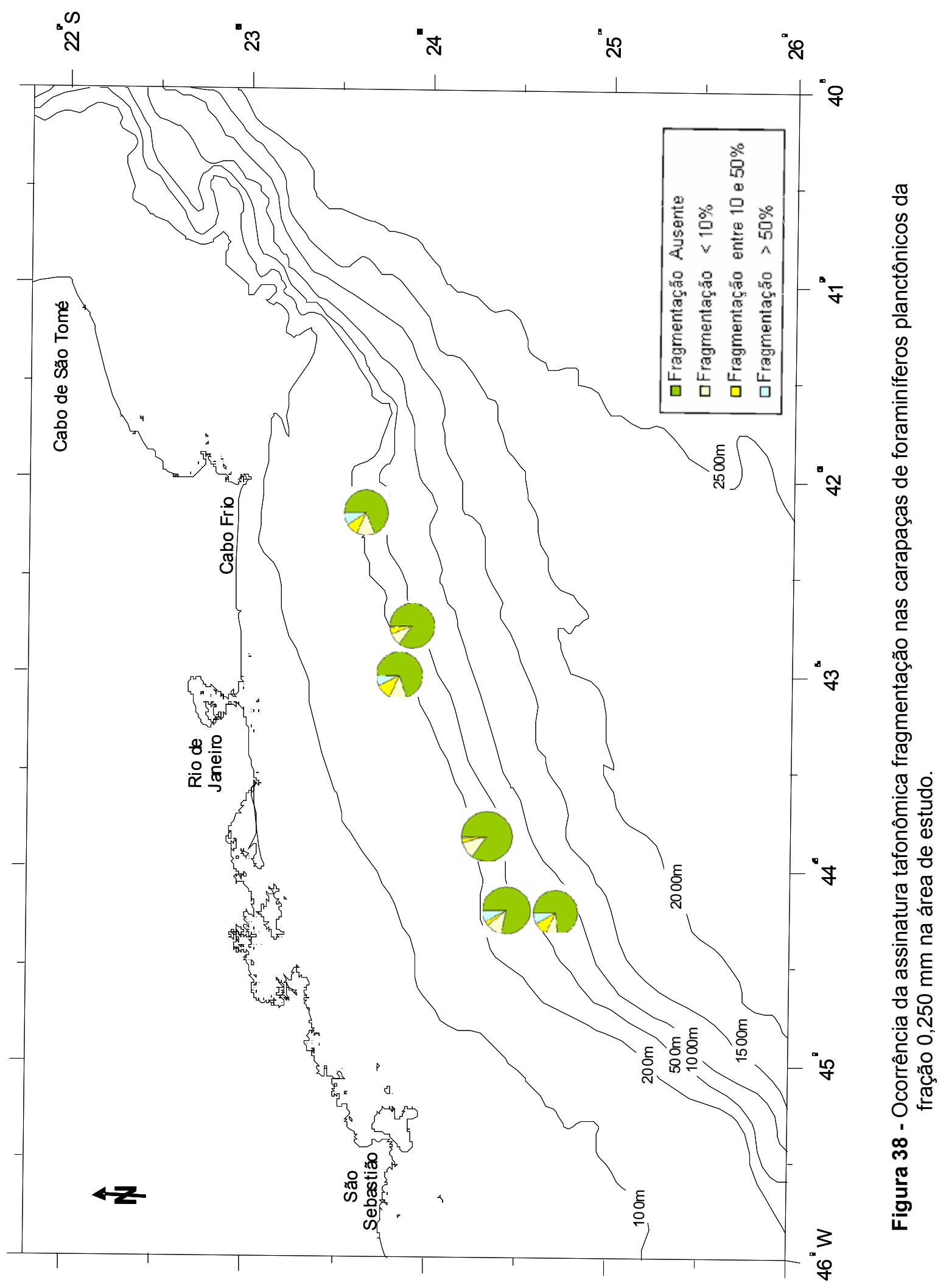




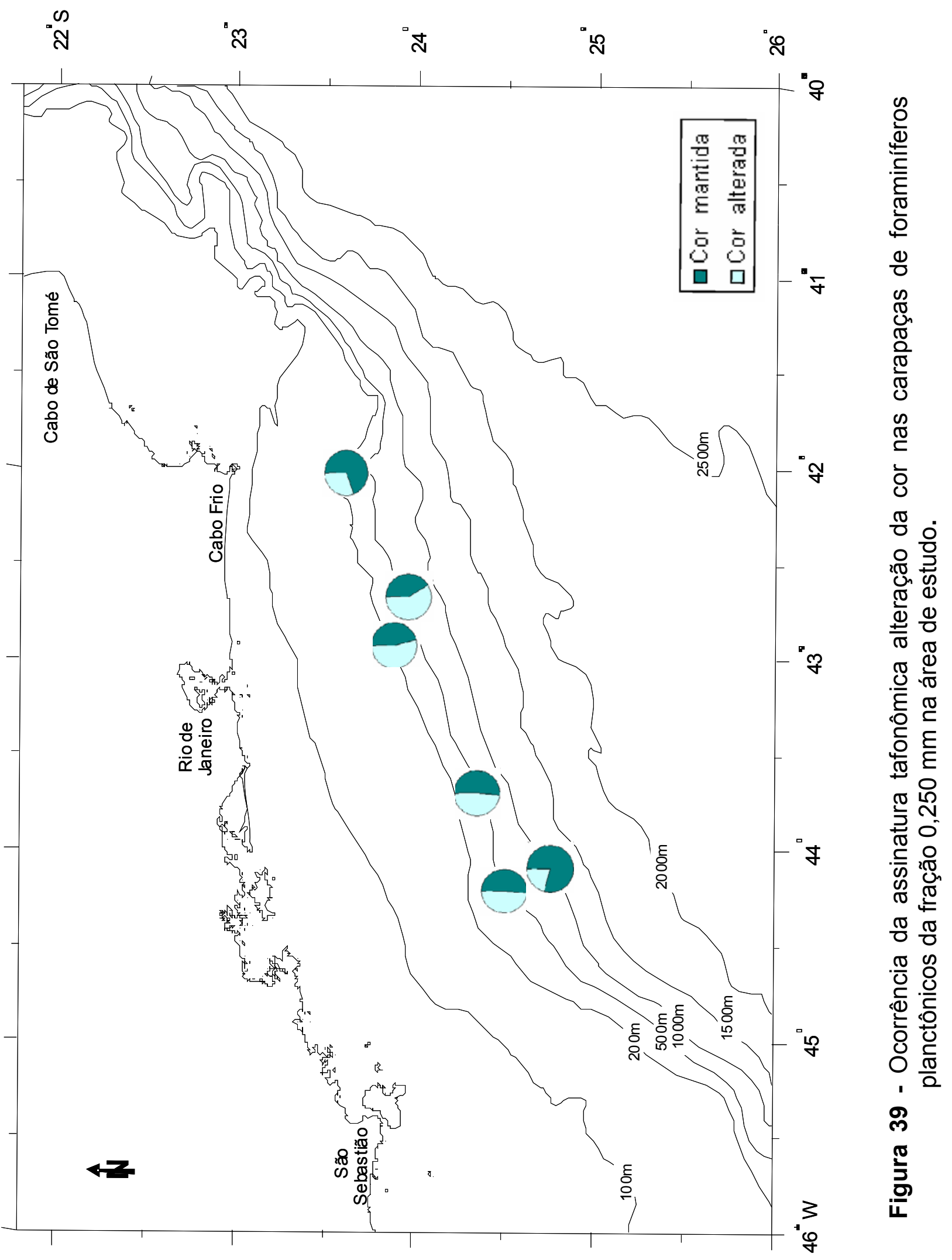




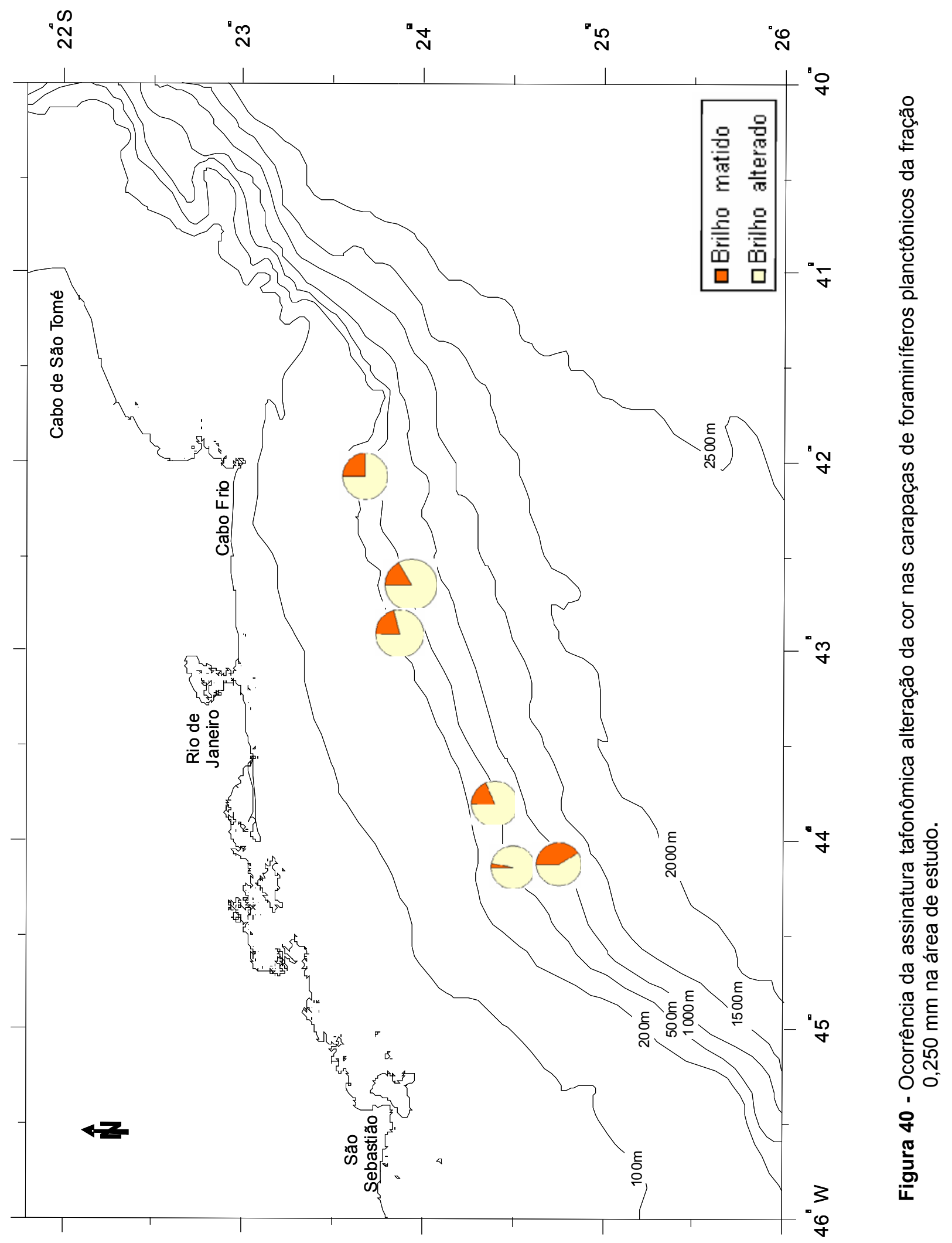




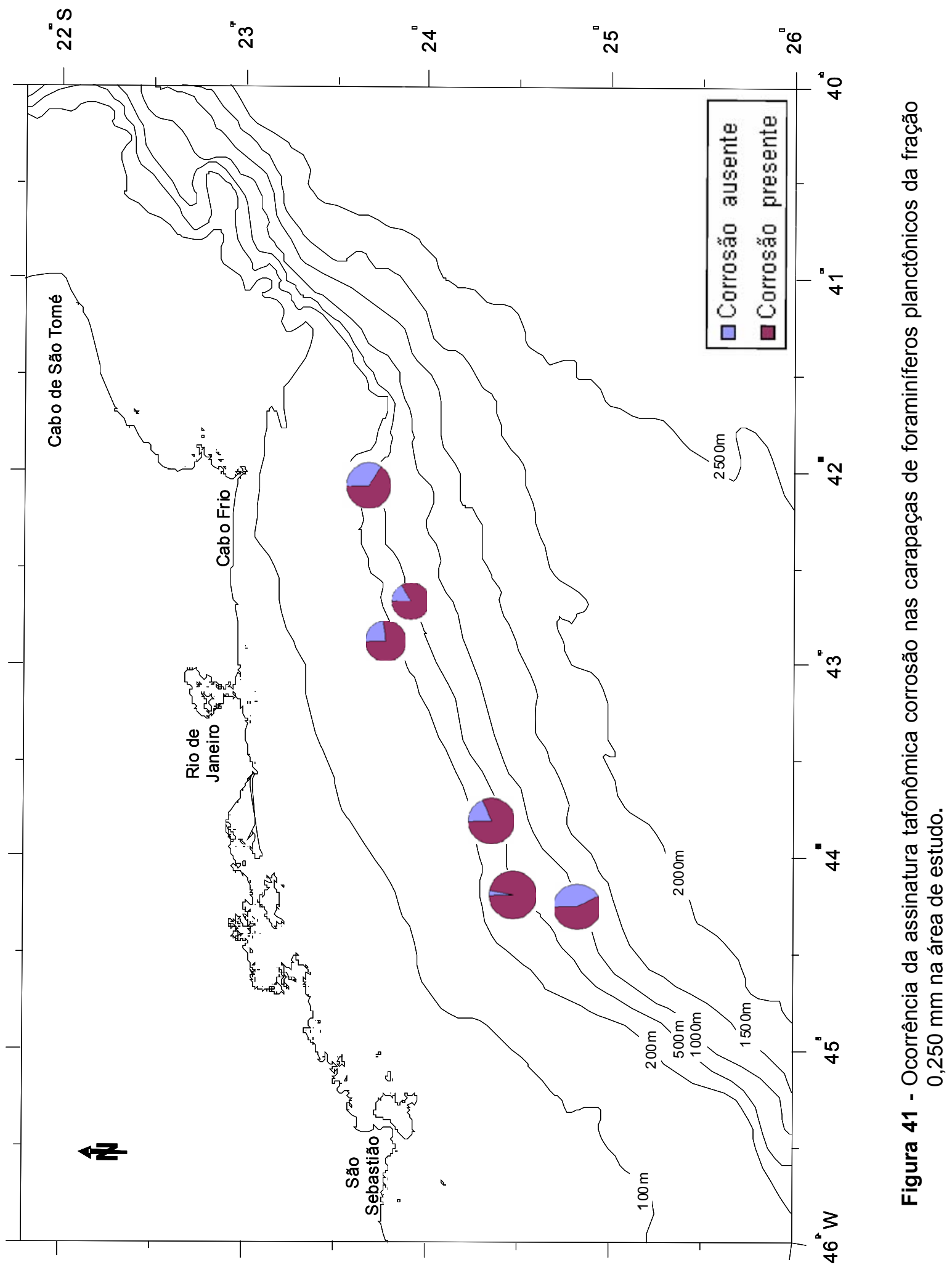




\section{Discussão}

\section{4 - Discussão}

A análise de dados de $T$ e $S$ permitiu definir a ocorrência das massas de água AT, ACAS, AIA e APAN na área de estudo, assim como a profundidade da camada de mistura.

Durante o verão de 2002, tanto a base da camada de mistura quanto à interface entre as massas de água AT e ACAS encontram-se mais próximas da superfície em comparação ao inverno do mesmo ano, fato esse observado nas estações localizadas próximas da plataforma continental (estações 7110, 7121, e 7142). Isso se deve provavelmente à penetração da ACAS pelo fundo e seu conseqüente afloramento na plataforma interna, já relatada por Castro (1996); Silveira et al. (2000) e Mahiques et al. (2004) para a margem continental Sudeste Brasileira. Por outro lado, nas estações mais profundas, há o domínio nas águas superficiais da AT.

É notória a diferença sazonal de densidade total de espécimes de foraminíferos planctônicos observada na margem continental Sudeste Brasileira. Em geral, o número de indivíduos observados foi muito pequeno em relação aos valores de freqüência de foraminíferos planctônicos por $\mathrm{m}^{3}$ constatados no Atlântico Sudoeste (von Mücke \& Oberhänsli,1999), no Mar do Japão e no Oceano Pacífico (Kuroyanagi \& Kawahata, 2004). As maiores densidades de foraminíferos planctônicos constatados na área de estudo ocorrem nas estações mais afastadas da costa, como seria de se esperar.

Durante o inverno, devido à ausência da ACAS nas camadas superficiais, a base da camada de mistura encontra-se mais profunda, ocorrendo nas águas superficiais menor variação nos valores de temperatura e salinidade, além das condições ambientais serem relativamente mais oligotróficas. Acredita-se que a união desses vários fatores expliquem a diminuição expressiva na freqüência e no tamanho das carapaças de foraminíferos planctônicos encontrados na coluna d'água.

Em razão da baixa densidade de espécimes de foraminíferos planctônicos observados no inverno, serão aqui discutidos apenas a 
distribuição vertical desses organismos, para o verão de 2002, assim como os parâmetros ambientais controladores dessa distribuição.

De maneira geral, a análise estatística realizada nesse trabalho permite verificar correlação inversa entre os valores máximos de freqüência de espécimes de foraminíferos planctônicos e as maiores concentrações de clorofila a (ver figura 16), a exemplo do que foi observado por von Mücke \& Oberhänsli (1999), no Atlântico Sudeste e Bé et al (1985) no Atlântico Norte. De acordo com esses autores, em áreas de alta produtividade, a abundância de foraminíferos planctônicos pode ser controlada pela ação de predadores (e.g. copepoda e pteropoda).

Tal fato, talvez, possa explicar a relação inversa entre abundância de espécimes de foraminíferos e o teor de clorofila a encontrada na área de estudo, uma vez que o aporte de nutrientes para a coluna de água em decorrência do afloramento da ACAS na plataforma ocasionaria possivelmente a ocorrência de bloom de diatomáceas no local (Gaeta et al., 1994). Esse fato levaria subsequentemente, ao aumento de consumidores primários e secundários (e.g. radiolaria, copepoda ou pteropoda), o que poderia acarretar diminuição na abundância de foraminíferos planctônicos (von Mücke \& Oberhänsli, 1999). Dessa maneira, parece haver defasagem entre o desenvolvimento de foraminíferos planctônicos e o processo de ressurgência, ocorrendo aumento da população de foraminíferos somente após o consumo dos produtores primários. Todavia, essa hipótese deve ser confirmada.

No verão, a espécie Globigerinoides ruber (pink) é dominante no intervalo de $0 \mathrm{~m}$ a $40 \mathrm{~m}$ de profundidade, enquanto as espécies Globigerinoides ruber (white), Globigerina bulloides, Neogloboquadrina dutertrei e Globigerinella siphonifera apresentam o ótimo de desenvolvimento entre $40 \mathrm{~m}$ e $60 \mathrm{~m}$ de profundidade, conforme Sorano et al. (2004 e 2006). Todavia, Bé et al. (1985) e Huang et al. (2002), respectivamente, em estudos na Bacia do Panamá e no Mar da China, afirmam que G. bulloides e G. ruber apresentam máximos de abundância nos primeiros $25 \mathrm{~m}$ de profundidade na coluna d'agua, ao passo que von Mücke \& Oberhänsli (1999) estendem esse limite até $50 \mathrm{~m}$ de profundidade para a margem continental Sudeste Africana (Tabela 17). 
Apesar do baixo número de indivíduos encontrados no presente trabalho, pode-se dizer que as espécies Globorotalia menardii, Orbulina universa e Globigerina falconensis apresentam certa preferência por profundidades entre $60 \mathrm{~m}$ e $80 \mathrm{~m}$, o que se contrapõe aos dados apresentados por Bé et al. (1985) e por von Mücke \& Oberhänsli (1999), respectivamente, para Bacia do Panamá e Atlântico Sudeste. Segundo esses autores, tratam-se de espécies de superfície, que apresentam o ótimo de desenvolvimento acima de $50 \mathrm{~m}$ de profundidade. (Tabela 17)

A análise estatística aplicada nesse estudo indica correlação de algumas espécies de foraminíferos planctônicos (e.g., G. ruber (pink), G. ruber (white), G. bulloides, G. calida) presentes no verão, com a profundidade na coluna d’água. Entretanto, essa correlação nos parece ser mais complexa, podendo estar relacionada à profundidade da camada eufótica, visto que algumas espécies espinhosas, como Globigerinoides e algumas espécies de Globigerina, apresentam relação simbiótica com organismos fotossintetizantes, sendo por esse motivo encontradas, preferencialmente, dentro da camada eufótica (Bé et al., 1977 e Gast, 2001).

Além disso, a distribuição vertical de foraminíferos planctônicos no verão parece estar relacionada também, com a profundidade da camada de mistura, variação da temperatura, salinidade, cadeia alimentar e teor de nutrientes na água (Bé \& Tolderland, 1971; Bé et al., 1977; Duplessy et al., 1981; Fairbanks et al, 1982; Bé et al., 1985; Boltovskoy et al. 1996; Niebler et al., 1998; von Mücke \& Oberhänsli, 1999; Huang et al., 2002 e Kuroyanagi \& Kawahata, 2004). Dentro desse contexto, pôde-se notar que as espécies G. bulloides, Globigerinoides ruber (pink) e Globigenoides ruber (white) na margem continental Sudeste Brasileira têm suas condições ótimas de desenvolvimento acima da camada de mistura.

Por outro lado, as condições ambientais para o desenvolvimento da espécie Globigerinella siphonifera, encontram-se abaixo dessa camada, a semelhança das espécies Orbulina universa, Neogloboquadrina dutertrei e Globigerina falconensis. A correlação positiva entre a freqüência da espécie $G$. ruber (pink) e temperatura e a correlação negativa entre a freqüência da 
espécie G. falconensis e a temperatura parece corroborar o padrão de distribuição vertical dessas espécies na área de estudo.

Não foi possível verificar para as espécies Globigerinella calida, Globigerinoides sacculifer e Globorotalia menardii, constatadas no verão, nenhum padrão de ocorrência em relação à profundidade da camada de mistura na área de estudo.

\begin{tabular}{|c|c|c|c|c|c|}
\hline Espécie & $\begin{array}{l}\text { Presente } \\
\text { trabalho }\end{array}$ & $\begin{array}{c}\text { Bé \& } \\
\text { Tolderland } \\
(1971)\end{array}$ & $\begin{array}{l}\text { Bé et al. } \\
\text { (1977) }\end{array}$ & $\begin{array}{l}\text { Bé et al. } \\
\text { (1985) }\end{array}$ & $\begin{array}{c}\text { von Mücke \& } \\
\text { Oberhänsli (1999) }\end{array}$ \\
\hline G. bulloides & $40 m-60 m$ & $0 \mathrm{~m}-300 \mathrm{~m}$ & ------- & $0 \mathrm{~m}-25 \mathrm{~m}$ & $<50 \mathrm{~m}$ \\
\hline G. calida & ------- & ------- & ------- & $50 \mathrm{~m}-200 \mathrm{~m}$ & ------- \\
\hline G. falconensis & $60 m-80 m$ & ------- & ------- & ------- & $<50 \mathrm{~m}$ \\
\hline G. hirsuta & ------- & $0 m-300 m$ & $>250 \mathrm{~m}$ & ------- & ------- \\
\hline G. menardii & $60 m-80 m$ & $<50 \mathrm{~m}$ & ------- & $0 \mathrm{~m}-50 \mathrm{~m}$ & $50 m-100 m$ \\
\hline G. pachyderma & ------- & $10 m-300$ & $\begin{array}{l}------ \\
\end{array}$ & ------- & ------- \\
\hline G. ruber (pink) & $0 \mathrm{~m}-40 \mathrm{~m}$ & \multirow{2}{*}{$<50 \mathrm{~m}$} & ------- & \multirow{2}{*}{$0 m-25 m$} & \multirow{2}{*}{$<50 \mathrm{~m}$} \\
\hline G. ruber (white) & $40 m-60 m$ & & ------- & & \\
\hline G. sacculifer & ------- & $0 \mathrm{~m}-10 \mathrm{~m}$ & ------- & $0 m-50 m$ & $<50 \mathrm{~m}$ \\
\hline G. scitula & ------- & $10 m-300 m$ & $>250 \mathrm{~m}$ & ------- & $100 m-300 m$ \\
\hline G. siphonifera & $40 m-60 m$ & ------- & ------- & ------- & ------- \\
\hline G. truncatulinoides & ------- & $>300 \mathrm{~m}$ & ------- & ------- & ------- \\
\hline G. tumida & ------- & $10 m-300 m$ & ------- & ------- & ------- \\
\hline N. dutertrei & $40 m-60 m$ & $50 m-100 m$ & ------- & $25 m-50 m$ & $25 m-100 m$ \\
\hline O. universa & $60 m-80 m$ & $0 \mathrm{~m}-300 \mathrm{~m}$ & ------- & $0 m-50 m$ & ------- \\
\hline P. obliquiloculata & ------- & ------- & |------ & ------- & ------- \\
\hline
\end{tabular}

Tabela17- Profundidade ótima de desenvolvimento para espécies de foraminíferos planctônicos segundo diferentes autores.

-------- Representa informação não disponível.

Considerando ainda os fatores controladores na distribuição vertical dos foraminíferos planctônicos, constata-se que a espécie G. bulloides tem sido reportada na literatura (e.g. Pflaumann, 1985 e Oberhänsli et al., 1992) como uma espécie oportunista, que se desenvolve após o processo de ressurgência, preferindo temperaturas entre $15^{\circ} \mathrm{C}$ e $20{ }^{\circ} \mathrm{C}$. Entretanto, no presente trabalho essa espécie apresentou máximo de abundância entre $22{ }^{\circ} \mathrm{C}$ e $26{ }^{\circ} \mathrm{C}$ de temperatura.

G. ruber (pink) e G. ruber (white) são consideradas como espécies típicas das províncias subtropicais e tropicais (Bé et al, 1977 e Boltovskoy et al. 1996) ou seja, de águas quentes e salinas apresentando máximos de 
abundância em águas com temperatura em torno de $23{ }^{\circ} \mathrm{C}$. Tal fato sustenta os dados encontrados na área de estudo do presente trabalho, que indicam máximos de ocorrência para essas espécies entre $22,5{ }^{\circ} \mathrm{C}$ e $26,5{ }^{\circ} \mathrm{C}$, assim como correlação positiva com aumento de temperatura, à semelhança da espécie Globorotalia menardii (Bé, et al, 1977). Para as demais espécies identificadas, não foi possível relacionar sua distribuição na área de estudo ao parâmetro temperatura.

Segundo Bé et al. (1985), o principal fator controlador da distribuição de G. sacculifer e G. ruber é a salinidade, pois G. sacculifer apresenta ótimo de desenvolvimento em salinidades inferiores a 36, enquanto $G$. ruber apresenta máximos de abundância acima desse valor. No presente trabalho, tal fato não foi observado, pois ambas apresentam máximos de freqüência dentro do mesmo intervalo de salinidade (de 35,5 a 37). Os dados aqui obtidos não permitiram verificar correlação entre a salinidade $\mathrm{e}$ as espécies de foraminíferos planctônicos identificadas na margem continental Sudeste Brasileira.

Reconhece-se que a profundidade da nutriclina deve também influenciar na distribuição vertical dos foraminíferos planctônicos, visto que o teor de nutrientes na coluna d'água é fator limitante no desenvolvimento desses organismos (Bé \& Hutson, 1977; Niebler et al., 1998). Todavia, a inexistência de dados de não nos possibilita inferir sobre a influência da profundidade da nutriclina na distribuição dos foraminíferos planctônicos na margem Sudeste Brasileira.

A análise da tanatocenose das carapaças de foraminíferos planctônicos na área de estudo permitiu verificar que 60\% da biocenose, desses organismos, estão representados na tanatocenose. Há também correspondência entre a abundância das espécies no plâncton e no sedimento. Assim, espécies mais abundantes no plâncton (Globigerinoides ruber (white), Globigerinoides ruber (pink) e Globigerina bulloides) são as que ocorrem em maior freqüência no sedimento. Os dados apresentados por Passos (2006) corroboram essa afirmação.

O fato das espécies Globorotalia scitula, Globorotalia tumida, Globorotalia hirsuta, Globorotalia truncatulinoides, Neogloboquadrina 
pachyderma e Pulleniatina obliquiloculata não terem sido encontradas nas amostras de plâncton analisadas, e serem relativamente abundantes no sedimento, poderia ser explicado em parte por: (1) método de coleta do plâncton, cujas amostras representariam apenas um momento de coleta. (2) a profundidade máxima de coleta atingida pela rede de plâncton na coluna d'água (100 m), que segundo Bé (1977), e Gast (2001) não seria a profundidade ótima para a sobrevivência das espécies não observadas. Bé e Tolderlend (1971), Boltovskoy (1971) e Bé et al (1977) afirmam que a profundidade ótima de desenvolvimento para estas espécies estaria entre 250 m e 500 m de profundidade. (3) preservação seletiva, pois as espécies pertencentes ao gênero Globorotalia e a espécies Puleniatina obliquiloculata são consideradas espécies mais resistentes à dissolução (Boltovskoy, 1971).

Apesar de encontrar correspondência entre a fauna vivente de foraminíferos planctônicos e sua tanatocenose Bé et al. (1985) ressalta a existência de dissolução seletiva de $G$. ruber e preservação seletiva de $N$. dutertrei. No presente trabalho é observada certa diferença entre a freqüência de G. ruber (pink) encontrada na coluna d'água e no sedimento, entretanto o mesmo não acontece com $N$. dutertrei.

A constatação de correspondência entre biocenose e tanatocenose permite-nos afirmar que, apesar do número pequeno de amostras analisadas, as associações de foraminíferos planctônicos presentes nos sedimentos da margem continental Sudeste Brasileira podem ser utilizadas em análises ambientais e paleoceanográficas. Tal fato também foi observado nos trabalhos de von Mücke \& Oberhänsli (1999) para o Atlântico Sudeste e Boltovskoy et al. (1996 e 2000) para o Atlântico Sudoeste.

A análise tafonômica das carapaças de foraminíferos planctônicos permitiu verificar que a corrosão, tanto nas frações fina como grossa, é o processo tafonômico mais freqüentemente encontrado na área de estudo. É possível constatar também, que esse processo de dissolução de carapaças não foi capaz de gerar um tendenciamento na tanatocenose.

As carapaças corroídas exibem, em geral, alteração de textura/brilho e cor, evidenciando que tais processos poderiam ser concomitantes. 
A grande maioria das carapaças corroídas (de 80\% a 97\%) ocorre entre as isóbatas de $400 \mathrm{~m}$ e 500 m, que estão sob domínio das massas de água ACAS e AIA. Exceção a esse padrão, ocorre na profundidade de $964 \mathrm{~m}$, ainda sob o domínio da AIA, onde as freqüências de ocorrência de carapaças com corrosão não são superiores a 50\%.

Um dos fatores que poderia ocasionar a dissolução das carapaças calcárias seria a ocorrência de condições de pH mais ácidos nos sedimentos de fundo (Martin, 1999 e Cardoso, 2006). Essas condições poderiam ser decorrentes de maior conteúdo de matéria orgânica no sedimento. A presença conspícua de espécies de foraminíferos bentônicos (e.g., Uvigerina peregrina), considerada como indicadora de ambientes de maior produtividade (Loubere \& Fariduddin, 1999), na região do talude superior da área de estudo (Taniguchi, 2006), parece refletir maior aporte de nutrientes para essa área da margem continental.

Aparentemente, a baixa freqüência de testas com corrosão na isóbata de $900 \mathrm{~m}$ poderia estar relacionada a presença de correntes de fundo mais intensas nessa profundidade (velocidades de até $0,30 \mathrm{~m} . \mathrm{s}^{-1}$ ), conforme observado por Silveira et al. (2004).

A pequena ocorrência de carapaças fragmentadas na área de estudo não nos permite utilizar essa assinatura tafonômica na inferência sobre as condições ambientais da região. Segundo Brett \& Baird (1986), acumulações esqueletais geradas em ambientes de alta energia, seriam caracterizadas por altos índices de fragmentação.

A análise tafonômica permite também observar diferenciações na ocorrência das assinaturas tafonômicas entre as duas frações $(0,125 \mathrm{~mm}$ e 0,250 mm). Em geral, a fração fina apresenta maior freqüência de testas com alteração de core de textura, e corrosão. Tal fato, talvez, seja explicado em parte pelo tempo de decantação das carapaças de foraminíferos planctônicos através da coluna d’água, uma vez que testas vazias de foraminíferos planctônicos com diâmetro inferior a 0,125 mm decantam com velocidade de $0,3 \mathrm{~cm} \mathrm{~s}^{-1}$. Por outro lado, testas maiores que 0,250 $\mathrm{mm}$ decantam com velocidade de $2,3 \mathrm{~cm} \mathrm{~s}^{-1}$ (Berger \& Piper, 1972). Assim sendo, as testas da fração fina permaneceriam por mais tempo na coluna d'água antes de se 
depositarem (Bé et al, 1977 e Martin, 1999), estando assim menos sujeitas às condições dos processos bioestratinômicos presentes no substrato.

Mesmo tendo-se analisado um pequeno número amostral, foi possível nesse trabalho reconhecer padrões de ocorrência de assinaturas tafonômicas em foraminíferos planctônicos e sua aplicação no entendimento de condições ambientais da margem Sudeste Brasileira. Todavia, para comprovação da aplicação dessa ferramenta, faz-se necessário estudos futuros que utilizem maior número de amostras. 


\section{Capítulo V}

\section{5 - Conclusões}

De acordo com os resultados obtidos é possível concluir que:

a) $\mathrm{Na}$ área de estudo, durante o verão de 2002, tanto a base da camada de mistura quanto à interface entre as massas de água AT e ACAS encontram-se mais próximas da superfície, em comparação ao inverno do mesmo ano, em razão da penetração da ACAS pelo fundo e seu conseqüente afloramento na plataforma interna;

b) Há grande diferença sazonal na abundância e no tamanho de espécimes de foraminíferos planctônicos na margem continental Sudeste Brasileira;

c) A ocorrência de uma camada de mistura mais profunda, menor variação nos valores de temperatura e salinidade e águas relativamente mais oligotróficas, talvez expliquem a diminuição expressiva na freqüência e no tamanho dos indivíduos de foraminíferos planctônicos, durante o inverno na área de estudo;

d) Os valores máximos de freqüência de espécimes de foraminíferos planctônicos apresentam correlação inversa com as concentrações de clorofila a, a exemplo do que foi observado em outras regiões do Atlântico;

e) A distribuição vertical de foraminíferos planctônicos no verão na margem continental Brasileira parece estar relacionada à profundidade da camada de mistura, variação da temperatura, e cadeia alimentar.

f) A espécie Globigerinoides ruber (pink) é dominante no intervalo de $0 \mathrm{~m}$ a $40 \mathrm{~m}$ de profundidade, enquanto Globigerinoides ruber (white), Globigerina bulloides, Neogloboquadrina dutertrei e Globigerinella siphonifera apresentam o ótimo de desenvolvimento entre $40 \mathrm{~m}$ e $60 \mathrm{~m}$ de profundidade e Globorotalia menardii, Orbulina universa e Globigerina falconensis apresentam certa preferência por profundidades entre $60 \mathrm{~m}$ e $80 \mathrm{~m}$. 
g) Fica evidente que os padrões de distribuições verticais de foraminíferos planctônicos são reflexos de condições hidrodinâmicas, sendo assim específicos de determinadas regiões;

h) G. bulloides, considerada como espécie indicadora de condições ambientais geradas pelo processo de ressurgência, em outras regiões do Atlântico, não se revelou na margem continental Sudeste Brasileira, como espécie típica de águas frias;

i) Fica confirmado que as espécies G. ruber (pink), G. ruber (white) e Globorotalia menardii são indicadoras de águas quentes ;

j) Aparentemente, a distribuição das espécies de foraminíferos planctônicos identificadas na margem continental Sudeste Brasileira não é controlada pela salinidade das águas;

k) O registro sedimentar das espécies de foraminíferos planctônicos encontrado na área de estudo reflete a biocenose, podendo assim ser utilizado em análises ambientais e paleoceanográficas;

I) Apesar da corrosão ser a assinatura tafonômica com maior ocorrência na área de estudo, esse processo aparentemente não foi capaz de modificar totalmente a biocenose, não ocorrendo, portanto, um tendenciamento da tanatocenose;

m) As carapaças corroídas exibem, em geral, alteração de textura/brilho e cor, evidenciando que tais processos poderiam ser concomitantes;

n) A análise tafonômica mostrou que as testas de foraminíferos planctônicos da fração $0,250 \mathrm{~mm}$ encontram-se melhor preservadas do que as da fração $0,125 \mathrm{~mm}$;

o) As assinaturas tafonômicas observadas refletem as condições hidrodinâmicas presentes na área de estudo. 


\section{Bibliografia}

Alves, E.C. \& Ponzi, V.R.A., 1984. Características morfológico sedimentares da plataforma continental e talude superior da Margem Continental Sudeste do Brasil. XXXIII. Congresso Brasileiro de Geologia Rio de Janeiro.1629-1642.

Bé, A. W. H. \& Hutson, W. H., 1977. Ecology of planktonic foraminifera and biogeografic patterns of life and fossil assemblages in the Indian Ocean. Micropaleontology. 23(4):369-414, pls. 1-3, october.

Bé, A. W. H. \& Tolderlund, D. S., 1971, Distribution and ecology of lining planktonic foraminifera in surface waters of the Atlantic Indian Oceans. In: Funnel, B. M., Riedel, W. R. (Eds). Micropaleontology of Oceans. Cambridge Univ. Press. London. Pp 105-149.

Bé, A.W.H., Bishop, J.K.B., Sverdlov, M.S. \& Gardner, W.D., 1985. Standing stock, vertical distribution and flux of planktonic foraminifera in the Panama Basin. Marine Micropaleontology. 19, 307-333.

Bé, A.W.H.; Harrison, S.M. \& Lott, L., 1973. Orbulina universa in the Indian Ocean. Micropaleontology, 19(2):150-192.

Berger, W.H. \& Piper, 1972. Sedimentation of planktonic foraminifera. Marine Geology 11, 325- 358.

Boltovskoy, E., Scott, D. B. \& Medioli, F. S., 1991, Morphological variations of benthic foraminiferal tests in response to changes in ecological parameters: a review. Journal of Paleontology. 65(2): 175-185.

Boltovskoy, E.; Boltovskoy, D.;Correa, N. \& Brandini, F., 1996. Planktonic foraminifera from the Southwestern Atlantic $\left(30^{\circ}-60^{\circ} \mathrm{S}\right)$ species-specific patterns in the upper $50 \mathrm{~m}$. Marine Micropaleontology, 28:53-72. 
Brasier, M. D. 1980. Microfossils. George Allen \& Unwin, London.

Brett, C.E.B. \& Baird,G.C. 1986. Comparative thaphonomy: a key to paleoenvaironmental interpretation based on fossil preservation. Palaios, 1:207-227.

Campos, E.J.D.; Velhote, D. \& Silveira, I. C. A., 2000. Shelf break upwelling driven by Brazil Current cyclonic meanders. Geophys. Res. Lett. 77, 253-259.

Cardoso, P.K., 2006. Análise Tafonômica de testas de foraminíferos em sedimentos de sub superfície da Baía de Guanabara (RJ-Brasil). Instituto Oceanográfico (Tese de Doutorado). 133p.

Carroll, M.; Kowalewski, M.; Simoes, M. G. \& Rodland, D., 2003 Quantitative estimates of time-averaging in brachiopod shell accumulations. Paleobiology, 29, (3):382-403.

Castro, B. M. de, 1996: Correntes e massas de água da Plataforma Continental Norte De São Paulo. Tese de Livre-Docência. Instituto Oceanográfico, Universidade de São Paulo, São Paulo, São Paulo, 248 p.

Castro, B. M.; Miranda, L. B. \& Miyao, S, Y., 1987. Condições hidrográficas na Plataforma Continental ao Largo de Ubatuba: variações sazonais e em média escala. Boletim do Instituto Oceanográfico, 35(2):135-151.

Castro, B.M. \& Miranda, L.B., 1998. Physical Oceanography of the Western Atlantic Continental Shelf located between $4^{\circ} \mathrm{N}$ and $34^{\circ} \mathrm{S}$. The sea, 11. (ed. by Robinson, A.R. and Brink, K.H.). John Wiley and Sons, New York. 
Duleba, W., 1994. interpretações paleoambientais obtidas a partir das variações na coloração das carapaças de foraminíferos, na enseada do Flamengo, SP. Boletim do Instituto Oceanográfico, 42(1/2):63-72.

Duplessy, J.B. ; Bé, A.W.H. \& Blanc, P.L., 1981. Oxigen and carbon isotopc composition and biogeographic distribution of planktonic foraminifera in the Indian Ocean. Paleogeog Paleoclimatol Paleoecol, 33(1-3):9-46.

Fairbanks, R.G., Sverdlove R.F., Wiebe, P.H., \& Eacute A.W.H. 1982. Vertical distribution and isotopic fractionation of living planktonic foraminifera from the Panama Basin. Nature, 298:841-844.

Fairbranks, R.G. \& Wiebe, P.H., 1980. Foraminifera and chlorophyll maximum: Vertical distribution, seasonal succession, and paleoceanographic significance. Science, September 209: 1524-1526.

Folk, R.L. \& Ward, W.C., 1957. Brazos river bar: a study in the significance of grazin size parameters. J. Sedim. Petrology, 27(1): 3-26.

Gaeta, S.A.; Brino, O.L. \& Ribeiro, S.M.,1994. Distributions of $\mathrm{No}_{3}^{-}$, chlorophyll a and primary productivity in the South-Western region of the South Atlantic during summer. South-western Atlantic physical oceanography Workshop Report. Instituto Oceanográfico da Universidade de São Paulo, São Paulo, pp. 57-60.

Gast, R.J.,\& Caron, D.A., 2001. Phito symbiotic associations in planktonic foraminifera and radiolaria. Hidrobiologia, 461:1-7.

Godoi, S.S, 2005. Dinâmica quase-geostrófica do sistema Corrente do Brasil no Embaiamento de São Paulo (23,5 - 27 graus Sul). Instituto Oceanográfico da Universidade de São Paulo.Tese de Doutorado.

Grell, KG, 1973 Protozoology. Springer, New York, Hei-delberg, and Berlin 
Hemleben, C.; Spindler, M. \& Anderson, O.R., 1989, Modern planctonic foraminifera. springer, New York, Berlin, Heidelberg.

Holz, M. \& Simões, M. G., 2002. Elementos fundamentais de tafonomia. ed. Porto Alegre: Editora da Universidade - EDUFRGS, v. 1. 231 p.

Huang, B.;Jian, J.; Cheng, X. \& Wang, P., 2002. Foraminiferal responses to upwelling variations in the South China Sea over the last 220000 years. Marine Micropaleontology, 47, 1-15.

Ivanova, M.E., Conan, SM.H., Peeters, F.J. C. \& Troelstra, S.R. 1999. Living Neogloboquadrina pachiderma sin and its distribution in the sediments from Oman and Somalia upwelling areas. Marine Micropaleontology, 36:91-107.

Jones, R.W., 1994. The Challenger Foraminifera. Oxford University Press, Oxford, New York, Tokyo, $1049 \mathrm{p}$

Kennett, J.P. \& Srinivasan, 1983. Neogene planktonic Foraminifera. Hutchinson Ross Publishing Company, Stroudsburg, Pennsylvania, $265 p$.

Kidwell, S.M.; Rothfus, T.A. \& Best, M.M.R. 2001. Sensitivity of taphonomic signatures to sample size, sieve size, damage scoring system, and target Taxa. Palaios, 16:26-52.

Kowalewski, M. 1996. Time-averaging, overcompleteness, and the geological record. Journal of Geology 104:317-326.

Kowsmann, R.O. \& Costa, M.O.A., 1979. Sedimentação quaternária da Margem Continental Brasileira e as áreas oceânicas adjacentes (relatorio final). In. Projeto REMAC. Petrobras, Rio de Janeiro, pp. 155 . 
Kuroyanagi, A. \& Kawahata, H., 2004. Vertical distribution of living planktonic Foraminifera In The Seas Around Japan. Marine Micropaleontology, 53:173-196.

Loubere, P. \& Farduddin, M.,1999. Quantitative estimation of global patterns of surface variation on time scales from centuries to millenia. Global Biogeochemical Cycles, 13:115-133.

Mahiques, M.M.; Bícego, M.C.; Silveira, I.C.A; Sousa, S.H.M; Lourenço, R.A.; Fukumoto, M.M., 2005. Modern sedimentation in the Cabo Frio upwelling system, Southeastern Brazilian Shelf. Anais da Academia Brasileira de Ciências, Rio de Janeiro, 77(3):535-548.

Mahiques, M.M.; Tessler, M.G. \& Furtado, V.V., 1998. Characterization of energy gradient in enclosed bays of Ubatuba region, South-Eastern Brazil. Estuarine, Coastal and Shelf Science, 47:431-446.

Mahiques. M.M.; Tessler, M.G.; Ciotti, A. M.; Silveira; I.C.A.; Sousa, S.H.M.; Figueira, R.C.L.; Tassinari, C.C.G.; Furtado, V.V. \& Passos, R.F., 2004. Hidrodynamically driven patterns of recent sedimentation in the Shelf and upper Slope off Southeast Brazil. Continental Shelf Research, 24:1685-1697.

Mahiques; M.M.; Silveira; I.C.A.; Sousa; S.H.M. \& Rodriques; M., 2002. Post-LGM Sedimentation on the outer shelf-upper slope of the Northernmost part of the São Paulo Bigth, Southeastern Brazil. Marine Geology, 181:387-400.

Martin, R.E., 1999. Taphonomy: A Process Approach, Cambridge. University, Cambridge. 508p.

Martin, R.J.; Wehmiller, J.F.; Harris, M.S.; \& Liddell, W.D., 1996. Comparative taphonomy of bivalves and foraminifera from Holocene 
tidal flat sediments, Bahia La Choya, Sonora, Mexico (Northern Gulf Of California): Taphonomic Grades And Temporal Resolution. Paleobiology, 22:80-90.

Mücke, Kemle-von \& Oberhänsli, H., 1999. The Distribution Of Living Planktonic Foraminifera In Relation To Southeast Atlantic Oceanography. Em: Fischer, G., Wefer, G. (Eds.), Use of Proxies in Paleoceanography: Examples from the South Atlantic. Springer-Verlag, Berlin, pp. 91-115.

Nibler. H.-S. \& Gersond. R.,1998. A Planktic Foraminiferal Transfer Function For The Southern South Atlantic Ocean. Marine Micropaleontology 34:213-234.

Oberhänsli, H.; Bénier, C.; Meinecke, G.; Schmidt, H.; Schneider, R. \& Wefer, G., 1992. Planktonic foraminifers as tracers of ocean currents in the Eastern South Atlantic. Paleoceanography, 7:607-632.

Passos, R.F., 2006. Distribuição das associações de foraminíferos planctônicos na Margem Continental Brasileira, entre o Banco de Abrolhos (BA) e o Chuí (RS) e suas relações com as massas d'água, principalmente aquelas transportadas pela Corrente do Brasil (CB). Instituto Oceanográfico (Tese de Doutorado). 97p.

Postuma, J.A., 1971. Manual of planktonic foraminifera. Elsevier Publishing Company, Amsterdam, London, New York, 420 p.

Rodrigues, S.C., 2006. tafonomia de moluscos bivalves e braquiópodes das Enseadas de Ubatuba e Picinguaba, norte do Estado de São Paulo: Implicações do uso de assinaturas tafonômicas no reconhecimento de gradientes ambientais. Instituto de Geociências, Universidade de São Paulo, (Tese de Doutorado), 168p. 
Sen Gupta B.K.. 1999. Modern Foraminifera. Kluwer Academic Publishers. London, 371p.

Signorini, S.R.; Miranda, L.B.; Evans, D.L.; Stevenson, M.R. \& Inostrosa, H.M., 1989. Corrente do Brasil: Estrutura térmica entre $19^{\circ}$ e e $25^{\circ} \mathrm{S}$ e circulação geostrófica. Bolm. Inst. Oceanogr., Universidade de São Paulo, São Paulo, 37(1): 33-49.

Silveira, I.C.A.; Schmidt, A.C.K.; Campos, E.J.D.; Godoi, S.S. \& Ikeda, Y., 2000: A Corrente do Brasil ao Largo da Costa Leste Brasileira. Rev. Bras. Oceanogr., 48(2), 171-183.

Simões, M.G. \& Ghilardi, R.P., 2000. Protocolo tafonômicos / paleoauto ecológico como ferramenta nas analises paleossinecológicas de invertebrados: Exemplos de aplicação em concentrações fossilíferas do Paleozóico da Bacia do Paraná, Brasil. Pesquisas em Geociências, 27(2):3-13.

SORANO, M.R.G.S; Sousa, S.H.M. \& Lopes, R.M., 2004. Levantamento preliminar das espécies de foraminíferos planctônicos presentes na margem continental, entre a Ilha de São Sebastião, SP, e Cabo Frio, RJ, Brasil.. In: III Simpósio Brasileiro de Oceanografia, 2004, São Paulo. Resumos,1:100-101.

Soranna, M.R.G.S.; Sousa, S.H.M.E. \& Gaeta, S.A, 2006. Vertical distribution of planktonic foraminifera in the southwestern Atlantic. In: International Symposium on Foraminifera - FORAMS 2006, Natal. Anuário do Instituto de Goeicências. Rio de Janeiro : Universidade Federal do Rio de Janeiro,29:569-570.

Steineck, P.L. \& Casey, R.E. 1990. ecology and paleoecology of foraminifera and radiolaria. In Capriulo, G. M. (ed.), Ecology of marine Protozoa, Oxford University Press, New York, 46-138. 
Stramma, L. \& England, M., 1999. On the water masses and mean circulation of the South Atlantic Ocean. J. Geophys. Res.,104(C9), 20863-20883.

Tanaka, S. 1973. Stock assessment be means of ichthyoplankton surveys. FAO Fish. Tech. Pap., 122:33-51.

Taniguchi, K., 2006. Fforaminíferos bentônicos da Margem Continental Sudeste Brasileira e suas relações com massas de água. Instituto Oceanográfico (Trabalho de Conclusão de Curso).

Tomczak, M., \& Godfrey, J., 1994. regional oceanography: an introduction. 422 pp, Elsevier, New York.

Welschmeyer, N., 1994. Fluorometric analysis of chlorophyll a in the presence of chlorophyll b and pheopigments. limnol Oceanogr.;39(8):1985-192

Zembruscki, S.G. 1979. Geomorfologia da Margem Continental Sul Brasileira e das Bacias Oceânicas adjacentes. In: Chaves, H. A. F. ed. Geomorfologia da margem continental sul brasileira e das áreas oceânicas adjacentes. Rio de Janeiro, PETROBRAS. CENPES. DINTEP (Série Projeto REMAC NUM. 7). 
ANEXO 1 


\section{Lista das espécies encontradas}

REINO PROTISTA

FILO PROTOZOA

SUBFILO SARCODINA

SUPERCLASSE RHIZOPODA

ORDEM GLOBIGERINIDA

Família Gobigerinidae Carpenter, Parker e Jones, 1862

Gênero Globigerina d'Orbigny, 1826

Globigerina bulloides d'Orbigny, 1826

Globigerina falconensis Blow, 1959

Gênero Globigerinella Cushman, 1927

Globigerinella calida Parker, 1962

Globigerinella siphonifera d'Orbigny, 1839

Gênero Globigerinoides Cushman, 1927

Globigerinoides ruber (pink) d’Orbigny, 1839

Globigerinoides ruber (white) d'Orbigny, 1839

Globigerinoides sacculifer Brady, 1877

Gênero Orbulina d'Orbigny,1839

Orbulina universa d'Orbigny, 1839

Família Globorotaliidea Cushmam, 1927

Gênero Globorotalia Cushman, 1927

Globorotalia menardii d'Orbigny, 1865

Globorotalia hirsuta d'Orbigny

Globorotalia truncatulinoides d'Orbigny

Globorotalia scitula Ogniben, 1958 
Gênero Neogloboquadrina Bandy, Frerichs, e Vincent, 1967

Neogloboquadrina dutertrei d'Orbigny, 1839

Neogloboquadrina pachyderma Ehrenberg, 1894

Família Pulleniatinidae Cushman, 1927

Genero Pulleniatina Cushman, 1927

Pulleniatina obliquiloculata Parker e Jones, 1865 
ANEXO 2 


\section{Protocolo Tafonômico - Estação de coleta 7365 Fração 0,125 mm}

\begin{tabular}{|c|c|c|c|c|c|c|c|c|c|c|c|c|}
\hline \multirow{4}{*}{$\begin{array}{c}\text { Estação de } \\
\text { Coleta }\end{array}$} & \multirow{4}{*}{$\begin{array}{c}\text { Fração } \\
(\mathrm{mm})\end{array}$} & \multirow{4}{*}{ Eppendorf } & \multirow{2}{*}{\multicolumn{4}{|c|}{$\begin{array}{c}\text { Feições Físicas } \\
\text { Fragmentação }\end{array}$}} & \multicolumn{6}{|c|}{ Feições Químicas } \\
\hline & & & & & & & \multirow{3}{*}{ Mantida } & Cor & \multicolumn{2}{|c|}{ Brilho } & \multicolumn{2}{|c|}{ Corrosão } \\
\hline & & & \multirow{2}{*}{ Ausente } & \multicolumn{3}{|c|}{ Presente } & & Alterada & Mantido & Alterado & Aucente & Precente \\
\hline & & & & $<10 \%$ & entre $10 \%$ e $50 \%$ & $>50 \%$ & & The & pontros & 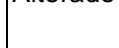 & 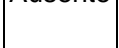 & T \\
\hline 7365 & 0,125 & 1 & 0 & & & & 0 & & 0 & & 0 & \\
\hline 7365 & 0,125 & 2 & 0 & & & & 0 & & 0 & & 0 & \\
\hline 7365 & 0,125 & 3 & 0 & & & & 0 & & 0 & & 0 & \\
\hline 7365 & 0,125 & 4 & & & 2 & & 0 & & 0 & & & 1 \\
\hline 7365 & 0,125 & 5 & & 1 & & & 0 & & 0 & & 0 & \\
\hline 7365 & 0,125 & 6 & 0 & & & & 0 & & & 1 & & 1 \\
\hline 7365 & 0,125 & 7 & 0 & & & & 0 & & 0 & & 0 & \\
\hline 7365 & 0,125 & 8 & 0 & & & & 0 & & 0 & & 0 & \\
\hline 7365 & 0,125 & 9 & 0 & & & & 0 & & 0 & & 0 & \\
\hline 7365 & 0,125 & 10 & 0 & & & & 0 & & 0 & & 0 & \\
\hline 7365 & 0,125 & 11 & 0 & & & & 0 & & 0 & & 0 & \\
\hline 7365 & 0,125 & 12 & 0 & & & & & 1 & & 1 & & 1 \\
\hline 7365 & 0,125 & 13 & 0 & & & & 0 & & 0 & & 0 & \\
\hline 7365 & 0,125 & 14 & 0 & & & & 0 & & 0 & & 0 & \\
\hline 7365 & 0,125 & 15 & & 1 & & & 0 & & 0 & & 0 & \\
\hline 7365 & 0,125 & 16 & 0 & & & & 0 & & 0 & & 0 & \\
\hline 7365 & 0,125 & 17 & 0 & & & & & 1 & & 1 & & 1 \\
\hline 7365 & 0,125 & 18 & 0 & & & & 0 & & 0 & & 0 & \\
\hline 7365 & 0,125 & 19 & 0 & & & & 0 & & & 1 & & 1 \\
\hline 7365 & 0,125 & 20 & 0 & & & & 0 & & & 1 & & 1 \\
\hline 7365 & 0,125 & 21 & 0 & & & & 0 & & 0 & & 0 & \\
\hline 7365 & 0,125 & 22 & & & & 3 & 0 & & 0 & & 0 & \\
\hline 7365 & 0,125 & 23 & 0 & & & & 0 & & & 1 & 0 & \\
\hline 7365 & 0,125 & 24 & 0 & & & & & 1 & & 1 & & 1 \\
\hline 7365 & 0,125 & 25 & 0 & & & & 0 & & 0 & & 0 & \\
\hline 7365 & 0,125 & 26 & 0 & & & & 0 & & 0 & & 0 & \\
\hline 7365 & 0,125 & 27 & 0 & & & & 0 & & 0 & & 0 & \\
\hline 7365 & 0,125 & 28 & 0 & & & & 0 & & & 1 & & 1 \\
\hline 7365 & 0,125 & 29 & 0 & & & & 0 & & 0 & & 0 & \\
\hline 7365 & 0,125 & 30 & 0 & & & & 0 & & 0 & & 0 & \\
\hline 7365 & 0,125 & 31 & 0 & & & & & 1 & & 1 & & 1 \\
\hline 7365 & 0,125 & 32 & 0 & & & & 0 & & & 1 & & 1 \\
\hline 7365 & 0,125 & 33 & 0 & & & & 0 & & & 1 & 0 & \\
\hline 7365 & 0,125 & 34 & 0 & & & & & 1 & 0 & & 0 & \\
\hline 7365 & 0,125 & 35 & 0 & & & & 0 & & 0 & & 0 & \\
\hline
\end{tabular}




\begin{tabular}{|c|c|c|c|c|c|c|c|c|c|c|c|c|}
\hline \multirow{4}{*}{$\begin{array}{c}\text { Estação de } \\
\text { Coleta }\end{array}$} & \multirow{4}{*}{$\begin{array}{c}\text { Fração } \\
(\mathrm{mm})\end{array} \mid$} & \multirow{4}{*}{ Eppendorf } & \multirow{2}{*}{\multicolumn{4}{|c|}{$\begin{array}{l}\text { Feições Físicas } \\
\text { Fragmentação }\end{array}$}} & \multicolumn{6}{|c|}{ Feições Químicas } \\
\hline & & & & & & & \multicolumn{2}{|c|}{ Cor } & \multicolumn{2}{|c|}{ Brilho } & \multicolumn{2}{|c|}{ Corrosão } \\
\hline & & & \multirow{2}{*}{ Ausente } & \multicolumn{3}{|c|}{ Presente } & \multirow{2}{*}{ Mantida } & \multirow{2}{*}{ Alterada } & \multirow{2}{*}{ Mantido } & \multirow{2}{*}{ Alterado } & \multirow{2}{*}{ Ausente } & \multirow{2}{*}{ Presente } \\
\hline & & & & $<10 \%$ & entre $10 \%$ e $50 \%$ & $>50 \%$ & & & & & & \\
\hline 7365 & 0,125 & 36 & 0 & & & & 0 & & & 1 & & 1 \\
\hline 7365 & 0,125 & 41 & 0 & & & & 0 & & 0 & & 0 & \\
\hline 7365 & 0,125 & 42 & & 1 & & & 0 & & & 1 & 0 & \\
\hline 7365 & 0,125 & 43 & 0 & & & & 0 & & & 1 & 0 & \\
\hline 7365 & 0,125 & 44 & 0 & & & & 0 & & 0 & & 0 & \\
\hline 7365 & 0,125 & 45 & 0 & & & & 0 & & 0 & & 0 & \\
\hline 7365 & 0,125 & 46 & & & 2 & & 0 & & & 1 & & 1 \\
\hline 7365 & 0,125 & 47 & 0 & & & & 0 & & 0 & & 0 & \\
\hline 7365 & 0,125 & 48 & 0 & & & & 0 & & 0 & & 0 & \\
\hline 7365 & 0,125 & 49 & 0 & & & & 0 & & 0 & & 0 & \\
\hline 7365 & 0,125 & 50 & 0 & & & & 0 & & 0 & & 0 & \\
\hline 7365 & 0,125 & 51 & 0 & & & & 0 & & & 1 & 0 & \\
\hline 7365 & 0,125 & 52 & 0 & & & & 0 & & 0 & & 0 & \\
\hline 7365 & 0,125 & 53 & & & & 3 & & 1 & & 1 & & 1 \\
\hline 7365 & 0,125 & 54 & 0 & & & & 0 & & 0 & & 0 & \\
\hline 7365 & 0,125 & 55 & & 1 & & & 0 & & 0 & & 0 & \\
\hline 7365 & 0,125 & 56 & 0 & & & & 0 & & & 1 & 0 & \\
\hline 7365 & 0,125 & 57 & 0 & & & & & 1 & 0 & & 0 & \\
\hline 7365 & 0,125 & 58 & 0 & & & & 0 & & 0 & & 0 & \\
\hline 7365 & 0,125 & 59 & 0 & & & & & 1 & & 1 & & 1 \\
\hline 7365 & 0,125 & 60 & 0 & & & & 0 & & & 1 & 0 & \\
\hline 7365 & 0,125 & 61 & 0 & & & & 0 & & & 1 & & 1 \\
\hline 7365 & 0,125 & 62 & 0 & & & & & 1 & & 1 & 0 & \\
\hline 7365 & 0,125 & 63 & 0 & & & & 0 & & & 1 & 0 & \\
\hline 7365 & 0,125 & 64 & 0 & & & & 0 & & & 1 & 0 & \\
\hline 7365 & 0,125 & 65 & & 1 & & & 0 & & & 1 & 0 & \\
\hline 7365 & 0,125 & 66 & & & 2 & & 0 & & 0 & & 0 & \\
\hline 7365 & 0,125 & 67 & 0 & & & & & 1 & & 1 & & 1 \\
\hline 7365 & 0,125 & 68 & 0 & & & & 0 & & 0 & & 0 & \\
\hline 7365 & 0,125 & 69 & 0 & & & & 0 & & 0 & & 0 & \\
\hline 7365 & 0,125 & 70 & 0 & & & & 0 & & 0 & & & 1 \\
\hline 7365 & 0,125 & 71 & 0 & & & & 0 & & & 1 & 0 & \\
\hline 7365 & 0,125 & 72 & 0 & & & & 0 & & 0 & & & 1 \\
\hline 7365 & 0,125 & 73 & 0 & & & & 0 & & & 1 & 0 & \\
\hline 7365 & 0,125 & 74 & 0 & & & & 0 & & 0 & & 0 & \\
\hline 7365 & 0,125 & 75 & 0 & & & & 0 & & 0 & & 0 & \\
\hline
\end{tabular}




\begin{tabular}{|c|c|c|c|c|c|c|c|c|c|c|c|c|}
\hline \multirow{4}{*}{$\begin{array}{c}\text { Estação de } \\
\text { Coleta }\end{array}$} & \multirow{4}{*}{$\begin{array}{c}\text { Fração } \\
\text { (mm) }\end{array}$} & \multirow{4}{*}{ Eppendorf } & \multirow{2}{*}{\multicolumn{4}{|c|}{$\begin{array}{c}\text { Feições Físicas } \\
\text { Fragmentação }\end{array}$}} & \multicolumn{6}{|c|}{ Feições Químicas } \\
\hline & & & & & & & \multicolumn{2}{|c|}{ Cor } & \multicolumn{2}{|c|}{ Brilho } & \multicolumn{2}{|c|}{ Corrosão } \\
\hline & & & \multirow{2}{*}{ Ausente } & \multicolumn{3}{|c|}{ Presente } & \multirow{2}{*}{ Mantida } & \multirow{2}{*}{ Alterada } & \multirow{2}{*}{ Mantido } & \multirow{2}{*}{ Alterado } & \multirow{2}{*}{ Ausente } & \multirow{2}{*}{ Present } \\
\hline & & & & $<10 \%$ & entre $10 \%$ e $50 \%$ & $>50 \%$ & & & & & & \\
\hline 7365 & 0,125 & 76 & 0 & & & & 0 & & & 1 & 0 & \\
\hline 7365 & 0,125 & 81 & 0 & & & & 0 & & & 1 & 0 & \\
\hline 7365 & 0,125 & 82 & 0 & & & & 0 & & 0 & & 0 & \\
\hline 7365 & 0,125 & 83 & & 1 & & & 0 & & & 1 & 0 & \\
\hline 7365 & 0,125 & 84 & 0 & & & & 0 & & & 1 & & 1 \\
\hline 7365 & 0,125 & 85 & & 1 & & & & 1 & & 1 & & 1 \\
\hline 7365 & 0,125 & 86 & 0 & & & & & 1 & & 1 & & 1 \\
\hline 7365 & 0,125 & 87 & 0 & & & & 0 & & 0 & & 0 & \\
\hline 7365 & 0,125 & 88 & 0 & & & & & 1 & & 1 & 0 & \\
\hline 7365 & 0,125 & 89 & 0 & & & & 0 & & & 1 & 0 & \\
\hline 7365 & 0,125 & 90 & 0 & & & & 0 & & 0 & & 0 & \\
\hline 7365 & 0,125 & 91 & 0 & & & & 0 & & 0 & & 0 & \\
\hline 7365 & 0,125 & 92 & & & & 3 & 0 & & & 1 & 0 & \\
\hline 7365 & 0,125 & 93 & 0 & & & & 0 & & & 1 & & 1 \\
\hline 7365 & 0,125 & 94 & 0 & & & & 0 & & 0 & & 0 & \\
\hline 7365 & 0,125 & 95 & 0 & & & & 0 & & & 1 & 0 & \\
\hline 7365 & 0,125 & 96 & & 1 & & & 0 & & & 1 & 0 & \\
\hline 7365 & 0,125 & 97 & 0 & & & & & 1 & & 1 & & 1 \\
\hline 7365 & 0,125 & 98 & 0 & & & & & 1 & & 1 & 0 & \\
\hline 7365 & 0,125 & 99 & 0 & & & & & 1 & 0 & & 0 & \\
\hline 7365 & 0,125 & 100 & & & 2 & & & 1 & & 1 & & 1 \\
\hline 7365 & 0,125 & 101 & & 1 & & & 0 & & & 1 & 0 & \\
\hline 7365 & 0,125 & 102 & 0 & & & & 0 & & & 1 & 0 & \\
\hline 7365 & 0,125 & 103 & 0 & & & & 0 & & & 1 & 0 & \\
\hline 7365 & 0,125 & 104 & 0 & & & & 0 & & 0 & & 0 & \\
\hline 7365 & 0,125 & 105 & 0 & & & & 0 & & & 1 & 0 & \\
\hline 7365 & 0,125 & 106 & 0 & & & & 0 & & & 1 & 0 & \\
\hline 7365 & 0,125 & 107 & & & & 3 & 0 & & 0 & & 0 & \\
\hline 7365 & 0,125 & 108 & & & 2 & & 0 & & & 1 & & 1 \\
\hline 7365 & 0,125 & 109 & 0 & & & & 0 & & & 1 & 0 & \\
\hline 7365 & 0,125 & 110 & 0 & & & & 0 & & & 1 & 0 & \\
\hline 7365 & 0,125 & 111 & 0 & & & & 0 & & & 1 & & 1 \\
\hline 7365 & 0,125 & 112 & 0 & & & & 0 & & & 1 & & 1 \\
\hline 7365 & 0,125 & 113 & 0 & & & & 0 & & & 1 & & 1 \\
\hline 7365 & 0,125 & 114 & & 1 & & & 0 & & & 1 & & 1 \\
\hline 7365 & 0,125 & 115 & 0 & & & & & 1 & & 1 & & 1 \\
\hline
\end{tabular}




\begin{tabular}{|c|c|c|c|c|c|c|c|c|c|c|c|c|}
\hline \multirow{4}{*}{$\begin{array}{l}\text { Estação de } \\
\text { Coleta }\end{array}$} & \multirow{4}{*}{$\begin{array}{c}\text { Fração } \\
\text { (mm) }\end{array}$} & \multirow{4}{*}{ Eppendorf } & \multirow{2}{*}{\multicolumn{4}{|c|}{$\begin{array}{c}\text { Feições Físicas } \\
\text { Fragmentação }\end{array}$}} & \multicolumn{6}{|c|}{ Feições Químicas } \\
\hline & & & & & & & \multicolumn{2}{|c|}{ Cor } & \multicolumn{2}{|c|}{ Brilho } & \multicolumn{2}{|c|}{ Corrosão } \\
\hline & & & \multirow{2}{*}{ Ausente } & \multicolumn{3}{|c|}{ Presente } & \multirow{2}{*}{ Mantida } & \multirow{2}{*}{ Alterada } & \multirow{2}{*}{ Mantido } & \multirow{2}{*}{ Alterado } & \multirow{2}{*}{ Ausente } & \multirow{2}{*}{ Presente } \\
\hline & & & & $<10 \%$ & entre $10 \%$ e $50 \%$ & $>50 \%$ & & & & & & \\
\hline 7365 & 0,125 & 116 & 0 & & & & 0 & & & 1 & & 1 \\
\hline 7365 & 0,125 & 117 & 0 & & & & 0 & & & 1 & 0 & \\
\hline 7365 & 0,125 & 118 & & & 2 & & 0 & & & 1 & & 1 \\
\hline 7365 & 0,125 & 119 & & 1 & & & & 1 & & 1 & & 1 \\
\hline 7365 & 0,125 & 120 & & & & 3 & & 1 & & 1 & & 1 \\
\hline 7365 & 0,125 & 121 & & & & 3 & 0 & & & 1 & 0 & \\
\hline 7365 & 0,125 & 122 & 0 & & & & 0 & & & 1 & 0 & \\
\hline 7365 & 0,125 & 123 & & 1 & & & & 1 & & 1 & & 1 \\
\hline 7365 & 0,125 & 124 & & & & 3 & & 1 & & 1 & & 1 \\
\hline 7365 & 0,125 & 125 & 0 & & & & 0 & & & 1 & 0 & \\
\hline 7365 & 0,125 & 126 & 0 & & & & 0 & & & 1 & 0 & \\
\hline 7365 & 0,125 & 127 & 0 & & & & 0 & & & 1 & & 1 \\
\hline 7365 & 0,125 & 128 & 0 & & & & & 1 & & 1 & & 1 \\
\hline 7365 & 0,125 & 129 & & & & 3 & 0 & & & 1 & & 1 \\
\hline 7365 & 0,125 & 130 & 0 & & & & 0 & & & 1 & & 1 \\
\hline 7365 & 0,125 & 131 & & & & 3 & 0 & & & 1 & & 1 \\
\hline 7365 & 0,125 & 132 & & 1 & & & 0 & & 0 & & 0 & \\
\hline 7365 & 0,125 & 133 & 0 & & & & & 1 & 0 & & & 1 \\
\hline 7365 & 0,125 & 134 & 0 & & & & 0 & & 0 & & 0 & \\
\hline 7365 & 0,125 & 135 & & 1 & & & & 1 & & 1 & 0 & \\
\hline 7365 & 0,125 & 136 & 0 & & & & 0 & & & 1 & 0 & \\
\hline 7365 & 0,125 & 137 & 0 & & & & 0 & & & 1 & & 1 \\
\hline 7365 & 0,125 & 138 & 0 & & & & 0 & & & 1 & 0 & \\
\hline 7365 & 0,125 & 139 & 0 & & & & 0 & & & 1 & & 1 \\
\hline 7365 & 0,125 & 140 & 0 & & & & 0 & & & 1 & 0 & \\
\hline 7365 & 0,125 & 141 & & 1 & & & 0 & & 0 & & 0 & \\
\hline 7365 & 0,125 & 142 & 0 & & & & 0 & & & 1 & & 1 \\
\hline 7365 & 0,125 & 143 & & & 2 & & 0 & & & 1 & & 1 \\
\hline 7365 & 0,125 & 144 & 0 & & & & 0 & & 0 & & 0 & \\
\hline 7365 & 0,125 & 145 & 0 & & & & 0 & & & 1 & & 1 \\
\hline 7365 & 0,125 & 146 & & & 2 & & 0 & & & 1 & & 1 \\
\hline 7365 & 0,125 & 147 & 0 & & & & 0 & & 0 & & 0 & \\
\hline 7365 & 0,125 & 148 & 0 & & & & 0 & & 0 & & 0 & \\
\hline 7365 & 0,125 & 149 & 0 & & & & & 1 & & 1 & & 1 \\
\hline 7365 & 0,125 & 150 & 0 & & & & & 1 & & 1 & & 1 \\
\hline
\end{tabular}



Protocolo Tafonômico - Estação de coleta 7618 Fração 0,125 mm

\begin{tabular}{|c|c|c|c|c|c|c|c|c|c|c|c|c|}
\hline \multirow{4}{*}{$\begin{array}{l}\text { Estação } \\
\text { de } \\
\text { Coleta }\end{array}$} & \multirow{4}{*}{$\begin{array}{c}\text { Fração } \\
(\mathrm{mm})\end{array}$} & \multirow{4}{*}{ Eppendorf } & \multirow{2}{*}{\multicolumn{4}{|c|}{$\begin{array}{c}\text { Feições Físicas } \\
\text { Fragmentação }\end{array}$}} & \multicolumn{6}{|c|}{ Feições Químicas } \\
\hline & & & & & & & \multicolumn{2}{|c|}{ Cor } & \multicolumn{2}{|c|}{ Brilho } & \multicolumn{2}{|c|}{ Corrosão } \\
\hline & & & \multirow{2}{*}{ Ausente } & \multicolumn{3}{|c|}{ Presente } & \multirow{2}{*}{ Mantida } & \multirow{2}{*}{ Alterada } & \multirow{2}{*}{ Mantido } & \multirow{2}{*}{ Alterado } & \multirow{2}{*}{ Ausente } & \multirow{2}{*}{ Presente } \\
\hline & & & & $<10 \%$ & entre $10 \%$ e $50 \%$ & $>50 \%$ & & & & & & \\
\hline 7618 & 0,125 & 1 & 0 & & & & & 1 & & 1 & & 1 \\
\hline 7618 & 0,125 & 2 & 0 & & & & & 1 & & 1 & & 1 \\
\hline 7618 & 0,125 & 3 & 0 & & & & & 1 & & 1 & & 1 \\
\hline 7618 & 0,125 & 4 & 0 & & & & & 1 & & 1 & & 1 \\
\hline 7618 & 0,125 & 5 & 0 & & & & & 1 & & 1 & & 1 \\
\hline 7618 & 0,125 & 6 & 0 & & & & & 1 & & 1 & & 1 \\
\hline 7618 & 0,125 & 7 & 0 & & & & & 1 & & 1 & & 1 \\
\hline 7618 & 0,125 & 8 & 0 & & & & & 1 & & 1 & & 1 \\
\hline 7618 & 0,125 & 9 & 0 & & & & & 1 & & 1 & & 1 \\
\hline 7618 & 0,125 & 10 & 0 & & & & & 1 & & 1 & & 1 \\
\hline 7618 & 0,125 & 11 & 0 & & & & & 1 & & 1 & & 1 \\
\hline 7618 & 0,125 & 12 & 0 & & & & & 1 & & 1 & & 1 \\
\hline 7618 & 0,125 & 13 & 0 & & & & & 1 & & 1 & & 1 \\
\hline 7618 & 0,125 & 14 & 0 & & & & & 1 & & 1 & & 1 \\
\hline 7618 & 0,125 & 15 & 0 & & & & & 1 & & 1 & & 1 \\
\hline 7618 & 0,125 & 16 & 0 & & & & & 1 & & 1 & & 1 \\
\hline 7618 & 0,125 & 17 & 0 & & & & & 1 & & 1 & & 1 \\
\hline 7618 & 0,125 & 18 & 0 & & & & & 1 & & 1 & & 1 \\
\hline 7618 & 0,125 & 19 & 0 & & & & & 1 & & 1 & & 1 \\
\hline 7618 & 0,125 & 20 & 0 & & & & & 1 & & 1 & & 1 \\
\hline 7618 & 0,125 & 21 & 0 & & & & & 1 & & 1 & & 1 \\
\hline 7618 & 0,125 & 22 & 0 & & & & & 1 & & 1 & & 1 \\
\hline 7618 & 0,125 & 23 & 0 & & & & & 1 & & 1 & & 1 \\
\hline 7618 & 0,125 & 24 & 0 & & & & & 1 & & 1 & & 1 \\
\hline 7618 & 0,125 & 25 & 0 & & & & & 1 & & 1 & & 1 \\
\hline 7618 & 0,125 & 26 & 0 & & & & & 1 & & 1 & & 1 \\
\hline 7618 & 0,125 & 27 & 0 & & & & & 1 & & 1 & & 1 \\
\hline 7618 & 0,125 & 28 & 0 & & & & & 1 & & 1 & & 1 \\
\hline 7618 & 0,125 & 29 & 0 & & & & & 1 & & 1 & & 1 \\
\hline 7618 & 0,125 & 30 & 0 & & & & & 1 & & 1 & & 1 \\
\hline 7618 & 0,125 & 31 & 0 & & & & & 1 & & 1 & & 1 \\
\hline 7618 & 0,125 & 32 & 0 & & & & & 1 & & 1 & & 1 \\
\hline 7618 & 0,125 & 33 & 0 & & & & & 1 & & 1 & & 1 \\
\hline 7618 & 0,125 & 34 & 0 & & & & & 1 & & 1 & & 1 \\
\hline
\end{tabular}




\begin{tabular}{|c|c|c|c|c|c|c|c|c|c|c|c|c|}
\hline \multirow{4}{*}{$\begin{array}{l}\text { Estação } \\
\text { de } \\
\text { Coleta }\end{array}$} & \multirow{4}{*}{$\begin{array}{c}\text { Fração } \\
(\mathrm{mm})\end{array}$} & \multirow{4}{*}{ Eppendorf } & \multirow{2}{*}{\multicolumn{4}{|c|}{$\begin{array}{l}\text { Feições Físicas } \\
\text { Fragmentação }\end{array}$}} & \multicolumn{6}{|c|}{ Feições Químicas } \\
\hline & & & & & & & \multicolumn{2}{|c|}{ Cor } & \multicolumn{2}{|c|}{ Brilho } & \multicolumn{2}{|c|}{ Corrosão } \\
\hline & & & \multirow{2}{*}{ Ausente } & \multicolumn{3}{|c|}{ Presente } & \multirow{2}{*}{ Mantida } & \multirow{2}{*}{ Alterada } & \multirow{2}{*}{ Mantido } & \multirow{2}{*}{ Alterado } & \multirow{2}{*}{ Ausente } & \multirow{2}{*}{ Presente } \\
\hline & & & & $<10 \%$ & entre $10 \%$ e $50 \%$ & $>50 \%$ & & & & & & \\
\hline 7618 & 0,125 & 35 & 0 & & & & & 1 & & 1 & & 1 \\
\hline 7618 & 0,125 & 36 & 0 & & & & & 1 & & 1 & & 1 \\
\hline 7618 & 0,125 & 37 & 0 & & & & & 1 & & 1 & & 1 \\
\hline 7618 & 0,125 & 38 & 0 & & & & & 1 & & 1 & & 1 \\
\hline 7618 & 0,125 & 39 & 0 & & & & & 1 & & 1 & & 1 \\
\hline 7618 & 0,125 & 40 & 0 & & & & & 1 & & 1 & & 1 \\
\hline 7618 & 0,125 & 41 & 0 & & & & & 1 & & 1 & & 1 \\
\hline 7618 & 0,125 & 42 & 0 & & & & 0 & & & 1 & & 1 \\
\hline 7618 & 0,125 & 43 & 0 & & & & 0 & & & 1 & & 1 \\
\hline 7618 & 0,125 & 44 & 0 & & & & 0 & & & 1 & & 1 \\
\hline 7618 & 0,125 & 45 & 0 & & & & 0 & & & 1 & & 1 \\
\hline 7618 & 0,125 & 46 & 0 & & & & 0 & & & 1 & & 1 \\
\hline 7618 & 0,125 & 47 & 0 & & & & 0 & & & 1 & & 1 \\
\hline 7618 & 0,125 & 48 & 0 & & & & 0 & & & 1 & & 1 \\
\hline 7618 & 0,125 & 49 & 0 & & & & 0 & & & 1 & & 1 \\
\hline 7618 & 0,125 & 50 & 0 & & & & 0 & & & 1 & & 1 \\
\hline 7618 & 0,125 & 51 & & 1 & & & & 1 & & 1 & & 1 \\
\hline 7618 & 0,125 & 52 & & 1 & & & & 1 & & 1 & & 1 \\
\hline 7618 & 0,125 & 53 & & 1 & & & & 1 & & 1 & & 1 \\
\hline 7618 & 0,125 & 54 & & 1 & & & & 1 & & 1 & & 1 \\
\hline 7618 & 0,125 & 55 & & 1 & & & & 1 & & 1 & & 1 \\
\hline 7618 & 0,125 & 56 & & 1 & & & & 1 & & 1 & & 1 \\
\hline 7618 & 0,125 & 57 & & 1 & & & & 1 & & 1 & & 1 \\
\hline 7618 & 0,125 & 58 & & 1 & & & & 1 & & 1 & & 1 \\
\hline 7618 & 0,125 & 59 & & 1 & & & & 1 & & 1 & & 1 \\
\hline 7618 & 0,125 & 60 & & 1 & & & & 1 & & 1 & & 1 \\
\hline 7618 & 0,125 & 61 & & 1 & & & & 1 & & 1 & & 1 \\
\hline 7618 & 0,125 & 62 & & & & 3 & 0 & & & 1 & & 1 \\
\hline 7618 & 0,125 & 63 & 0 & & & & 0 & & & 1 & & 1 \\
\hline 7618 & 0,125 & 64 & 0 & & & & 0 & & & 1 & & 1 \\
\hline 7618 & 0,125 & 65 & 0 & & & & 0 & & & 1 & & 1 \\
\hline 7618 & 0,125 & 66 & 0 & & & & 0 & & & 1 & & 1 \\
\hline 7618 & 0,125 & 67 & 0 & & & & 0 & & & 1 & & 1 \\
\hline 7618 & 0,125 & 68 & 0 & & & & 0 & & & 1 & & 1 \\
\hline 7618 & 0,125 & 69 & 0 & & & & 0 & & & 1 & & 1 \\
\hline 7618 & 0,125 & 70 & 0 & & & & 0 & & & 1 & & 1 \\
\hline
\end{tabular}




\begin{tabular}{|c|c|c|c|c|c|c|c|c|c|c|c|c|}
\hline \multirow{4}{*}{$\begin{array}{l}\text { Estação } \\
\text { de } \\
\text { Coleta }\end{array}$} & \multirow{4}{*}{$\begin{array}{c}\text { Fração } \\
(\mathrm{mm})\end{array}$} & \multirow{4}{*}{ Eppendorf } & \multirow{2}{*}{\multicolumn{4}{|c|}{$\begin{array}{l}\text { Feições Físicas } \\
\text { Fragmentação }\end{array}$}} & \multicolumn{6}{|c|}{ Feições Químicas } \\
\hline & & & & & & & \multicolumn{2}{|c|}{ Cor } & \multicolumn{2}{|c|}{ Brilho } & \multicolumn{2}{|c|}{ Corrosão } \\
\hline & & & \multirow{2}{*}{ Ausente } & \multicolumn{3}{|c|}{ Presente } & \multirow{2}{*}{ Mantida } & \multirow{2}{*}{ Alterada } & \multirow{2}{*}{ Mantido } & \multirow{2}{*}{ Alterado } & \multirow{2}{*}{ Ausente } & \multirow{2}{*}{ Presente } \\
\hline & & & & $<10 \%$ & entre $10 \%$ e $50 \%$ & $>50 \%$ & & & & & & \\
\hline 7618 & 0,125 & 71 & 0 & & & & 0 & & & 1 & & 1 \\
\hline 7618 & 0,125 & 72 & 0 & & & & 0 & & & 1 & & 1 \\
\hline 7618 & 0,125 & 73 & 0 & & & & 0 & & & 1 & & 1 \\
\hline 7618 & 0,125 & 74 & 0 & & & & 0 & & & 1 & & 1 \\
\hline 7618 & 0,125 & 75 & 0 & & & & 0 & & & 1 & & 1 \\
\hline 7618 & 0,125 & 76 & 0 & & & & 0 & & & 1 & & 1 \\
\hline 7618 & 0,125 & 77 & 0 & & & & 0 & & & 1 & & 1 \\
\hline 7618 & 0,125 & 78 & 0 & & & & 0 & & & 1 & & 1 \\
\hline 7618 & 0,125 & 79 & 0 & & & & 0 & & & 1 & & 1 \\
\hline 7618 & 0,125 & 80 & 0 & & & & 0 & & & 1 & & 1 \\
\hline 7618 & 0,125 & 81 & 0 & & & & 0 & & & 1 & & 1 \\
\hline 7618 & 0,125 & 82 & 0 & & & & 0 & & & 1 & & 1 \\
\hline 7618 & 0,125 & 83 & 0 & & & & 0 & & & 1 & & 1 \\
\hline 7618 & 0,125 & 84 & 0 & & & & 0 & & & 1 & & 1 \\
\hline 7618 & 0,125 & 85 & 0 & & & & 0 & & & 1 & & 1 \\
\hline 7618 & 0,125 & 86 & 0 & & & & & 1 & & 1 & & 1 \\
\hline 7618 & 0,125 & 87 & 0 & & & & & 1 & & 1 & & 1 \\
\hline 7618 & 0,125 & 88 & 0 & & & & & 1 & & 1 & & 1 \\
\hline 7618 & 0,125 & 89 & 0 & & & & & 1 & & 1 & & 1 \\
\hline 7618 & 0,125 & 90 & 0 & & & & & 1 & & 1 & & 1 \\
\hline 7618 & 0,125 & 91 & 0 & & & & & 1 & & 1 & & 1 \\
\hline 7618 & 0,125 & 92 & 0 & & & & & 1 & & 1 & & 1 \\
\hline 7618 & 0,125 & 93 & 0 & & & & & 1 & & 1 & & 1 \\
\hline 7618 & 0,125 & 94 & & 1 & & & 0 & & & 1 & & 1 \\
\hline 7618 & 0,125 & 95 & & 1 & & & 0 & & & 1 & & 1 \\
\hline 7618 & 0,125 & 96 & 0 & & & & 0 & & & 1 & & 1 \\
\hline 7618 & 0,125 & 97 & 0 & & & & 0 & & & 1 & & 1 \\
\hline 7618 & 0,125 & 98 & & 1 & & & & 1 & & 1 & & 1 \\
\hline 7618 & 0,125 & 99 & 0 & & & & 0 & & & 1 & & 1 \\
\hline 7618 & 0,125 & 100 & 0 & & & & 0 & & 0 & & 0 & \\
\hline 7618 & 0,125 & 101 & 0 & & & & 0 & & 0 & & 0 & \\
\hline 7618 & 0,125 & 102 & 0 & & & & 0 & & 0 & & 0 & \\
\hline 7618 & 0,125 & 103 & 0 & & & & 0 & & & 1 & & 1 \\
\hline 7618 & 0,125 & 104 & 0 & & & & 0 & & & 1 & & 1 \\
\hline 7618 & 0,125 & 105 & 0 & & & & 0 & & & 1 & & 1 \\
\hline 7618 & 0,125 & 106 & 0 & & & & 0 & & & 1 & & 1 \\
\hline
\end{tabular}




\begin{tabular}{|c|c|c|c|c|c|c|c|c|c|c|c|c|}
\hline \multirow{4}{*}{$\begin{array}{l}\text { Estação } \\
\text { de } \\
\text { Coleta }\end{array}$} & \multirow{4}{*}{$\begin{array}{c}\text { Fração } \\
(\mathrm{mm})\end{array}$} & \multirow{4}{*}{ Eppendorf } & \multirow{2}{*}{\multicolumn{4}{|c|}{$\begin{array}{l}\text { Feições Físicas } \\
\text { Fragmentação }\end{array}$}} & \multicolumn{6}{|c|}{ Feições Químicas } \\
\hline & & & & & & & \multicolumn{2}{|c|}{ Cor } & \multicolumn{2}{|c|}{ Brilho } & \multicolumn{2}{|c|}{ Corrosão } \\
\hline & & & \multirow{2}{*}{ Ausente } & \multicolumn{3}{|c|}{ Presente } & \multirow{2}{*}{ Mantida } & \multirow{2}{*}{ Alterada } & \multirow{2}{*}{ Mantido } & \multirow{2}{*}{ Alterado } & \multirow{2}{*}{ Ausente } & \multirow{2}{*}{ Presente } \\
\hline & & & & $<10 \%$ & entre $10 \%$ e $50 \%$ & $>50 \%$ & & & & & & \\
\hline 7618 & 0,125 & 107 & 0 & & & & 0 & & & 1 & & 1 \\
\hline 7618 & 0,125 & 108 & 0 & & & & 0 & & & 1 & & 1 \\
\hline 7618 & 0,125 & 109 & 0 & & & & & 1 & & 1 & & 1 \\
\hline 7618 & 0,125 & 110 & 0 & & & & & 1 & & 1 & & 1 \\
\hline 7618 & 0,125 & 111 & 0 & & & & & 1 & & 1 & & 1 \\
\hline 7618 & 0,125 & 112 & 0 & & & & & 1 & & 1 & & 1 \\
\hline 7618 & 0,125 & 113 & 0 & & & & & 1 & & 1 & & 1 \\
\hline 7618 & 0,125 & 114 & 0 & & & & & 1 & & 1 & & 1 \\
\hline 7618 & 0,125 & 115 & 0 & & & & & 1 & & 1 & & 1 \\
\hline 7618 & 0,125 & 116 & 0 & & & & & 1 & & 1 & & 1 \\
\hline 7618 & 0,125 & 117 & & 1 & & & & 1 & & 1 & & 1 \\
\hline 7618 & 0,125 & 118 & & 1 & & & & 1 & & 1 & & 1 \\
\hline 7618 & 0,125 & 119 & & 1 & & & & 1 & & 1 & & 1 \\
\hline 7618 & 0,125 & 120 & & 1 & & & & 1 & & 1 & & 1 \\
\hline 7618 & 0,125 & 121 & & 1 & & & & 1 & & 1 & & 1 \\
\hline 7618 & 0,125 & 122 & & 1 & & & & 1 & & 1 & & 1 \\
\hline 7618 & 0,125 & 123 & & 1 & & & & 1 & & 1 & & 1 \\
\hline 7618 & 0,125 & 124 & & 1 & & & & 1 & & 1 & & 1 \\
\hline 7618 & 0,125 & 125 & & 1 & & & & 1 & & 1 & & 1 \\
\hline 7618 & 0,125 & 126 & & & 2 & & & 1 & & 1 & & 1 \\
\hline 7618 & 0,125 & 127 & & & 2 & & & 1 & & 1 & & 1 \\
\hline 7618 & 0,125 & 128 & & & 2 & & & 1 & & 1 & & 1 \\
\hline 7618 & 0,125 & 129 & & & 2 & & & 1 & & 1 & & 1 \\
\hline 7618 & 0,125 & 130 & & & 2 & & & 1 & & 1 & & 1 \\
\hline 7618 & 0,125 & 131 & & & & 3 & & 1 & & 1 & & 1 \\
\hline 7618 & 0,125 & 132 & & & & 3 & & 1 & & 1 & & 1 \\
\hline 7618 & 0,125 & 133 & & & & 3 & & 1 & & 1 & & 1 \\
\hline 7618 & 0,125 & 134 & & & & 3 & & 1 & & 1 & & 1 \\
\hline 7618 & 0,125 & 135 & & & & 3 & & 1 & & 1 & & 1 \\
\hline 7618 & 0,125 & 136 & 0 & & & & & 1 & & 1 & & 1 \\
\hline 7618 & 0,125 & 137 & 0 & & & & & 1 & & 1 & & 1 \\
\hline 7618 & 0,125 & 138 & 0 & & & & & 1 & & 1 & & 1 \\
\hline 7618 & 0,125 & 139 & 0 & & & & & 1 & & 1 & & 1 \\
\hline 7618 & 0,125 & 140 & 0 & & & & & 1 & & 1 & & 1 \\
\hline 7618 & 0,125 & 141 & 0 & & & & & 1 & & 1 & & 1 \\
\hline 7618 & 0,125 & 142 & 0 & & & & & 1 & & 1 & & 1 \\
\hline
\end{tabular}




\begin{tabular}{|c|c|c|c|c|c|c|c|c|c|c|c|c|}
\hline \multirow{4}{*}{$\begin{array}{l}\text { Estação } \\
\text { de } \\
\text { Coleta }\end{array}$} & \multirow{4}{*}{$\begin{array}{c}\text { Fração } \\
(\mathrm{mm})\end{array}$} & \multirow{4}{*}{ Eppendorf } & \multirow{2}{*}{\multicolumn{4}{|c|}{$\begin{array}{c}\text { Feições Físicas } \\
\text { Fragmentação }\end{array}$}} & \multicolumn{6}{|c|}{ Feições Químicas } \\
\hline & & & & & & & \multicolumn{2}{|c|}{ Cor } & \multicolumn{2}{|c|}{ Brilho } & \multicolumn{2}{|c|}{ Corrosão } \\
\hline & & & \multirow{2}{*}{ Ausente } & \multicolumn{3}{|c|}{ Presente } & \multirow{2}{*}{ Mantida } & \multirow{2}{*}{ Alterada } & \multirow{2}{*}{ Mantido } & \multirow{2}{*}{ Alterado } & \multirow{2}{*}{ Ausente } & \multirow{2}{*}{ Presente } \\
\hline & & & & $<10 \%$ & entre $10 \%$ e $50 \%$ & $>50 \%$ & & & & & & \\
\hline 7618 & 0,125 & 143 & 0 & & & & & 1 & & 1 & & 1 \\
\hline 7618 & 0,125 & 144 & 0 & & & & & 1 & & 1 & & 1 \\
\hline 7618 & 0,125 & 145 & 0 & & & & & 1 & & 1 & & 1 \\
\hline 7618 & 0,125 & 146 & 0 & & & & & 1 & & 1 & & 1 \\
\hline 7618 & 0,125 & 147 & 0 & & & & & 1 & & 1 & & 1 \\
\hline 7618 & 0,125 & 148 & 0 & & & & & 1 & & 1 & & 1 \\
\hline 7618 & 0,125 & 149 & 0 & & & & & 1 & & 1 & & 1 \\
\hline 7618 & 0,125 & 150 & 0 & & & & 0 & & 0 & & 0 & \\
\hline
\end{tabular}




\section{Protocolo Tafonômico - Estação de coleta 7619, fração 0,125 mm}

\begin{tabular}{|c|c|c|c|c|c|c|c|c|c|c|c|c|}
\hline \multirow{4}{*}{$\begin{array}{c}\text { Estação } \\
\text { de } \\
\text { Coleta }\end{array}$} & \multirow{4}{*}{$\begin{array}{c}\text { Fração } \\
\text { (mm) }\end{array}$} & \multirow{4}{*}{ Eppendorf } & \multirow{2}{*}{\multicolumn{4}{|c|}{$\begin{array}{l}\text { Feições Físicas } \\
\text { Fragmentação }\end{array}$}} & \multicolumn{6}{|c|}{ Feições Químicas } \\
\hline & & & & & & & \multirow{3}{*}{ Mantida } & Cor & \multicolumn{2}{|c|}{ Brilho } & \multicolumn{2}{|c|}{ Corrosão } \\
\hline & & & \multirow{2}{*}{ Ausente } & \multicolumn{3}{|c|}{ Presente } & & & & & & \\
\hline & & & & $<10 \%$ & entre $10 \%$ e $50 \%$ & $>50 \%$ & & & & & & \\
\hline 7619 & 0,125 & 1 & 0 & & & & & 1 & & 1 & & 1 \\
\hline 7619 & 0,125 & 2 & 0 & & & & & 1 & & 1 & & 1 \\
\hline 7619 & 0,125 & 3 & 0 & & & & & 1 & & 1 & & 1 \\
\hline 7619 & 0,125 & 4 & 0 & & & & & 1 & & 1 & & 1 \\
\hline 7619 & 0,125 & 5 & 0 & & & & & 1 & & 1 & & 1 \\
\hline 7619 & 0,125 & 6 & 0 & & & & & 1 & & 1 & & 1 \\
\hline 7619 & 0,125 & 7 & 0 & & & & & 1 & & 1 & & 1 \\
\hline 7619 & 0,125 & 8 & 0 & & & & & 1 & & 1 & & 1 \\
\hline 7619 & 0,125 & 9 & 0 & & & & & 1 & & 1 & & 1 \\
\hline 7619 & 0,125 & 10 & 0 & & & & & 1 & & 1 & & 1 \\
\hline 7619 & 0,125 & 11 & 0 & & & & & 1 & & 1 & & 1 \\
\hline 7619 & 0,125 & 12 & 0 & & & & & 1 & & 1 & & 1 \\
\hline 7619 & 0,125 & 13 & 0 & & & & & 1 & & 1 & & 1 \\
\hline 7619 & 0,125 & 14 & 0 & & & & & 1 & & 1 & & 1 \\
\hline 7619 & 0,125 & 15 & 0 & & & & & 1 & & 1 & & 1 \\
\hline 7619 & 0,125 & 16 & 0 & & & & & 1 & & 1 & & 1 \\
\hline 7619 & 0,125 & 17 & 0 & & & & & 1 & & 1 & & 1 \\
\hline 7619 & 0,125 & 18 & 0 & & & & & 1 & & 1 & & 1 \\
\hline 7619 & 0,125 & 19 & 0 & & & & & 1 & & 1 & & 1 \\
\hline 7619 & 0,125 & 20 & 0 & & & & & 1 & & 1 & & 1 \\
\hline 7619 & 0,125 & 21 & 0 & & & & & 1 & & 1 & & 1 \\
\hline 7619 & 0,125 & 22 & 0 & & & & & 1 & & 1 & & 1 \\
\hline 7619 & 0,125 & 23 & 0 & & & & & 1 & & 1 & & 1 \\
\hline 7619 & 0,125 & 24 & 0 & & & & & 1 & & 1 & & 1 \\
\hline 7619 & 0,125 & 25 & 0 & & & & & 1 & & 1 & & 1 \\
\hline 7619 & 0,125 & 26 & 0 & & & & & 1 & & 1 & & 1 \\
\hline 7619 & 0,125 & 27 & 0 & & & & & 1 & & 1 & & 1 \\
\hline 7619 & 0,125 & 28 & 0 & & & & & 1 & & 1 & & 1 \\
\hline 7619 & 0,125 & 29 & 0 & & & & & 1 & & 1 & & 1 \\
\hline 7619 & 0,125 & 30 & 0 & & & & & 1 & & 1 & & 1 \\
\hline 7619 & 0,125 & 31 & 0 & & & & & 1 & & 1 & & 1 \\
\hline 7619 & 0,125 & 32 & 0 & & & & 0 & & & 1 & & 1 \\
\hline 7619 & 0,125 & 33 & 0 & & & & 0 & & & 1 & & 1 \\
\hline 7619 & 0,125 & 34 & 0 & & & & 0 & & & 1 & & 1 \\
\hline 7619 & 0,125 & 35 & 0 & & & & 0 & & & 1 & & 1 \\
\hline
\end{tabular}




\begin{tabular}{|c|c|c|c|c|c|c|c|c|c|c|c|c|}
\hline \multirow{4}{*}{$\begin{array}{l}\text { Estação } \\
\text { de } \\
\text { Coleta }\end{array}$} & \multirow{4}{*}{$\begin{array}{c}\text { Fração } \\
(\mathrm{mm})\end{array}$} & \multirow{4}{*}{ Eppendorf } & \multirow{2}{*}{\multicolumn{4}{|c|}{$\begin{array}{c}\text { Feições Físicas } \\
\text { Fragmentação }\end{array}$}} & \multicolumn{6}{|c|}{ Feições Químicas } \\
\hline & & & & & & & \multirow{3}{*}{ Mantida } & Cor & \multicolumn{2}{|c|}{ Brilho } & \multicolumn{2}{|c|}{ Corrosão } \\
\hline & & & \multirow{2}{*}{ Ausente } & \multicolumn{3}{|c|}{ Presente } & & I lo & or to & a tom & a ousto & Drapant \\
\hline & & & & $<10 \%$ & entre $10 \%$ e $50 \%$ & $>50 \%$ & & & & & & \\
\hline 7619 & 0,125 & 36 & 0 & & & & 0 & & & 1 & & 1 \\
\hline 7619 & 0,125 & 37 & 0 & & & & 0 & & & 1 & & 1 \\
\hline 7619 & 0,125 & 38 & 0 & & & & 0 & & & 1 & & 1 \\
\hline 7619 & 0,125 & 39 & & 1 & & & & 1 & & 1 & & 1 \\
\hline 7619 & 0,125 & 40 & & 1 & & & & 1 & & 1 & & 1 \\
\hline 7619 & 0,125 & 41 & & 1 & & & & 1 & & 1 & & 1 \\
\hline 7619 & 0,125 & 42 & & & 2 & & & 1 & & 1 & & 1 \\
\hline 7619 & 0,125 & 43 & & & 2 & & & 1 & & 1 & & 1 \\
\hline 7619 & 0,125 & 44 & & & 2 & & & 1 & & 1 & & 1 \\
\hline 7619 & 0,125 & 45 & & & 2 & & & 1 & & 1 & & 1 \\
\hline 7619 & 0,125 & 46 & & & 2 & & & 1 & & 1 & & 1 \\
\hline 7619 & 0,125 & 47 & & & 2 & & & 1 & & 1 & & 1 \\
\hline 7619 & 0,125 & 48 & 0 & & & & 0 & & & 1 & & 1 \\
\hline 7619 & 0,125 & 49 & 0 & & & & 0 & & & 1 & & 1 \\
\hline 7619 & 0,125 & 50 & 0 & & & & 0 & & & 1 & & 1 \\
\hline 7619 & 0,125 & 51 & 0 & & & & 0 & & & 1 & & 1 \\
\hline 7619 & 0,125 & 52 & 0 & & & & 0 & & & 1 & & 1 \\
\hline 7619 & 0,125 & 53 & 0 & & & & 0 & & & 1 & & 1 \\
\hline 7619 & 0,125 & 54 & 0 & & & & 0 & & & 1 & & 1 \\
\hline 7619 & 0,125 & 55 & 0 & & & & 0 & & & 1 & & 1 \\
\hline 7619 & 0,125 & 56 & 0 & & & & 0 & & & 1 & & 1 \\
\hline 7619 & 0,125 & 57 & 0 & & & & & 1 & & 1 & & 1 \\
\hline 7619 & 0,125 & 58 & & & 2 & & & 1 & & 1 & & 1 \\
\hline 7619 & 0,125 & 59 & 0 & & & & & 1 & & 1 & & 1 \\
\hline 7619 & 0,125 & 60 & 0 & & & & & 1 & & 1 & & 1 \\
\hline 7619 & 0,125 & 61 & & & & 3 & 0 & & & 1 & & 1 \\
\hline 7619 & 0,125 & 62 & 0 & & & & & 1 & & 1 & & 1 \\
\hline 7619 & 0,125 & 63 & 0 & & & & & 1 & & 1 & & 1 \\
\hline 7619 & 0,125 & 64 & & & & 3 & & 1 & & 1 & & 1 \\
\hline 7619 & 0,125 & 65 & & & & 3 & & 1 & & 1 & & 1 \\
\hline 7619 & 0,125 & 66 & 0 & & & & & 1 & & 1 & & 1 \\
\hline 7619 & 0,125 & 67 & & & & 3 & & 1 & & 1 & & 1 \\
\hline 7619 & 0,125 & 68 & & & 2 & & 0 & & & 1 & & 1 \\
\hline 7619 & 0,125 & 69 & & & & 3 & & 1 & & 1 & & 1 \\
\hline 7619 & 0,125 & 70 & 0 & & & & 0 & & & 1 & & 1 \\
\hline 7619 & 0,125 & 71 & & & 2 & & & 1 & & 1 & & 1 \\
\hline
\end{tabular}




\begin{tabular}{|c|c|c|c|c|c|c|c|c|c|c|c|c|}
\hline \multirow{4}{*}{$\begin{array}{l}\text { Estação } \\
\text { de } \\
\text { Coleta }\end{array}$} & \multirow{4}{*}{$\begin{array}{c}\text { Fração } \\
(\mathrm{mm})\end{array}$} & \multirow{4}{*}{ Eppendorf } & \multirow{2}{*}{\multicolumn{4}{|c|}{$\begin{array}{c}\text { Feições Físicas } \\
\text { Fragmentação }\end{array}$}} & \multicolumn{6}{|c|}{ Feições Químicas } \\
\hline & & & & & & & \multirow{3}{*}{ Mantida } & Cor & \multicolumn{2}{|c|}{ Brilho } & \multicolumn{2}{|c|}{ Corrosão } \\
\hline & & & \multirow{2}{*}{ Ausente } & \multicolumn{3}{|c|}{ Presente } & & I lo & or to & a tom & a ousto & Dramara \\
\hline & & & & $<10 \%$ & entre $10 \%$ e $50 \%$ & $>50 \%$ & & & & & & \\
\hline 7619 & 0,125 & 72 & & & 2 & & 0 & & & 1 & & 1 \\
\hline 7619 & 0,125 & 73 & & & & 3 & & 1 & & 1 & & 1 \\
\hline 7619 & 0,125 & 74 & & & 2 & & & 1 & & 1 & & 1 \\
\hline 7619 & 0,125 & 75 & 0 & & & & 0 & & & 1 & & 1 \\
\hline 7619 & 0,125 & 76 & & & 2 & & & 1 & & 1 & & 1 \\
\hline 7619 & 0,125 & 77 & 0 & & & & & 1 & & 1 & & 1 \\
\hline 7619 & 0,125 & 78 & & & & 3 & & 1 & & 1 & & 1 \\
\hline 7619 & 0,125 & 79 & & & & 3 & & 1 & & 1 & & 1 \\
\hline 7619 & 0,125 & 80 & 0 & & & & & 1 & & 1 & & 1 \\
\hline 7619 & 0,125 & 81 & 0 & & 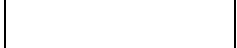 & & 0 & & & 1 & & 1 \\
\hline 7619 & 0,125 & 82 & 0 & & & & 0 & & & 1 & & 1 \\
\hline 7619 & 0,125 & 83 & 0 & & & & 0 & & & 1 & & 1 \\
\hline 7619 & 0,125 & 84 & 0 & & & & & 1 & & 1 & & 1 \\
\hline 7619 & 0,125 & 85 & 0 & & & & & 1 & & 1 & & 1 \\
\hline 7619 & 0,125 & 86 & 0 & & & & & 1 & & 1 & & 1 \\
\hline 7619 & 0,125 & 87 & 0 & & & & 0 & & 0 & & 0 & \\
\hline 7619 & 0,125 & 88 & 0 & & & & & 1 & & 1 & & 1 \\
\hline 7619 & 0,125 & 89 & & & & 3 & 0 & & 0 & & 0 & \\
\hline 7619 & 0,125 & 90 & 0 & & & & 0 & & 0 & & 0 & \\
\hline 7619 & 0,125 & 91 & 0 & & & & 0 & & 0 & & 0 & \\
\hline 7619 & 0,125 & 92 & 0 & & & & & 1 & & 1 & & 1 \\
\hline 7619 & 0,125 & 93 & 0 & & & & 0 & & 0 & & & 1 \\
\hline 7619 & 0,125 & 94 & 0 & & & & 0 & & 0 & & & 1 \\
\hline 7619 & 0,125 & 95 & 0 & & & & & 1 & & 1 & & 1 \\
\hline 7619 & 0,125 & 96 & 0 & & & & 0 & & 0 & & & 1 \\
\hline 7619 & 0,125 & 97 & 0 & & & & 0 & & & 1 & & 1 \\
\hline 7619 & 0,125 & 98 & 0 & & & & & 1 & & 1 & & 1 \\
\hline 7619 & 0,125 & 99 & 0 & & & & & 1 & & 1 & & 1 \\
\hline 7619 & 0,125 & 100 & 0 & & & & & 1 & & 1 & & 1 \\
\hline 7619 & 0,125 & 101 & 0 & & & & & 1 & & 1 & & 1 \\
\hline 7619 & 0,125 & 102 & 0 & & & & & 1 & & 1 & & 1 \\
\hline 7619 & 0,125 & 103 & 0 & & & & & 1 & & 1 & & 1 \\
\hline 7619 & 0,125 & 104 & 0 & & & & & 1 & & 1 & & 1 \\
\hline 7619 & 0,125 & 105 & 0 & & & & & 1 & & 1 & & 1 \\
\hline 7619 & 0,125 & 106 & 0 & & & & 0 & & 0 & & 0 & \\
\hline 7619 & 0,125 & 107 & 0 & & & & & 1 & & 1 & & 1 \\
\hline
\end{tabular}




\begin{tabular}{|c|c|c|c|c|c|c|c|c|c|c|c|c|}
\hline \multirow{4}{*}{$\begin{array}{l}\text { Estação } \\
\text { de } \\
\text { Coleta }\end{array}$} & \multirow{4}{*}{$\begin{array}{c}\text { Fração } \\
(\mathrm{mm})\end{array}$} & \multirow{4}{*}{ Eppendorf } & \multirow{2}{*}{\multicolumn{4}{|c|}{$\begin{array}{c}\text { Feições Físicas } \\
\text { Fragmentação }\end{array}$}} & \multicolumn{6}{|c|}{ Feições Químicas } \\
\hline & & & & & & & \multirow{3}{*}{ Mantida } & Cor & \multicolumn{2}{|c|}{ Brilho } & \multicolumn{2}{|c|}{ Corrosão } \\
\hline & & & \multirow{2}{*}{ Ausente } & \multicolumn{3}{|c|}{ Presente } & & I lo & or to & a tom & a ousto & Dramara \\
\hline & & & & $<10 \%$ & entre $10 \%$ e $50 \%$ & $>50 \%$ & & & & & & \\
\hline 7619 & 0,125 & 108 & 0 & & & & 0 & & & 1 & & 1 \\
\hline 7619 & 0,125 & 109 & 0 & & & & & 1 & & 1 & & 1 \\
\hline 7619 & 0,125 & 110 & 0 & & & & & 1 & & 1 & & 1 \\
\hline 7619 & 0,125 & 111 & & & 2 & & & 1 & & 1 & & 1 \\
\hline 7619 & 0,125 & 112 & 0 & & & & & 1 & & 1 & & 1 \\
\hline 7619 & 0,125 & 113 & 0 & & & & & 1 & & 1 & & 1 \\
\hline 7619 & 0,125 & 114 & 0 & & & & & 1 & & 1 & & 1 \\
\hline 7619 & 0,125 & 115 & 0 & & & & & 1 & & 1 & & 1 \\
\hline 7619 & 0,125 & 116 & 0 & & & & & 1 & & 1 & & 1 \\
\hline 7619 & 0,125 & 117 & 0 & & & & & 1 & & 1 & & 1 \\
\hline 7619 & 0,125 & 118 & 0 & & & & & 1 & & 1 & & 1 \\
\hline 7619 & 0,125 & 119 & & & & 3 & & 1 & & 1 & & 1 \\
\hline 7619 & 0,125 & 120 & & 1 & & & 0 & & 0 & & 0 & \\
\hline 7619 & 0,125 & 121 & 0 & & & & 0 & & & 1 & & 1 \\
\hline 7619 & 0,125 & 122 & & & & 3 & & 1 & & 1 & & 1 \\
\hline 7619 & 0,125 & 123 & & & & 3 & & 1 & & 1 & & 1 \\
\hline 7619 & 0,125 & 124 & & & & 3 & & 1 & & 1 & & 1 \\
\hline 7619 & 0,125 & 125 & & 1 & & & & 1 & & 1 & & 1 \\
\hline 7619 & 0,125 & 126 & & 1 & & & 0 & & & 1 & & 1 \\
\hline 7619 & 0,125 & 127 & & 1 & & & & 1 & & 1 & & 1 \\
\hline 7619 & 0,125 & 128 & & 1 & & & & 1 & & 1 & & 1 \\
\hline 7619 & 0,125 & 129 & & 1 & & & & 1 & & 1 & & 1 \\
\hline 7619 & 0,125 & 130 & 0 & & & & 0 & & & 1 & & 1 \\
\hline 7619 & 0,125 & 131 & 0 & & & & 0 & & & 1 & & 1 \\
\hline 7619 & 0,125 & 132 & 0 & & & & 0 & & & 1 & & 1 \\
\hline 7619 & 0,125 & 133 & 0 & & & & 0 & & 0 & & 0 & \\
\hline 7619 & 0,125 & 134 & 0 & & & & & 1 & & 1 & & 1 \\
\hline 7619 & 0,125 & 135 & 0 & & & & & 1 & & 1 & & 1 \\
\hline 7619 & 0,125 & 136 & 0 & & & & & 1 & & 1 & & 1 \\
\hline 7619 & 0,125 & 137 & & & 2 & & 0 & & & 1 & & 1 \\
\hline 7619 & 0,125 & 138 & 0 & & & & & 1 & & 1 & & 1 \\
\hline 7619 & 0,125 & 139 & 0 & & & & 0 & & & 1 & & 1 \\
\hline 7619 & 0,125 & 140 & 0 & & & & & 1 & & 1 & & 1 \\
\hline 7619 & 0,125 & 141 & 0 & & & & & 1 & & 1 & & 1 \\
\hline 7619 & 0,125 & 142 & 0 & & & & & 1 & & 1 & & 1 \\
\hline 7619 & 0,125 & 143 & 0 & & & & & 1 & & 1 & & 1 \\
\hline
\end{tabular}




\begin{tabular}{|c|c|c|c|c|c|c|c|c|c|c|c|c|}
\hline \multirow{4}{*}{$\begin{array}{l}\text { Estação } \\
\text { de } \\
\text { Coleta }\end{array}$} & \multirow{4}{*}{$\begin{array}{c}\text { Fração } \\
(\mathrm{mm})\end{array}$} & \multirow{4}{*}{ Eppendorf } & \multirow{2}{*}{\multicolumn{4}{|c|}{$\begin{array}{l}\text { Feições Físicas } \\
\text { Fragmentação }\end{array}$}} & \multicolumn{6}{|c|}{ Feições Químicas } \\
\hline & & & & & & & & or & & ilho & Corre & rosão \\
\hline & & & \multirow{2}{*}{ Ausente } & \multicolumn{3}{|c|}{ Presente } & \multirow{2}{*}{ Mantida } & \multirow{2}{*}{ Alterada } & \multirow{2}{*}{ Mantido } & \multirow{2}{*}{ Alterado } & \multirow{2}{*}{ Ausente } & \multirow{2}{*}{ Presente } \\
\hline & & & & $<10 \%$ & entre $10 \%$ e $50 \%$ & $>50 \%$ & & & & & & \\
\hline 7619 & 0,125 & 144 & 0 & & & & & 1 & & 1 & & 1 \\
\hline 7619 & 0,125 & 145 & 0 & & & & & 1 & & 1 & & 1 \\
\hline 7619 & 0,125 & 146 & 0 & & & & & 1 & & 1 & & 1 \\
\hline 7619 & 0,125 & 147 & 0 & & & & 0 & & 0 & & 0 & \\
\hline 7619 & 0,125 & 148 & 0 & & & & 0 & & & 1 & & 1 \\
\hline 7619 & 0,125 & 149 & 0 & & & & & 1 & & 1 & & 1 \\
\hline 7619 & 0,125 & 150 & 0 & & & & & 1 & & 1 & & 1 \\
\hline
\end{tabular}




\section{Protocolo Tafonômico - Estação de coleta 7621, fração 0,125 mm}

\begin{tabular}{|c|c|c|c|c|c|c|c|c|c|c|c|c|}
\hline \multirow{4}{*}{$\begin{array}{l}\text { Estação } \\
\text { de coleta }\end{array}$} & \multirow{4}{*}{$\begin{array}{c}\text { Fração } \\
\text { (mm) }\end{array}$} & \multirow{4}{*}{ Eppendorf } & \multirow{2}{*}{\multicolumn{4}{|c|}{$\begin{array}{l}\text { Feições Físicas } \\
\text { Fragmentação }\end{array}$}} & \multicolumn{6}{|c|}{ Feições Químicas } \\
\hline & & & & & & & \multicolumn{2}{|c|}{ Cor } & \multicolumn{2}{|c|}{ Brilho } & \multicolumn{2}{|c|}{ Corrosão } \\
\hline & & & \multirow{2}{*}{ Ausente } & \multicolumn{3}{|c|}{ Presente } & \multirow{2}{*}{ Mantida } & \multirow{2}{*}{ Alterada } & \multirow{2}{*}{ Mantida } & \multirow{2}{*}{ Alterada } & \multirow{2}{*}{ Ausente } & \multirow{2}{*}{ Presente } \\
\hline & & & & $<10 \%$ & entre $10 \%$ e $50 \%$ & $>50 \%$ & & & & & & \\
\hline 7621 & 0,125 & 1 & 0 & & & & 0 & & & 1 & & 1 \\
\hline 7621 & 0,125 & 2 & 0 & & & & 0 & & & 1 & & 1 \\
\hline 7621 & 0,125 & 3 & 0 & & & & 0 & & & 1 & & 1 \\
\hline 7621 & 0,125 & 4 & 0 & & & & 0 & & & 1 & & 1 \\
\hline 7621 & 0,125 & 5 & 0 & & & & 0 & & & 1 & & 1 \\
\hline 7621 & 0,125 & 6 & 0 & & & & 0 & & & 1 & & 1 \\
\hline 7621 & 0,125 & 7 & 0 & & & & 0 & & & 1 & & 1 \\
\hline 7621 & 0,125 & 8 & 0 & & & & 0 & & & 1 & & 1 \\
\hline 7621 & 0,125 & 9 & 0 & & & & 0 & & & 1 & & 1 \\
\hline 7621 & 0,125 & 10 & 0 & & & & 0 & & & 1 & & 1 \\
\hline 7621 & 0,125 & 11 & 0 & & & & 0 & & & 1 & & 1 \\
\hline 7621 & 0,125 & 12 & 0 & & & & & 1 & & 1 & & 1 \\
\hline 7621 & 0,125 & 13 & 0 & & & & & 1 & & 1 & & 1 \\
\hline 7621 & 0,125 & 14 & 0 & & & & & 1 & & 1 & & 1 \\
\hline 7621 & 0,125 & 15 & 0 & & & & & 1 & & 1 & & 1 \\
\hline 7621 & 0,125 & 16 & 0 & & & & & 1 & & 1 & & 1 \\
\hline 7621 & 0,125 & 17 & 0 & & & & & 1 & & 1 & & 1 \\
\hline 7621 & 0,125 & 18 & 0 & & & & & 1 & & 1 & & 1 \\
\hline 7621 & 0,125 & 19 & 0 & & & & & 1 & & 1 & & 1 \\
\hline 7621 & 0,125 & 20 & 0 & & & & & 1 & & 1 & & 1 \\
\hline 7621 & 0,125 & 21 & 0 & & & & & 1 & & 1 & & 1 \\
\hline 7621 & 0,125 & 22 & 0 & & & & & 1 & & 1 & & 1 \\
\hline 7621 & 0,125 & 23 & & & 2 & & 0 & & & 1 & & 1 \\
\hline 7621 & 0,125 & 24 & & & 2 & & 0 & & & 1 & & 1 \\
\hline 7621 & 0,125 & 25 & & & 2 & & 0 & & & 1 & & 1 \\
\hline 7621 & 0,125 & 26 & & & 2 & & 0 & & & 1 & & 1 \\
\hline 7621 & 0,125 & 27 & & 1 & & & 0 & & & 1 & & 1 \\
\hline 7621 & 0,125 & 28 & 0 & & & & & 1 & & 1 & & 1 \\
\hline 7621 & 0,125 & 29 & 0 & & & & & 1 & & 1 & & 1 \\
\hline 7621 & 0,125 & 30 & 0 & & & & & 1 & & 1 & & 1 \\
\hline 7621 & 0,125 & 31 & 0 & & & & & 1 & & 1 & & 1 \\
\hline 7621 & 0,125 & 32 & 0 & & & & & 1 & & 1 & & 1 \\
\hline 7621 & 0,125 & 33 & 0 & & & & & 1 & & 1 & & 1 \\
\hline 7621 & 0,125 & 34 & 0 & & & & & 1 & & 1 & & 1 \\
\hline 7621 & 0,125 & 35 & 0 & & & & & 1 & & 1 & & 1 \\
\hline
\end{tabular}




\begin{tabular}{|c|c|c|c|c|c|c|c|c|c|c|c|c|}
\hline \multirow{4}{*}{$\begin{array}{c}\text { Estação } \\
\text { de coleta }\end{array}$} & \multirow{4}{*}{$\begin{array}{c}\text { Fração } \\
(\mathrm{mm})\end{array}$} & \multirow{4}{*}{ Eppendorf } & \multirow{2}{*}{\multicolumn{4}{|c|}{$\begin{array}{l}\text { Feições Físicas } \\
\text { Fragmentação }\end{array}$}} & \multicolumn{6}{|c|}{ Feições Químicas } \\
\hline & & & & & & & \multirow{3}{*}{ Mantida } & Cor & \multicolumn{2}{|c|}{ Brilho } & \multicolumn{2}{|c|}{ Corrosão } \\
\hline & & & \multirow{2}{*}{ Ausente } & \multicolumn{3}{|c|}{ Presente } & & Altorada & Mantida & Altarada & Aucento & Dresente \\
\hline & & & & $<10 \%$ & entre $10 \%$ e $50 \%$ & $>50 \%$ & & & & & & \\
\hline 7621 & 0,125 & 36 & 0 & & & & & 1 & & 1 & & 1 \\
\hline 7621 & 0,125 & 37 & 0 & & & & & 1 & & 1 & & 1 \\
\hline 7621 & 0,125 & 38 & 0 & & & & & 1 & & 1 & & 1 \\
\hline 7621 & 0,125 & 39 & 0 & & & & & 1 & & 1 & & 1 \\
\hline 7621 & 0,125 & 40 & 0 & & & & & 1 & & 1 & & 1 \\
\hline 7621 & 0,125 & 41 & 0 & & & & & 1 & & 1 & & 1 \\
\hline 7621 & 0,125 & 42 & 0 & & & & & 1 & & 1 & & 1 \\
\hline 7621 & 0,125 & 43 & 0 & & & & & 1 & & 1 & & 1 \\
\hline 7621 & 0,125 & 44 & 0 & & & & & 1 & & 1 & & 1 \\
\hline 7621 & 0,125 & 45 & 0 & & & & & 1 & & 1 & & 1 \\
\hline 7621 & 0,125 & 46 & 0 & & & & & 1 & & 1 & & 1 \\
\hline 7621 & 0,125 & 47 & 0 & & & & & 1 & & 1 & & 1 \\
\hline 7621 & 0,125 & 48 & 0 & & & & & 1 & & 1 & & 1 \\
\hline 7621 & 0,125 & 49 & 0 & & & & & 1 & & 1 & & 1 \\
\hline 7621 & 0,125 & 50 & 0 & & & & & 1 & & 1 & & 1 \\
\hline 7621 & 0,125 & 51 & 0 & & & & & 1 & & 1 & & 1 \\
\hline 7621 & 0,125 & 52 & 0 & & & & & 1 & & 1 & & 1 \\
\hline 7621 & 0,125 & 53 & 0 & & & & & 1 & & 1 & & 1 \\
\hline 7621 & 0,125 & 54 & 0 & & & & & 1 & & 1 & & 1 \\
\hline 7621 & 0,125 & 55 & 0 & & & & & 1 & & 1 & & 1 \\
\hline 7621 & 0,125 & 56 & & & 2 & & & 1 & & 1 & & 1 \\
\hline 7621 & 0,125 & 57 & & & 2 & & & 1 & & 1 & & 1 \\
\hline 7621 & 0,125 & 58 & & & 2 & & & 1 & & 1 & & 1 \\
\hline 7621 & 0,125 & 59 & 0 & & & & & 1 & & 1 & & 1 \\
\hline 7621 & 0,125 & 60 & 0 & & & & 0 & & 0 & & & 1 \\
\hline 7621 & 0,125 & 61 & & & & 3 & & 1 & & 1 & & 1 \\
\hline 7621 & 0,125 & 62 & 0 & & & & 0 & & & 1 & & 1 \\
\hline 7621 & 0,125 & 63 & 0 & & & & 0 & & & 1 & & 1 \\
\hline 7621 & 0,125 & 64 & 0 & & & & 0 & & & 1 & & 1 \\
\hline 7621 & 0,125 & 65 & 0 & & & & 0 & & & 1 & & 1 \\
\hline 7621 & 0,125 & 66 & 0 & & & & 0 & & & 1 & & 1 \\
\hline 7621 & 0,125 & 67 & 0 & & & & 0 & & & 1 & & 1 \\
\hline 7621 & 0,125 & 68 & 0 & & & & 0 & & & 1 & & 1 \\
\hline 7621 & 0,125 & 69 & 0 & & & & 0 & & & 1 & & 1 \\
\hline 7621 & 0,125 & 70 & 0 & & & & 0 & & & 1 & & 1 \\
\hline 7621 & 0,125 & 71 & 0 & & & & 0 & & & 1 & & 1 \\
\hline
\end{tabular}




\begin{tabular}{|c|c|c|c|c|c|c|c|c|c|c|c|c|}
\hline \multirow{4}{*}{$\begin{array}{c}\text { Estação } \\
\text { de coleta }\end{array}$} & \multirow{4}{*}{$\begin{array}{c}\text { Fração } \\
(\mathrm{mm})\end{array}$} & \multirow{4}{*}{ Eppendorf } & \multirow{2}{*}{\multicolumn{4}{|c|}{$\begin{array}{l}\text { Feições Físicas } \\
\text { Fragmentação }\end{array}$}} & \multicolumn{6}{|c|}{ Feições Químicas } \\
\hline & & & & & & & \multirow{3}{*}{ Mantida } & Cor & \multicolumn{2}{|c|}{ Brilho } & \multicolumn{2}{|c|}{ Corrosão } \\
\hline & & & \multirow{2}{*}{ Ausente } & \multicolumn{3}{|c|}{ Presente } & & Altorada & Mantida & Altarada & Aucento & Dresente \\
\hline & & & & $<10 \%$ & entre $10 \%$ e $50 \%$ & $>50 \%$ & & & & & & \\
\hline 7621 & 0,125 & 72 & 0 & & & & 0 & & & 1 & & 1 \\
\hline 7621 & 0,125 & 73 & 0 & & & & 0 & & & 1 & & 1 \\
\hline 7621 & 0,125 & 74 & 0 & & & & 0 & & 0 & & & 1 \\
\hline 7621 & 0,125 & 75 & 0 & & & & 0 & & 0 & & & 1 \\
\hline 7621 & 0,125 & 76 & 0 & & & & 0 & & 0 & & 0 & \\
\hline 7621 & 0,125 & 77 & & 1 & & & & 1 & & 1 & & 1 \\
\hline 7621 & 0,125 & 78 & & 1 & & & & 1 & & 1 & & 1 \\
\hline 7621 & 0,125 & 79 & 0 & & & & & 1 & & 1 & & 1 \\
\hline 7621 & 0,125 & 80 & 0 & & & & & 1 & & 1 & & 1 \\
\hline 7621 & 0,125 & 81 & 0 & & & & & 1 & & 1 & & 1 \\
\hline 7621 & 0,125 & 82 & 0 & & & & & 1 & & 1 & & 1 \\
\hline 7621 & 0,125 & 83 & 0 & & & & & 1 & & 1 & & 1 \\
\hline 7621 & 0,125 & 84 & 0 & & & & & 1 & & 1 & & 1 \\
\hline 7621 & 0,125 & 85 & 0 & & & & & 1 & & 1 & & 1 \\
\hline 7621 & 0,125 & 86 & 0 & & & & & 1 & & 1 & & 1 \\
\hline 7621 & 0,125 & 87 & 0 & & & & & 1 & & 1 & & 1 \\
\hline 7621 & 0,125 & 88 & 0 & & & & & 1 & & 1 & & 1 \\
\hline 7621 & 0,125 & 89 & 0 & & & & & 1 & & 1 & & 1 \\
\hline 7621 & 0,125 & 90 & 0 & & & & & 1 & & 1 & & 1 \\
\hline 7621 & 0,125 & 91 & 0 & & & & 0 & & & 1 & & 1 \\
\hline 7621 & 0,125 & 92 & & 1 & & & 0 & & & 1 & & 1 \\
\hline 7621 & 0,125 & 93 & & & 2 & & & 1 & & 1 & & 1 \\
\hline 7621 & 0,125 & 94 & & & 2 & & & 1 & & 1 & & 1 \\
\hline 7621 & 0,125 & 95 & & 1 & & & & 1 & & 1 & & 1 \\
\hline 7621 & 0,125 & 96 & & 1 & & & & 1 & & 1 & & 1 \\
\hline 7621 & 0,125 & 97 & & 1 & & & & 1 & & 1 & & 1 \\
\hline 7621 & 0,125 & 98 & & 1 & & & & 1 & & 1 & & 1 \\
\hline 7621 & 0,125 & 99 & & 1 & & & & 1 & & 1 & & 1 \\
\hline 7621 & 0,125 & 100 & & 1 & & & & 1 & & 1 & & 1 \\
\hline 7621 & 0,125 & 101 & & 1 & & & & 1 & & 1 & & 1 \\
\hline 7621 & 0,125 & 102 & 0 & & & & & 1 & & 1 & & 1 \\
\hline 7621 & 0,125 & 103 & 0 & & & & & 1 & & 1 & & 1 \\
\hline 7621 & 0,125 & 104 & 0 & & & & & 1 & & 1 & & 1 \\
\hline 7621 & 0,125 & 105 & 0 & & & & & 1 & & 1 & & 1 \\
\hline 7621 & 0,125 & 106 & 0 & & & & & 1 & & 1 & & 1 \\
\hline 7621 & 0,125 & 107 & 0 & & & & & 1 & & 1 & & 1 \\
\hline
\end{tabular}




\begin{tabular}{|c|c|c|c|c|c|c|c|c|c|c|c|c|}
\hline \multirow{4}{*}{$\begin{array}{c}\text { Estação } \\
\text { de coleta }\end{array}$} & \multirow{4}{*}{$\begin{array}{c}\text { Fração } \\
(\mathrm{mm})\end{array}$} & \multirow{4}{*}{ Eppendorf } & \multirow{2}{*}{\multicolumn{4}{|c|}{$\begin{array}{l}\text { Feições Físicas } \\
\text { Fragmentação }\end{array}$}} & \multicolumn{6}{|c|}{ Feições Químicas } \\
\hline & & & & & & & \multirow{3}{*}{ Mantida } & Cor & \multicolumn{2}{|c|}{ Brilho } & \multicolumn{2}{|c|}{ Corrosão } \\
\hline & & & \multirow{2}{*}{ Ausente } & \multicolumn{3}{|c|}{ Presente } & & Altorada & Mantida & Altarada & Auconto & Dresente \\
\hline & & & & $<10 \%$ & entre $10 \%$ e $50 \%$ & $>50 \%$ & & & & & & \\
\hline 7621 & 0,125 & 108 & 0 & & & & & 1 & & 1 & & 1 \\
\hline 7621 & 0,125 & 109 & 0 & & & & & 1 & & 1 & & 1 \\
\hline 7621 & 0,125 & 110 & 0 & & & & & 1 & & 1 & & 1 \\
\hline 7621 & 0,125 & 111 & 0 & & & & & 1 & & 1 & & 1 \\
\hline 7621 & 0,125 & 112 & 0 & & & & & 1 & & 1 & & 1 \\
\hline 7621 & 0,125 & 113 & 0 & & & & & 1 & & 1 & & 1 \\
\hline 7621 & 0,125 & 114 & 0 & & & & & 1 & & 1 & & 1 \\
\hline 7621 & 0,125 & 115 & 0 & & & & & 1 & & 1 & & 1 \\
\hline 7621 & 0,125 & 116 & 0 & & & & & 1 & & 1 & & 1 \\
\hline 7621 & 0,125 & 117 & 0 & & & & & 1 & & 1 & & 1 \\
\hline 7621 & 0,125 & 118 & 0 & & & & & 1 & & 1 & & 1 \\
\hline 7621 & 0,125 & 119 & 0 & & & & & 1 & & 1 & & 1 \\
\hline 7621 & 0,125 & 120 & 0 & & & & & 1 & & 1 & & 1 \\
\hline 7621 & 0,125 & 121 & 0 & & & & & 1 & & 1 & & 1 \\
\hline 7621 & 0,125 & 122 & 0 & & & & & 1 & & 1 & & 1 \\
\hline 7621 & 0,125 & 123 & & 1 & & & & 1 & & 1 & & 1 \\
\hline 7621 & 0,125 & 124 & & & 2 & & & 1 & & 1 & & 1 \\
\hline 7621 & 0,125 & 125 & & & 2 & & & 1 & & 1 & & 1 \\
\hline 7621 & 0,125 & 126 & & & 2 & & & 1 & & 1 & & 1 \\
\hline 7621 & 0,125 & 127 & & & 2 & & & 1 & & 1 & & 1 \\
\hline 7621 & 0,125 & 128 & 0 & & & & & 1 & & 1 & & 1 \\
\hline 7621 & 0,125 & 129 & 0 & & & & & 1 & & 1 & & 1 \\
\hline 7621 & 0,125 & 130 & 0 & & & & & 1 & & 1 & & 1 \\
\hline 7621 & 0,125 & 131 & 0 & & & & & 1 & & 1 & & 1 \\
\hline 7621 & 0,125 & 132 & 0 & & & & & 1 & & 1 & & 1 \\
\hline 7621 & 0,125 & 133 & 0 & & & & & 1 & & 1 & & 1 \\
\hline 7621 & 0,125 & 134 & 0 & & & & & 1 & & 1 & & 1 \\
\hline 7621 & 0,125 & 135 & 0 & & & & & 1 & & 1 & & 1 \\
\hline 7621 & 0,125 & 136 & 0 & & & & 0 & & 0 & & 0 & \\
\hline 7621 & 0,125 & 137 & 0 & & & & 0 & & 0 & & 0 & \\
\hline 7621 & 0,125 & 138 & 0 & & & & & 1 & & 1 & & 1 \\
\hline 7621 & 0,125 & 139 & 0 & & & & & 1 & & 1 & & 1 \\
\hline 7621 & 0,125 & 140 & 0 & & & & & 1 & & 1 & & 1 \\
\hline 7621 & 0,125 & 141 & 0 & & & & & 1 & & 1 & & 1 \\
\hline 7621 & 0,125 & 142 & 0 & & & & & 1 & & 1 & & 1 \\
\hline 7621 & 0,125 & 143 & 0 & & & & & 1 & & 1 & & 1 \\
\hline
\end{tabular}




\begin{tabular}{|c|c|c|c|c|c|c|c|c|c|c|c|c|}
\hline \multirow{4}{*}{$\begin{array}{c}\text { Estação } \\
\text { de coleta }\end{array}$} & \multirow{4}{*}{$\begin{array}{c}\text { Fração } \\
(\mathrm{mm})\end{array}$} & \multirow{4}{*}{ Eppendorf } & \multirow{2}{*}{\multicolumn{4}{|c|}{$\frac{\text { Feições Físicas }}{\text { Fragmentação }}$}} & \multicolumn{6}{|c|}{ Feições Químicas } \\
\hline & & & & & & & \multirow{3}{*}{ Mantida } & Cor & \multicolumn{2}{|c|}{ Brilho } & \multicolumn{2}{|c|}{ Corrosão } \\
\hline & & & \multirow{2}{*}{ Ausente } & \multicolumn{3}{|c|}{ Presente } & & & & & & \\
\hline & & & & $<10 \%$ & entre $10 \%$ e $50 \%$ & $>50 \%$ & & & & & & \\
\hline 7621 & 0,125 & 144 & 0 & & & & & 1 & & 1 & & 1 \\
\hline 7621 & 0,125 & 145 & 0 & & & & & 1 & & 1 & & 1 \\
\hline 7621 & 0,125 & 146 & 0 & & & & & 1 & & 1 & & 1 \\
\hline 7621 & 0,125 & 147 & 0 & & & & 0 & & & 1 & & 1 \\
\hline 7621 & 0,125 & 148 & 0 & & & & 0 & & & 1 & & 1 \\
\hline 7621 & 0,125 & 149 & & 1 & & & 0 & & 0 & & 0 & \\
\hline 7621 & 0,125 & 150 & 0 & & & & 0 & & & 1 & & 1 \\
\hline
\end{tabular}




\section{Protocolo Tafonômico - Estação de coleta 7622, fração 0,125 mm}

\begin{tabular}{|c|c|c|c|c|c|c|c|c|c|c|c|c|}
\hline \multirow{4}{*}{$\begin{array}{l}\text { Estação } \\
\text { de } \\
\text { Coleta }\end{array}$} & \multirow{4}{*}{$\begin{array}{c}\text { Fração } \\
(\mathrm{mm})\end{array}$} & \multirow{4}{*}{ Eppendorf } & \multirow{2}{*}{\multicolumn{4}{|c|}{$\begin{array}{l}\text { Feições Físicas } \\
\text { Fragmentação }\end{array}$}} & \multicolumn{6}{|c|}{ Feições Químicas } \\
\hline & & & & & & & \multirow{3}{*}{ Mantida } & Cor & \multicolumn{2}{|c|}{ Brilho } & \multicolumn{2}{|c|}{ Corrosão } \\
\hline & & & \multirow{2}{*}{ Ausente } & \multicolumn{3}{|c|}{ Presente } & & Altorodo & Montidla & Altarado & I A uconto & Drosont \\
\hline & & & & $<10 \%$ & entre $10 \%$ e $50 \%$ & $>50 \%$ & & & & & & \\
\hline 7622 & 0,125 & 1 & 0 & & & & & 1 & & 1 & & 1 \\
\hline 7622 & 0,125 & 2 & 0 & & & & & 1 & & 1 & & 1 \\
\hline 7622 & 0,125 & 3 & 0 & & & & & 1 & & 1 & & 1 \\
\hline 7622 & 0,125 & 4 & 0 & & & & & 1 & & 1 & & 1 \\
\hline 7622 & 0,125 & 5 & 0 & & & & & 1 & & 1 & & 1 \\
\hline 7622 & 0,125 & 6 & 0 & & & & & 1 & & 1 & & 1 \\
\hline 7622 & 0,125 & 7 & 0 & & & & & 1 & & 1 & & 1 \\
\hline 7622 & 0,125 & 8 & 0 & & & & & 1 & & 1 & & 1 \\
\hline 7622 & 0,125 & 9 & 0 & & & & & 1 & & 1 & & 1 \\
\hline 7622 & 0,125 & 10 & 0 & & & & & 1 & & 1 & & 1 \\
\hline 7622 & 0,125 & 11 & 0 & & & & & 1 & & 1 & & 1 \\
\hline 7622 & 0,125 & 12 & 0 & & & & & 1 & & 1 & & 1 \\
\hline 7622 & 0,125 & 13 & 0 & & & & & 1 & & 1 & & 1 \\
\hline 7622 & 0,125 & 14 & 0 & & & & & 1 & & 1 & & 1 \\
\hline 7622 & 0,125 & 15 & 0 & & & & & 1 & & 1 & & 1 \\
\hline 7622 & 0,125 & 16 & 0 & & & & & 1 & & 1 & & 1 \\
\hline 7622 & 0,125 & 17 & 0 & & & & & 1 & & 1 & & 1 \\
\hline 7622 & 0,125 & 18 & 0 & & & & & 1 & & 1 & & 1 \\
\hline 7622 & 0,125 & 19 & 0 & & & & & 1 & & 1 & & 1 \\
\hline 7622 & 0,125 & 20 & 0 & & & & & 1 & & 1 & & 1 \\
\hline 7622 & 0,125 & 21 & 0 & & & & & 1 & & 1 & & 1 \\
\hline 7622 & 0,125 & 22 & 0 & & & & & 1 & & 1 & & 1 \\
\hline 7622 & 0,125 & 23 & 0 & & & & & 1 & & 1 & & 1 \\
\hline 7622 & 0,125 & 24 & 0 & & & & & 1 & & 1 & & 1 \\
\hline 7622 & 0,125 & 25 & 0 & & & & & 1 & & 1 & & 1 \\
\hline 7622 & 0,125 & 26 & 0 & & & & & 1 & & 1 & & 1 \\
\hline 7622 & 0,125 & 27 & 0 & & & & & 1 & & 1 & & 1 \\
\hline 7622 & 0,125 & 28 & & 1 & & & & 1 & & 1 & & 1 \\
\hline 7622 & 0,125 & 29 & & 1 & & & & 1 & & 1 & & 1 \\
\hline 7622 & 0,125 & 30 & & 1 & & & & 1 & & 1 & & 1 \\
\hline 7622 & 0,125 & 31 & & 1 & & & & 1 & & 1 & & 1 \\
\hline 7622 & 0,125 & 32 & & 1 & & & & 1 & & 1 & & 1 \\
\hline 7622 & 0,125 & 33 & & 1 & & & & 1 & & 1 & & 1 \\
\hline 7622 & 0,125 & 34 & & 1 & & & & 1 & & 1 & & 1 \\
\hline 7622 & 0,125 & 35 & & 1 & & & & 1 & & 1 & & 1 \\
\hline
\end{tabular}




\begin{tabular}{|c|c|c|c|c|c|c|c|c|c|c|c|c|}
\hline \multirow{4}{*}{$\begin{array}{c}\text { Estação } \\
\text { de } \\
\text { Coleta }\end{array}$} & \multirow{4}{*}{$\begin{array}{c}\text { Fração } \\
(\mathrm{mm})\end{array}$} & \multirow{4}{*}{ Eppendorf } & \multirow{2}{*}{\multicolumn{4}{|c|}{$\begin{array}{c}\text { Feições Físicas } \\
\text { Fragmentação }\end{array}$}} & \multicolumn{6}{|c|}{ Feições Químicas } \\
\hline & & & & & & & \multirow{3}{*}{ Mantida } & Cor & \multicolumn{2}{|c|}{ Brilho } & \multicolumn{2}{|c|}{ Corrosão } \\
\hline & & & \multirow{2}{*}{ Ausente } & \multicolumn{3}{|c|}{ Presente } & & altorat & Mompis & I I & I & Ornos \\
\hline & & & & $<10 \%$ & entre $10 \%$ e $50 \%$ & $>50 \%$ & & & & & & \\
\hline 7622 & 0,125 & 36 & 0 & & & & 0 & & 0 & & 0 & \\
\hline 7622 & 0,125 & 37 & 0 & & & & 0 & & 0 & & 0 & \\
\hline 7622 & 0,125 & 38 & 0 & & & & 0 & & 0 & & 0 & \\
\hline 7622 & 0,125 & 39 & 0 & & & & 0 & & 0 & & 0 & \\
\hline 7622 & 0,125 & 40 & 0 & & & & 0 & & 0 & & 0 & \\
\hline 7622 & 0,125 & 41 & 0 & & & & 0 & & 0 & & 0 & \\
\hline 7622 & 0,125 & 42 & 0 & & & & 0 & & 0 & & 0 & \\
\hline 7622 & 0,125 & 43 & 0 & & & & & 1 & & 1 & & 1 \\
\hline 7622 & 0,125 & 44 & 0 & & & & & 1 & & 1 & & 1 \\
\hline 7622 & 0,125 & 45 & 0 & & & & & 1 & & 1 & & 1 \\
\hline 7622 & 0,125 & 46 & & 1 & & & & 1 & & 1 & & 1 \\
\hline 7622 & 0,125 & 47 & & 1 & & & & 1 & & 1 & & 1 \\
\hline 7622 & 0,125 & 48 & & 1 & & & & 1 & & 1 & & 1 \\
\hline 7622 & 0,125 & 49 & & 1 & & & & 1 & & 1 & & 1 \\
\hline 7622 & 0,125 & 50 & & 1 & & & & 1 & & 1 & & 1 \\
\hline 7622 & 0,125 & 51 & & 1 & & & & 1 & & 1 & & 1 \\
\hline 7622 & 0,125 & 52 & 0 & & & & & 1 & & 1 & & 1 \\
\hline 7622 & 0,125 & 53 & 0 & & & & & 1 & & 1 & & 1 \\
\hline 7622 & 0,125 & 54 & 0 & & & & & 1 & & 1 & & 1 \\
\hline 7622 & 0,125 & 55 & 0 & & & & & 1 & & 1 & & 1 \\
\hline 7622 & 0,125 & 56 & 0 & & & & & 1 & & 1 & & 1 \\
\hline 7622 & 0,125 & 57 & 0 & & & & & 1 & & 1 & & 1 \\
\hline 7622 & 0,125 & 58 & 0 & & & & 0 & & & 1 & & 1 \\
\hline 7622 & 0,125 & 59 & 0 & & & & 0 & & & 1 & & 1 \\
\hline 7622 & 0,125 & 60 & 0 & & & & 0 & & & 1 & & 1 \\
\hline 7622 & 0,125 & 61 & 0 & & & & & 1 & & 1 & & 1 \\
\hline 7622 & 0,125 & 62 & 0 & & & & & 1 & & 1 & & 1 \\
\hline 7622 & 0,125 & 63 & 0 & & & & & 1 & & 1 & & 1 \\
\hline 7622 & 0,125 & 64 & 0 & & & & & 1 & & 1 & & 1 \\
\hline 7622 & 0,125 & 65 & 0 & & & & & 1 & & 1 & & 1 \\
\hline 7622 & 0,125 & 66 & 0 & & & & & 1 & & 1 & & 1 \\
\hline 7622 & 0,125 & 67 & 0 & & & & & 1 & & 1 & & 1 \\
\hline 7622 & 0,125 & 68 & 0 & & & & & 1 & & 1 & & 1 \\
\hline 7622 & 0,125 & 69 & 0 & & & & & 1 & & 1 & & 1 \\
\hline 7622 & 0,125 & 70 & 0 & & & & & 1 & & 1 & & 1 \\
\hline 7622 & 0,125 & 71 & 0 & & & & & 1 & & 1 & & 1 \\
\hline
\end{tabular}




\begin{tabular}{|c|c|c|c|c|c|c|c|c|c|c|c|c|}
\hline \multirow{4}{*}{$\begin{array}{l}\text { Estação } \\
\text { de } \\
\text { Coleta }\end{array}$} & \multirow{4}{*}{$\begin{array}{c}\text { Fração } \\
(\mathbf{m m})\end{array}$} & \multirow{4}{*}{ Eppendorf } & \multirow{2}{*}{\multicolumn{4}{|c|}{$\begin{array}{c}\text { Feições Físicas } \\
\text { Fragmentação }\end{array}$}} & \multicolumn{6}{|c|}{ Feições Químicas } \\
\hline & & & & & & & \multirow{3}{*}{ Mantida } & Cor & \multicolumn{2}{|c|}{ Brilho } & \multicolumn{2}{|c|}{ Corrosão } \\
\hline & & & \multirow{2}{*}{ Ausente } & \multicolumn{3}{|c|}{ Presente } & & altorat & Mompis & I I & I & Ornos \\
\hline & & & & $<10 \%$ & entre $10 \%$ e $50 \%$ & $>50 \%$ & & & & & & \\
\hline 7622 & 0,125 & 72 & 0 & & & & & 1 & & 1 & & 1 \\
\hline 7622 & 0,125 & 73 & & & 2 & & & 1 & & 1 & & 1 \\
\hline 7622 & 0,125 & 74 & & & 2 & & & 1 & & 1 & & 1 \\
\hline 7622 & 0,125 & 75 & & & & 3 & & 1 & & 1 & & 1 \\
\hline 7622 & 0,125 & 76 & & & & 3 & & 1 & & 1 & & 1 \\
\hline 7622 & 0,125 & 77 & & & & 3 & & 1 & & 1 & & 1 \\
\hline 7622 & 0,125 & 78 & 0 & & & & & 1 & & 1 & & 1 \\
\hline 7622 & 0,125 & 79 & 0 & & & & & 1 & & 1 & & 1 \\
\hline 7622 & 0,125 & 80 & 0 & & & & & 1 & & 1 & & 1 \\
\hline 7622 & 0,125 & 81 & 0 & & & & & 1 & & 1 & & 1 \\
\hline 7622 & 0,125 & 82 & 0 & & & & & 1 & & 1 & & 1 \\
\hline 7622 & 0,125 & 83 & 0 & & & & & 1 & & 1 & & 1 \\
\hline 7622 & 0,125 & 84 & 0 & & & & & 1 & & 1 & & 1 \\
\hline 7622 & 0,125 & 85 & 0 & & & & & 1 & & 1 & & 1 \\
\hline 7622 & 0,125 & 86 & 0 & & & & & 1 & & 1 & & 1 \\
\hline 7622 & 0,125 & 87 & 0 & & & & & 1 & & 1 & & 1 \\
\hline 7622 & 0,125 & 88 & 0 & & & & 0 & & 0 & & 0 & \\
\hline 7622 & 0,125 & 89 & 0 & & & & 0 & & 0 & & 0 & \\
\hline 7622 & 0,125 & 90 & 0 & & & & 0 & & & 1 & & 1 \\
\hline 7622 & 0,125 & 91 & 0 & & & & 0 & & & 1 & & 1 \\
\hline 7622 & 0,125 & 92 & 0 & & & & 0 & & & 1 & & 1 \\
\hline 7622 & 0,125 & 93 & 0 & & & & & 1 & & 1 & & 1 \\
\hline 7622 & 0,125 & 94 & 0 & & & & & 1 & & 1 & & 1 \\
\hline 7622 & 0,125 & 95 & 0 & & & & & 1 & & 1 & & 1 \\
\hline 7622 & 0,125 & 96 & 0 & & & & & 1 & & 1 & & 1 \\
\hline 7622 & 0,125 & 97 & 0 & & & & & 1 & & 1 & & 1 \\
\hline 7622 & 0,125 & 98 & 0 & & & & & 1 & & 1 & & 1 \\
\hline 7622 & 0,125 & 99 & 0 & & & & & 1 & & 1 & & 1 \\
\hline 7622 & 0,125 & 100 & 0 & & & & & 1 & & 1 & & 1 \\
\hline 7622 & 0,125 & 101 & 0 & & & & & 1 & & 1 & & 1 \\
\hline 7622 & 0,125 & 102 & 0 & & & & & 1 & & 1 & & 1 \\
\hline 7622 & 0,125 & 103 & 0 & & & & & 1 & & 1 & & 1 \\
\hline 7622 & 0,125 & 104 & 0 & & & & & 1 & & 1 & & 1 \\
\hline 7622 & 0,125 & 105 & 0 & & & & & 1 & & 1 & & 1 \\
\hline 7622 & 0,125 & 106 & 0 & & & & & 1 & & 1 & & 1 \\
\hline 7622 & 0,125 & 107 & 0 & & & & & 1 & & 1 & & 1 \\
\hline
\end{tabular}




\begin{tabular}{|c|c|c|c|c|c|c|c|c|c|c|c|c|}
\hline \multirow{4}{*}{$\begin{array}{l}\text { Estação } \\
\text { de } \\
\text { Coleta }\end{array}$} & \multirow{4}{*}{$\begin{array}{c}\text { Fração } \\
(\mathrm{mm})\end{array}$} & \multirow{4}{*}{ Eppendorf } & \multirow{2}{*}{\multicolumn{4}{|c|}{$\begin{array}{c}\text { Feições Físicas } \\
\text { Fragmentação }\end{array}$}} & \multicolumn{6}{|c|}{ Feições Químicas } \\
\hline & & & & & & & \multirow{3}{*}{ Mantida } & Cor & \multicolumn{2}{|c|}{ Brilho } & \multicolumn{2}{|c|}{ Corrosão } \\
\hline & & & \multirow{2}{*}{ Ausente } & \multicolumn{3}{|c|}{ Presente } & & Oltor & Mompis & I I & I & Inotost \\
\hline & & & & $<10 \%$ & entre $10 \%$ e $50 \%$ & $>50 \%$ & & & & & & \\
\hline 7622 & 0,125 & 108 & 0 & & & & & 1 & & 1 & & 1 \\
\hline 7622 & 0,125 & 109 & 0 & & & & & 1 & & 1 & & 1 \\
\hline 7622 & 0,125 & 110 & 0 & & & & & 1 & & 1 & & 1 \\
\hline 7622 & 0,125 & 111 & 0 & & & & & 1 & & 1 & & 1 \\
\hline 7622 & 0,125 & 112 & 0 & & & & & 1 & & 1 & & 1 \\
\hline 7622 & 0,125 & 113 & 0 & & & & & 1 & & 1 & & 1 \\
\hline 7622 & 0,125 & 114 & 0 & & & & & 1 & & 1 & & 1 \\
\hline 7622 & 0,125 & 115 & 0 & & & & & 1 & & 1 & & 1 \\
\hline 7622 & 0,125 & 116 & 0 & & & & & 1 & & 1 & & 1 \\
\hline 7622 & 0,125 & 117 & 0 & & & & & 1 & & 1 & & 1 \\
\hline 7622 & 0,125 & 118 & & & 2 & & & 1 & & 1 & & 1 \\
\hline 7622 & 0,125 & 119 & 0 & & & & 0 & & 0 & & 0 & \\
\hline 7622 & 0,125 & 120 & 0 & & & & & 1 & & 1 & & 1 \\
\hline 7622 & 0,125 & 121 & 0 & & & & & 1 & & 1 & & 1 \\
\hline 7622 & 0,125 & 122 & 0 & & & & & 1 & & 1 & & 1 \\
\hline 7622 & 0,125 & 123 & 0 & & & & & 1 & & 1 & & 1 \\
\hline 7622 & 0,125 & 124 & 0 & & & & & 1 & & 1 & & 1 \\
\hline 7622 & 0,125 & 125 & 0 & & & & & 1 & & 1 & & 1 \\
\hline 7622 & 0,125 & 126 & 0 & & & & & 1 & & 1 & & 1 \\
\hline 7622 & 0,125 & 127 & 0 & & & & & 1 & & 1 & & 1 \\
\hline 7622 & 0,125 & 128 & 0 & & & & & 1 & & 1 & & 1 \\
\hline 7622 & 0,125 & 129 & 0 & & & & & 1 & & 1 & & 1 \\
\hline 7622 & 0,125 & 130 & 0 & & & & & 1 & & 1 & & 1 \\
\hline 7622 & 0,125 & 131 & 0 & & & & & 1 & & 1 & & 1 \\
\hline 7622 & 0,125 & 132 & 0 & & & & & 1 & & 1 & & 1 \\
\hline 7622 & 0,125 & 133 & 0 & & & & & 1 & & 1 & & 1 \\
\hline 7622 & 0,125 & 134 & 0 & & & & 0 & & 0 & & 0 & \\
\hline 7622 & 0,125 & 135 & 0 & & & & 0 & & 0 & & 0 & \\
\hline 7622 & 0,125 & 136 & 0 & & & & 0 & & 0 & & 0 & \\
\hline 7622 & 0,125 & 137 & 0 & & & & 0 & & 0 & & 0 & \\
\hline 7622 & 0,125 & 138 & & & 2 & & & 1 & & 1 & & 1 \\
\hline 7622 & 0,125 & 139 & & & 2 & & & 1 & & 1 & & 1 \\
\hline 7622 & 0,125 & 140 & & & 2 & & & 1 & & 1 & & 1 \\
\hline 7622 & 0,125 & 141 & & & 2 & & & 1 & & 1 & & 1 \\
\hline 7622 & 0,125 & 142 & & & 2 & & & 1 & & 1 & & 1 \\
\hline 7622 & 0,125 & 143 & 0 & & & & & 1 & & 1 & & 1 \\
\hline
\end{tabular}




\begin{tabular}{|c|c|c|c|c|c|c|c|c|c|c|c|c|}
\hline \multirow{4}{*}{$\begin{array}{c}\text { Estação } \\
\text { de } \\
\text { Coleta }\end{array}$} & \multirow{4}{*}{$\begin{array}{c}\text { Fração } \\
(\mathrm{mm})\end{array}$} & \multirow{4}{*}{ Eppendorf } & \multirow{2}{*}{\multicolumn{4}{|c|}{$\begin{array}{l}\text { Feições Físicas } \\
\text { Fragmentação }\end{array}$}} & \multicolumn{6}{|c|}{ Feições Químicas } \\
\hline & & & & & & & & or & Bri & Illho & Corr & rosão \\
\hline & & & \multirow{2}{*}{ Ausente } & \multicolumn{3}{|c|}{ Presente } & \multirow{2}{*}{ Mantida } & \multirow{2}{*}{ Alterada } & \multirow{2}{*}{ Mantida } & \multirow{2}{*}{ Alterada } & \multirow{2}{*}{ Ausente } & \multirow{2}{*}{ Presente } \\
\hline & & & & $<10 \%$ & entre $10 \%$ e $50 \%$ & $>50 \%$ & & & & & & \\
\hline 7622 & 0,125 & 144 & 0 & & & & & 1 & & 1 & & 1 \\
\hline 7622 & 0,125 & 145 & 0 & & & & & 1 & & 1 & & 1 \\
\hline 7622 & 0,125 & 146 & 0 & & & & & 1 & & 1 & & 1 \\
\hline 7622 & 0,125 & 147 & 0 & & & & & 1 & & 1 & & 1 \\
\hline 7622 & 0,125 & 148 & 0 & & & & & 1 & & 1 & & 1 \\
\hline 7622 & 0,125 & 149 & 0 & & & & & 1 & & 1 & & 1 \\
\hline 7622 & 0,125 & 150 & 0 & & & & & 1 & & 1 & & 1 \\
\hline
\end{tabular}




\section{Protocolo Tafonômico - Estação de coleta 7623, fração 0,125 mm}

\begin{tabular}{|c|c|c|c|c|c|c|c|c|c|c|c|c|}
\hline \multirow{4}{*}{$\begin{array}{c}\text { Estação } \\
\text { de } \\
\text { Coleta }\end{array}$} & \multirow{4}{*}{$\begin{array}{c}\text { Fração } \\
\text { (mm) }\end{array}$} & \multirow{4}{*}{ Eppendorf } & \multirow{2}{*}{\multicolumn{4}{|c|}{$\frac{\text { Feições Físicas }}{\text { Fragmentação }}$}} & \multicolumn{6}{|c|}{ Feições Químicas } \\
\hline & & & & & & & \multirow{3}{*}{ Mantida } & Cor & \multicolumn{2}{|c|}{ Brilho } & \multicolumn{2}{|c|}{ Corrosão } \\
\hline & & & \multirow{2}{*}{ Ausente } & \multicolumn{3}{|c|}{ Presente } & & Altarado & Mantida & Altarada & Aucente & Droconte \\
\hline & & & & $<10 \%$ & entre $10 \%$ e $50 \%$ & $>50 \%$ & & & & & & \\
\hline 7623 & 0,125 & 1 & 0 & & & & & 1 & & 1 & & 1 \\
\hline 7623 & 0,125 & 2 & 0 & & & & & 1 & & 1 & & 1 \\
\hline 7623 & 0,125 & 3 & 0 & & & & & 1 & & 1 & & 1 \\
\hline 7623 & 0,125 & 4 & 0 & & & & & 1 & & 1 & & 1 \\
\hline 7623 & 0,125 & 5 & 0 & & & & & 1 & & 1 & & 1 \\
\hline 7623 & 0,125 & 6 & 0 & & & & & 1 & & 1 & & 1 \\
\hline 7623 & 0,125 & 7 & 0 & & & & & 1 & & 1 & & 1 \\
\hline 7623 & 0,125 & 8 & 0 & & & & & 1 & & 1 & & 1 \\
\hline 7623 & 0,125 & 9 & 0 & & & & & 1 & & 1 & & 1 \\
\hline 7623 & 0,125 & 10 & 0 & & & & & 1 & & 1 & & 1 \\
\hline 7623 & 0,125 & 11 & 0 & & & & & 1 & & 1 & & 1 \\
\hline 7623 & 0,125 & 12 & 0 & & & & & 1 & & 1 & & 1 \\
\hline 7623 & 0,125 & 13 & 0 & & & & & 1 & & 1 & & 1 \\
\hline 7623 & 0,125 & 14 & 0 & & & & & 1 & & 1 & & 1 \\
\hline 7623 & 0,125 & 15 & 0 & & & & & 1 & & 1 & & 1 \\
\hline 7623 & 0,125 & 16 & 0 & & & & & 1 & & 1 & & 1 \\
\hline 7623 & 0,125 & 17 & 0 & & & & & 1 & & 1 & & 1 \\
\hline 7623 & 0,125 & 18 & 0 & & & & & 1 & & 1 & & 1 \\
\hline 7623 & 0,125 & 19 & 0 & & & & & 1 & & 1 & & 1 \\
\hline 7623 & 0,125 & 20 & 0 & & & & & 1 & & 1 & & 1 \\
\hline 7623 & 0,125 & 21 & 0 & & & & & 1 & & 1 & & 1 \\
\hline 7623 & 0,125 & 22 & 0 & & & & & 1 & & 1 & & 1 \\
\hline 7623 & 0,125 & 23 & 0 & & & & & 1 & & 1 & & 1 \\
\hline 7623 & 0,125 & 24 & 0 & & & & & 1 & & 1 & & 1 \\
\hline 7623 & 0,125 & 25 & 0 & & & & & 1 & & 1 & & 1 \\
\hline 7623 & 0,125 & 26 & 0 & & & & & 1 & & 1 & & 1 \\
\hline 7623 & 0,125 & 27 & 0 & & & & & 1 & & 1 & & 1 \\
\hline 7623 & 0,125 & 28 & 0 & & & & & 1 & & 1 & & 1 \\
\hline 7623 & 0,125 & 29 & 0 & & & & & 1 & & 1 & & 1 \\
\hline 7623 & 0,125 & 30 & 0 & & & & 0 & & & 1 & & 1 \\
\hline 7623 & 0,125 & 31 & 0 & & & & 0 & & & 1 & & 1 \\
\hline 7623 & 0,125 & 32 & 0 & & & & 0 & & & 1 & & 1 \\
\hline 7623 & 0,125 & 33 & 0 & & & & 0 & & & 1 & & 1 \\
\hline 7623 & 0,125 & 34 & 0 & & & & 0 & & & 1 & & 1 \\
\hline 7623 & 0,125 & 35 & 0 & & & & 0 & & & 1 & & 1 \\
\hline 7623 & 0,125 & 36 & 0 & & & & 0 & & & 1 & & 1 \\
\hline 7623 & 0,125 & 37 & 0 & & & & 0 & & & 1 & & 1 \\
\hline 7623 & 0,125 & 38 & 0 & & & & 0 & & & 1 & & 1 \\
\hline 7623 & 0,125 & 39 & 0 & & & & 0 & & & 1 & & 1 \\
\hline 7623 & 0,125 & 40 & 0 & & & & 0 & & & 1 & & 1 \\
\hline
\end{tabular}




\begin{tabular}{|c|c|c|c|c|c|c|c|c|c|c|c|c|}
\hline \multirow{4}{*}{$\begin{array}{c}\text { Estação } \\
\text { de } \\
\text { Coleta }\end{array}$} & \multirow{4}{*}{$\begin{array}{c}\text { Fração } \\
(\mathrm{mm})\end{array}$} & \multirow{4}{*}{ Eppendorf } & \multirow{2}{*}{\multicolumn{4}{|c|}{$\begin{array}{c}\text { Feições Físicas } \\
\text { Fragmentação }\end{array}$}} & \multicolumn{6}{|c|}{ Feições Químicas } \\
\hline & & & & & & & \multicolumn{2}{|c|}{ Cor } & \multicolumn{2}{|c|}{ Brilho } & \multicolumn{2}{|c|}{ Corrosão } \\
\hline & & & \multirow{2}{*}{ Ausente } & \multicolumn{3}{|c|}{ Presente } & \multirow{2}{*}{ Mantida } & \multirow{2}{*}{ Alterada } & \multirow{2}{*}{ Mantida } & \multirow{2}{*}{ Alterada } & \multirow{2}{*}{ Ausente } & \multirow{2}{*}{ Presente } \\
\hline & & & & $<10 \%$ & entre $10 \%$ e $50 \% \mid>$ & $>50 \%$ & & & & & & \\
\hline 7623 & 0,125 & 41 & & & 2 & & 0 & & & 1 & & 1 \\
\hline 7623 & 0,125 & 42 & & & 2 & & 0 & & & 1 & & 1 \\
\hline 7623 & 0,125 & 43 & & & 2 & & & 1 & & 1 & & 1 \\
\hline 7623 & 0,125 & 44 & & & 2 & & & 1 & & 1 & & 1 \\
\hline 7623 & 0,125 & 45 & & & 2 & & & 1 & & 1 & & 1 \\
\hline 7623 & 0,125 & 46 & & & 2 & & & 1 & & 1 & & 1 \\
\hline 7623 & 0,125 & 47 & & & 2 & & & 1 & & 1 & & 1 \\
\hline 7623 & 0,125 & 48 & & & 2 & & & 1 & & 1 & & 1 \\
\hline 7623 & 0,125 & 49 & & & & 3 & & 1 & & 1 & & 1 \\
\hline 7623 & 0,125 & 50 & & & & 3 & & 1 & & 1 & & 1 \\
\hline 7623 & 0,125 & 51 & & & & 3 & & 1 & & 1 & & 1 \\
\hline 7623 & 0,125 & 52 & & & & 3 & & 1 & & 1 & & 1 \\
\hline 7623 & 0,125 & 53 & & & & 3 & & 1 & & 1 & & 1 \\
\hline 7623 & 0,125 & 54 & & & & 3 & & 1 & & 1 & & 1 \\
\hline 7623 & 0,125 & 55 & & & & 3 & & 1 & & 1 & & 1 \\
\hline 7623 & 0,125 & 56 & & & & 3 & & 1 & & 1 & & 1 \\
\hline 7623 & 0,125 & 57 & 0 & & & & & 1 & & 1 & & 1 \\
\hline 7623 & 0,125 & 58 & 0 & & & & & 1 & & 1 & & 1 \\
\hline 7623 & 0,125 & 59 & 0 & & & & & 1 & & 1 & & 1 \\
\hline 7623 & 0,125 & 60 & 0 & & & & & 1 & & 1 & & 1 \\
\hline 7623 & 0,125 & 61 & 0 & & & & & 1 & & 1 & & 1 \\
\hline 7623 & 0,125 & 62 & 0 & & & & & 1 & & 1 & & 1 \\
\hline 7623 & 0,125 & 63 & 0 & & & & & 1 & & 1 & & 1 \\
\hline 7623 & 0,125 & 64 & 0 & & & & & 1 & & 1 & & 1 \\
\hline 7623 & 0,125 & 65 & 0 & & & & & 1 & & 1 & & 1 \\
\hline 7623 & 0,125 & 66 & 0 & & & & & 1 & & 1 & & 1 \\
\hline 7623 & 0,125 & 67 & 0 & & & & & 1 & & 1 & & 1 \\
\hline 7623 & 0,125 & 68 & 0 & & & & & 1 & & 1 & & 1 \\
\hline 7623 & 0,125 & 69 & 0 & & & & & 1 & & 1 & & 1 \\
\hline 7623 & 0,125 & 70 & 0 & & & & & 1 & & 1 & & 1 \\
\hline 7623 & 0,125 & 71 & 0 & & & & & 1 & & 1 & & 1 \\
\hline 7623 & 0,125 & 72 & 0 & & & & & 1 & & 1 & & 1 \\
\hline 7623 & 0,125 & 73 & 0 & & & & & 1 & & 1 & & 1 \\
\hline 7623 & 0,125 & 74 & 0 & & & & & 1 & & 1 & & 1 \\
\hline 7623 & 0,125 & 75 & 0 & & & & & 1 & & 1 & & 1 \\
\hline 7623 & 0,125 & 76 & & 1 & & & & 1 & & 1 & & 1 \\
\hline 7623 & 0,125 & 77 & & 1 & & & & 1 & & 1 & & 1 \\
\hline 7623 & 0,125 & 78 & & & & 3 & & 1 & & 1 & & 1 \\
\hline 7623 & 0,125 & 79 & & & & 3 & & 1 & & 1 & & 1 \\
\hline 7623 & 0,125 & 80 & & & & 3 & & 1 & & 1 & & 1 \\
\hline 7623 & 0,125 & 81 & & & & 3 & & 1 & & 1 & & 1 \\
\hline
\end{tabular}




\begin{tabular}{|c|c|c|c|c|c|c|c|c|c|c|c|c|}
\hline \multirow{4}{*}{$\begin{array}{c}\text { Estação } \\
\text { de } \\
\text { Coleta }\end{array}$} & \multirow{4}{*}{$\begin{array}{c}\text { Fração } \\
(\mathrm{mm})\end{array}$} & \multirow{4}{*}{ Eppendorf } & \multirow{2}{*}{\multicolumn{4}{|c|}{$\begin{array}{c}\text { Feições Físicas } \\
\text { Fragmentação }\end{array}$}} & \multicolumn{6}{|c|}{ Feições Químicas } \\
\hline & & & & & & & \multicolumn{2}{|c|}{ Cor } & \multicolumn{2}{|c|}{ Brilho } & \multicolumn{2}{|c|}{ Corrosão } \\
\hline & & & \multirow{2}{*}{ Ausente } & \multicolumn{3}{|c|}{ Presente } & \multirow{2}{*}{ Mantida } & \multirow{2}{*}{ Alterada } & \multirow{2}{*}{ Mantida } & \multirow{2}{*}{ Alterada } & \multirow{2}{*}{ Ausente } & \multirow{2}{*}{ Presente } \\
\hline & & & & $<10 \%$ & entre $10 \%$ e $50 \%$ & $>50 \%$ & & & & & & \\
\hline 7623 & 0,125 & 82 & & & & 3 & & 1 & & 1 & & 1 \\
\hline 7623 & 0,125 & 83 & & & 2 & & & 1 & & 1 & & 1 \\
\hline 7623 & 0,125 & 84 & 0 & & & & 0 & & & 1 & & 1 \\
\hline 7623 & 0,125 & 85 & 0 & & & & 0 & & & 1 & & 1 \\
\hline 7623 & 0,125 & 86 & 0 & & & & 0 & & & 1 & & 1 \\
\hline 7623 & 0,125 & 87 & 0 & & & & 0 & & & 1 & & 1 \\
\hline 7623 & 0,125 & 88 & 0 & & & & 0 & & & 1 & & 1 \\
\hline 7623 & 0,125 & 89 & 0 & & & & 0 & & & 1 & & 1 \\
\hline 7623 & 0,125 & 90 & 0 & & & & & 1 & & 1 & & 1 \\
\hline 7623 & 0,125 & 91 & 0 & & & & & 1 & & 1 & & 1 \\
\hline 7623 & 0,125 & 92 & 0 & & & & & 1 & & 1 & & 1 \\
\hline 7623 & 0,125 & 93 & 0 & & & & & 1 & & 1 & & 1 \\
\hline 7623 & 0,125 & 94 & 0 & & & & & 1 & & 1 & & 1 \\
\hline 7623 & 0,125 & 95 & 0 & & & & & 1 & & 1 & & 1 \\
\hline 7623 & 0,125 & 96 & 0 & & & & & 1 & & 1 & & 1 \\
\hline 7623 & 0,125 & 97 & 0 & & & & 0 & & 0 & & 0 & \\
\hline 7623 & 0,125 & 98 & 0 & & & & 0 & & 0 & & 0 & \\
\hline 7623 & 0,125 & 99 & 0 & & & & 0 & & 0 & & 0 & \\
\hline 7623 & 0,125 & 100 & 0 & & & & & 1 & & 1 & & 1 \\
\hline 7623 & 0,125 & 101 & 0 & & & & & 1 & & 1 & & 1 \\
\hline 7623 & 0,125 & 102 & 0 & & & & & 1 & & 1 & & 1 \\
\hline 7623 & 0,125 & 103 & 0 & & & & & 1 & & 1 & & 1 \\
\hline 7623 & 0,125 & 104 & 0 & & & & & 1 & & 1 & & 1 \\
\hline 7623 & 0,125 & 105 & 0 & & & & & 1 & & 1 & & 1 \\
\hline 7623 & 0,125 & 106 & 0 & & & & & 1 & & 1 & & 1 \\
\hline 7623 & 0,125 & 107 & 0 & & & & & 1 & & 1 & & 1 \\
\hline 7623 & 0,125 & 108 & 0 & & & & & 1 & & 1 & & 1 \\
\hline 7623 & 0,125 & 109 & & & 2 & & & 1 & & 1 & & 1 \\
\hline 7623 & 0,125 & 110 & & & 2 & & & 1 & & 1 & & 1 \\
\hline 7623 & 0,125 & 111 & & & 2 & & & 1 & & 1 & & 1 \\
\hline 7623 & 0,125 & 112 & 0 & & & & & 1 & & 1 & & 1 \\
\hline 7623 & 0,125 & 113 & 0 & & & & & 1 & & 1 & & 1 \\
\hline 7623 & 0,125 & 114 & 0 & & & & & 1 & & 1 & & 1 \\
\hline 7623 & 0,125 & 115 & 0 & & & & & 1 & & 1 & & 1 \\
\hline 7623 & 0,125 & 116 & 0 & & & & 0 & & & 1 & & 1 \\
\hline 7623 & 0,125 & 117 & 0 & & & & 0 & & & 1 & & 1 \\
\hline 7623 & 0,125 & 118 & 0 & & & & 0 & & & 1 & & 1 \\
\hline 7623 & 0,125 & 119 & 0 & & & & 0 & & & 1 & & 1 \\
\hline 7623 & 0,125 & 120 & 0 & & & & 0 & & & 1 & & 1 \\
\hline 7623 & 0,125 & 121 & 0 & & & & 0 & & 0 & & 0 & \\
\hline 7623 & 0,125 & 122 & 0 & & & & 0 & & & 1 & & 1 \\
\hline
\end{tabular}




\begin{tabular}{|c|c|c|c|c|c|c|c|c|c|c|c|c|}
\hline \multirow{4}{*}{$\begin{array}{c}\text { Estação } \\
\text { de } \\
\text { Coleta }\end{array}$} & \multirow{4}{*}{$\begin{array}{c}\text { Fração } \\
(\mathbf{m m})\end{array}$} & \multirow{4}{*}{ Eppendorf } & \multirow{2}{*}{\multicolumn{4}{|c|}{$\begin{array}{c}\text { Feições Físicas } \\
\text { Fragmentação }\end{array}$}} & \multicolumn{6}{|c|}{ Feições Químicas } \\
\hline & & & & & & & \multicolumn{2}{|c|}{ Cor } & \multicolumn{2}{|c|}{ Brilho } & \multicolumn{2}{|c|}{ Corrosão } \\
\hline & & & \multirow{2}{*}{ Ausente } & \multicolumn{3}{|c|}{ Presente } & \multirow{2}{*}{ Mantida } & \multirow{2}{*}{ Alterada } & \multirow{2}{*}{ Mantida } & \multirow{2}{*}{ Alterada } & \multirow{2}{*}{ Ausente } & \multirow{2}{*}{ Presente } \\
\hline & & & & $<10 \%$ & entre $10 \%$ e $50 \%$ & $>50 \%$ & & & & & & \\
\hline 7623 & 0,125 & 123 & 0 & & & & 0 & & & 1 & & 1 \\
\hline 7623 & 0,125 & 124 & 0 & & & & 0 & & & 1 & & 1 \\
\hline 7623 & 0,125 & 125 & 0 & & & & 0 & & & 1 & & 1 \\
\hline 7623 & 0,125 & 126 & 0 & & & & 0 & & & 1 & & 1 \\
\hline 7623 & 0,125 & 127 & 0 & & & & & 1 & & 1 & & 1 \\
\hline 7623 & 0,125 & 128 & 0 & & & & & 1 & & 1 & & 1 \\
\hline 7623 & 0,125 & 129 & 0 & & & & & 1 & & 1 & & 1 \\
\hline 7623 & 0,125 & 130 & 0 & & & & & 1 & & 1 & & 1 \\
\hline 7623 & 0,125 & 131 & 0 & & & & & 1 & & 1 & & 1 \\
\hline 7623 & 0,125 & 132 & 0 & & & & & 1 & & 1 & & 1 \\
\hline 7623 & 0,125 & 133 & & & 2 & & & 1 & & 1 & & 1 \\
\hline 7623 & 0,125 & 134 & & & 2 & & & 1 & & 1 & & 1 \\
\hline 7623 & 0,125 & 135 & & & 2 & & & 1 & & 1 & & 1 \\
\hline 7623 & 0,125 & 136 & 0 & & & & 0 & & 0 & & 0 & \\
\hline 7623 & 0,125 & 137 & 0 & & & & & 1 & & 1 & & 1 \\
\hline 7623 & 0,125 & 138 & 0 & & & & & 1 & & 1 & & 1 \\
\hline 7623 & 0,125 & 139 & 0 & & & & & 1 & & 1 & & 1 \\
\hline 7623 & 0,125 & 140 & 0 & & & & & 1 & & 1 & & 1 \\
\hline 7623 & 0,125 & 141 & 0 & & & & & 1 & & 1 & & 1 \\
\hline 7623 & 0,125 & 142 & 0 & & & & & 1 & & 1 & & 1 \\
\hline 7623 & 0,125 & 143 & 0 & & & & & 1 & & 1 & & 1 \\
\hline 7623 & 0,125 & 144 & 0 & & & & & 1 & & 1 & & 1 \\
\hline 7623 & 0,125 & 145 & 0 & & & & & 1 & & 1 & & 1 \\
\hline 7623 & 0,125 & 146 & 0 & & & & & 1 & & 1 & & 1 \\
\hline 7623 & 0,125 & 147 & & & & 3 & & 1 & & 1 & & 1 \\
\hline 7623 & 0,125 & 148 & & & & 3 & & 1 & & 1 & & 1 \\
\hline 7623 & 0,125 & 149 & & & & 3 & & 1 & & 1 & & 1 \\
\hline 7623 & 0,125 & 150 & & & & 3 & & 1 & & 1 & & 1 \\
\hline
\end{tabular}




\section{Protocolo Tafonômico - Estação de coleta 7365, fração 0,250 mm}

\begin{tabular}{|c|c|c|c|c|c|c|c|c|c|c|c|c|}
\hline \multirow{4}{*}{$\begin{array}{c}\text { Estação } \\
\text { de } \\
\text { Coleta }\end{array}$} & \multirow{4}{*}{$\begin{array}{c}\text { Fração } \\
(\mathrm{mm})\end{array}$} & \multirow{4}{*}{ Eppendorf } & \multirow{2}{*}{\multicolumn{4}{|c|}{$\begin{array}{c}\text { Feições Físicas } \\
\text { Fragmentação }\end{array}$}} & \multicolumn{6}{|c|}{ Feições Químicas } \\
\hline & & & & & & & \multicolumn{2}{|c|}{ Cor } & \multicolumn{2}{|c|}{ Brilho } & \multicolumn{2}{|c|}{ Corrosão } \\
\hline & & & \multirow{2}{*}{ Ausente } & \multicolumn{3}{|c|}{ Presente } & \multirow{2}{*}{ Mantida } & \multirow{2}{*}{ Alterada } & \multirow{2}{*}{ Mantido } & \multirow{2}{*}{ Alterado } & \multirow{2}{*}{ Ausente } & \multirow{2}{*}{ Presente } \\
\hline & & & & $<10 \%$ & entre $10 \%$ e $50 \%$ & $>5 \%$ & & & & & & \\
\hline 7365 & 0,250 & 1 & 0 & & & & 0 & & 0 & & 0 & \\
\hline 7365 & 0,250 & 2 & 0 & & & & 0 & & 0 & & 0 & \\
\hline 7365 & 0,250 & 3 & 0 & & & & & 1 & & 1 & & 1 \\
\hline 7365 & 0,250 & 4 & & & 2 & & 0 & & 0 & & & 1 \\
\hline 7365 & 0,250 & 5 & 0 & & & & 0 & & 0 & & & 1 \\
\hline 7365 & 0,250 & 6 & 0 & & & & & 1 & 0 & & & 1 \\
\hline 7365 & 0,250 & 7 & 0 & & & & & 1 & & 1 & 0 & \\
\hline 7365 & 0,250 & 8 & 0 & & & & 0 & & 0 & & & 1 \\
\hline 7365 & 0,250 & 9 & 0 & & & & 0 & & 0 & & 0 & \\
\hline 7365 & 0,250 & 10 & 0 & & & & & 1 & & 1 & & 1 \\
\hline 7365 & 0,250 & 11 & 0 & & & & & 1 & & 1 & & 1 \\
\hline 7365 & 0,250 & 12 & 0 & & & & & 1 & & 1 & & 1 \\
\hline 7365 & 0,250 & 13 & 0 & & & & 0 & & & 1 & 0 & \\
\hline 7365 & 0,250 & 14 & & & 2 & & 0 & & 0 & & & 1 \\
\hline 7365 & 0,250 & 15 & 0 & & & & 0 & & 0 & & & 1 \\
\hline 7365 & 0,250 & 16 & & & & 3 & 0 & & 0 & & & 1 \\
\hline 7365 & 0,250 & 17 & 0 & & & & 0 & & & 1 & & 1 \\
\hline 7365 & 0,250 & 18 & 0 & & & & 0 & & 0 & & 0 & \\
\hline 7365 & 0,250 & 19 & 0 & & & & 0 & & 0 & & 0 & \\
\hline 7365 & 0,250 & 20 & 0 & & & & 0 & & 0 & & 0 & \\
\hline 7365 & 0,250 & 21 & & & 2 & & 0 & & & 1 & & 1 \\
\hline 7365 & 0,250 & 22 & 0 & & & & 0 & & & 1 & & 1 \\
\hline 7365 & 0,250 & 23 & 0 & & & & & 1 & & 1 & & 1 \\
\hline 7365 & 0,250 & 24 & & & & 3 & 0 & & & 1 & & 1 \\
\hline 7365 & 0,250 & 25 & 0 & & & & & 1 & & 1 & & 1 \\
\hline 7365 & 0,250 & 26 & 0 & & & & & 1 & & 1 & & 1 \\
\hline 7365 & 0,250 & 27 & 0 & & & & & 1 & & 1 & & 1 \\
\hline 7365 & 0,250 & 28 & 0 & & & & 0 & & & 1 & & 1 \\
\hline 7365 & 0,250 & 29 & & & & 3 & & 1 & & 1 & & 1 \\
\hline 7365 & 0,250 & 30 & 0 & & & & 0 & & 0 & & 0 & \\
\hline 7365 & 0,250 & 31 & & & & 3 & & 1 & & 1 & & 1 \\
\hline 7365 & 0,250 & 32 & 0 & & & & & 1 & 0 & & 0 & \\
\hline 7365 & 0,250 & 33 & 0 & & & & 0 & & & 1 & & 1 \\
\hline 7365 & 0,250 & 34 & & & 2 & & 0 & & & 1 & & 1 \\
\hline 7365 & 0,250 & 35 & & & & 3 & 0 & & & 1 & & 1 \\
\hline 7365 & 0,250 & 36 & & & 2 & & & 1 & & 1 & & 1 \\
\hline 7365 & 0,250 & 37 & 0 & & & & 0 & & & 1 & & 1 \\
\hline 7365 & 0,250 & 38 & 0 & & & & & 1 & & 1 & & 1 \\
\hline 7365 & 0,250 & 39 & 0 & & & & 0 & & 0 & & 0 & \\
\hline 7365 & 0,250 & 40 & 0 & & & & 0 & & 0 & & 0 & \\
\hline 7365 & 0,250 & 41 & & 1 & & & 0 & & & 1 & & 1 \\
\hline 7365 & 0,250 & 42 & & & 2 & & 0 & & & 1 & & 1 \\
\hline 7365 & 0,250 & 43 & 0 & & & & & 1 & & 1 & & 1 \\
\hline 7365 & 0,250 & 44 & & & 2 & & 0 & & 0 & & 0 & \\
\hline 7365 & 0,250 & 45 & 0 & & & & 0 & & 0 & & & 1 \\
\hline 7365 & 0,250 & 46 & & & & 3 & 0 & & & 1 & & 1 \\
\hline
\end{tabular}




\begin{tabular}{|c|c|c|c|c|c|c|c|c|c|c|c|c|}
\hline \multirow{4}{*}{$\begin{array}{l}\text { Estação } \\
\text { de } \\
\text { Coleta }\end{array}$} & \multirow{4}{*}{$\begin{array}{c}\text { Fração } \\
(\mathrm{mm})\end{array}$} & \multirow{4}{*}{ Eppendorf } & \multirow{2}{*}{\multicolumn{4}{|c|}{$\begin{array}{c}\text { Feições Físicas } \\
\text { Fragmentação }\end{array}$}} & \multicolumn{6}{|c|}{ Feições Químicas } \\
\hline & & & & & & & \multicolumn{2}{|c|}{ Cor } & \multicolumn{2}{|c|}{ Brilho } & \multicolumn{2}{|c|}{ Corrosão } \\
\hline & & & \multirow{2}{*}{ Ausente } & \multicolumn{3}{|c|}{ Presente } & \multirow{2}{*}{ Mantida } & \multirow{2}{*}{ Alterada } & \multirow{2}{*}{ Mantido } & \multirow{2}{*}{ Alterado } & \multirow{2}{*}{ Ausente } & \multirow{2}{*}{ Presente } \\
\hline & & & & $<10 \%$ & entre $10 \%$ e $50 \%$ & $>5 \%$ & & & & & & \\
\hline 7365 & 0,250 & 47 & 0 & & & & 0 & & & 1 & & 1 \\
\hline 7365 & 0,250 & 48 & & & 2 & & & 1 & & 1 & & 1 \\
\hline 7365 & 0,250 & 49 & 0 & & & & 0 & & 0 & & 0 & \\
\hline 7365 & 0,250 & 50 & & 1 & & & 0 & & 0 & & 0 & \\
\hline 7365 & 0,250 & 51 & 0 & & & & & 1 & 0 & & & 1 \\
\hline 7365 & 0,250 & 52 & 0 & & & & 0 & & 0 & & 0 & \\
\hline 7365 & 0,250 & 53 & 0 & & & & & 1 & & 1 & & 1 \\
\hline 7365 & 0,250 & 54 & 0 & & & & 0 & & & 1 & & 1 \\
\hline 7365 & 0,250 & 55 & 0 & & & & 0 & & 0 & & & 1 \\
\hline 7365 & 0,250 & 56 & & & & 3 & 0 & & & 1 & 0 & \\
\hline 7365 & 0,250 & 57 & 0 & & & & 0 & & & 1 & 0 & \\
\hline 7365 & 0,250 & 58 & 0 & & & & 0 & & 0 & & 0 & \\
\hline 7365 & 0,250 & 59 & 0 & & & & 0 & & 0 & & 0 & \\
\hline 7365 & 0,250 & 60 & 0 & & & & 0 & & 0 & & & 1 \\
\hline 7365 & 0,250 & 61 & 0 & & & & 0 & & 0 & & 0 & \\
\hline 7365 & 0,250 & 62 & 0 & & & & & 1 & & 1 & 0 & \\
\hline 7365 & 0,250 & 63 & & & 2 & & 0 & & & 1 & & 1 \\
\hline 7365 & 0,250 & 64 & 0 & & & & 0 & & & 1 & & 1 \\
\hline 7365 & 0,250 & 65 & 0 & & & & & 1 & & 1 & 0 & \\
\hline 7365 & 0,250 & 66 & & 1 & & & 0 & & 0 & & 0 & \\
\hline 7365 & 0,250 & 67 & & 1 & & & 0 & & 0 & & & 1 \\
\hline 7365 & 0,250 & 68 & & 1 & & & 0 & & 0 & & 0 & \\
\hline 7365 & 0,250 & 69 & & 1 & & & & 1 & & 1 & & 1 \\
\hline 7365 & 0,250 & 70 & 0 & & & & 0 & & & 1 & & 1 \\
\hline 7365 & 0,250 & 71 & 0 & & & & 0 & & & 1 & 0 & \\
\hline 7365 & 0,250 & 72 & & & 2 & & 0 & & & 1 & & 1 \\
\hline 7365 & 0,250 & 73 & & & 2 & & & 1 & & 1 & & 1 \\
\hline 7365 & 0,250 & 74 & 0 & & & & 0 & & & 1 & & 1 \\
\hline 7365 & 0,250 & 75 & 0 & & & & 0 & & 0 & & 0 & \\
\hline 7365 & 0,250 & 76 & 0 & & & & 0 & & 0 & & & 1 \\
\hline 7365 & 0,250 & 77 & & 1 & & & 0 & & 0 & & & 1 \\
\hline 7365 & 0,250 & 78 & 0 & & & & 0 & & 0 & & 0 & \\
\hline 7365 & 0,250 & 79 & 0 & & & & 0 & & & 1 & 0 & \\
\hline 7365 & 0,250 & 80 & 0 & & & & 0 & & & 1 & 0 & \\
\hline 7365 & 0,250 & 81 & & & & 3 & & 1 & & 1 & & 1 \\
\hline 7365 & 0,250 & 82 & 0 & & & & 0 & & 0 & & 0 & \\
\hline 7365 & 0,250 & 83 & & & & 3 & 0 & & & 1 & & 1 \\
\hline 7365 & 0,250 & 84 & 0 & & & & 0 & & 0 & & 0 & \\
\hline 7365 & 0,250 & 85 & 0 & & & & 0 & & & 1 & 0 & \\
\hline 7365 & 0,250 & 86 & & & 2 & & 0 & & 0 & & & 1 \\
\hline 7365 & 0,250 & 87 & 0 & & & & 0 & & & 1 & & 1 \\
\hline 7365 & 0,250 & 88 & & & 2 & & & 1 & & 1 & 0 & \\
\hline 7365 & 0,250 & 89 & & 1 & & & 0 & & & 1 & & 1 \\
\hline 7365 & 0,250 & 90 & 0 & & & & 0 & & & 1 & & 1 \\
\hline 7365 & 0,250 & 91 & 0 & & & & 0 & & & 1 & 0 & \\
\hline 7365 & 0,250 & 92 & 0 & & & & 0 & & 0 & & 0 & \\
\hline 7365 & 0,250 & 93 & 0 & & & & & 1 & & 1 & 0 & \\
\hline 7365 & 0,250 & 94 & & 1 & & & 0 & & & 1 & 0 & \\
\hline
\end{tabular}




\begin{tabular}{|c|c|c|c|c|c|c|c|c|c|c|c|c|}
\hline \multirow{4}{*}{$\begin{array}{l}\text { Estação } \\
\text { de } \\
\text { Coleta }\end{array}$} & \multirow{4}{*}{$\begin{array}{c}\text { Fração } \\
(\mathrm{mm})\end{array}$} & \multirow{4}{*}{ Eppendorf } & \multirow{2}{*}{\multicolumn{4}{|c|}{$\begin{array}{c}\text { Feições Físicas } \\
\text { Fragmentação }\end{array}$}} & \multicolumn{6}{|c|}{ Feições Químicas } \\
\hline & & & & & & & \multicolumn{2}{|c|}{ Cor } & \multicolumn{2}{|c|}{ Brilho } & \multicolumn{2}{|c|}{ Corrosão } \\
\hline & & & \multirow{2}{*}{ Ausente } & \multicolumn{3}{|c|}{ Presente } & \multirow{2}{*}{ Mantida } & \multirow{2}{*}{ Alterada } & \multirow{2}{*}{ Mantido } & \multirow{2}{*}{ Alterado } & \multirow{2}{*}{ Ausente } & \multirow{2}{*}{ Presente } \\
\hline & & & & $<10 \%$ & entre $10 \%$ e $50 \%$ & $>5 \%$ & & & & & & \\
\hline 7365 & 0,250 & 95 & 0 & & & & & 1 & 0 & & 0 & \\
\hline 7365 & 0,250 & 96 & 0 & & & & 0 & & 0 & & 0 & \\
\hline 7365 & 0,250 & 97 & 0 & & & & 0 & & & 1 & 0 & \\
\hline 7365 & 0,250 & 98 & 0 & & & & 0 & & 0 & & 0 & \\
\hline 7365 & 0,250 & 99 & 0 & & & & 0 & & & 1 & & 1 \\
\hline 7365 & 0,250 & 100 & 0 & & & & 0 & & & 1 & & 1 \\
\hline 7365 & 0,250 & 101 & 0 & & & & & 1 & 0 & & 0 & \\
\hline 7365 & 0,250 & 102 & 0 & & & & 0 & & & 1 & & 1 \\
\hline 7365 & 0,250 & 103 & 0 & & & & 0 & & 0 & & 0 & \\
\hline 7365 & 0,250 & 104 & 0 & & & & 0 & & 0 & & 0 & \\
\hline 7365 & 0,250 & 105 & 0 & & & & 0 & & 0 & & 0 & \\
\hline 7365 & 0,250 & 106 & & & 2 & & 0 & & & 1 & & 1 \\
\hline 7365 & 0,250 & 107 & 0 & & & & 0 & & 0 & & 0 & \\
\hline 7365 & 0,250 & 108 & 0 & & & & 0 & & & 1 & & 1 \\
\hline 7365 & 0,250 & 109 & 0 & & & & & 1 & & 1 & & 1 \\
\hline 7365 & 0,250 & 110 & 0 & & & & 0 & & 0 & & 0 & \\
\hline 7365 & 0,250 & 111 & & 1 & & & 0 & & & 1 & & 1 \\
\hline 7365 & 0,250 & 112 & & & & 3 & & 1 & & 1 & & 1 \\
\hline 7365 & 0,250 & 113 & 0 & & & & 0 & & & 1 & 0 & \\
\hline 7365 & 0,250 & 114 & 0 & & & & 0 & & & 1 & 0 & \\
\hline 7365 & 0,250 & 115 & & & & 3 & 0 & & 0 & & & 1 \\
\hline 7365 & 0,250 & 116 & 0 & & & & 0 & & & 1 & & 1 \\
\hline 7365 & 0,250 & 117 & 0 & & & & 0 & & & 1 & & 1 \\
\hline 7365 & 0,250 & 118 & 0 & & & & 0 & & & 1 & 0 & \\
\hline 7365 & 0,250 & 119 & & 1 & & & 0 & & & 1 & & 1 \\
\hline 7365 & 0,250 & 120 & 0 & & & & 0 & & & 1 & 0 & \\
\hline 7365 & 0,250 & 121 & 0 & & & & & 1 & & 1 & 0 & \\
\hline 7365 & 0,250 & 122 & 0 & & & & 0 & & & 1 & & 1 \\
\hline 7365 & 0,250 & 123 & 0 & & & & 0 & & & 1 & & 1 \\
\hline 7365 & 0,250 & 124 & 0 & & & & 0 & & & 1 & & 1 \\
\hline 7365 & 0,250 & 125 & 0 & & & & 0 & & 0 & & 0 & \\
\hline 7365 & 0,250 & 126 & 0 & & & & 0 & & & 1 & & 1 \\
\hline 7365 & 0,250 & 127 & & 1 & & & 0 & & 0 & & & 1 \\
\hline 7365 & 0,250 & 128 & & & 2 & & 0 & & & 1 & & 1 \\
\hline 7365 & 0,250 & 129 & & 1 & & & 0 & & 0 & & 0 & \\
\hline 7365 & 0,250 & 130 & & 1 & & & 0 & & 0 & & 0 & \\
\hline 7365 & 0,250 & 131 & 0 & & & & 0 & & & 1 & & 1 \\
\hline 7365 & 0,250 & 132 & 0 & & & & 0 & & 0 & & & 1 \\
\hline 7365 & 0,250 & 133 & 0 & & & & 0 & & 0 & & 0 & \\
\hline 7365 & 0,250 & 134 & 0 & & & & 0 & & 0 & & 0 & \\
\hline 7365 & 0,250 & 135 & 0 & & & & 0 & & 0 & & 0 & \\
\hline 7365 & 0,250 & 136 & 0 & & & & 0 & & 0 & & & 1 \\
\hline 7365 & 0,250 & 137 & 0 & & & & 0 & & & 1 & & 1 \\
\hline 7365 & 0,250 & 138 & 0 & & & & 0 & & & 1 & & 1 \\
\hline 7365 & 0,250 & 139 & 0 & & & & 0 & & & 1 & & 1 \\
\hline 7365 & 0,250 & 140 & 0 & & & & 0 & & & 1 & & 1 \\
\hline 7365 & 0,250 & 141 & 0 & & & & 0 & & & 1 & 0 & \\
\hline 7365 & 0,250 & 142 & 0 & & & & 0 & & 0 & & 0 & \\
\hline
\end{tabular}




\begin{tabular}{|c|c|c|c|c|c|c|c|c|c|c|c|c|}
\hline \multirow{4}{*}{$\begin{array}{c}\text { Estação } \\
\text { de } \\
\text { Coleta }\end{array}$} & \multirow{4}{*}{$\begin{array}{c}\text { Fração } \\
(\mathrm{mm})\end{array}$} & \multirow{4}{*}{ Eppendorf } & \multirow{2}{*}{\multicolumn{4}{|c|}{$\begin{array}{c}\text { Feições Físicas } \\
\text { Fragmentação }\end{array}$}} & \multicolumn{6}{|c|}{ Feições Químicas } \\
\hline & & & & & & & \multicolumn{2}{|c|}{ Cor } & \multicolumn{2}{|c|}{ Brilho } & \multicolumn{2}{|c|}{ Corrosão } \\
\hline & & & \multirow{2}{*}{ Ausente } & \multicolumn{3}{|c|}{ Presente } & \multirow{2}{*}{ Mantida } & \multirow{2}{*}{ Alterada } & \multirow{2}{*}{ Mantido } & \multirow{2}{*}{ Alterado } & \multirow{2}{*}{ Ausente } & \multirow{2}{*}{ Presente } \\
\hline & & & & $<10 \%$ & entre $10 \%$ e $50 \%$ & $>5 \%$ & & & & & & \\
\hline 7365 & 0,250 & 143 & 0 & & & & 0 & & 0 & & 0 & \\
\hline 7365 & 0,250 & 144 & 0 & & & & 0 & & 0 & & & 1 \\
\hline 7365 & 0,250 & 145 & 0 & & & & 0 & & 0 & & & 1 \\
\hline 7365 & 0,250 & 146 & & & & 3 & 0 & & & 1 & & 1 \\
\hline 7365 & 0,250 & 147 & 0 & & & & 0 & & & 1 & & 1 \\
\hline 7365 & 0,250 & 148 & 0 & & & & 0 & & & 1 & 0 & \\
\hline 7365 & 0,250 & 149 & 0 & & & & 0 & & & 1 & & 1 \\
\hline 7365 & 0,250 & 150 & 0 & & & & & 1 & & 1 & & 1 \\
\hline
\end{tabular}




\section{Protocolo Tafonômico - Estação de coleta 7618, fração 0,250 mm}

\begin{tabular}{|c|c|c|c|c|c|c|c|c|c|c|c|c|}
\hline \multirow{4}{*}{$\begin{array}{c}\text { Estação } \\
\text { de } \\
\text { coleta }\end{array}$} & \multirow{4}{*}{$\begin{array}{c}\text { Fração } \\
(\mathrm{mm})\end{array}$} & \multirow{4}{*}{ Eppendorf } & \multirow{2}{*}{\multicolumn{4}{|c|}{$\begin{array}{l}\text { Feições Físicas } \\
\text { Fragmentação }\end{array}$}} & \multicolumn{6}{|c|}{ Feições Químicas } \\
\hline & & & & & & & \multirow{3}{*}{ Mantida } & Cor & \multicolumn{2}{|c|}{ Brilho } & \multicolumn{2}{|c|}{ Corrosão } \\
\hline & & & \multirow{2}{*}{ Ausente } & \multicolumn{3}{|c|}{ Presente } & & Alterada & Mantido & Alterado & Aucente & Precente \\
\hline & & & & $<10 \%$ & entre 10 e $50 \%$ & $>50 \%$ & & & & & & T. \\
\hline 7618 & 0,250 & 1 & 0 & & & & 0 & & & 1 & & 1 \\
\hline 7618 & 0,250 & 2 & 0 & & & & 0 & & 0 & & 0 & \\
\hline 7618 & 0,250 & 3 & 0 & & & & & 1 & & 1 & & 1 \\
\hline 7618 & 0,250 & 4 & 0 & & & & 0 & & & 1 & & 1 \\
\hline 7618 & 0,250 & 5 & & & & 3 & & 1 & & 1 & & 1 \\
\hline 7618 & 0,250 & 6 & 0 & & & & & 1 & & 1 & & 1 \\
\hline 7618 & 0,250 & 7 & 0 & & & & & 1 & & 1 & & 1 \\
\hline 7618 & 0,250 & 8 & & & & 3 & & 1 & & 1 & & 1 \\
\hline 7618 & 0,250 & 9 & 0 & & & & 0 & & & 1 & & 1 \\
\hline 7618 & 0,250 & 10 & 0 & & & & 0 & & & 1 & & 1 \\
\hline 7618 & 0,250 & 11 & 0 & & & & & 1 & & 1 & & 1 \\
\hline 7618 & 0,250 & 12 & 0 & & & & & 1 & & 1 & & 1 \\
\hline 7618 & 0,250 & 13 & & & & 3 & 0 & & 0 & & 0 & \\
\hline 7618 & 0,250 & 14 & 0 & & & & 0 & & 0 & & 0 & \\
\hline 7618 & 0,250 & 15 & 0 & & & & & 1 & & 1 & 0 & \\
\hline 7618 & 0,250 & 16 & 0 & & & & & 1 & & 1 & & 1 \\
\hline 7618 & 0,250 & 17 & 0 & & & & & 1 & & 1 & & 1 \\
\hline 7618 & 0,250 & 18 & & & 2 & & & 1 & & 1 & & 1 \\
\hline 7618 & 0,250 & 19 & 0 & & & & 0 & & & 1 & & 1 \\
\hline 7618 & 0,250 & 20 & 0 & & & & 0 & & & 1 & & 1 \\
\hline 7618 & 0,250 & 21 & & & & 3 & & 1 & & 1 & & 1 \\
\hline 7618 & 0,250 & 22 & & & 2 & & 0 & & 0 & & 0 & \\
\hline 7618 & 0,250 & 23 & 0 & & & & & 1 & & 1 & & 1 \\
\hline 7618 & 0,250 & 24 & & & 2 & & & 1 & & 1 & & 1 \\
\hline 7618 & 0,250 & 25 & 0 & & & & & 1 & & 1 & & 1 \\
\hline 7618 & 0,250 & 26 & 0 & & & & 0 & & 0 & & 0 & \\
\hline 7618 & 0,250 & 27 & & 1 & & & 0 & & & 1 & & 1 \\
\hline 7618 & 0,250 & 28 & 0 & & & & 0 & & 0 & & 0 & \\
\hline 7618 & 0,250 & 29 & 0 & & & & 0 & & 0 & & 0 & \\
\hline 7618 & 0,250 & 30 & & & & 3 & & 1 & & 1 & & 1 \\
\hline 7618 & 0,250 & 31 & 0 & & & & 0 & & 0 & & 0 & \\
\hline 7618 & 0,250 & 32 & 0 & & & & & 1 & & 1 & & 1 \\
\hline 7618 & 0,250 & 33 & & 1 & & & & 1 & & 1 & & 1 \\
\hline 7618 & 0,250 & 34 & & 1 & & & & 1 & & 1 & & 1 \\
\hline 7618 & 0,250 & 35 & 0 & & & & & 1 & & 1 & & 1 \\
\hline 7618 & 0,250 & 36 & 0 & & & & & 1 & & 1 & & 1 \\
\hline 7618 & 0,250 & 37 & 0 & & & & & 1 & & 1 & & 1 \\
\hline 7618 & 0,250 & 38 & 0 & & & & 0 & & & 1 & & 1 \\
\hline 7618 & 0,250 & 39 & 0 & & & & 0 & & & 1 & & 1 \\
\hline 7618 & 0,250 & 40 & 0 & & & & 0 & & & 1 & & 1 \\
\hline
\end{tabular}




\begin{tabular}{|c|c|c|c|c|c|c|c|c|c|c|c|c|}
\hline \multirow{4}{*}{$\begin{array}{c}\text { Estação } \\
\text { de } \\
\text { coleta }\end{array}$} & \multirow{4}{*}{$\begin{array}{c}\text { Fração } \\
(\mathrm{mm})\end{array}$} & \multirow{4}{*}{ Eppendorf } & \multirow{2}{*}{\multicolumn{4}{|c|}{$\begin{array}{l}\text { Feições Físicas } \\
\text { Fragmentação }\end{array}$}} & \multicolumn{6}{|c|}{ Feições Químicas } \\
\hline & & & & & & & \multicolumn{2}{|c|}{ Cor } & \multicolumn{2}{|c|}{ Brilho } & \multicolumn{2}{|c|}{ Corrosão } \\
\hline & & & \multirow{2}{*}{ Ausente } & \multicolumn{3}{|c|}{ Presente } & \multirow{2}{*}{ Mantida } & \multirow{2}{*}{ Alterada } & \multirow{2}{*}{ Mantido } & \multirow{2}{*}{ Alterado } & \multirow{2}{*}{ Ausente } & \multirow{2}{*}{ Presente } \\
\hline & & & & $<10 \%$ & entre 10 e $50 \% \mid$ & $>50 \%$ & & & & & & \\
\hline 7618 & 0,250 & 41 & 0 & & & & 0 & & & 1 & & 1 \\
\hline 7618 & 0,250 & 42 & & 1 & & & 0 & & & 1 & & 1 \\
\hline 7618 & 0,250 & 43 & & & & 3 & 0 & & & 1 & & 1 \\
\hline 7618 & 0,250 & 44 & 0 & & & & 0 & & & 1 & & 1 \\
\hline 7618 & 0,250 & 45 & & 1 & & & 0 & & & 1 & & 1 \\
\hline 7618 & 0,250 & 46 & & & & & & & & & & \\
\hline 7618 & 0,250 & 47 & & & & & & & & & & \\
\hline 7618 & 0,250 & 48 & 0 & & & & & 1 & & 1 & & 1 \\
\hline 7618 & 0,250 & 49 & 0 & & & & & 1 & & 1 & & 1 \\
\hline 7618 & 0,250 & 50 & & & & & & & & & & \\
\hline 7618 & 0,250 & 51 & & & 2 & & & 1 & & 1 & & 1 \\
\hline 7618 & 0,250 & 52 & 0 & & & & 0 & & 0 & & 0 & \\
\hline 7618 & 0,250 & 53 & 0 & & & & 0 & & 0 & & 0 & \\
\hline 7618 & 0,250 & 54 & 0 & & & & & 1 & & 1 & & 1 \\
\hline 7618 & 0,250 & 55 & 0 & & & & & 1 & & 1 & & 1 \\
\hline 7618 & 0,250 & 56 & 0 & & & & 0 & & & 1 & & 1 \\
\hline 7618 & 0,250 & 57 & & 1 & & & & 1 & & 1 & & 1 \\
\hline 7618 & 0,250 & 58 & & & 2 & & & 1 & & 1 & & 1 \\
\hline 7618 & 0,250 & 59 & & 1 & & & 0 & & & 1 & & 1 \\
\hline 7618 & 0,250 & 60 & & & & 3 & & 1 & & 1 & & 1 \\
\hline 7618 & 0,250 & 61 & 0 & & & & 0 & & & 1 & & 1 \\
\hline 7618 & 0,250 & 62 & & & 2 & & 0 & & & 1 & & 1 \\
\hline 7618 & 0,250 & 63 & 0 & & & & 0 & & & 1 & & 1 \\
\hline 7618 & 0,250 & 64 & 0 & & & & 0 & & & 1 & & 1 \\
\hline 7618 & 0,250 & 65 & 0 & & & & 0 & & & 1 & & 1 \\
\hline 7618 & 0,250 & 66 & 0 & & & & & 1 & & 1 & & 1 \\
\hline 7618 & 0,250 & 67 & & 1 & & & & 1 & & 1 & & 1 \\
\hline 7618 & 0,250 & 68 & & & & 3 & & 1 & & 1 & & 1 \\
\hline 7618 & 0,250 & 69 & & & 2 & & & 1 & & 1 & & 1 \\
\hline 7618 & 0,250 & 70 & & 1 & & & 0 & & & 1 & & 1 \\
\hline 7618 & 0,250 & 71 & & & 2 & & & 1 & & 1 & & 1 \\
\hline 7618 & 0,250 & 72 & 0 & & & & & 1 & & 1 & & 1 \\
\hline 7618 & 0,250 & 73 & 0 & & & & & 1 & & 1 & & 1 \\
\hline 7618 & 0,250 & 74 & 0 & & & & & 1 & & 1 & & 1 \\
\hline 7618 & 0,250 & 75 & & 1 & & & 0 & & 0 & & 0 & \\
\hline 7618 & 0,250 & 76 & 0 & & & & & 1 & & 1 & & 1 \\
\hline 7618 & 0,250 & 77 & 0 & & & & 0 & & 0 & & 0 & \\
\hline 7618 & 0,250 & 78 & 0 & & & & & 1 & & 1 & & 1 \\
\hline 7618 & 0,250 & 79 & & & 2 & & & 1 & & 1 & & 1 \\
\hline 7618 & 0,250 & 80 & 0 & & & & & 1 & & 1 & & 1 \\
\hline 7618 & 0,250 & 81 & 0 & & & & & 1 & & 1 & & 1 \\
\hline
\end{tabular}




\begin{tabular}{|c|c|c|c|c|c|c|c|c|c|c|c|c|}
\hline \multirow{4}{*}{$\begin{array}{c}\text { Estação } \\
\text { de } \\
\text { coleta }\end{array}$} & \multirow{4}{*}{$\begin{array}{c}\text { Fração } \\
(\mathrm{mm})\end{array}$} & \multirow{4}{*}{ Eppendorf } & \multirow{2}{*}{\multicolumn{4}{|c|}{$\begin{array}{l}\text { Feições Físicas } \\
\text { Fragmentação }\end{array}$}} & \multicolumn{6}{|c|}{ Feições Químicas } \\
\hline & & & & & & & \multicolumn{2}{|c|}{ Cor } & \multicolumn{2}{|c|}{ Brilho } & \multicolumn{2}{|c|}{ Corrosão } \\
\hline & & & \multirow{2}{*}{ Ausente } & \multicolumn{3}{|c|}{ Presente } & \multirow{2}{*}{ Mantida } & \multirow{2}{*}{ Alterada } & \multirow{2}{*}{ Mantido } & \multirow{2}{*}{ Alterado } & \multirow{2}{*}{ Ausente } & \multirow{2}{*}{ Presente } \\
\hline & & & & $<10 \%$ & entre 10 e $50 \%$ & $>50 \%$ & & & & & & \\
\hline 7618 & 0,250 & 82 & 0 & & & & & 1 & & 1 & & 1 \\
\hline 7618 & 0,250 & 83 & & & 2 & & & 1 & & 1 & & 1 \\
\hline 7618 & 0,250 & 84 & & 1 & & & & 1 & & 1 & & 1 \\
\hline 7618 & 0,250 & 85 & 0 & & & & & 1 & & 1 & & 1 \\
\hline 7618 & 0,250 & 86 & 0 & & & & & 1 & & 1 & & 1 \\
\hline 7618 & 0,250 & 87 & 0 & & & & 0 & & & 1 & & 1 \\
\hline 7618 & 0,250 & 88 & 0 & & & & & 1 & & 1 & & 1 \\
\hline 7618 & 0,250 & 89 & 0 & & & & & 1 & & 1 & & 1 \\
\hline 7618 & 0,250 & 90 & 0 & & & & & 1 & & 1 & & 1 \\
\hline 7618 & 0,250 & 91 & 0 & & & & & 1 & & 1 & & 1 \\
\hline 7618 & 0,250 & 92 & 0 & & & & & 1 & & 1 & & 1 \\
\hline 7618 & 0,250 & 93 & 0 & & & & 0 & & 0 & & 0 & \\
\hline 7618 & 0,250 & 94 & 0 & & & & 0 & & 0 & & & 1 \\
\hline 7618 & 0,250 & 95 & 0 & & & & & 1 & & 1 & & 1 \\
\hline 7618 & 0,250 & 96 & 0 & & & & 0 & & 0 & & 0 & \\
\hline 7618 & 0,250 & 97 & 0 & & & & & 1 & & 1 & & 1 \\
\hline 7618 & 0,250 & 98 & 0 & & & & 0 & & & 1 & & 1 \\
\hline 7618 & 0,250 & 99 & & 1 & & & 0 & & 0 & & 0 & \\
\hline 7618 & 0,250 & 100 & 0 & & & & 0 & & & 1 & & 1 \\
\hline 7618 & 0,250 & 101 & 0 & & & & 0 & & & 1 & & 1 \\
\hline 7618 & 0,250 & 102 & 0 & & & & 0 & & 0 & & 0 & \\
\hline 7618 & 0,250 & 103 & & & 2 & & & 1 & & 1 & & 1 \\
\hline 7618 & 0,250 & 104 & 0 & & & & 0 & & & 1 & 0 & \\
\hline 7618 & 0,250 & 105 & 0 & & & & & 1 & & 1 & & 1 \\
\hline 7618 & 0,250 & 106 & 0 & & & & 0 & & & 1 & & 1 \\
\hline 7618 & 0,250 & 107 & & & & 3 & & 1 & & 1 & & 1 \\
\hline 7618 & 0,250 & 108 & 0 & & & & 0 & & & 1 & & 1 \\
\hline 7618 & 0,250 & 109 & 0 & & & & & 1 & & 1 & & 1 \\
\hline 7618 & 0,250 & 110 & & 1 & & & & 1 & & 1 & & 1 \\
\hline 7618 & 0,250 & 111 & & & 2 & & & 1 & & 1 & & 1 \\
\hline 7618 & 0,250 & 112 & 0 & & & & & 1 & & 1 & & 1 \\
\hline 7618 & 0,250 & 113 & 0 & & & & 0 & & 0 & & 0 & \\
\hline 7618 & 0,250 & 114 & 0 & & & & & 1 & & 1 & & 1 \\
\hline 7618 & 0,250 & 115 & 0 & & & & 0 & & 0 & & 0 & \\
\hline 7618 & 0,250 & 116 & 0 & & & & & 1 & & 1 & & 1 \\
\hline 7618 & 0,250 & 117 & 0 & & & & 0 & & & 1 & & 1 \\
\hline 7618 & 0,250 & 118 & 0 & & & & 0 & & 0 & & 0 & \\
\hline 7618 & 0,250 & 119 & 0 & & & & & 1 & & 1 & & 1 \\
\hline 7618 & 0,250 & 120 & 0 & & & & & 1 & & 1 & & 1 \\
\hline 7618 & 0,250 & 121 & 0 & & & & 0 & & 0 & & 0 & \\
\hline 7618 & 0,250 & 122 & 0 & & & & 0 & & & 1 & 0 & \\
\hline
\end{tabular}




\begin{tabular}{|c|c|c|c|c|c|c|c|c|c|c|c|c|}
\hline \multirow{4}{*}{$\begin{array}{l}\text { Estação } \\
\text { de } \\
\text { coleta }\end{array}$} & \multirow{4}{*}{$\begin{array}{c}\text { Fração } \\
(\mathrm{mm})\end{array}$} & \multirow{4}{*}{ Eppendorf } & \multirow{2}{*}{\multicolumn{4}{|c|}{$\begin{array}{c}\text { Feições Físicas } \\
\text { Fragmentação }\end{array}$}} & \multicolumn{6}{|c|}{ Feições Químicas } \\
\hline & & & & & & & \multicolumn{2}{|c|}{ Cor } & \multicolumn{2}{|c|}{ Brilho } & \multicolumn{2}{|c|}{ Corrosão } \\
\hline & & & \multirow{2}{*}{ Ausente } & \multicolumn{3}{|c|}{ Presente } & \multirow{2}{*}{ Mantida } & \multirow{2}{*}{ Alterada } & \multirow{2}{*}{ Mantido } & \multirow{2}{*}{ Alterado } & \multirow{2}{*}{ Ausente } & \multirow{2}{*}{ Presente } \\
\hline & & & & $<10 \%$ & entre 10 e $50 \%$ & $>50 \%$ & & & & & & \\
\hline 7618 & 0,250 & 123 & 0 & & & & 0 & & 0 & & 0 & \\
\hline 7618 & 0,250 & 124 & 0 & & & & 0 & & 0 & & 0 & \\
\hline 7618 & 0,250 & 125 & & 1 & & & & 1 & & 1 & & 1 \\
\hline 7618 & 0,250 & 126 & 0 & & & & 0 & & 0 & & 0 & \\
\hline 7618 & 0,250 & 127 & 0 & & & & & 1 & & 1 & & 1 \\
\hline 7618 & 0,250 & 128 & 0 & & & & & 1 & & 1 & & 1 \\
\hline 7618 & 0,250 & 129 & 0 & & & & 0 & & & 1 & & 1 \\
\hline 7618 & 0,250 & 130 & & & 2 & & & 1 & & 1 & & 1 \\
\hline 7618 & 0,250 & 131 & 0 & & & & & 1 & & 1 & & 1 \\
\hline 7618 & 0,250 & 132 & 0 & & & & & 1 & 0 & & 0 & \\
\hline 7618 & 0,250 & 133 & & & 2 & & & 1 & & 1 & & 1 \\
\hline 7618 & 0,250 & 134 & & & & 3 & 0 & & 0 & & 0 & \\
\hline 7618 & 0,250 & 135 & 0 & & & & 0 & & & 1 & & 1 \\
\hline 7618 & 0,250 & 136 & 0 & & & & 0 & & 0 & & 0 & \\
\hline 7618 & 0,250 & 137 & & 1 & & & 0 & & & 1 & & 1 \\
\hline 7618 & 0,250 & 138 & 0 & & & & 0 & & 0 & & 0 & \\
\hline 7618 & 0,250 & 139 & & 1 & & & 0 & & & 1 & & 1 \\
\hline 7618 & 0,250 & 140 & 0 & & & & 0 & & & 1 & 0 & \\
\hline 7618 & 0,250 & 141 & & 1 & & & & 1 & & 1 & & 1 \\
\hline 7618 & 0,250 & 142 & & & 2 & & & 1 & & 1 & & 1 \\
\hline 7618 & 0,250 & 143 & 0 & & & & 0 & & 0 & & 0 & \\
\hline 7618 & 0,250 & 144 & 0 & & & & & 1 & & 1 & & 1 \\
\hline 7618 & 0,250 & 145 & & 1 & & & & 1 & & 1 & & 1 \\
\hline 7618 & 0,250 & 146 & & & & 3 & 0 & & 0 & & 0 & \\
\hline 7618 & 0,250 & 147 & 0 & & & & 0 & & & 1 & & 1 \\
\hline 7618 & 0,250 & 148 & 0 & & & & & 1 & & 1 & & 1 \\
\hline 7618 & 0,250 & 149 & 0 & & & & 0 & & 0 & & 0 & \\
\hline 7618 & 0,250 & 150 & & & 2 & & & 1 & & 1 & & 1 \\
\hline
\end{tabular}




\section{Protocolo Tafonômico - Estação de coleta 7619, fração 0,250 mm}

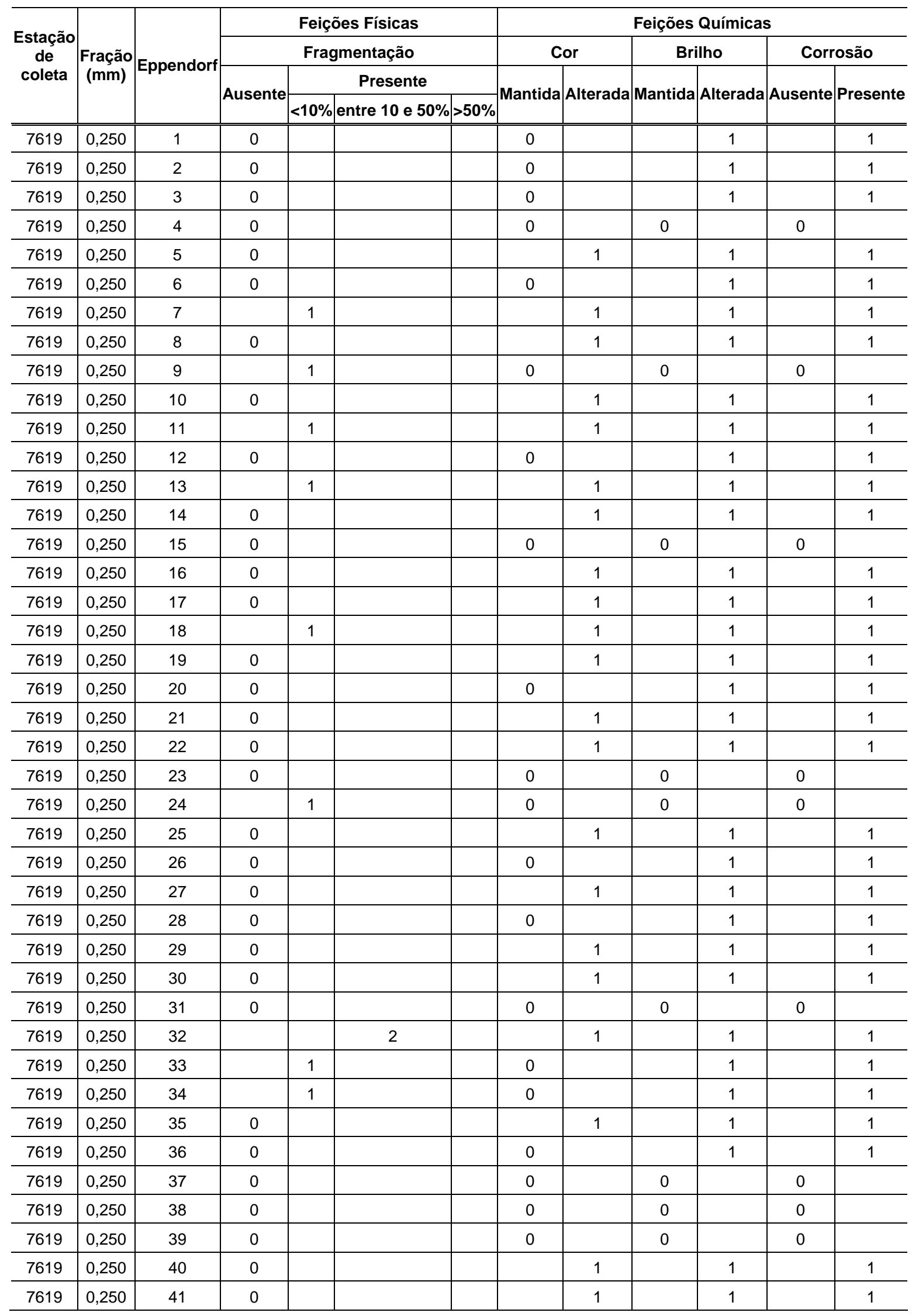




\begin{tabular}{|c|c|c|c|c|c|c|c|c|c|c|c|c|}
\hline \multirow{4}{*}{$\begin{array}{c}\text { Estação } \\
\text { de } \\
\text { coleta }\end{array}$} & \multirow{4}{*}{$\begin{array}{l}\text { Fração } \\
\text { (mm) }\end{array}$} & \multirow{4}{*}{ Eppendorf } & \multirow{2}{*}{\multicolumn{4}{|c|}{$\begin{array}{c}\text { Feições Físicas } \\
\text { Fragmentação }\end{array}$}} & \multicolumn{6}{|c|}{ Feições Químicas } \\
\hline & & & & & & & \multicolumn{2}{|c|}{ Cor } & \multicolumn{2}{|c|}{ Brilho } & \multicolumn{2}{|c|}{ Corrosão } \\
\hline & & & \multirow{2}{*}{ Ausente } & \multicolumn{3}{|c|}{ Presente } & \multirow{2}{*}{ Mantida } & \multirow{2}{*}{ Alterada } & \multirow{2}{*}{ Mantida } & \multirow{2}{*}{ Alterada } & \multirow{2}{*}{ Ausente } & \multirow{2}{*}{ Presente } \\
\hline & & & & $<10 \%$ & entre 10 e $50 \%$ & $>50 \%$ & & & & & & \\
\hline 7619 & 0,250 & 42 & & & 2 & & 0 & & & 1 & & 1 \\
\hline 7619 & 0,250 & 43 & 0 & & & & 0 & & & 1 & & 1 \\
\hline 7619 & 0,250 & 44 & 0 & & & & & 1 & & 1 & & 1 \\
\hline 7619 & 0,250 & 45 & 0 & & & & 0 & & 0 & & 0 & \\
\hline 7619 & 0,250 & 46 & 0 & & & & 0 & & 0 & & 0 & \\
\hline 7619 & 0,250 & 47 & & 1 & & & & 1 & & 1 & & 1 \\
\hline 7619 & 0,250 & 48 & 0 & & & & & 1 & & 1 & & 1 \\
\hline 7619 & 0,250 & 49 & 0 & & & & 0 & & & 1 & & 1 \\
\hline 7619 & 0,250 & 50 & 0 & & & & & 1 & & 1 & & 1 \\
\hline 7619 & 0,250 & 51 & 0 & & & & & 1 & & 1 & & 1 \\
\hline 7619 & 0,250 & 52 & 0 & & & & & 1 & & 1 & & 1 \\
\hline 7619 & 0,250 & 53 & 0 & & & & 0 & & 0 & & 0 & \\
\hline 7619 & 0,250 & 54 & 0 & & & & & 1 & & 1 & & 1 \\
\hline 7619 & 0,250 & 55 & 0 & & & & 0 & & & 1 & & 1 \\
\hline 7619 & 0,250 & 56 & 0 & & & & 0 & & & 1 & & 1 \\
\hline 7619 & 0,250 & 57 & 0 & & & & & 1 & & 1 & & 1 \\
\hline 7619 & 0,250 & 58 & 0 & & & & 0 & & 0 & & 0 & \\
\hline 7619 & 0,250 & 59 & & & 2 & & & 1 & & 1 & & 1 \\
\hline 7619 & 0,250 & 60 & 0 & & & & & 1 & & 1 & & 1 \\
\hline 7619 & 0,250 & 61 & 0 & & & & & 1 & 0 & & 0 & \\
\hline 7619 & 0,250 & 62 & 0 & & & & 0 & & 0 & & 0 & \\
\hline 7619 & 0,250 & 63 & 0 & & & & & 1 & & 1 & & 1 \\
\hline 7619 & 0,250 & 64 & 0 & & & & 0 & & 0 & & 0 & \\
\hline 7619 & 0,250 & 65 & 0 & & & & & 1 & & 1 & & 1 \\
\hline 7619 & 0,250 & 66 & 0 & & & & 0 & & & 1 & & 1 \\
\hline 7619 & 0,250 & 67 & 0 & & & & & 1 & & 1 & & 1 \\
\hline 7619 & 0,250 & 68 & & 1 & & & 0 & & & 1 & & 1 \\
\hline 7619 & 0,250 & 69 & 0 & & & & & 1 & & 1 & & 1 \\
\hline 7619 & 0,250 & 70 & & & 2 & & & 1 & & 1 & & 1 \\
\hline 7619 & 0,250 & 71 & & 1 & & & 0 & & & 1 & & 1 \\
\hline 7619 & 0,250 & 72 & 0 & & & & 0 & & 0 & & 0 & \\
\hline 7619 & 0,250 & 73 & 0 & & & & & 1 & & 1 & & 1 \\
\hline 7619 & 0,250 & 74 & 0 & & & & 0 & & 0 & & 0 & \\
\hline 7619 & 0,250 & 75 & 0 & & & & & 1 & & 1 & & 1 \\
\hline 7619 & 0,250 & 76 & 0 & & & & 0 & & & 1 & & 1 \\
\hline 7619 & 0,250 & 77 & 0 & & & & & 1 & & 1 & & 1 \\
\hline 7619 & 0,250 & 78 & 0 & & & & & 1 & & 1 & & 1 \\
\hline 7619 & 0,250 & 79 & 0 & & & & 0 & & 0 & & 0 & \\
\hline 7619 & 0,250 & 80 & 0 & & & & & 1 & & 1 & & 1 \\
\hline 7619 & 0,250 & 81 & 0 & & & & & 1 & & 1 & & 1 \\
\hline 7619 & 0,250 & 82 & 0 & & & & & 1 & & 1 & & 1 \\
\hline 7619 & 0,250 & 83 & & & 2 & & & 1 & & 1 & & 1 \\
\hline 7619 & 0,250 & 84 & 0 & & & & & 1 & 0 & & & 1 \\
\hline
\end{tabular}




\begin{tabular}{|c|c|c|c|c|c|c|c|c|c|c|c|c|}
\hline \multirow{4}{*}{$\begin{array}{c}\text { Estação } \\
\text { de } \\
\text { coleta }\end{array}$} & \multirow{4}{*}{$\begin{array}{l}\text { Fração } \\
\text { (mm) }\end{array}$} & \multirow{4}{*}{ Eppendorf } & \multirow{2}{*}{\multicolumn{4}{|c|}{$\begin{array}{c}\text { Feições Físicas } \\
\text { Fragmentação }\end{array}$}} & \multicolumn{6}{|c|}{ Feições Químicas } \\
\hline & & & & & & & \multicolumn{2}{|c|}{ Cor } & \multicolumn{2}{|c|}{ Brilho } & \multicolumn{2}{|c|}{ Corrosão } \\
\hline & & & \multirow{2}{*}{ Ausente } & \multicolumn{3}{|c|}{ Presente } & \multirow{2}{*}{ Mantida } & \multirow{2}{*}{ Alterada } & \multirow{2}{*}{ Mantida } & \multirow{2}{*}{ Alterada } & \multirow{2}{*}{ Ausente } & \multirow{2}{*}{ Presente } \\
\hline & & & & $<10 \%$ & entre 10 e $50 \%$ & $>50 \%$ & & & & & & \\
\hline 7619 & 0,250 & 85 & 0 & & & & & 1 & & 1 & & 1 \\
\hline 7619 & 0,250 & 86 & 0 & & & & & 1 & & 1 & & 1 \\
\hline 7619 & 0,250 & 87 & 0 & & & & 0 & & & 1 & & 1 \\
\hline 7619 & 0,250 & 88 & & & 2 & & & 1 & & 1 & & 1 \\
\hline 7619 & 0,250 & 89 & 0 & & & & & 1 & & 1 & & 1 \\
\hline 7619 & 0,250 & 90 & 0 & & & & & 1 & & 1 & & 1 \\
\hline 7619 & 0,250 & 91 & 0 & & & & 0 & & & 1 & & 1 \\
\hline 7619 & 0,250 & 92 & 0 & & & & & 1 & & 1 & & 1 \\
\hline 7619 & 0,250 & 93 & 0 & & & & 0 & & & 1 & & 1 \\
\hline 7619 & 0,250 & 94 & 0 & & & & & 1 & & 1 & & 1 \\
\hline 7619 & 0,250 & 95 & 0 & & & & & 1 & & 1 & & 1 \\
\hline 7619 & 0,250 & 96 & 0 & & & & 0 & & & 1 & 0 & \\
\hline 7619 & 0,250 & 97 & 0 & & & & & 1 & & 1 & & 1 \\
\hline 7619 & 0,250 & 98 & 0 & & & & & 1 & & 1 & & 1 \\
\hline 7619 & 0,250 & 99 & 0 & & & & 0 & & 0 & & 0 & \\
\hline 7619 & 0,250 & 100 & 0 & & & & & 1 & & 1 & & 1 \\
\hline 7619 & 0,250 & 101 & 0 & & & & & 1 & & 1 & & 1 \\
\hline 7619 & 0,250 & 102 & 0 & & & & & 1 & & 1 & & 1 \\
\hline 7619 & 0,250 & 103 & 0 & & & & 0 & & & 1 & & 1 \\
\hline 7619 & 0,250 & 104 & & & 2 & & 0 & & & 1 & & 1 \\
\hline 7619 & 0,250 & 105 & 0 & & & & & 1 & & 1 & & 1 \\
\hline 7619 & 0,250 & 106 & & 1 & & & & 1 & & 1 & & 1 \\
\hline 7619 & 0,250 & 107 & 0 & & & & & 1 & & 1 & & 1 \\
\hline 7619 & 0,250 & 108 & 0 & & & & & 1 & & 1 & & 1 \\
\hline 7619 & 0,250 & 109 & 0 & & & & & 1 & & 1 & & 1 \\
\hline 7619 & 0,250 & 110 & 0 & & & & 0 & & 0 & & 0 & \\
\hline 7619 & 0,250 & 111 & 0 & & & & & 1 & & 1 & & 1 \\
\hline 7619 & 0,250 & 112 & 0 & & & & & 1 & & 1 & & 1 \\
\hline 7619 & 0,250 & 113 & 0 & & & & & 1 & & 1 & & 1 \\
\hline 7619 & 0,250 & 114 & 0 & & & & 0 & & & 1 & & 1 \\
\hline 7619 & 0,250 & 115 & 0 & & & & 0 & & 0 & & 0 & \\
\hline 7619 & 0,250 & 116 & 0 & & & & & 1 & & 1 & & 1 \\
\hline 7619 & 0,250 & 117 & 0 & & & & & 1 & & 1 & & 1 \\
\hline 7619 & 0,250 & 118 & 0 & & & & & 1 & & 1 & & 1 \\
\hline 7619 & 0,250 & 119 & 0 & & & & & 1 & & 1 & & 1 \\
\hline 7619 & 0,250 & 120 & 0 & & & & & 1 & & 1 & & 1 \\
\hline 7619 & 0,250 & 121 & 0 & & & & & 1 & & 1 & & 1 \\
\hline 7619 & 0,250 & 122 & 0 & & & & 0 & & & 1 & & 1 \\
\hline 7619 & 0,250 & 123 & 0 & & & & & 1 & & 1 & & 1 \\
\hline 7619 & 0,250 & 124 & 0 & & & & 0 & & 0 & & 0 & \\
\hline 7619 & 0,250 & 125 & & & & 3 & & 1 & & 1 & & 1 \\
\hline 7619 & 0,250 & 126 & 0 & & & & 0 & & & 1 & & 1 \\
\hline 7619 & 0,250 & 127 & 0 & & & & & 1 & & 1 & & 1 \\
\hline
\end{tabular}




\begin{tabular}{|c|c|c|c|c|c|c|c|c|c|c|c|c|}
\hline \multirow{4}{*}{$\begin{array}{c}\text { Estação } \\
\text { de } \\
\text { coleta }\end{array}$} & \multirow{4}{*}{$\begin{array}{c}\text { Fração } \\
\text { (mm) }\end{array}$} & \multirow{4}{*}{ Eppendorf } & \multirow{2}{*}{\multicolumn{4}{|c|}{$\begin{array}{c}\text { Feições Físicas } \\
\text { Fragmentação }\end{array}$}} & \multicolumn{6}{|c|}{ Feições Químicas } \\
\hline & & & & & & & \multicolumn{2}{|c|}{ Cor } & \multicolumn{2}{|c|}{ Brilho } & \multicolumn{2}{|c|}{ Corrosão } \\
\hline & & & \multirow{2}{*}{ Ausente } & \multicolumn{3}{|c|}{ Presente } & \multirow{2}{*}{ Mantida } & \multirow{2}{*}{ Alterada } & \multirow{2}{*}{ Mantida } & \multirow{2}{*}{ Alterada } & \multirow{2}{*}{ Ausente } & \multirow{2}{*}{ Presente } \\
\hline & & & & $<10 \%$ & entre 10 e $50 \%$ & $>50 \%$ & & & & & & \\
\hline 7619 & 0,250 & 128 & 0 & & & & 0 & & & 1 & & 1 \\
\hline 7619 & 0,250 & 129 & 0 & & & & & 1 & & 1 & & 1 \\
\hline 7619 & 0,250 & 130 & 0 & & & & 0 & & & 1 & & 1 \\
\hline 7619 & 0,250 & 131 & 0 & & & & & 1 & & 1 & & 1 \\
\hline 7619 & 0,250 & 132 & 0 & & & & & 1 & & 1 & & 1 \\
\hline 7619 & 0,250 & 133 & & & 2 & & & 1 & & 1 & & 1 \\
\hline 7619 & 0,250 & 134 & 0 & & & & 0 & & & 1 & & 1 \\
\hline 7619 & 0,250 & 135 & & 1 & & & & 1 & & 1 & & 1 \\
\hline 7619 & 0,250 & 136 & 0 & & & & 0 & & 0 & & 0 & \\
\hline 7619 & 0,250 & 137 & 0 & & & & & 1 & & 1 & & 1 \\
\hline 7619 & 0,250 & 138 & & 1 & & & & 1 & & 1 & & 1 \\
\hline 7619 & 0,250 & 139 & 0 & & & & & 1 & & 1 & & 1 \\
\hline 7619 & 0,250 & 140 & 0 & & & & 0 & & & 1 & & 1 \\
\hline 7619 & 0,250 & 141 & 0 & & & & & 1 & & 1 & & 1 \\
\hline 7619 & 0,250 & 142 & 0 & & & & & 1 & & 1 & & 1 \\
\hline 7619 & 0,250 & 143 & 0 & & & & 0 & & & 1 & & 1 \\
\hline 7619 & 0,250 & 144 & 0 & & & & 0 & & & 1 & & 1 \\
\hline 7619 & 0,250 & 145 & 0 & & & & & 1 & & 1 & & 1 \\
\hline 7619 & 0,250 & 146 & 0 & & & & 0 & & & 1 & & 1 \\
\hline 7619 & 0,250 & 147 & 0 & & & & 0 & & & 1 & & 1 \\
\hline 7619 & 0,250 & 148 & 0 & & & & & 1 & & 1 & & 1 \\
\hline 7619 & 0,250 & 149 & 0 & & & & & 1 & & 1 & & 1 \\
\hline 7619 & 0,250 & 150 & 0 & & & & 0 & & & 1 & & 1 \\
\hline
\end{tabular}




\section{Protocolo Tafonômico - Estação de coleta 7621, fração 0,250 mm}

\begin{tabular}{|c|c|c|c|c|c|c|c|c|c|c|c|c|}
\hline \multirow{4}{*}{$\begin{array}{c}\text { Estação } \\
\text { de } \\
\text { coleta }\end{array}$} & \multirow{4}{*}{$\begin{array}{c}\text { Fração } \\
\text { (mm) }\end{array}$} & \multirow{4}{*}{ Eppendorf } & \multirow{2}{*}{\multicolumn{4}{|c|}{$\begin{array}{c}\text { Feições Físicas } \\
\text { Fragmentação }\end{array}$}} & \multicolumn{6}{|c|}{ Feições Químicas } \\
\hline & & & & & & & \multicolumn{2}{|c|}{ Cor } & \multicolumn{2}{|c|}{ Brilho } & \multicolumn{2}{|c|}{ Corrosão } \\
\hline & & & \multirow{2}{*}{ Ausente } & \multicolumn{3}{|c|}{\begin{tabular}{|c|} 
Presente \\
\end{tabular}} & \multirow{2}{*}{ Mantida } & \multirow{2}{*}{ Alterada } & & & & \\
\hline & & & & $<10 \%$ & entre $10 \%$ e $50 \%$ & $>50 \%$ & & & |vantido & Alterado & Ausente & Presente \\
\hline 7621 & 0,250 & 1 & 0 & & & & 0 & & & 1 & 0 & \\
\hline 7621 & 0,250 & 2 & 0 & & & & 0 & & & 1 & & 1 \\
\hline 7621 & 0,250 & 3 & 0 & & & & 0 & & & 1 & & 1 \\
\hline 7621 & 0,250 & 4 & 0 & & & & & 1 & & 1 & & 1 \\
\hline 7621 & 0,250 & 5 & & & 2 & & 0 & & & 1 & 0 & \\
\hline 7621 & 0,250 & 6 & & & 2 & & & 1 & & 1 & & 1 \\
\hline 7621 & 0,250 & 7 & 0 & & & & 0 & & & 1 & & 1 \\
\hline 7621 & 0,250 & 8 & 0 & & & & & 1 & & 1 & 0 & \\
\hline 7621 & 0,250 & 9 & 0 & & & & 0 & & & 1 & 0 & \\
\hline 7621 & 0,250 & 10 & 0 & & & & 0 & & & 1 & 0 & \\
\hline 7621 & 0,250 & 11 & 0 & & & & & 1 & & 1 & & 1 \\
\hline 7621 & 0,250 & 12 & & 1 & & & & 1 & & 1 & 0 & \\
\hline 7621 & 0,250 & 13 & & 1 & & & & 1 & & 1 & & 1 \\
\hline 7621 & 0,250 & 14 & 0 & & & & & 1 & & 1 & & 1 \\
\hline 7621 & 0,250 & 15 & 0 & & & & 0 & & 0 & & 0 & \\
\hline 7621 & 0,250 & 16 & & 1 & & & & 1 & & 1 & & 1 \\
\hline 7621 & 0,250 & 17 & 0 & & & & & 1 & & 1 & & 1 \\
\hline 7621 & 0,250 & 18 & 0 & & & & 0 & & 0 & & 0 & \\
\hline 7621 & 0,250 & 19 & & & & 3 & & 1 & & 1 & & 1 \\
\hline 7621 & 0,250 & 20 & 0 & & & & & 1 & & 1 & & 1 \\
\hline 7621 & 0,250 & 21 & 0 & & & & & 1 & & 1 & & 1 \\
\hline 7621 & 0,250 & 22 & 0 & & & & 0 & & & 1 & & 1 \\
\hline 7621 & 0,250 & 23 & 0 & & & & 0 & & 0 & & 0 & \\
\hline 7621 & 0,250 & 24 & 0 & & & & 0 & & & 1 & & 1 \\
\hline 7621 & 0,250 & 25 & & & & 3 & & 1 & & 1 & & 1 \\
\hline 7621 & 0,250 & 26 & 0 & & & & 0 & & & 1 & 0 & \\
\hline 7621 & 0,250 & 27 & 0 & & & & 0 & & & 1 & & 1 \\
\hline 7621 & 0,250 & 28 & 0 & & & & 0 & & & 1 & & 1 \\
\hline 7621 & 0,250 & 29 & & & & 3 & 0 & & & 1 & 0 & \\
\hline 7621 & 0,250 & 30 & 0 & & & & 0 & & 0 & & 0 & \\
\hline 7621 & 0,250 & 31 & 0 & & & & 0 & & 0 & & & 1 \\
\hline 7621 & 0,250 & 32 & 0 & & & & 0 & & & 1 & & 1 \\
\hline 7621 & 0,250 & 33 & 0 & & & & 0 & & & 1 & & 1 \\
\hline 7621 & 0,250 & 34 & & 1 & & & 0 & & & 1 & & 1 \\
\hline 7621 & 0,250 & 35 & 0 & & & & 0 & & & 1 & & 1 \\
\hline 7621 & 0,250 & 36 & 0 & & & & 0 & & & 1 & & 1 \\
\hline 7621 & 0,250 & 37 & 0 & & & & 0 & & 0 & & 0 & \\
\hline 7621 & 0,250 & 38 & 0 & & & & 0 & & & 1 & & 1 \\
\hline 7621 & 0,250 & 39 & 0 & & & & 0 & & & 1 & 0 & \\
\hline 7621 & 0,250 & 40 & 0 & & & & 0 & & & 1 & & 1 \\
\hline 7621 & 0,250 & 41 & 0 & & & & 0 & & & 1 & 0 & \\
\hline 7621 & 0,250 & 42 & 0 & & & & 0 & & & 1 & & 1 \\
\hline 7621 & 0,250 & 43 & & & & 3 & 0 & & & 1 & 0 & \\
\hline 7621 & 0,250 & 44 & & 1 & & & & 1 & & 1 & & 1 \\
\hline 7621 & 0,250 & 45 & & 1 & & & 0 & & 0 & & 0 & \\
\hline 7621 & 0,250 & 46 & & 1 & & & 0 & & & 1 & & 1 \\
\hline 7621 & 0,250 & 47 & 0 & & & & 0 & & & 1 & & 1 \\
\hline 7621 & 0,250 & 48 & 0 & & & & 0 & & & 1 & & 1 \\
\hline 7621 & 0,250 & 49 & & 1 & & & & 1 & & 1 & & 1 \\
\hline 7621 & 0,250 & 50 & 0 & & & & 0 & & 0 & & 0 & \\
\hline 7621 & 0,250 & 51 & 0 & & & & & 1 & & 1 & & 1 \\
\hline 7621 & 0,250 & 52 & 0 & & & & & 1 & & 1 & & 1 \\
\hline 7621 & 0,250 & 53 & 0 & & & & 0 & & & 1 & & 1 \\
\hline 7621 & 0,250 & 54 & 0 & & & & & 1 & & 1 & & 1 \\
\hline 7621 & 0,250 & 55 & 0 & & & & 0 & & & 1 & & 1 \\
\hline 7621 & 0,250 & 56 & 0 & & & & 0 & & 0 & & 0 & \\
\hline 7621 & 0,250 & 57 & 0 & & & & 0 & & & 1 & 0 & \\
\hline 7621 & 0,250 & 58 & 0 & & & & 0 & & 0 & & 0 & \\
\hline
\end{tabular}




\begin{tabular}{|c|c|c|c|c|c|c|c|c|c|c|c|c|}
\hline \multirow{3}{*}{$\begin{array}{c}\text { Estação } \\
\text { de } \\
\text { coleta }\end{array}$} & \multirow{3}{*}{$\begin{array}{c}\text { Fração } \\
\text { (mm) }\end{array}$} & \multirow{3}{*}{ Eppendorf } & \multirow{2}{*}{\multicolumn{4}{|c|}{$\begin{array}{c}\text { Feições Físicas } \\
\text { Fragmentação }\end{array}$}} & \multicolumn{6}{|c|}{ Feições Químicas } \\
\hline & & & & & & & \multicolumn{2}{|c|}{ Cor } & \multicolumn{2}{|c|}{ Brilho } & \multicolumn{2}{|c|}{ Corrosão } \\
\hline & & & Ausente & \multicolumn{3}{|c|}{ Presente } & Mantida & Alterada & Mantido & Alterado & Ausente & Presente \\
\hline 7621 & 0,250 & $\overline{c 59}$ & $\overline{0}$ & & & & $\overline{0}$ & & & 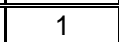 & & $\overline{11}$ \\
\hline 7621 & 0,250 & 60 & & & & 3 & & 1 & & 1 & & 1 \\
\hline 7621 & 0,250 & 61 & 0 & & & & 0 & & 0 & & 0 & \\
\hline 7621 & 0,250 & 62 & 0 & & & & 0 & & & 1 & 0 & \\
\hline 7621 & 0,250 & 63 & & 1 & & & 0 & & & 1 & & 1 \\
\hline 7621 & 0,250 & 64 & & & 2 & & 0 & & & 1 & & 1 \\
\hline 7621 & 0,250 & 65 & 0 & & & & 0 & & 0 & & 0 & \\
\hline 7621 & 0,250 & 66 & & 1 & & & 0 & & 0 & & 0 & \\
\hline 7621 & 0,250 & 67 & 0 & & & & 0 & & & 1 & & 1 \\
\hline 7621 & 0,250 & 68 & 0 & & & & 0 & & & 1 & 0 & \\
\hline 7621 & 0,250 & 69 & & & & 3 & 0 & & & 1 & & 1 \\
\hline 7621 & 0,250 & 70 & & & & & & & & & & \\
\hline 7621 & 0,250 & 71 & 0 & & & & 0 & & 0 & & 0 & \\
\hline 7621 & 0,250 & 72 & 0 & & & & 0 & & 0 & & 0 & \\
\hline 7621 & 0,250 & 73 & & 1 & & & & 1 & & 1 & & 1 \\
\hline 7621 & 0,250 & 74 & 0 & & & & 0 & & 0 & & & 1 \\
\hline 7621 & 0,250 & 75 & 0 & & & & & 1 & & 1 & & 1 \\
\hline 7621 & 0,250 & 76 & 0 & & & & & 1 & & 1 & & 1 \\
\hline 7621 & 0,250 & 77 & 0 & & & & 0 & & 0 & & & 1 \\
\hline 7621 & 0,250 & 78 & & & 2 & & & 1 & & 1 & & 1 \\
\hline 7621 & 0,250 & 79 & & 1 & & & 0 & & & 1 & 0 & \\
\hline 7621 & 0,250 & 80 & 0 & & & & & 1 & & 1 & & 1 \\
\hline 7621 & 0,250 & 81 & 0 & & & & 0 & & 0 & & 0 & \\
\hline 7621 & 0,250 & 82 & & & 2 & & & 1 & & 1 & & 1 \\
\hline 7621 & 0,250 & 83 & & & 2 & & 0 & & & 1 & & 1 \\
\hline 7621 & 0,250 & 84 & 0 & & & & 0 & & & 1 & 0 & \\
\hline 7621 & 0,250 & 85 & 0 & & & & 0 & & & 1 & 0 & \\
\hline 7621 & 0,250 & 86 & & 1 & & & & 1 & & 1 & & 1 \\
\hline 7621 & 0,250 & 87 & 0 & & & & 0 & & & 1 & & 1 \\
\hline 7621 & 0,250 & 88 & 0 & & & & 0 & & 0 & & 0 & \\
\hline 7621 & 0,250 & 89 & 0 & & & & 0 & & & 1 & & 1 \\
\hline 7621 & 0,250 & 90 & & 1 & & & 0 & & & 1 & & 1 \\
\hline 7621 & 0,250 & 91 & 0 & & & & 0 & & & 1 & & 1 \\
\hline 7621 & 0,250 & 92 & 0 & & & & 0 & & & 1 & & 1 \\
\hline 7621 & 0,250 & 93 & 0 & & & & 0 & & & 1 & & 1 \\
\hline 7621 & 0,250 & 94 & 0 & & & & 0 & & & 1 & & 1 \\
\hline 7621 & 0,250 & 95 & 0 & & & & 0 & & & 1 & & 1 \\
\hline 7621 & 0,250 & 96 & & & & 3 & 0 & & & 1 & & 1 \\
\hline 7621 & 0,250 & 97 & 0 & & & & 0 & & & 1 & & 1 \\
\hline 7621 & 0,250 & 98 & & 1 & & & 0 & & & 1 & & 1 \\
\hline 7621 & 0,250 & 99 & 0 & & & & 0 & & 0 & & 0 & \\
\hline 7621 & 0,250 & 100 & & & 2 & & 0 & & & 1 & & 1 \\
\hline 7621 & 0,250 & 101 & 0 & 0 & 0 & 0 & 0 & 1 & 0 & 1 & 0 & 1 \\
\hline 7621 & 0,250 & 102 & 0 & 0 & 0 & 0 & 0 & 0 & 0 & 0 & 0 & 1 \\
\hline 7621 & 0,250 & 103 & 0 & 0 & 0 & 0 & 0 & 0 & 0 & 0 & 0 & 0 \\
\hline 7621 & 0,250 & 104 & 0 & 0 & 0 & 0 & 0 & 0 & 0 & 1 & 0 & 0 \\
\hline 7621 & 0,250 & 105 & 0 & 0 & 0 & 0 & 0 & 1 & 0 & 1 & 0 & 1 \\
\hline 7621 & 0,250 & 106 & 0 & 0 & 0 & 0 & 0 & 1 & 0 & 1 & 0 & 1 \\
\hline 7621 & 0,250 & 107 & 0 & 0 & 2 & 0 & 0 & 0 & 0 & 1 & 0 & 1 \\
\hline 7621 & 0,250 & 108 & 0 & 0 & 2 & 0 & 0 & 1 & 0 & 1 & 0 & 1 \\
\hline 7621 & 0,250 & 109 & 0 & 0 & 2 & 0 & 0 & 1 & 0 & 1 & 0 & 1 \\
\hline 7621 & 0,250 & 110 & 0 & 0 & 0 & 3 & 0 & 0 & 0 & 1 & 0 & 1 \\
\hline 7621 & 0,250 & 111 & 0 & 0 & 0 & 0 & 0 & 0 & 0 & 0 & 0 & 0 \\
\hline 7621 & 0,250 & 112 & 0 & 1 & 0 & 0 & 0 & 0 & 0 & 0 & 0 & 0 \\
\hline 7621 & 0,250 & 113 & 0 & 0 & 0 & 3 & 0 & 0 & 0 & 0 & 0 & 0 \\
\hline 7621 & 0,250 & 114 & 0 & 0 & 0 & 3 & 0 & 0 & 0 & 1 & 0 & 1 \\
\hline 7621 & 0,250 & 115 & 0 & 0 & 0 & 0 & 0 & 1 & 0 & 1 & 0 & 1 \\
\hline 7621 & 0,250 & 116 & 0 & 0 & 0 & 0 & 0 & 1 & 0 & 1 & 0 & 1 \\
\hline 7621 & 0,250 & 117 & 0 & 0 & 0 & 0 & 0 & 0 & 0 & 0 & 0 & 0 \\
\hline 7621 & 0,250 & 118 & 0 & 0 & 0 & 0 & 0 & 0 & 0 & 1 & 0 & 0 \\
\hline
\end{tabular}




\begin{tabular}{|c|c|c|c|c|c|c|c|c|c|c|c|c|}
\hline \multirow{4}{*}{$\begin{array}{c}\text { Estação } \\
\text { de } \\
\text { coleta }\end{array}$} & \multirow{4}{*}{$\begin{array}{c}\text { Fração } \\
\text { (mm) }\end{array}$} & \multirow{4}{*}{ Eppendorf } & \multirow{2}{*}{\multicolumn{4}{|c|}{$\begin{array}{l}\text { Feições Físicas } \\
\text { Fragmentação }\end{array}$}} & \multicolumn{6}{|c|}{ Feições Químicas } \\
\hline & & & & & & & \multicolumn{2}{|c|}{ Cor } & \multicolumn{2}{|c|}{ Brilho } & \multicolumn{2}{|c|}{ Corrosão } \\
\hline & & & \multirow{2}{*}{ Ausente } & \multicolumn{3}{|c|}{ Presente } & \multirow{2}{*}{ Mantida } & \multirow[t]{2}{*}{ Alterada } & \multirow[t]{2}{*}{ Mantido } & \multirow[t]{2}{*}{ Alterado } & \multirow{2}{*}{ Ausente } & \multirow{2}{*}{ Presente } \\
\hline & & & & $<10 \%$ & entre $10 \%$ e $50 \%$ & $>50 \%$ & & & & & & \\
\hline$\overline{77621}$ & 0,250 & 119 & 0 & 0 & 2 & 0 & 0 & 0 & 0 & 0 & 0 & 1 \\
\hline 7621 & 0,250 & 120 & 0 & 1 & 0 & 0 & 0 & 1 & 0 & 1 & 0 & 1 \\
\hline 7621 & 0,250 & 121 & 0 & 0 & 0 & 0 & 0 & 0 & 0 & 1 & 0 & 1 \\
\hline 7621 & 0,250 & 122 & 0 & 0 & 0 & 0 & 0 & 1 & 0 & 1 & 0 & 1 \\
\hline 7621 & 0,250 & 123 & 0 & 0 & 0 & 0 & 0 & 0 & 0 & 0 & 0 & 0 \\
\hline 7621 & 0,250 & 124 & 0 & 0 & 0 & 0 & 0 & 0 & 0 & 1 & 0 & 1 \\
\hline 7621 & 0,250 & 125 & 0 & 0 & 0 & 0 & 0 & 0 & 0 & 1 & 0 & 1 \\
\hline 7621 & 0,250 & 126 & 0 & 0 & 0 & 3 & 0 & 0 & 0 & 1 & 0 & 1 \\
\hline 7621 & 0,250 & 127 & 0 & 1 & 0 & 0 & 0 & 1 & 0 & 1 & 0 & 1 \\
\hline 7621 & 0,250 & 128 & 0 & 1 & 0 & 0 & 0 & 1 & 0 & 1 & 0 & 1 \\
\hline 7621 & 0,250 & 129 & 0 & 0 & 0 & 0 & 0 & 0 & 0 & 0 & 0 & 0 \\
\hline 7621 & 0,250 & 130 & 0 & 0 & 0 & 3 & 0 & 1 & 0 & 1 & 0 & 1 \\
\hline 7621 & 0,250 & 131 & 0 & 0 & 0 & 0 & 0 & 1 & 0 & 1 & 0 & 1 \\
\hline 7621 & 0,250 & 132 & 0 & 0 & 0 & 0 & 0 & 0 & 0 & 1 & 0 & 1 \\
\hline 7621 & 0,250 & 133 & 0 & 0 & 0 & 0 & 0 & 0 & 0 & 0 & 0 & 0 \\
\hline 7621 & 0,250 & 134 & 0 & 0 & 0 & 0 & 0 & 1 & 0 & 1 & 0 & 1 \\
\hline 7621 & 0,250 & 135 & 0 & 0 & 2 & 0 & 0 & 0 & 0 & 1 & 0 & 1 \\
\hline 7621 & 0,250 & 136 & 0 & 0 & 0 & 0 & 0 & 0 & 0 & 0 & 0 & 0 \\
\hline 7621 & 0,250 & 137 & 0 & 0 & 0 & 0 & 0 & 1 & 0 & 1 & 0 & 1 \\
\hline 7621 & 0,250 & 138 & 0 & 0 & 0 & 3 & 0 & 0 & 0 & 0 & 0 & 0 \\
\hline 7621 & 0,250 & 139 & 0 & 1 & 0 & 0 & 0 & 1 & 0 & 1 & 0 & 1 \\
\hline 7621 & 0,250 & 140 & 0 & 0 & 2 & 0 & 0 & 1 & 0 & 1 & 0 & 1 \\
\hline 7621 & 0,250 & 141 & 0 & 0 & 0 & 0 & 0 & 0 & 0 & 0 & 0 & 0 \\
\hline 7621 & 0,250 & 142 & 0 & 0 & 0 & 0 & 0 & 0 & 0 & 1 & 0 & 1 \\
\hline 7621 & 0,250 & 143 & 0 & 0 & 0 & 0 & 0 & 0 & 0 & 0 & 0 & 0 \\
\hline 7621 & 0,250 & 144 & 0 & 0 & 0 & 0 & 0 & 1 & 0 & 1 & 0 & 1 \\
\hline 7621 & 0,250 & 145 & 0 & 0 & 0 & 0 & 0 & 0 & 0 & 0 & 0 & 0 \\
\hline 7621 & 0,250 & 146 & 0 & 1 & 0 & 0 & 0 & 1 & 0 & 1 & 0 & 1 \\
\hline 7621 & 0,250 & 147 & 0 & 0 & 0 & 0 & 0 & 0 & 0 & 0 & 0 & 0 \\
\hline 7621 & 0,250 & 148 & 0 & 0 & 0 & 0 & 0 & 1 & 0 & 1 & 0 & 1 \\
\hline 7621 & 0,250 & 149 & 0 & 0 & 0 & 0 & 0 & 0 & 0 & 0 & 0 & 0 \\
\hline 7621 & 0,250 & 150 & 0 & 0 & 0 & 0 & 0 & 0 & 0 & 0 & 0 & 1 \\
\hline
\end{tabular}




\section{Protocolo Tafonômico - Estação de coleta 7622, fração 0,250 mm}

\begin{tabular}{|c|c|c|c|c|c|c|c|c|c|c|c|c|}
\hline \multirow{4}{*}{$\begin{array}{c}\text { Estação } \\
\text { de } \\
\text { coleta }\end{array}$} & \multirow{4}{*}{$\begin{array}{c}\text { Fração } \\
(\mathrm{mm})\end{array}$} & \multirow{4}{*}{ Eppendorf } & \multirow{2}{*}{\multicolumn{4}{|c|}{$\begin{array}{c}\text { Feições Físicas } \\
\text { Fragmentação }\end{array}$}} & \multicolumn{6}{|c|}{ Feições Químicas } \\
\hline & & & & & & & \multicolumn{2}{|c|}{ Cor } & \multicolumn{2}{|c|}{ Brilho } & \multicolumn{2}{|c|}{ Corrosão } \\
\hline & & & \multirow{2}{*}{ Ausente } & \multicolumn{3}{|c|}{ Presente } & Mantida & Alterada & Mantido & Alterado & Ausente & Presente \\
\hline & & & & $<10 \%$ & entre $10 \%$ e $50 \%$ & $>50 \%$ & & Alterada & & Alterado & Ausente & Presente \\
\hline 7622 & 0,250 & 1 & 0 & & & & 0 & & 0 & & & 1 \\
\hline 7622 & 0,250 & 2 & 0 & & & & & 1 & & 1 & & 1 \\
\hline 7622 & 0,250 & 3 & 0 & & & & 0 & & 0 & & 0 & \\
\hline 7622 & 0,250 & 4 & 0 & & & & 0 & & & 1 & & 1 \\
\hline 7622 & 0,250 & 5 & 0 & & & & & 1 & & 1 & & 1 \\
\hline 7622 & 0,250 & 6 & 0 & & & & & 1 & & 1 & 0 & \\
\hline 7622 & 0,250 & 7 & 0 & & & & & 1 & & 1 & & 1 \\
\hline 7622 & 0,250 & 8 & 0 & & & & 0 & & 0 & & 0 & \\
\hline 7622 & 0,250 & 9 & 0 & & & & & 1 & & 1 & & 1 \\
\hline 7622 & 0,250 & 10 & 0 & & & & & 1 & & 1 & & 1 \\
\hline 7622 & 0,250 & 11 & 0 & & & & 0 & & & 1 & & 1 \\
\hline 7622 & 0,250 & 12 & 0 & & & & 0 & & & 1 & & 1 \\
\hline 7622 & 0,250 & 13 & 0 & & & & 0 & & & 1 & & 1 \\
\hline 7622 & 0,250 & 14 & 0 & & & & 0 & & 0 & & 0 & \\
\hline 7622 & 0,250 & 15 & & 1 & & & & 1 & & 1 & & 1 \\
\hline 7622 & 0,250 & 16 & 0 & & & & 0 & & 0 & & 0 & \\
\hline 7622 & 0,250 & 17 & & & 2 & & & 1 & & 1 & & 1 \\
\hline 7622 & 0,250 & 18 & 0 & & & & & 1 & & 1 & & 1 \\
\hline 7622 & 0,250 & 19 & 0 & & & & 0 & & & 1 & & 1 \\
\hline 7622 & 0,250 & 20 & 0 & & & & & 1 & & 1 & & 1 \\
\hline 7622 & 0,250 & 21 & 0 & & & & 0 & & & 1 & & 1 \\
\hline 7622 & 0,250 & 22 & 0 & & & & 0 & & & 1 & & 1 \\
\hline 7622 & 0,250 & 23 & 0 & & & & 0 & & 0 & & 0 & \\
\hline 7622 & 0,250 & 24 & & & & 3 & & 1 & & 1 & & 1 \\
\hline 7622 & 0,250 & 25 & 0 & & & & & 1 & & 1 & & 1 \\
\hline 7622 & 0,250 & 26 & 0 & & & & & 1 & & 1 & & 1 \\
\hline 7622 & 0,250 & 27 & 0 & & & & & 1 & & 1 & & 1 \\
\hline 7622 & 0,250 & 28 & & 1 & & & 0 & & 0 & & 0 & \\
\hline 7622 & 0,250 & 29 & 0 & & & & & 1 & 0 & & & 1 \\
\hline 7622 & 0,250 & 30 & 0 & & & & & 1 & & 1 & & 1 \\
\hline 7622 & 0,250 & 31 & 0 & & & & & 1 & & 1 & & 1 \\
\hline 7622 & 0,250 & 32 & 0 & & & & & 1 & & 1 & & 1 \\
\hline 7622 & 0,250 & 33 & 0 & & & & & 1 & & 1 & & 1 \\
\hline 7622 & 0,250 & 34 & 0 & & & & & 1 & & 1 & & 1 \\
\hline 7622 & 0,250 & 35 & 0 & & & & & 1 & & 1 & & 1 \\
\hline 7622 & 0,250 & 36 & 0 & & & & & 1 & & 1 & & 1 \\
\hline 7622 & 0,250 & 37 & 0 & & & & & 1 & & 1 & & 1 \\
\hline 7622 & 0,250 & 38 & 0 & & & & & 1 & & 1 & & 1 \\
\hline 7622 & 0,250 & 39 & & 1 & & & 0 & & 0 & & 0 & \\
\hline 7622 & 0,250 & 40 & & & 2 & & & 1 & & 1 & & 1 \\
\hline 7622 & 0,250 & 41 & 0 & & & & 0 & & & 1 & & 1 \\
\hline 7622 & 0,250 & 42 & 0 & & & & 0 & & & 1 & & 1 \\
\hline 7622 & 0,250 & 43 & 0 & & & & 0 & & & 1 & & 1 \\
\hline 7622 & 0,250 & 44 & 0 & & & & 0 & & & 1 & & 1 \\
\hline 7622 & 0,250 & 45 & 0 & & & & 0 & & & 1 & & 1 \\
\hline 7622 & 0,250 & 46 & 0 & & & & & 1 & & 1 & & 1 \\
\hline 7622 & 0,250 & 47 & & 1 & & & & 1 & & 1 & & 1 \\
\hline
\end{tabular}




\begin{tabular}{|c|c|c|c|c|c|c|c|c|c|c|c|}
\hline \multirow{4}{*}{$\begin{array}{c}\text { Estação } \\
\text { de } \\
\text { coleta }\end{array}$} & \multirow{4}{*}{$\begin{array}{c}\text { Fração } \\
(\mathrm{mm})\end{array}$} & \multirow{4}{*}{ Eppendorf } & \multirow{2}{*}{\multicolumn{3}{|c|}{$\begin{array}{c}\text { Feições Físicas } \\
\text { Fragmentação }\end{array}$}} & \multicolumn{6}{|c|}{ Feições Químicas } \\
\hline & & & & & & \multicolumn{2}{|c|}{ Cor } & \multicolumn{2}{|c|}{\begin{tabular}{|c|} 
Brilho \\
\end{tabular}} & \multicolumn{2}{|c|}{ Corrosão } \\
\hline & & & \multirow{2}{*}{ Ausente } & & Presente & Mantida & Alterada & Mantido $A$ & Alterado & Ausente & Presente \\
\hline & & & & $<10 \%$ & entre $10 \%$ e $50 \%>50 \%$ & & & & & & \\
\hline 7622 & 0,250 & 48 & 0 & & & 0 & & 0 & & 0 & \\
\hline 7622 & 0,250 & 49 & & 1 & & & 1 & & 1 & & 1 \\
\hline 7622 & 0,250 & 50 & 0 & & & & 1 & & 1 & & 1 \\
\hline 7622 & 0,250 & 51 & 0 & & & & 1 & & 1 & & 1 \\
\hline 7622 & 0,250 & 52 & 0 & & & & 1 & & 1 & & 1 \\
\hline 7622 & 0,250 & 53 & 0 & & & & 1 & & 1 & & 1 \\
\hline 7622 & 0,250 & 54 & 0 & & & & 1 & & 1 & & 1 \\
\hline 7622 & 0,250 & 55 & 0 & & & & 1 & & 1 & & 1 \\
\hline 7622 & 0,250 & 56 & 0 & & & & 1 & & 1 & & 1 \\
\hline 7622 & 0,250 & 57 & 0 & & & & 1 & & 1 & & 1 \\
\hline 7622 & 0,250 & 58 & 0 & & & & 1 & & 1 & & 1 \\
\hline 7622 & 0,250 & 59 & 0 & & & & 1 & & 1 & & 1 \\
\hline 7622 & 0,250 & 60 & 0 & & & 0 & & & 1 & & 1 \\
\hline 7622 & 0,250 & 61 & 0 & & & 0 & & & 1 & & 1 \\
\hline 7622 & 0,250 & 62 & & 1 & & 0 & & & 1 & & 1 \\
\hline 7622 & 0,250 & 63 & & 1 & & 0 & & & 1 & & 1 \\
\hline 7622 & 0,250 & 64 & 0 & & & 0 & & & 1 & & 1 \\
\hline 7622 & 0,250 & 65 & 0 & & & 0 & & & 1 & & 1 \\
\hline 7622 & 0,250 & 66 & 0 & & & 0 & & & 1 & & 1 \\
\hline 7622 & 0,250 & 67 & 0 & & & 0 & & & 1 & & 1 \\
\hline 7622 & 0,250 & 68 & 0 & & & 0 & & & 1 & & 1 \\
\hline 7622 & 0,250 & 69 & 0 & & & 0 & & & 1 & & 1 \\
\hline 7622 & 0,250 & 70 & 0 & & & 0 & & & 1 & & 1 \\
\hline 7622 & 0,250 & 71 & 0 & & & 0 & & & 1 & & 1 \\
\hline 7622 & 0,250 & 72 & 0 & & & 0 & & & 1 & & 1 \\
\hline 7622 & 0,250 & 73 & 0 & & & 0 & & & 1 & & 1 \\
\hline 7622 & 0,250 & 74 & 0 & & & 0 & & & 1 & & 1 \\
\hline 7622 & 0,250 & 75 & 0 & & & 0 & & & 1 & & 1 \\
\hline 7622 & 0,250 & 76 & 0 & & & 0 & & & 1 & & 1 \\
\hline 7622 & 0,250 & 77 & 0 & & & 0 & & & 1 & & 1 \\
\hline 7622 & 0,250 & 78 & 0 & & & 0 & & & 1 & & 1 \\
\hline 7622 & 0,250 & 79 & & 1 & & & 1 & & 1 & & 1 \\
\hline 7622 & 0,250 & 80 & & 1 & & & 1 & & 1 & & 1 \\
\hline 7622 & 0,250 & 81 & 0 & & & 0 & & 0 & & 0 & \\
\hline 7622 & 0,250 & 82 & 0 & & & 0 & & 0 & & 0 & \\
\hline 7622 & 0,250 & 83 & 0 & & & 0 & & 0 & & 0 & \\
\hline 7622 & 0,250 & 84 & 0 & & & 0 & & 0 & & 0 & \\
\hline 7622 & 0,250 & 85 & 0 & & & 0 & & 0 & & 0 & \\
\hline 7622 & 0,250 & 86 & 0 & & & 0 & & 0 & & 0 & \\
\hline 7622 & 0,250 & 87 & 0 & & & 0 & & 0 & & 0 & \\
\hline 7622 & 0,250 & 88 & 0 & & & & 1 & & 1 & & 1 \\
\hline 7622 & 0,250 & 89 & 0 & & & & 1 & & 1 & & 1 \\
\hline 7622 & 0,250 & 90 & 0 & & & & 1 & & 1 & & 1 \\
\hline 7622 & 0,250 & 91 & 0 & & & & 1 & & 1 & & 1 \\
\hline 7622 & 0,250 & 92 & 0 & & & & 1 & & 1 & & 1 \\
\hline 7622 & 0,250 & 93 & 0 & & & & 1 & & 1 & & 1 \\
\hline 7622 & 0,250 & 94 & 0 & & & & 1 & & 1 & & 1 \\
\hline 7622 & 0,250 & 95 & 0 & & & & 1 & & 1 & & 1 \\
\hline 7622 & 0,250 & 96 & 0 & & & & 1 & & 1 & & 1 \\
\hline
\end{tabular}




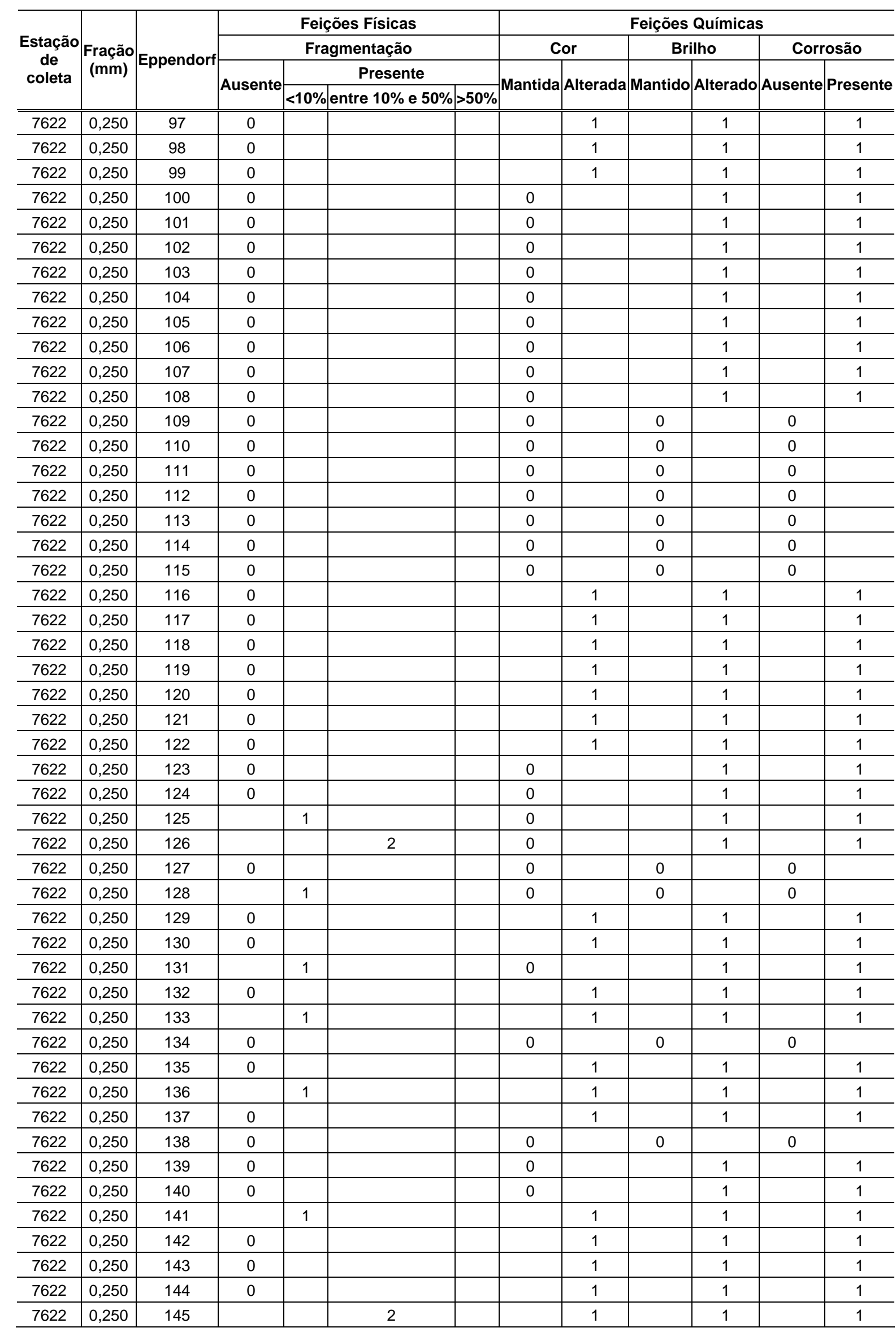




\begin{tabular}{|c|c|c|c|c|c|c|c|c|c|c|c|c|}
\hline \multirow{4}{*}{$\begin{array}{c}\text { Estação } \\
\text { de } \\
\text { coleta }\end{array}$} & \multirow{4}{*}{$\begin{array}{c}\text { Fração } \\
(\mathrm{mm})\end{array}$} & \multirow{4}{*}{ Eppendorf } & \multirow{2}{*}{\multicolumn{4}{|c|}{$\begin{array}{l}\text { Feições Físicas } \\
\text { Fragmentação }\end{array}$}} & \multicolumn{6}{|c|}{ Feições Químicas } \\
\hline & & & & & & & \multicolumn{2}{|c|}{ Cor } & \multicolumn{2}{|c|}{ Brilho } & \multicolumn{2}{|c|}{ Corrosão } \\
\hline & & & \multirow{2}{*}{ Ausente } & & Presente & & Mantida & Alterada & Mantido & & & \\
\hline & & & & $<10 \%$ & $\%$ entre $10 \%$ e $50 \%$ & $>50 \%$ & IVíantiua & Aileraua & Mantido & Alterado & Ausente & Presente \\
\hline 7622 & 0,250 & 146 & 0 & & & & 0 & & 0 & & 0 & \\
\hline 7622 & 0,250 & 147 & & & 2 & & & 1 & & 1 & & 1 \\
\hline 7622 & 0,250 & 148 & & 1 & & & & 1 & & 1 & & 1 \\
\hline 7622 & 0,250 & 149 & 0 & & & & & 1 & & 1 & & 1 \\
\hline 7622 & 0,250 & 150 & 0 & & & & 0 & & & 1 & & 1 \\
\hline
\end{tabular}




\section{Protocolo Tafonômico - Estação de coleta 7623, fração 0,250 mm}

\begin{tabular}{|c|c|c|c|c|c|c|c|c|c|c|c|c|}
\hline \multirow{4}{*}{$\begin{array}{c}\text { Estação } \\
\text { de } \\
\text { coleta }\end{array}$} & \multirow{4}{*}{$\begin{array}{c}\text { Fração } \\
(\mathrm{mm})\end{array}$} & \multirow{4}{*}{ Eppendorf } & \multirow{2}{*}{\multicolumn{4}{|c|}{$\begin{array}{l}\text { Feições Físicas } \\
\text { Fragmentação }\end{array}$}} & \multicolumn{6}{|c|}{ Feições Químicas } \\
\hline & & & & & & & \multicolumn{2}{|c|}{ Cor } & \multicolumn{2}{|c|}{ Brilho } & \multicolumn{2}{|c|}{ Corrosão } \\
\hline & & & \multirow{2}{*}{ Ausente } & & Presente & & Mantida & Alterada & Mantido & Alterado & Ausente & Presente \\
\hline & & & & $<10 \%$ & entre $10 \%$ e $50 \%$ & $>50 \%$ & & Alterada I & yiviantioo & Alterado & Ausente & Presente \\
\hline 7623 & 0,250 & 1 & 0 & & & & & 1 & & 1 & & 1 \\
\hline 7623 & 0,250 & 2 & 0 & & & & & 1 & & 1 & & 1 \\
\hline 7623 & 0,250 & 3 & 0 & & & & & 1 & & 1 & & 1 \\
\hline 7623 & 0,250 & 4 & 0 & & & & & 1 & & 1 & & 1 \\
\hline 7623 & 0,250 & 5 & 0 & & & & 0 & & & 1 & & 1 \\
\hline 7623 & 0,250 & 6 & 0 & & & & 0 & & & 1 & & 1 \\
\hline 7623 & 0,250 & 7 & 0 & & & & 0 & & & 1 & & 1 \\
\hline 7623 & 0,250 & 8 & 0 & & & & 0 & & & 1 & & 1 \\
\hline 7623 & 0,250 & 9 & 0 & & & & 0 & & & 1 & & 1 \\
\hline 7623 & 0,250 & 10 & 0 & & & & 0 & & & 1 & & 1 \\
\hline 7623 & 0,250 & 11 & 0 & & & & 0 & & & 1 & & 1 \\
\hline 7623 & 0,250 & 12 & 0 & & & & 0 & & & 1 & & 1 \\
\hline 7623 & 0,250 & 13 & 0 & & & & 0 & & & 1 & & 1 \\
\hline 7623 & 0,250 & 14 & 0 & & & & 0 & & & 1 & & 1 \\
\hline 7623 & 0,250 & 15 & 0 & & & & 0 & & & 1 & & 1 \\
\hline 7623 & 0,250 & 16 & 0 & & & & 0 & & & 1 & & 1 \\
\hline 7623 & 0,250 & 17 & 0 & & & & 0 & & & 1 & & 1 \\
\hline 7623 & 0,250 & 18 & 0 & & & & 0 & & & 1 & & 1 \\
\hline 7623 & 0,250 & 19 & 0 & & & & 0 & & & 1 & & 1 \\
\hline 7623 & 0,250 & 20 & 0 & & & & 0 & & & 1 & & 1 \\
\hline 7623 & 0,250 & 21 & 0 & & & & 0 & & & 1 & & 1 \\
\hline 7623 & 0,250 & 22 & 0 & & & & 0 & & & 1 & & 1 \\
\hline 7623 & 0,250 & 23 & 0 & & & & 0 & & & 1 & & 1 \\
\hline 7623 & 0,250 & 24 & 0 & & & & 0 & & & 1 & & 1 \\
\hline 7623 & 0,250 & 25 & 0 & & & & 0 & & & 1 & & 1 \\
\hline 7623 & 0,250 & 26 & 0 & & & & 0 & & & 1 & & 1 \\
\hline 7623 & 0,250 & 27 & 0 & & & & 0 & & & 1 & & 1 \\
\hline 7623 & 0,250 & 28 & 0 & & & & 0 & & & 1 & & 1 \\
\hline 7623 & 0,250 & 29 & 0 & & & & & 1 & & 1 & & 1 \\
\hline 7623 & 0,250 & 30 & 0 & & & & & 1 & & 1 & & 1 \\
\hline 7623 & 0,250 & 31 & 0 & & & & & 1 & & 1 & & 1 \\
\hline 7623 & 0,250 & 32 & 0 & & & & & 1 & & 1 & & 1 \\
\hline 7623 & 0,250 & 33 & 0 & & & & & 1 & & 1 & & 1 \\
\hline 7623 & 0,250 & 34 & 0 & & & & & 1 & & 1 & & 1 \\
\hline 7623 & 0,250 & 35 & 0 & & & & & 1 & & 1 & & 1 \\
\hline 7623 & 0,250 & 36 & 0 & & & & & 1 & & 1 & & 1 \\
\hline 7623 & 0,250 & 37 & 0 & & & & & 1 & & 1 & & 1 \\
\hline 7623 & 0,250 & 38 & 0 & & & & & 1 & & 1 & & 1 \\
\hline 7623 & 0,250 & 39 & 0 & & & & & 1 & & 1 & & 1 \\
\hline 7623 & 0,250 & 40 & 0 & & & & & 1 & & 1 & & 1 \\
\hline 7623 & 0,250 & 41 & 0 & & & & & 1 & & 1 & & 1 \\
\hline 7623 & 0,250 & 42 & & & 2 & & & 1 & & 1 & & 1 \\
\hline 7623 & 0,250 & 43 & & & 2 & & & 1 & & 1 & & 1 \\
\hline 7623 & 0,250 & 44 & & & 2 & & & 1 & & 1 & & 1 \\
\hline 7623 & 0,250 & 45 & & & 2 & & & 1 & & 1 & & 1 \\
\hline 7623 & 0,250 & 46 & & 1 & & & & 1 & & 1 & & 1 \\
\hline 7623 & 0,250 & 47 & & 1 & & & & 1 & & 1 & & 1 \\
\hline
\end{tabular}




\begin{tabular}{|c|c|c|c|c|c|c|c|c|c|c|c|c|}
\hline \multirow{4}{*}{$\begin{array}{c}\text { Estação } \\
\text { de } \\
\text { coleta }\end{array}$} & \multirow{4}{*}{$\begin{array}{c}\text { Fração } \\
(\mathrm{mm})\end{array}$} & \multirow{4}{*}{ Eppendorf } & \multirow{2}{*}{\multicolumn{4}{|c|}{$\begin{array}{c}\text { Feições Físicas } \\
\text { Fragmentação }\end{array}$}} & \multicolumn{6}{|c|}{ Feições Químicas } \\
\hline & & & & & & & \multicolumn{2}{|c|}{ Cor } & \multicolumn{2}{|c|}{ Brilho } & \multicolumn{2}{|c|}{ Corrosão } \\
\hline & & & \multirow{2}{*}{ Ausente } & \multicolumn{3}{|c|}{ Presente } & - Mantida & Alterada & Mantido & Alterado & Ausente & Presente \\
\hline & & & & $<10 \%$ & entre $10 \%$ e $50 \%$ & $>50 \%$ & 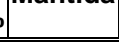 & 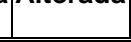 & - & De & 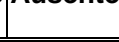 & [. \\
\hline 7623 & 0,250 & 48 & & 1 & & & & 1 & & 1 & & 1 \\
\hline 7623 & 0,250 & 49 & & 1 & & & & 1 & & 1 & & 1 \\
\hline 7623 & 0,250 & 50 & & & & 3 & & 1 & & 1 & & 1 \\
\hline 7623 & 0,250 & 51 & & & & 3 & & 1 & & 1 & & 1 \\
\hline 7623 & 0,250 & 52 & & & & 3 & & 1 & & 1 & & 1 \\
\hline 7623 & 0,250 & 53 & & & & 3 & & 1 & & 1 & & 1 \\
\hline 7623 & 0,250 & 54 & & & & 3 & & 1 & & 1 & & 1 \\
\hline 7623 & 0,250 & 55 & & & & 3 & & 1 & & 1 & & 1 \\
\hline 7623 & 0,250 & 56 & & & & 3 & & 1 & & 1 & & 1 \\
\hline 7623 & 0,250 & 57 & & & & 3 & & 1 & & 1 & & 1 \\
\hline 7623 & 0,250 & 58 & & 1 & & & 0 & & & 1 & & 1 \\
\hline 7623 & 0,250 & 59 & & 1 & & & 0 & & & 1 & & 1 \\
\hline 7623 & 0,250 & 60 & 0 & & & & 0 & & & 1 & & 1 \\
\hline 7623 & 0,250 & 61 & 0 & & & & 0 & & & 1 & & 1 \\
\hline 7623 & 0,250 & 62 & 0 & & & & 0 & & & 1 & & 1 \\
\hline 7623 & 0,250 & 63 & 0 & & & & 0 & & & 1 & & 1 \\
\hline 7623 & 0,250 & 64 & 0 & & & & 0 & & & 1 & & 1 \\
\hline 7623 & 0,250 & 65 & 0 & & & & 0 & & & 1 & & 1 \\
\hline 7623 & 0,250 & 66 & 0 & & & & 0 & & & 1 & & 1 \\
\hline 7623 & 0,250 & 67 & 0 & & & & 0 & & & 1 & & 1 \\
\hline 7623 & 0,250 & 68 & 0 & & & & 0 & & & 1 & & 1 \\
\hline 7623 & 0,250 & 69 & 0 & & & & 0 & & & 1 & & 1 \\
\hline 7623 & 0,250 & 70 & 0 & & & & 0 & & & 1 & & 1 \\
\hline 7623 & 0,250 & 71 & 0 & & & & 0 & & & 1 & & 1 \\
\hline 7623 & 0,250 & 72 & 0 & & & & 0 & & & 1 & & 1 \\
\hline 7623 & 0,250 & 73 & 0 & & & & 0 & & & 1 & & 1 \\
\hline 7623 & 0,250 & 74 & 0 & & & & 0 & & & 1 & & 1 \\
\hline 7623 & 0,250 & 75 & 0 & & & & 0 & & & 1 & & 1 \\
\hline 7623 & 0,250 & 76 & 0 & & & & 0 & & & 1 & & 1 \\
\hline 7623 & 0,250 & 77 & 0 & & & & 0 & & & 1 & & 1 \\
\hline 7623 & 0,250 & 78 & 0 & & & & 0 & & & 1 & & 1 \\
\hline 7623 & 0,250 & 79 & 0 & & & & & 1 & & 1 & & 1 \\
\hline 7623 & 0,250 & 80 & 0 & & & & & 1 & & 1 & & 1 \\
\hline 7623 & 0,250 & 81 & 0 & & & & & 1 & & 1 & & 1 \\
\hline 7623 & 0,250 & 82 & 0 & & & & & 1 & & 1 & & 1 \\
\hline 7623 & 0,250 & 83 & 0 & & & & & 1 & & 1 & & 1 \\
\hline 7623 & 0,250 & 84 & 0 & & & & & 1 & & 1 & & 1 \\
\hline 7623 & 0,250 & 85 & 0 & & & & & 1 & & 1 & & 1 \\
\hline 7623 & 0,250 & 86 & 0 & & & & & 1 & & 1 & & 1 \\
\hline 7623 & 0,250 & 87 & 0 & & & & & 1 & & 1 & & 1 \\
\hline 7623 & 0,250 & 88 & 0 & & & & & 1 & & 1 & & 1 \\
\hline 7623 & 0,250 & 89 & 0 & & & & & 1 & & 1 & & 1 \\
\hline 7623 & 0,250 & 90 & 0 & & & & & 1 & & 1 & & 1 \\
\hline 7623 & 0,250 & 91 & 0 & & & & & 1 & & 1 & & 1 \\
\hline 7623 & 0,250 & 92 & 0 & & & & & 1 & & 1 & & 1 \\
\hline 7623 & 0,250 & 93 & 0 & & & & & 1 & & 1 & & 1 \\
\hline 7623 & 0,250 & 94 & 0 & & & & & 1 & & 1 & & 1 \\
\hline 7623 & 0,250 & 95 & & & 2 & & & 1 & & 1 & & 1 \\
\hline 7623 & 0,250 & 96 & & & & 3 & & 1 & & 1 & & 1 \\
\hline
\end{tabular}




\begin{tabular}{|c|c|c|c|c|c|c|c|c|c|c|c|c|}
\hline \multirow{4}{*}{$\begin{array}{l}\text { Estação } \\
\text { de } \\
\text { coleta }\end{array}$} & \multirow{4}{*}{$\begin{array}{c}\text { Fração } \\
(\mathrm{mm})\end{array}$} & \multirow{4}{*}{ Eppendorf } & \multirow{2}{*}{\multicolumn{4}{|c|}{$\begin{array}{c}\text { Feições Físicas } \\
\text { Fragmentação }\end{array}$}} & \multicolumn{6}{|c|}{ Feições Químicas } \\
\hline & & & & & & & \multicolumn{2}{|c|}{ Cor } & \multicolumn{2}{|c|}{ Brilho } & \multicolumn{2}{|c|}{ Corrosão } \\
\hline & & & \multirow{2}{*}{ Ausente } & \multicolumn{3}{|c|}{ Presente } & - Mantida & Alterada & Mantido & Alterado & Ausente & Presente \\
\hline & & & & $<10 \%$ & entre $10 \%$ e $50 \%$ & $>50 \%$ & Tintio & aptiterava & xiviantiug & Anter adu & Ausentefe & priesemint \\
\hline 7623 & 0,250 & 97 & & 1 & & & & 1 & & 1 & & 1 \\
\hline 7623 & 0,250 & 98 & & & & 3 & 0 & & & 1 & & 1 \\
\hline 7623 & 0,250 & 99 & 0 & & & & 0 & & & 1 & & 1 \\
\hline 7623 & 0,250 & 100 & 0 & & & & 0 & & & 1 & & 1 \\
\hline 7623 & 0,250 & 101 & 0 & & & & 0 & & 0 & & 0 & \\
\hline 7623 & 0,250 & 102 & 0 & & & & 0 & & 0 & & 0 & \\
\hline 7623 & 0,250 & 103 & 0 & & & & 0 & & 0 & & 0 & \\
\hline 7623 & 0,250 & 104 & 0 & & & & 0 & & 0 & & 0 & \\
\hline 7623 & 0,250 & 105 & 0 & & & & 0 & & 0 & & 0 & \\
\hline 7623 & 0,250 & 106 & & 1 & & & & 1 & & 1 & & 1 \\
\hline 7623 & 0,250 & 107 & & 1 & & & & 1 & & 1 & & 1 \\
\hline 7623 & 0,250 & 108 & & 1 & & & & 1 & & 1 & & 1 \\
\hline 7623 & 0,250 & 109 & & 1 & & & & 1 & & 1 & & 1 \\
\hline 7623 & 0,250 & 110 & & 1 & & & & 1 & & 1 & & 1 \\
\hline 7623 & 0,250 & 111 & & 1 & & & & 1 & & 1 & & 1 \\
\hline 7623 & 0,250 & 112 & & 1 & & & & 1 & & 1 & & 1 \\
\hline 7623 & 0,250 & 113 & & & & 3 & 0 & & & 1 & & 1 \\
\hline 7623 & 0,250 & 114 & & & & 3 & 0 & & & 1 & & 1 \\
\hline 7623 & 0,250 & 115 & & 1 & & & & 1 & & 1 & & 1 \\
\hline 7623 & 0,250 & 116 & 0 & & & & 0 & & & 1 & & 1 \\
\hline 7623 & 0,250 & 117 & 0 & & & & 0 & & & 1 & & 1 \\
\hline 7623 & 0,250 & 118 & 0 & & & & 0 & & & 1 & & 1 \\
\hline 7623 & 0,250 & 119 & 0 & & & & 0 & & & 1 & & 1 \\
\hline 7623 & 0,250 & 120 & 0 & & & & 0 & & & 1 & & 1 \\
\hline 7623 & 0,250 & 121 & 0 & & & & 0 & & & 1 & & 1 \\
\hline 7623 & 0,250 & 122 & 0 & & & & 0 & & & 1 & & 1 \\
\hline 7623 & 0,250 & 123 & 0 & & & & 0 & & & 1 & & 1 \\
\hline 7623 & 0,250 & 124 & 0 & & & & 0 & & & 1 & & 1 \\
\hline 7623 & 0,250 & 125 & 0 & & & & 0 & & & 1 & & 1 \\
\hline 7623 & 0,250 & 126 & 0 & & & & 0 & & & 1 & & 1 \\
\hline 7623 & 0,250 & 127 & 0 & & & & 0 & & & 1 & & 1 \\
\hline 7623 & 0,250 & 128 & 0 & & & & 0 & & & 1 & & 1 \\
\hline 7623 & 0,250 & 129 & 0 & & & & 0 & & & 1 & & 1 \\
\hline 7623 & 0,250 & 130 & 0 & & & & 0 & & & 1 & & 1 \\
\hline 7623 & 0,250 & 131 & 0 & & & & 0 & & & 1 & & 1 \\
\hline 7623 & 0,250 & 132 & 0 & & & & & 1 & & 1 & & 1 \\
\hline 7623 & 0,250 & 133 & 0 & & & & & 1 & & 1 & & 1 \\
\hline 7623 & 0,250 & 134 & 0 & & & & & 1 & & 1 & & 1 \\
\hline 7623 & 0,250 & 135 & 0 & & & & & 1 & & 1 & & 1 \\
\hline 7623 & 0,250 & 136 & 0 & & & & & 1 & & 1 & & 1 \\
\hline 7623 & 0,250 & 137 & 0 & & & & & 1 & & 1 & & 1 \\
\hline 7623 & 0,250 & 138 & 0 & & & & & 1 & & 1 & & 1 \\
\hline 7623 & 0,250 & 139 & 0 & & & & & 1 & & 1 & & 1 \\
\hline 7623 & 0,250 & 140 & 0 & & & & & 1 & & 1 & & 1 \\
\hline 7623 & 0,250 & 141 & 0 & & & & 0 & & & 1 & & 1 \\
\hline 7623 & 0,250 & 142 & 0 & & & & 0 & & & 1 & & 1 \\
\hline 7623 & 0,250 & 143 & 0 & & & & 0 & & & 1 & & 1 \\
\hline 7623 & 0,250 & 144 & 0 & & & & 0 & & & 1 & & 1 \\
\hline 7623 & 0,250 & 145 & 0 & & & & 0 & & & 1 & & 1 \\
\hline
\end{tabular}




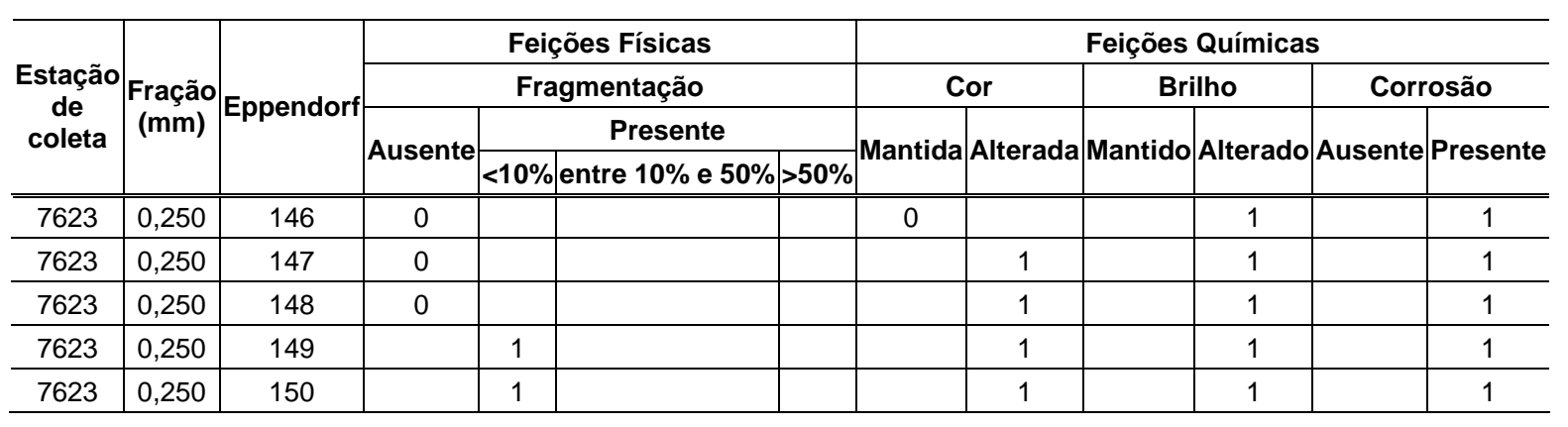




\section{Prancha 1}

Figura A - Globigerinoides ruber (white) d'Orbigny, 1839

Vista ventral

Figura B - Globigerinoides ruber (white) d'Orbigny, 1839

Vista dorsal

Figura C - Globorotalia menardii d'Orbigny, 1865

Vista ventral

Figura D - Globorotalia menardii d'Orbigny, 1865

Vista dorsal

Figura E - Neogloboquadrina dutertrei d'Orbigny, 1839

Vista ventral

Figura F - Neogloboquadrina dutertrei d'Orbigny, 1839

Vista dorsal

Figura G - Globigerinella siphonifera d'Orbigny, 1839

Vista dorsal

Figura H - Orbulina universa d'Orbigny, 1839 


\section{Prancha 1}

A

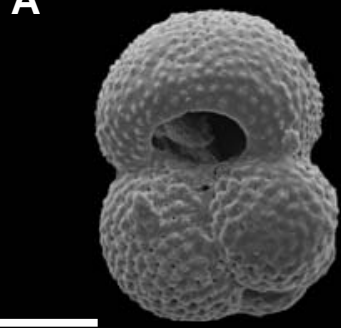

$100 \mu \mathrm{m}$

C

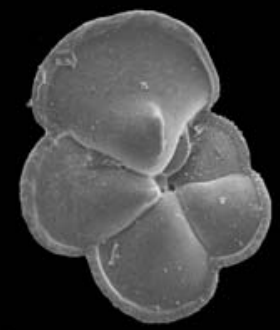

$100 \mu \mathrm{m}$

E

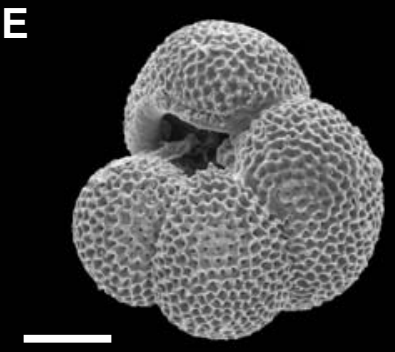

$100 \mu \mathrm{m}$

G

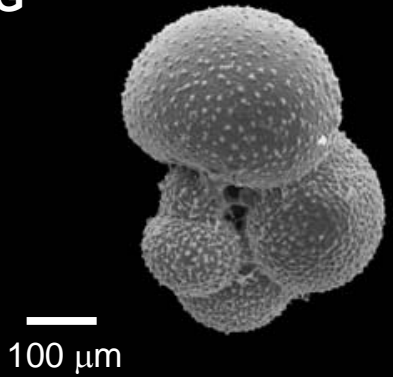

B

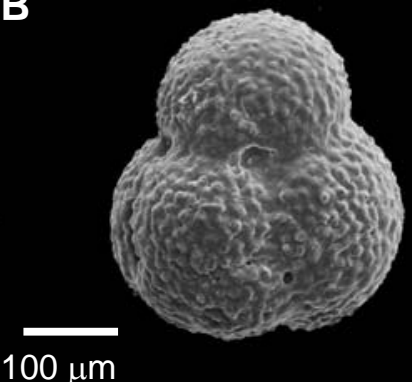

D

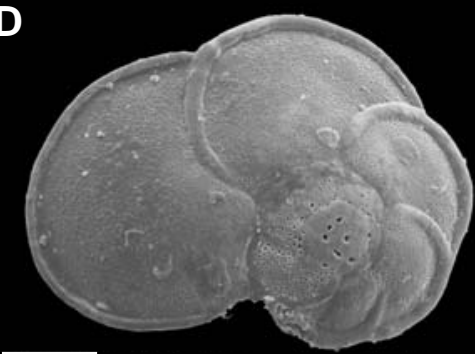

$100 \mu \mathrm{m}$

F

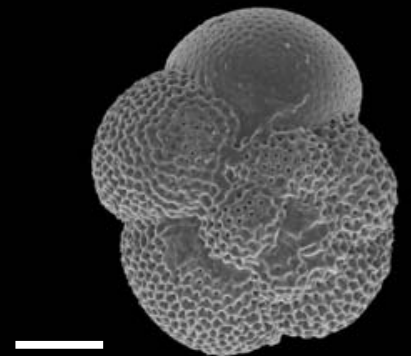

$100 \mu \mathrm{m}$

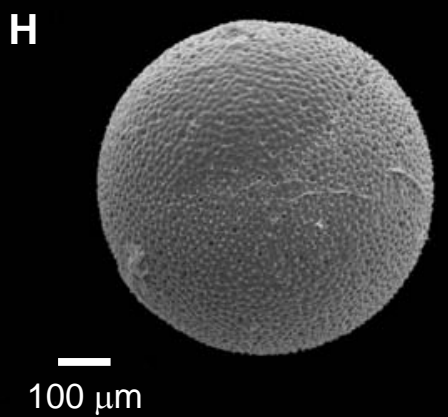




\section{Prancha 2}
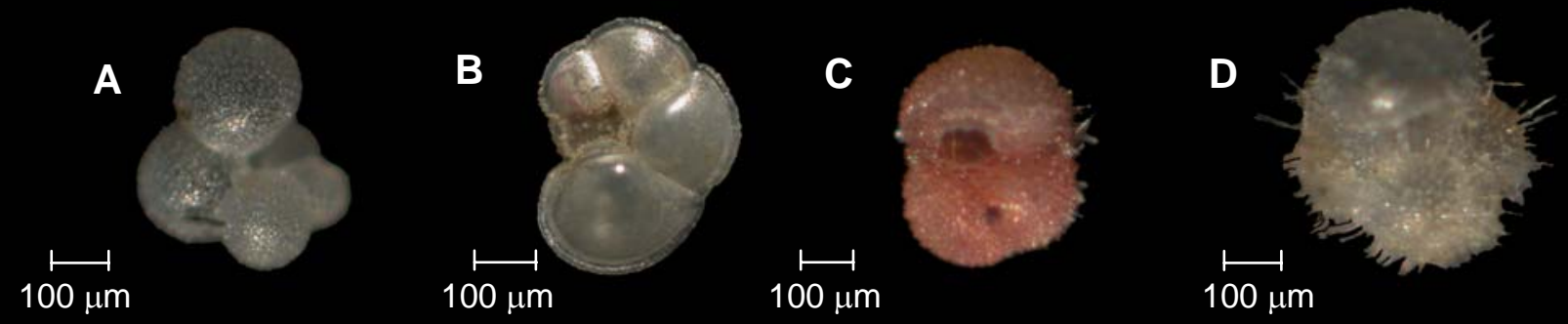

Padrão das testas de foraminíferos planctônicos isentas de assinaturas tafonômicas observadas em estereomicroscópio (A-D).

E

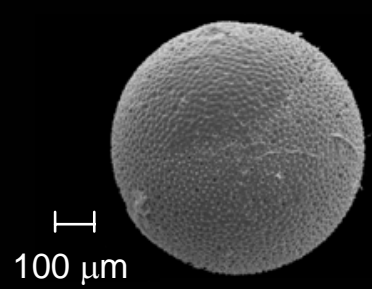

$\mathbf{F}$

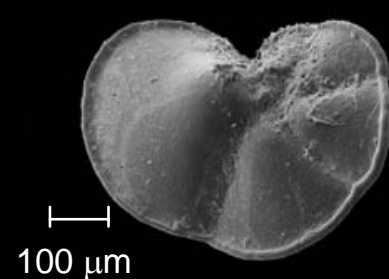

$\mathbf{G}$

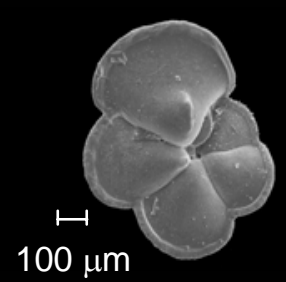

H

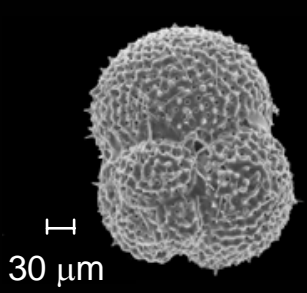

Padrão das testas de foraminíferos planctônicos isentas de assinaturas tafonômicas observadas em microscopia eletrônica de varredura $(E-H)$. 

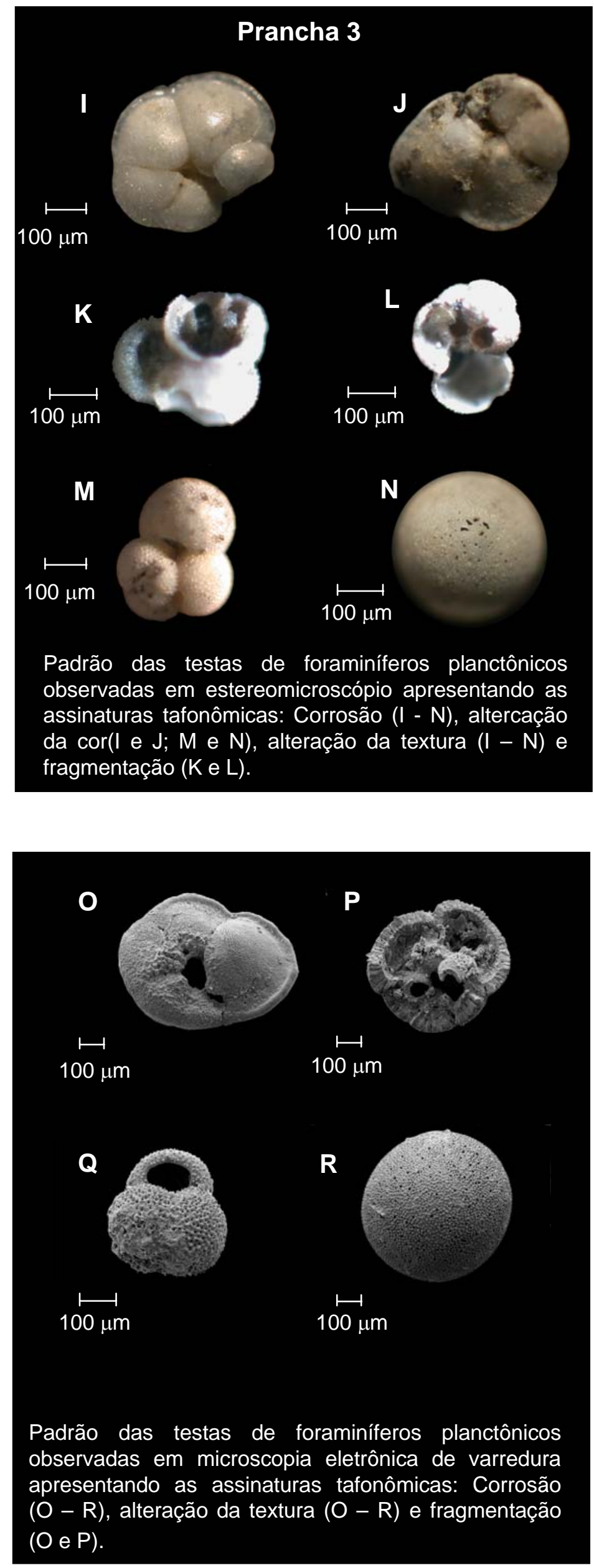